\title{
Synthesis of fluorescent toxin and nucleotide derivatives to specifically address membrane proteins
}

\section{Dissertation}

zur Erlangung des mathematisch-naturwissenschaftlichen Doktorgrades

\author{
"Doctor rerum naturalium" \\ der Georg-August-Universität Göttingen \\ im Promotionsprogramm Chemie \\ der Georg-August University School of Science (GAUSS)
}

vorgelegt von

Hanna Agnes Radzey

geboren in Bremen

Göttingen, 2015 


\section{Betreuungsausschuss}

Prof. Dr. Ulf Diederichsen

Prof. Dr. Andreas Janshoff
Institut für Organische und Biomolekulare Chemie Georg-August-Universität Göttingen

Institut für Physikalische Chemie

Georg-August-Universität Göttingen

\section{Mitglieder der Prüfungskommission}

\section{Referent}

Prof. Dr. Ulf Diederichsen

Institut für Organische und Biomolekulare Chemie Georg-August-Universität Göttingen

\section{Korreferent}

Prof. Dr. Andreas Janshoff

Institut für Physikalische Chemie

Georg-August-Universität Göttingen

\section{Weitere Mitglieder der Prüfungskommission}

Prof. Dr. Lutz Ackermann

Prof. Dr. Konrad Koszinowski

Prof. Dr. Claudia Höbartner

Dr. Inke Siewert
Institut für Organische und Biomolekulare Chemie Georg-August-Universität Göttingen

Institut für Organische und Biomolekulare Chemie Georg-August-Universität Göttingen

Institut für Organische und Biomolekulare Chemie Georg-August-Universität Göttingen

Institut für Anorganische Chemie Georg-August-Universität Göttingen 
The work presented in this doctoral thesis has been carried out under the guidance and supervision of Prof. Dr Ulf Diederichsen at the Institute for Organic and Biomolecular Chemistry of the GeorgAugust-University Göttingen between May 2011 and November 2014.

This work was supported by the Cluster of Excellence and DFG Research Center Nanoscale Microscopy and Molecular Physiology of the Brain (CNMPB). 


\section{Table of contents}

1 Introduction. 1

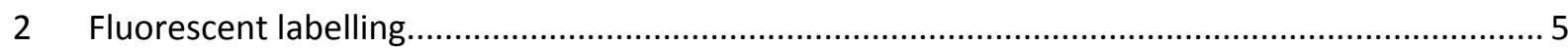

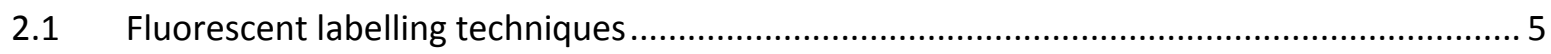

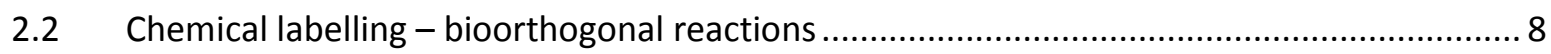

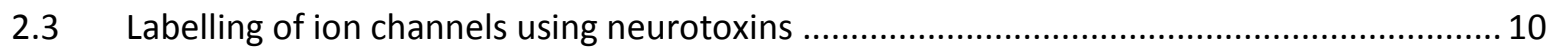

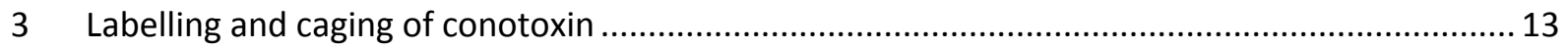

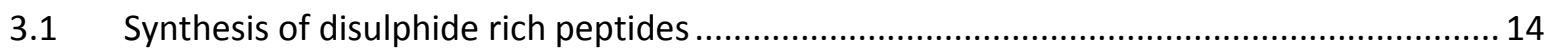

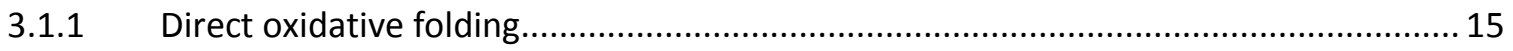

3.1.2 Regioselective oxidation using different protecting groups.......................................... 16

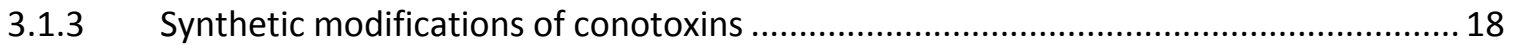

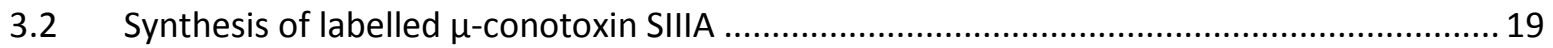

3.2.1 Structural and functional analysis of $\mu$-conotoxin SIIIA ................................................. 21

3.2.2 Modifications of $\mu$-conotoxin SIIIA and their influence on activity ............................. 22

3.2.3 Synthesis and labelling of alkyne modified $\mu$-conotoxin SIIIA ....................................... 23

3.2.4 Synthesis of thiol modified $\mu$-conotoxin SIIIA …........................................................... 36

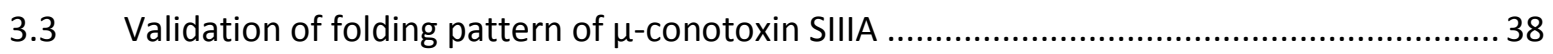

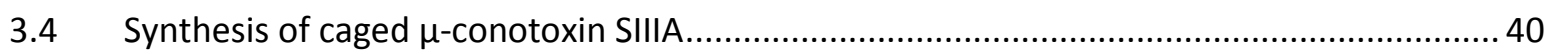

3.4.1 Characteristics and applications of photolabile compounds ......................................... 40

3.4.2 Photolabile nitrobenzyl protecting groups: mechanism and derivatives....................... 41

3.4.3 Structural analysis of $\mu$-conotoxin SIIIA regarding the introduction of a caging group 42

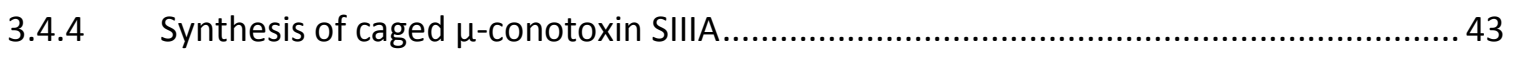

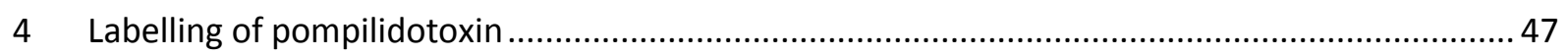

4.1 Characteristics and applications of pompilidotoxin ........................................................... 47

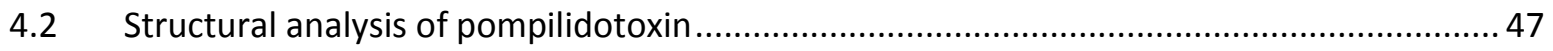

$4.3 \quad$ Synthesis of modified and labelled pompilidotoxin .............................................................. 48

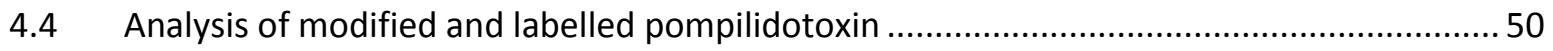

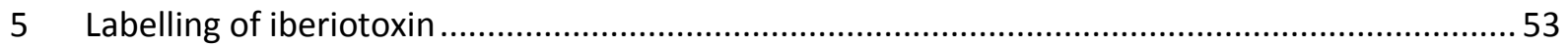




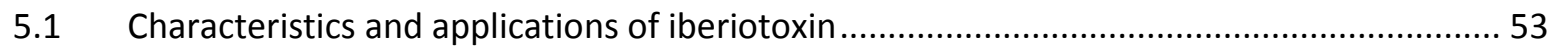

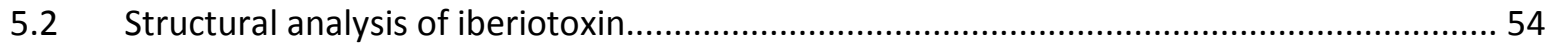

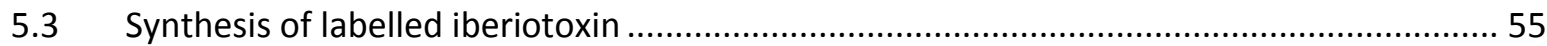

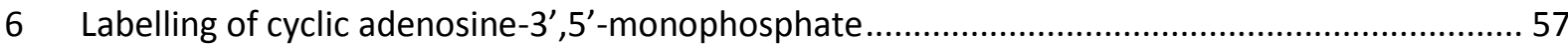

6.1 Role of cyclic adenosine-3',5'-monophosphate in the chemotaxis of Dictyostelium discoideum

6.2 Structural analysis of cyclic adenosine- $3^{\prime}, 5^{\prime}$-monophosphate with regard to the binding to cAMP receptors of $D$. discoideum cells 58

6.3 Syntheses of labelled cyclic adenosine-3', $5^{\prime}$-monophosphates.............................................. 58

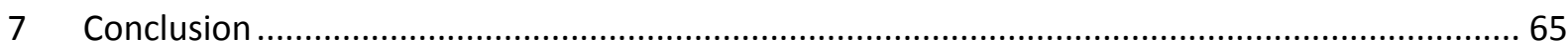

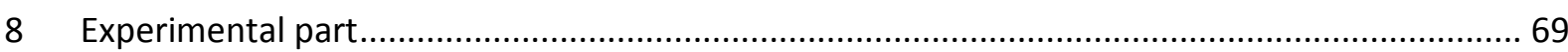

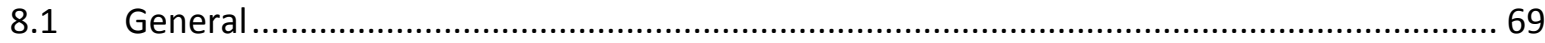

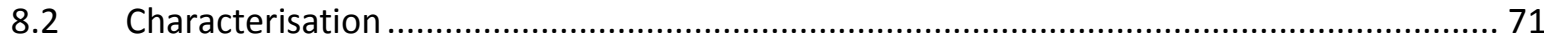

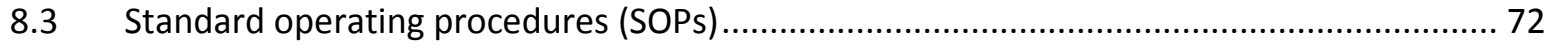

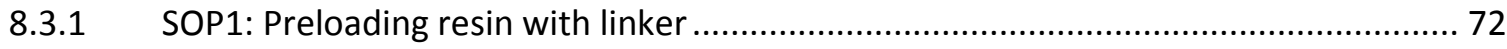

8.3.2 SOP2: Loading resin with first amino acid.................................................................. 72

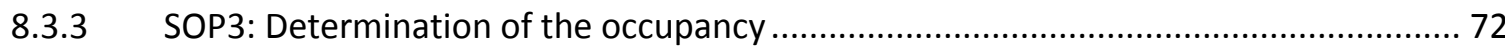

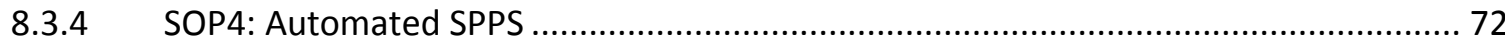

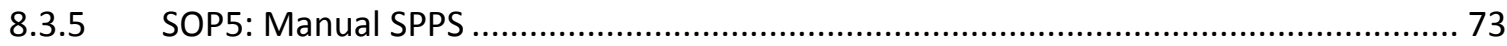

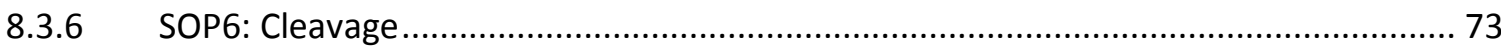

8.3.7 SOP7: Synthesis of $\mu$-conotoxin SIIIA: formation of the first disulphide bridge and

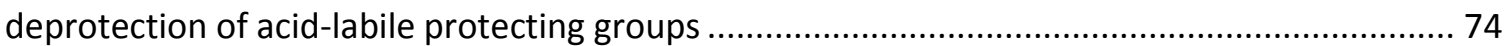

8.3.8 SOP8: Synthesis of $\mu$-conotoxin SIIIA: formation of the second disulphide bridge ...... 74

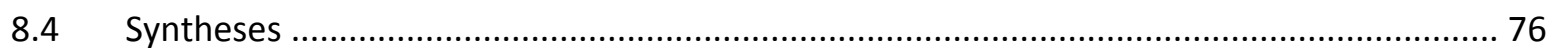

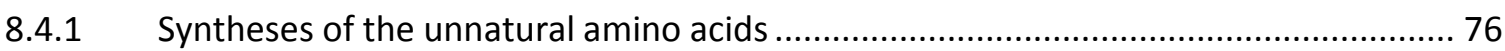

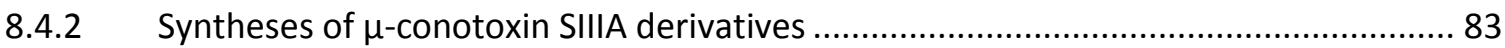

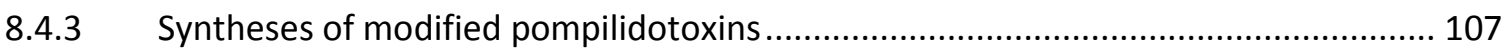

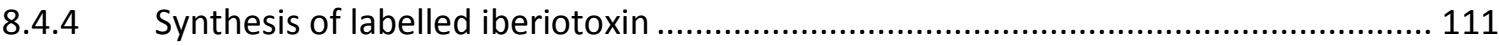

8.4.5 Syntheses of modified cyclic adenosine-3', 5'-monophosphates ................................ 112

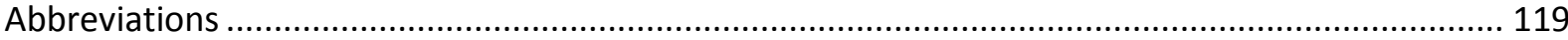

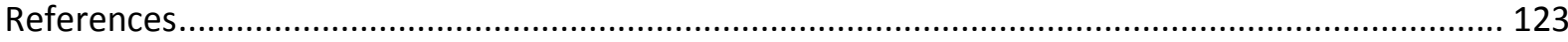

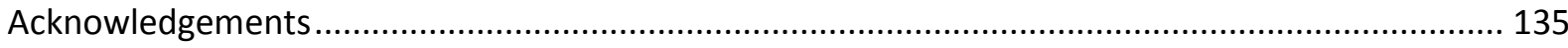

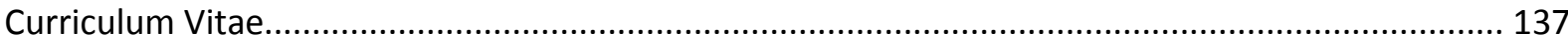





\section{Introduction}

Proteins as well as nucleic acids play a crucial role in many cellular processes. Hence, chemists in collaboration with biologists and physicists are involved in the development of new methods to study these biomolecules in their native environment. ${ }^{[1]}$ To investigate their locations, structures and distinct processes they are involved in, fast, sensitive and reliable detection methods are needed. ${ }^{[2]}$ Additionally, reporter groups need to be attached to the protein of interest (POI), e. g. by radioactive labelling or the introduction of isotope markers, in order to track these molecules. ${ }^{[3]}$ One of the most common methods is the labelling with fluorophores. It has several advantages over other labelling techniques such as its non-destructive nature and high sensitivity, which allows even single molecule detection. ${ }^{[4]}$ Furthermore, fluorophores are available in multiple colours enabling the simultaneous detection of different processes and proteins.

Modern fluorescent probes that are introduced to the POls range from small organic fluorophores, which are widely applied for chemical labelling, to fluorescent proteins of larger size. Since the first fluorescent labelling of proteins in vivo with the green fluorescent protein (GFP) in 1994, an increasing number of fluorescent proteins have been developed, such as the cyan fluorescent protein or the yellow fluorescent protein as well as new fluorescent proteins derived from other bioluminescent species. ${ }^{[5,6]}$ These fluorescent proteins are attached to POIs on DNA level and introduced into the required system by recombinant expression. Although, this method of fluorescent labelling is widely applied, limitations are the size of the fluorescent protein (GFP contains 238 amino acids) and thereby its influence on function, movement and activity of POls. ${ }^{[6]}$ Due to these disadvantages of fluorescent proteins, a number of small synthetic fluorescent probes have been investigated for in vivo labelling. Synthetic fluorescent probes are variable in properties and functionalities and can be derivatised with a number of reactive groups in order to link them to POls. Even though labelling with synthetic fluorescent probes in vivo might be difficult, as reactivity and specificity towards POIs must be high to avoid background labelling, the introduction of bioorthogonal groups into POIs by recombinant expression is one way to realize it. Furthermore, synthetic fluorescent probes are combined with proteins that target membrane proteins on the cell surface. This chemical labelling prior to the application in imaging studies offers a higher variability in the proteins that are labelled with a 
fluorescent marker. The POIs may even be synthetically modified by the introduction of additional functionalities.

Ion channels are a class of membrane proteins, which are widely investigated and represent interesting targets for labelling studies. They are pore forming proteins, which allow the inward and outward flux of ions across the cell membrane and consequently distribute to electrical potential generation and action potential propagation. ${ }^{[7]}$ The ion channel distribution and localisation along cell membranes are of high interest for researches to clarify the picture of how they establish their mode of action during stimulus conduction. In order to label ion channels, specific binding tools need to be acquired, which bind selectively and are easily modified in order to attach a fluorescent probe. Nowadays, a number of specific binding neurotoxins, derived from animal venoms, have been identified which interact with specific ion channels or even ion channel subtypes.

In this thesis a number of novel labelled neurotoxins (conotoxin, pompilidotoxin and iberiotoxin) for the selective binding to specific ion channels will be presented. Following an in-depth structural analysis of functional residues important for the ion channel/neurotoxin interaction, an adjusted synthetic strategy is developed to prevent reduced binding affinities. For one of the synthesized neurotoxins (conotoxin), bearing three disulphide bridges, an elaborate synthetic pathway is developed to induce the correct disulphide linkages and therefore, enforce the structure necessary for binding to the specific ion channel. The selective introduction of a fluorescent marker will be accomplished by bioorthogonal strategies making use of synthetically inserted alkyne or thiol functionalities or natural occurring amines. These novel synthesized labelled neurotoxins, which retain their activity, allow the investigation of ion channels regarding their quantification, distribution and localisation by our cooperation partners ANDREAS NEEF and co-workers, and the SCHILD research group (see Scheme 1). Furthermore, a photocleavable protecting group is introduced into a conotoxin on functional residues, which are important for binding. Thereby, a neurotoxin will be available, which can be switched from the inactive state (no binding affinity) to the active state (binding and thereby blocking ion channels) by light providing an additional tool for ion channel investigations. 


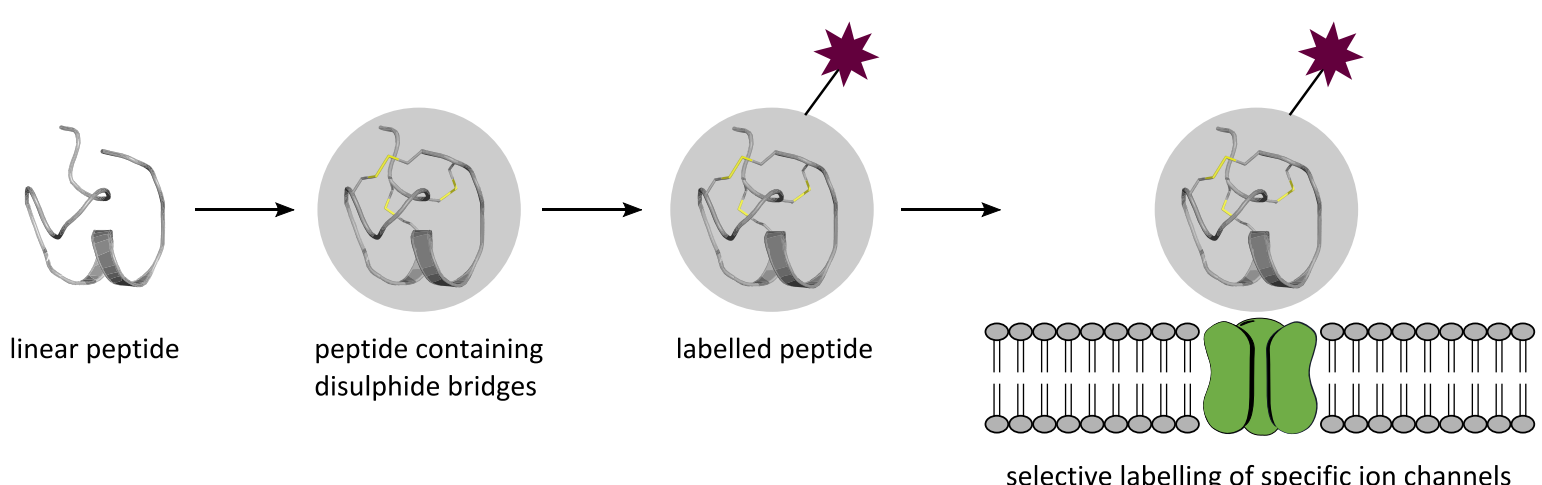

Scheme 1: Overview of the synthetic approach for labelling neurotoxins. The first step is the synthesis of a linear peptide containing either alkyne, thiol or amine functionality for bioorthogonal labelling. For neurotoxins containing disulphide bridges, multiple synthetic steps are necessary to consecutively form the complex structure. Subsequently, the labelling reaction is performed without affecting the binding side of the neurotoxin, thereby, enabling investigations on specific ion channels.

In a second project in cooperation with MARCO TARANTOLA and co-workers, the labelling of a nucleotide will be described. Cyclic adenosine-3',5'-monophosphate (cAMP) acts as a chemoattractant for the amoeboid Dictyostelium discoideum, which migrates in a cAMP gradient towards the highest concentration. With the intention of labelling CAMP, an alkyne moiety will be introduced in two different positions. By the introduction of a bioorthogonal group, such as an alkyne, a number of different groups and functional tools can be linked to cAMP via copper-catalysed azide-alkyne cycloaddition of functionalised azides e. g. different fluorescent probes. In this thesis two azide functionalised fluorophores (either Alexa Fluor ${ }^{\circledR} 555$ or 488 ) will be attached and these labelled cAMP derivatives may help to elucidate the cAMP dependent chemotaxis of the amoeboid Dictyostelium discoideum. This offers a tool for the quantification and visualisation of cAMP concentrations (monitored by a confocal laser scanning microscope), which are necessary for an induction of chemotaxis, and furthermore, it may contribute to the precise analysis of chemotaxis parameters. 



\section{Fluorescent labelling}

Fluorescent labelling is generally performed by linking a reactive derivative of the fluorophore to a protein of interest (POI) containing the corresponding reactive functionality. Combination of fluorescent labelling methods with advanced fluorescence microscopy allows to investigate in vivo/in vitro protein distribution, translocation and interaction. The different methods, by which labelling is mostly accomplished, are further described in section 2.1. Certain requirements must be considered before selecting one of the methods provided. On the one hand, the size of the fluorescent probe and its stability towards different environments need to be reflected in order to avoid changes in the mode of action and to maintain the activity of the POI. On the other hand, the efficiency and applicability of the labelling reaction to the $\mathrm{POI}$, with a preference for covalent linkage, needs to be considered. ${ }^{[3]}$

\subsection{Fluorescent labelling techniques}

Fluorescent labelling methods can be divided into four main strategies: genetic, enzymatic, tag or chemical labelling, as described in a review by SAHOO (see Figure 1). ${ }^{[3]}$ One of the most applied tools for genetic labelling, which is used in vivo, is the recombinant expression of POI together with fluorescent proteins. Due to the large size of fluorescent proteins of approximately $27 \mathrm{kDa}$, proteins such as GFP easily influence the structure and activity of POls. ${ }^{[8]}$ Additionally, unnatural fluorescent amino acids are incorporated into proteins via tRNA that has previously been aminoacylated with an unnatural amino acid, such as 7-methoxycoumarine modified aspartic acid. ${ }^{[9]}$ For the introduction of commercially available fluorophores, unnatural amino acids with non-proteinogenic reactive groups like azide, alkyne or ketone may be introduced into POIs, which are derivatised with the respective fluorophores. Due to the low yields of this labelling technique, this method is seldom utilised. The direct labelling of tRNA for the study of its dynamics on ribosome during translation is accomplished via selective reduction of dihydrouridine followed by an attachment of dihydrazide modified fluorophore (see Figure 1: genetic). ${ }^{[10]}$ These genetic labelling methods are frequently used for in vivo labelling. Nowadays, enzymatic labelling attracts even more attention for both in vivo and in vitro labelling. Enzymatic reactions are generally fast, efficient and selective, though the limitations are, that usually a large peptide is attached to the POI for the recognition by the respective enzyme. For the 
application of Sortase A, the most commonly used enzyme for labelling reactions, two motifs are linked to the POI and fluorophore, respectively: on the one hand, a Leu-Pro-X-Thr-Gly (LPXTG) motif at the $\mathrm{C}$-terminus of the $\mathrm{POI}$ or fluorophore and on the other hand, a polyglycine sequence at the $\mathrm{N}$-terminus of either. ${ }^{[11]}$ Sortase A recognises the LPXTG motif, cleaves the Thr-Gly peptide bond and forms a bond to the $\mathrm{N}$-terminus of the polyglycine sequence. Sortase $\mathrm{A}$ has been widely used and allows even unnatural moieties beyond the LPXTG or polyglycine motif. ${ }^{[12]}$ The disadvantage is its characteristic to hydrolyse intrinsic peptide bonds, whenever the LPXTG motif is present.
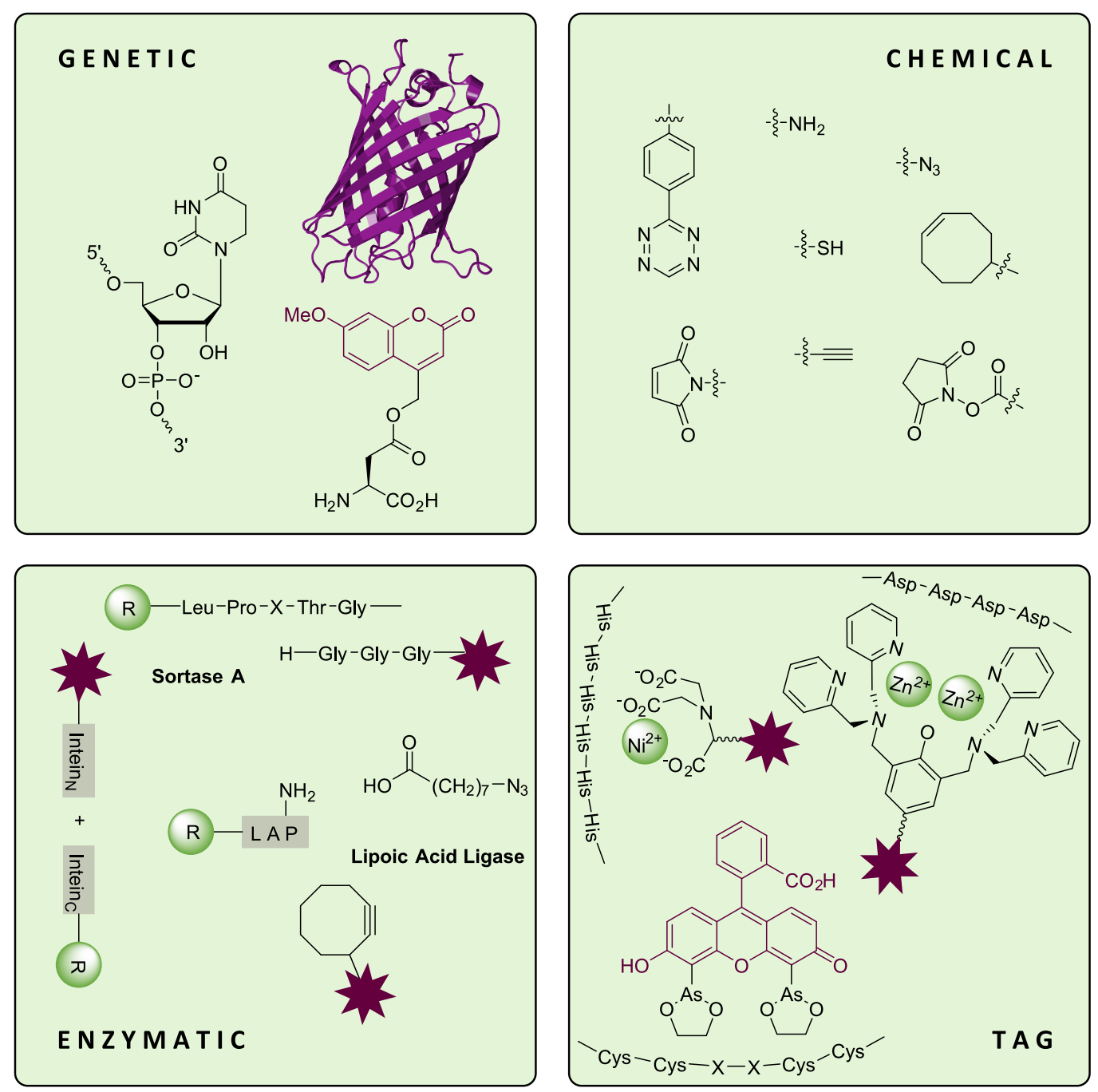

Figure 1: Overview of the various approaches for labelling proteins (figure adapted from the review by SAноO). ${ }^{[3]}$ Genetic labelling is achieved by the introduction of a fluorescent protein (e. g. GFP) or unnatural fluorescent amino acids or a modification of tRNA. Chemical labelling is conducted by the application of unnatural amino acids, for reactions via copper(I)-catalysed azide-alkyne cycloaddition and inverse-demand DIELS-ALDER reactions, or natural amino acids via activated ester or maleimide functionalities. Enzymes such as Sortase A or lipoic acid ligase or self-modified enzymes such as intein are utilised for enzymatic labelling. Specific tags for instance His tag, the tetracysteine motif or Asp tag are recognized through physical or chemical interactions by specific ligands such as $\mathrm{Ni}$ (II) complexes, bisarsenical ligands or $\mathrm{Zn}$ (II) complexes. 
Recently, FERNÁNDEZ-SUÁREZ et al. developed a method for labelling POls with small fluorescent probes by means of lipoic acid ligase (LpIA). ${ }^{[13]}$ LpIA facilitates the addition of small molecules, which is lipoic acid in nature but may be substituted e. g. with functionalized octanoic acid, to an amine side chain functionality of the 22 amino acid containing LpIA acceptor peptide (LAP). Generally, the labelling is enabled by the LpIA catalysed reaction with an alkyl azide, which is selectively functionalised with a fluorophore bearing a cyclooctyne moiety. In contrast to the previously discussed enzymes, intein is a self-modifying enzyme, which was first utilised by MUIR et al. as a tool for protein semisynthesis. ${ }^{[14]}$ To introduce intein it is expressed at the $C$-terminus of the POI. After the formation of a thioester between $C$-terminus of the POI and linked intein, thiol exchange reaction with any cysteine containing moiety occurs, to which a fluorophore is attached, affording the desired labelled POI. ${ }^{[15,16]}$ The major disadvantage of these described enzymatic labelling methods (see Figure 1: enzymatic) is the disability to label a protein of interest in the middle of its sequence.

The tag labelling is an approach, which allows labelling at different sites ( $N$-terminal, $C$-terminal and internal) combined with the introduction of only small artificial sequences, which thereby have a smaller influence on the function and activity of POls, and with high selectivity of the labelling process. ${ }^{[3]}$ Of the large diversity of different tags, only the three most commonly utilised will be introduced here (see Figure 1: tag). GRIFFIN et al. introduced the cysteine tag (Cys-Cys-X-X-Cys-Cys), which is addressed by a biarsenical ligand (such as FIAsH-EDT $2=4^{\prime}, 5^{\prime}$-bis(1,3,2-dithioarcolan-2yl)fluorescein). ${ }^{[17]}$ This bisarsenical ligand is membrane permeant and non-fluorescent until it binds with high affinity to the tetracysteine sequence. One of the drawbacks of this method is background labelling, which occurs as single or multiple cysteines also interact with these dyes, even though in a smaller amount. A second tag technique worth mentioning is the histidine tag, an oligohistidine sequence of six histidines or more, which selectively coordinates nickel ions, as discovered by HOCHULI et al. in 1987. ${ }^{[18]}$ GUIGNET et al. applied this method for labelling by introducing a fluorescent probe to complexes such as $\mathrm{Ni}(\mathrm{II})$ nitrilotriacetic acid (Ni(II)NTA). ${ }^{[19]}$ With these complexes genetically encoded His tags of membrane proteins are labelled in vivo. Besides the histidine tags, an aspartate tag (AspAsp-Asp-Asp), which coordinates Zn(II) ion is utilised for in vitro and in vivo labelling. OJIDA et al. showed a high selectivity and affinity for the binuclear Zn(II)-Dpa (2,2'-dipicolylamine) complex based on a tyrosine scaffold, where a fluorophore probe is attached to tyrosine. ${ }^{[20]}$ Comparable to the His tag, this method provides a system for the labelling of membrane proteins acting orthogonal to His tags without having the disadvantages included by Cys tag labelling.

Another approach, which includes the introduction of small fluorescent probes, but provides covalent linkages in contrast to tag labelling, is chemical labelling. It is mostly applied in vitro rather than in vivo 
and either utilises natural occurring amino acids or the introduction of unnatural amino acids. A detailed overview of the different bioorthogonal methods, which are applied for chemical labelling is given in the following chapter.

\subsection{Chemical labelling - bioorthogonal reactions}

The easiest chemical labelling approach comprises the reaction of activated fluorophores with side chains of intrinsic proteogenic amino acids. The amino acids mostly addressed are lysine and cysteine. A great number of amine labelling reactions (of either the $\varepsilon$-amino group of lysine or $N$-terminal amino group) are facilitated by the reaction with $\mathrm{N}$-hydroxysuccinimide ester (NHS-ester) activated fluorophores (Scheme 2, A). This reaction occurs fast, in high yields and forms a stable amide bond. Due to the high occurrence of lysine in almost all proteins, the labelling reaction is not specific enough for most systems. ${ }^{[3]}$ In comparison, cysteine is less prevalent and is at a $\mathrm{pH}$ range of 6.5-7.5 specifically labelled by a MICHAEL addition with maleimide activated fluorophores (Scheme 2, B). At higher pH values, unwanted side reactions with amines take place. ${ }^{[21]}$ Labelling reactions with the remaining 18 proteogenic amino acids have only been minimally exploited, and will not be further discussed here. In addition to side chain modifications, the $N$-terminus is also available for labelling reaction e. g. by NATIVE Chemical LIGATION (in the presence of a $N$-terminal cysteine). ${ }^{[22]}$

In addition, the introduction of unnatural amino acids for application in bioorthogonal labelling reactions is widely utilised. The breakthrough in bioorthogonal chemistry was the development of the copper(I)-catalysed azide-alkyne cycloaddition (CUAAC) independently by SHARPLESS et al. and MELDAL et al. in 2002 (Scheme 2, C). ${ }^{[23,24]}$ The copper(I) catalyst strongly enhances the reaction of an azide with a terminal alkyne. While CuAAC is widely applied in vitro, the cell toxicity of copper(I) minimises its applicability in vivo. The strain-promoted azide-alkyne cycloaddition (SPAAC) obviates the need for copper(I), by utilising reactive cyclooctyne scaffolds. ${ }^{[25]}$ The drawback of this method is the quick reaction of cyclooctyne and its derivatives with cellular nucleophiles, e. g. thiols. The reaction rate of CUAAC is enhanced by the introduction of tris(triazolylmethyl)amine ligands (including TBTA and its derivatives), which also protect copper(I) from oxidation. ${ }^{[26]}$ Furthermore, BROTHERTON et al. described an azide substrate containing an auxiliary ligand (such as picolyl azide) and thereby increasing the reaction rate, by directing copper to the azide moiety. ${ }^{[27]}$ By the combination of these techniques, the reaction of azides and alkynes is accomplished even in vivo. 
A<smiles>Nc1ccccc1</smiles><smiles>O=C(ON1C(=O)CCC1=O)c1ccccc1</smiles><smiles>C=C</smiles><smiles>O=C(Nc1ccccc1)c1ccccc1</smiles>

B<smiles>Sc1ccccc1</smiles><smiles>[R]CCC1CCCCC1CN1C(=O)C=CC1=O</smiles><smiles>O=C1CC(Sc2ccccc2)C(=O)N1Cc1ccccc1</smiles>

C<smiles>[NH3+]c1ccccc1</smiles><smiles>C#Cc1ccccc1</smiles><smiles>[R]C1CCCCC1c1cn(-c2ccccc2)nn1</smiles>

D<smiles>[N]c1ccccc1</smiles><smiles>COC(=O)c1ccccc1-c1ccccc1</smiles><smiles>[R][Y]1(c2ccccc2)C=CC(P)=C(C(=O)Nc2ccccc2P)C=C1</smiles>

E

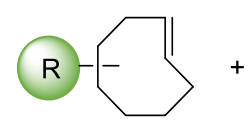<smiles>[R]CCc1nnc([R])nn1</smiles><smiles>CCCCC</smiles>

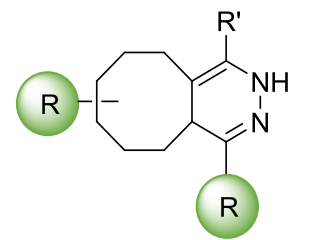

Scheme 2: Overview of chemical labelling techniques frequently applied. A) and B): reactions with natural occurring amino acids, C): copper(I)-catalysed azide-alkyne cycloaddition, D): STAUDINGER ligation, E) inverse electron demand DIELS-ALDER reaction.

An additional method making use of azide functionality is the STAUDINGER ligation (Scheme 2, D). The reaction of an azide with a triaryl phosphine is a popular choice for in vivo labelling owing to its selectivity and compatibility with cells and tissues although being slower than most other bioorthogonal techniques. ${ }^{[28]}$ Furthermore, DIELS-ALDER cycloadditions are being employed for chemical labelling. BLACKMAN et al. described the reaction of tetrazines with trans-cyclooctene derivatives in water and cell media, tolerating a broad range of functionalities (Scheme 2, E). ${ }^{[29]}$ As this is one of the fastest bioorthogonal reactions so far, it was immediately applied to a number of investigations.

In this thesis labelling was performed either directly, meaning the target was labelled (see chapter 6 "Labelling of cyclic adenosine-3',5'-monophosphate"), or indirectly, meaning the targets, being ion channels in this thesis, were addressed by specific, labelled compounds. In order to address ion channels specifically, neurotoxins are being widely applied, which will be discussed in the following section. 


\subsection{Labelling of ion channels using neurotoxins}

Ion channels are pore-forming transmembrane proteins, which are responsible for signal translation and propagation in excitable cells, such as muscle or nerve cells. They play key roles in the generation and shaping of action potentials. ${ }^{[7]}$ In order to study their localisation and distribution, two major methodical approaches have been pursued. The first approach is the application of the patch-clamp technique to detect ion currents across membranes, which allows the monitoring of channel activity in localised regions of plasma membranes. However, the distribution of ion channels in whole cell membranes of living cells cannot be assigned by applying this method. ${ }^{[30]}$ The second approach is specific labelling by immunostaining, in which labelled antibodies are applied for the direct imaging of specific proteins. Although a number of antibodies for ion channels are commercially available, most of these address intracellular epitopes, generating the need for cell fixation and permeabilisation prior to labelling experiments. While there are some antibodies on the market addressing extracellular epitopes, the selectivity towards specific ion channels is limited due to the high sequence homology between the extracellular domains of different ion channels. ${ }^{[31]}$

These problems are overcome by the implementation of labelled neurotoxins. Neurotoxins, derived from animal venoms, are potent tools for distinguishing the various isoforms of channels. Recently, toxin labelling was extended from radiolabelling, which has the disadvantage of working with radioactivity, to the labelling with fluorophores, which are attached by the application of bioorthogonal strategies (described in chapter 2.2). The site-specific introduction of fluorophores has already been described for a few toxins, including hongotoxin, stichodactyla toxin, $\alpha$-conotoxin and iberiotoxin. ${ }^{[32-36]}$ These labelled toxins have a broad applicability, e. g. labelled hongotoxin is utilised to investigate the localisation of potassium channels in different brain sections. ${ }^{[32]}$ Due to the high diversity of different ion channels and their existing subtypes, the need for specific binding toxins bearing a fluorescent marker is still great.

This thesis focusses on three major neurotoxins: $\mu$-conotoxin SIIIA, pompilidotoxin and iberiotoxin, whose targets are specific ion channels such as voltage-gated sodium channels and large conductance calcium- activated potassium channels.

The first targets of this study are voltage-gated sodium channels (VGSCs), which control the flux of sodium ions across cell membranes. When the cell interior is at a potential much more negative than the exterior (-80 mV), VGSCs are in a closed state. Upon depolarization, e. g. to -40 mV, VGSCs open. The resulting sodium influx is the basis of action potential generation and propagation in excitable cells. Activation of the channels is followed by a transition into an inactivated, closed state, which 
renders the cells refractory for new stimuli. Subsequent de-inactivation makes the channels available again. ${ }^{[37]}$ Structurally, VGSCs consist of a core protein ( $\alpha$-subunit), enabling sodium ion permeability, and one or more regulatory subunits. Until now, nine mammalian $\alpha$-subunit isoforms (Nav1.1-Nav1.9) are known. Our cooperation partners NEEF and co-workers are interested in visualising sodium channels Nav1.2 and Nav1.6, which are mainly expressed in the central nervous system. Up to now, there is a long-standing discussion about the local density of these sodium channels in the axon-initial segment of pyramidal cells. COLBERT and PAN observed via patch-clamp experiments a low density comparable to that of the somatic membrane, whereas immune-histochemistry studies, for instance by WolLner and CATERALL, suggested a high density. ${ }^{[38,39]}$ To clarify the local density of these channels advanced single-molecule imaging can be used. The visualisation of Nav1.2 and Nav1.6 may be accomplished by synthesis of labelled neurotoxins that bind specifically to these channels. The toxin of choice was $\mu$-conotoxin SIIIA, a 20 amino acid peptide with a rigid structure stabilized by three disulphide bridges. The synthesis and labelling will be discussed in chapter 3: "Labelling and caging of conotoxin". Within this topic a caged conotoxin will also be presented, which might be used to further investigate sodium channels.

Neurotoxins are also used to influence the gating properties of ion channels. Pompilidotoxin, a small linear peptide, slows or abolishes the inactivation of VGSCs. This neurotoxin is less specific than $\mu$-conotoxin as it binds to Nav1.1-1.3 and Nav1.6-1.7 although, Nav1.2 and Nav1.6 are the isoforms with the highest affinity. ${ }^{[40]}$ However, it is much easier to synthesize and label because of the lack of disulphide bridges. The SCHILD research group was interested in a labelled pompilidotoxin to study the involvement of VGSCs in odour sensing in olfactory receptor neurons. The synthesis and labelling of pompilidotoxin will be discussed in chapter 4: "Labelling of pompilidotoxin".

Additionally, large conductance calcium-activated potassium channels (also known as big potassium channels $=$ BK channels) were targeted. These channels, together with voltage-gated calcium channels (VGCCs), are involved in the fine tuning of action potentials in many neurons. Upon depolarization as a result of a stimulus, VGCCs are activated. The following influx of $\mathrm{Ca}^{2+}$ further depolarizes the cell and the local $\mathrm{Ca}^{2+}$ concentration is increased. This leads to an activation of BK channels congregating with VGCCs. The outward flow of $\mathrm{K}^{+}$repolarizes the cell, resulting in the closing of VGCCs and priming the cell for another cycle of oscillation. ${ }^{[41]}$ The involvement of these channels in odour sensing in olfactory receptor neurons (ORNs) is being investigated by BAO in the SCHILD research group. Recent studies by BAO show a co-localisation of VGCCS and BK channels on the surface of ORNs of Xenopus laevis (see Figure 2). ${ }^{[42]}$ In these studies, localisation of VGCCs is accomplished by using Fluo-5F, a fluorescent calcium indicator exhibiting a hundredfold increase in fluorescence upon the binding of calcium. 
BK channels are visualized by labelling iberiotoxin (Ibtx), a BK channel specific toxin, with Alexa Fluor ${ }^{\circledast}$ 488 or 546 protein labelling kit. As these kits specifically label amines and lbtx contains $5(+1$, if the $\mathrm{N}$-terminus is free) amine groups, multiple labelling may occur. A quantification study on the number of fluorophores per Ibtx reveals that three to four fluorophores are attached to one Ibtx, making a further quantification study of BK channels impossible. ${ }^{[42]}$ For a precise quantification of BK channels present in VGCC/BK channel clusters mono-labelled Ibtx need to be developed. This will be discussed in chapter 5 "Labelling of iberiotoxin".
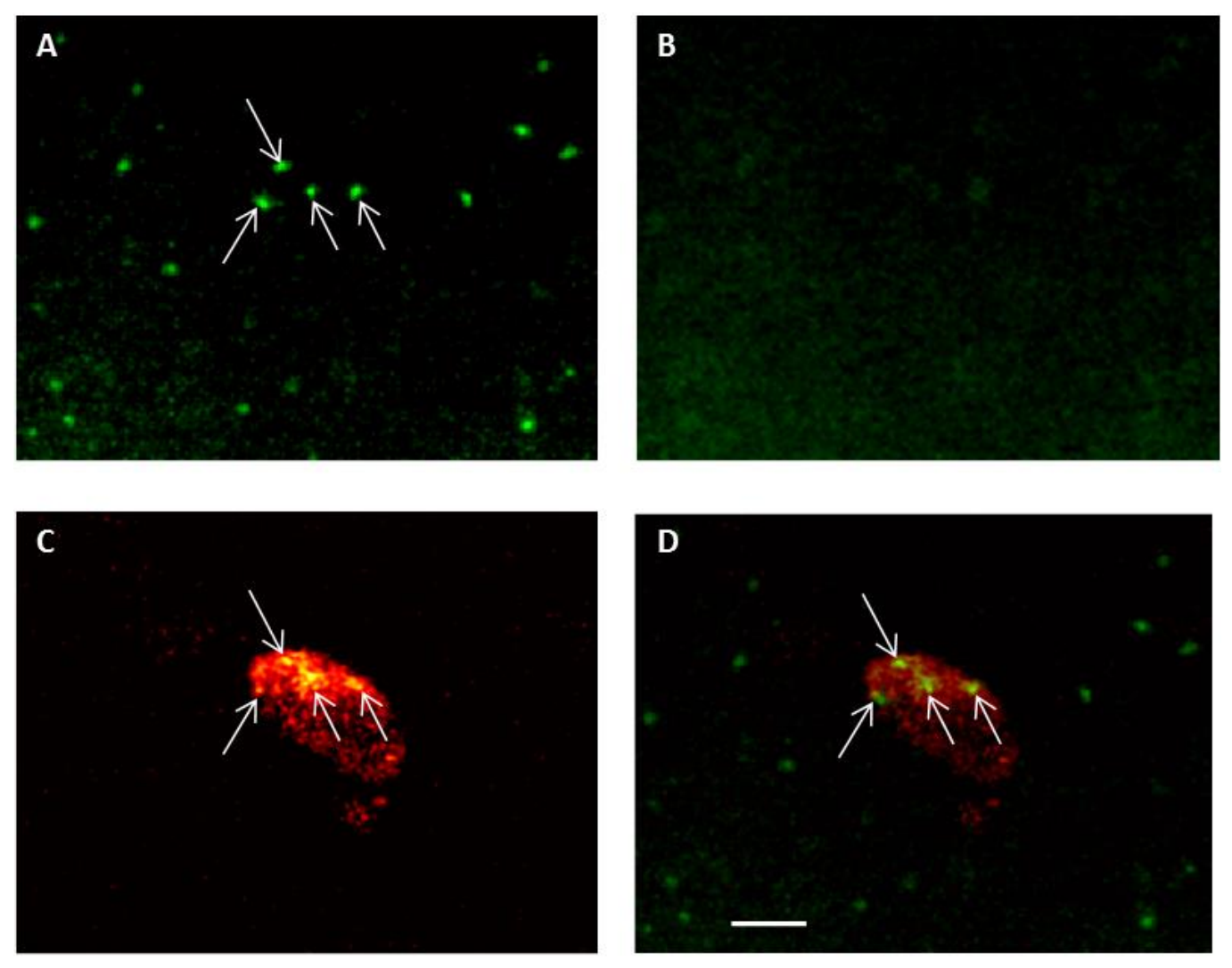

Figure 2: Co-localisation of BK channels and VGCCs (scale $=5 \mu \mathrm{m})$. (A) Image of BK channels stained with Alexa Fluor $^{\circledR} 488$ labelled Ibtx. (B) Image after washing for $30 \mathrm{~min}$ after staining. (C) Image of VGCCs during depolarization stained with Fluo-5F. (D) Images (A) and (C) merged together, arrows indicate co-localisation. ${ }^{[42]}$ 


\section{Labelling and caging of conotoxin}

Conotoxins were first isolated and characterized almost four decades ago. Rapidly, they have emerged as valuable neuroscience probes and drug leads because of their unparalleled potency and selectivity for ion channels and membrane receptors. ${ }^{[43,44]}$ Conotoxins are produced by cone snails together with a mixture of other conopeptides to paralyze their prey. Up to now, around 700 species of cone snails have been discovered, each of them expressing an extensive variety of conopeptides. This leads to an enormous diversity of conotoxins with around 1700 toxins researched so far. ${ }^{[45,46]}$ These toxins act on a wide range of ion channels such as voltage-gated sodium-, potassium- and calcium-channels as well as ligand-gated ion channels, for instance nicotinic acetylcholine receptors and serotonin receptors. ${ }^{[4]}$ Additional targets are the adrenergic receptor and the norephinephrine transporter. ${ }^{[48,49]}$ Having such a variety of targets, conotoxins are used to gain further information about them at the pharmacological, physiological or structural level. ${ }^{[50-53]}$ Besides, they serve as drug candidates such as Prialt ${ }^{\circledR}$, a $\omega$-conotoxin, which is the first marine drug approved by the US Food and Drug Administration (FDA) having potent and selective calcium channel activity and therefore is used to treat chronic pain. ${ }^{[54]}$

Structurally, conotoxins are mainly small peptides composed of 10 to 45 amino acid residues. ${ }^{[47]}$ They contain multiple disulphide bonds and post-translational modifications (PTMs) accounting for the high diversity of conotoxins found in nature. The disulphide bonds are important for the structure and thereby function of conotoxins as they constrain and define the three-dimensional structure. In vivo conotoxins are first translated as a precursor. The $\mathrm{N}$-terminal propeptide then facilitates proteindisulphide-isomerase (PDI)-catalysed folding of the conotoxin precursor (see Scheme 3). Whether posttranslational modification occurs before, concurrent with, or after the formation of disulphide bonds is not yet determined. ${ }^{[55]}$ Identified modifications include $N$-terminal modifications, $C$-terminal modifications, hydroxylation, $\mathrm{Y}$-carboxylation, sulphation, bromination, $O$-glycosylation, and epimerization. ${ }^{[56]}$ In contrast, the in vitro synthesis of conotoxins is more challenging because of a missing complex folding apparatus present in vivo. 


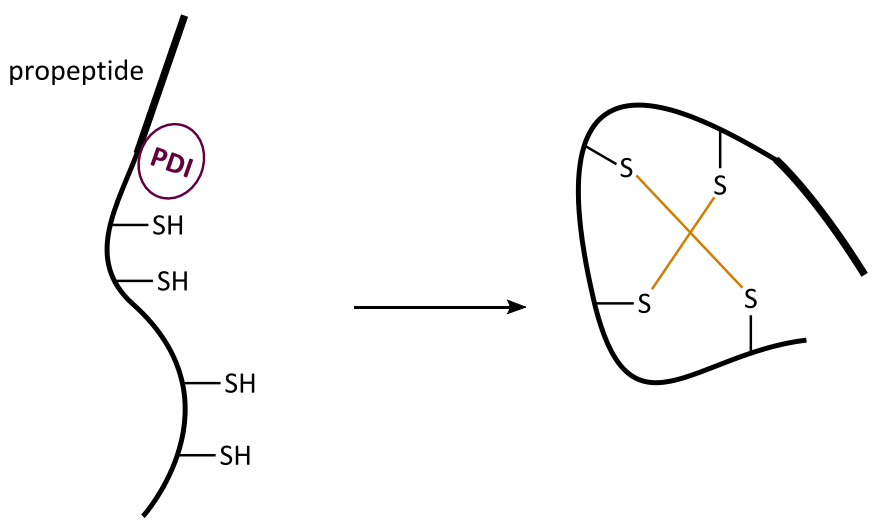

Scheme 3: Native folding of the conotoxin precursor. The $\mathbf{N}$-terminal propeptide facilitates binding of PDI catalysing the folding process. ${ }^{[55]}$

\subsection{Synthesis of disulphide rich peptides}

Today two approaches are being employed for the synthesis of conotoxins. The first one is using recombinant expression in heterologous expression systems such as $E$. coli which is applied for a number of conotoxins. ${ }^{[57-59]}$ Introducing unnatural amino acids, which is sometimes needed for the attachment of labels and incorporation of a variety of PTMs, is still a challenging task using recombinant expression. Due to the small size of conotoxins a second approach using chemical synthesis is applied. This method eliminates undesired (host) protein contamination by the use of recombinant expression and facilitates more control over disulphide bridging as well as the introduction of modifications. ${ }^{[47]}$ The first step of the synthesis of conotoxins is solid phase peptide synthesis (SPPS) using the Boc/Bzl or Fmoc/t Bu strategy. ${ }^{[60-63]}$ Difficulties concerning aggregation, secondary structure formation, incomplete coupling/ $\mathrm{Na}$-deprotection, and racemisation are overcome by using an optimized Boc in situ neutralization protocol coupled with SPPS if necessary. ${ }^{[64]}$ The second step of the synthesis is oxidation of cysteine amino acids forming distinct disulphide bridges and thereby inducing a folding of the conotoxin. Correct oxidative folding is important for the formation of secondary structures such as $\alpha$-helices, $\beta$-sheets and turns which are crucial for receptor recognition, potency and selectivity. The number of possible isomers during this step depends on the number of cysteine residues present in the peptide explicitly: $(2 n) ! /\left(2^{n} n !\right)$ with $n$ being the number of disulphide bonds, resulting in e. g. 15 possible isomers for three disulphide bridges excluding topological isomers. ${ }^{[4]}$ Thus far, conotoxins have been known to have five disulphide bridges at the most, therefore, correct formation of all disulphide bridges is highly important. ${ }^{[45,46]}$ In the following section the oxidative folding will be described using firstly random oxidation of the fully deprotected peptide and secondly regioselective oxidation using different protecting groups and strategies. 
Additionally, chemical modifications will be shown that simplify the synthesis of conotoxins and expand their stability.

\subsubsection{Direct oxidative folding}

Direct oxidative folding has the advantage of limited steps, as few, if any, different protecting groups need to be applied. As described above either the fully deprotected peptide is used or the cysteine residues are protected e. g. using the acetoamidomethyl $(\mathrm{Acm})$ or tert-butylthio $\left(\mathrm{S}^{t} \mathrm{Bu}\right)$ group. These groups are orthogonal to both $\mathrm{Fmoc} /{ }^{\mathrm{t}} \mathrm{Bu}$ and $\mathrm{Boc} / \mathrm{Bzl}$ strategies and thereby purification of the crude peptide is possible prior to deprotection of the cysteine residues and oxidative folding. Chromatographic purification of peptides containing free cysteine residues may lead to partial oxidation, which hinders efficient chromatography. ${ }^{[65]}$ The free cysteine containing peptide is then employed for oxidative folding involving several processes namely oxidation, reduction, isomerization or scrambling. ${ }^{[6]}$ Oxidative folding is conducted using either disulphide-containing small molecules (e. g. oxidized glutathione or cystine), electron accepting reagents (e. g. molecular oxygen or dimethyl sulphoxide) or a recently investigated selenoxide reagent. ${ }^{[67,68]}$ Disulphide containing small molecules reversibly react with cysteine residues initially forming mixed disulphide species. The rate of this step depends on the $\mathrm{pK}_{\mathrm{a}}$ of the thiol and therefore on the environment of the thiol as well as on the $\mathrm{pH}$ of the solvent. Afterwards the asymmetric disulphide is attacked by another peptide thiolate generating the desired disulphide bridge and correct folding at the same time. In the second approach using electron accepting reagents, the first step is oxidation of peptide thiolate to a peptide sulphenic acid which is attacked by a second thiolate leading to the formation of the disulphide bridge (see Scheme 4A). ${ }^{[67]}$ The recently investigated selenoxide reagent 1 reacts with the peptide thiolate to form an unstable Se-S-intermediate which is rapidly attacked by another peptide thiolate to form the disulphide bridge and $\mathbf{2}$ as a byproduct (see Scheme 4B). This method accepts a wide $\mathrm{pH}$ range of 3-9. ${ }^{[68]}$

A

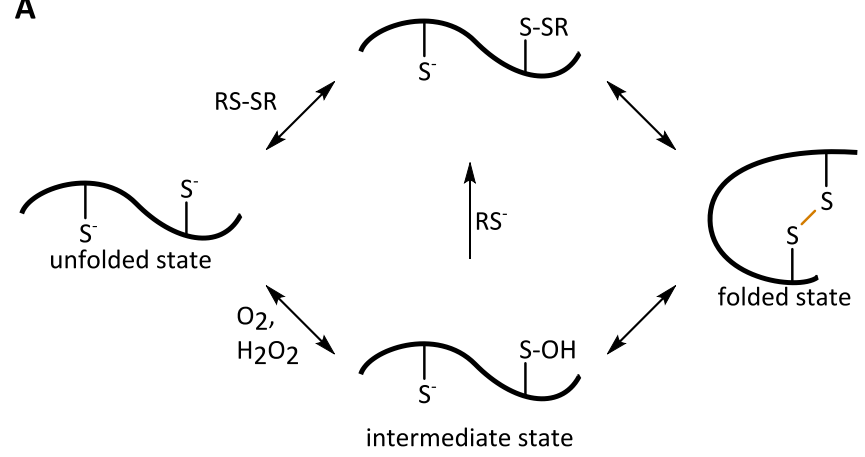

B

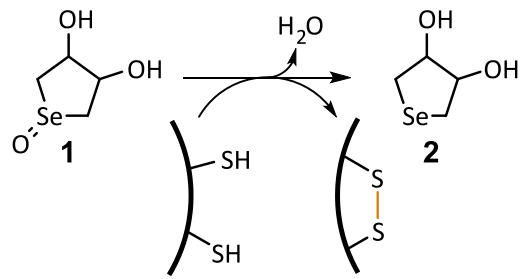

Scheme 4: Oxidative folding using A: disulphide containing small molecules or electron accepting reagents or B: recently investigated selenoxide reagent $1 .{ }^{[67,68]}$ 
In all these methods the disulphide bridge can be formed either intra- or intermolecular dictating the need to work under high dilution in order to prevent the formation of oligomeric side products. ${ }^{[67]}$ Moreover, an already formed disulphide bridge may be attacked by another peptide thiolate from the same molecule, leading to a reshuffling of disulphide bridges. ${ }^{[67]}$ This process allows the formation of the more thermodynamically stable disulphide isomers. Random oxidative folding is influenced by proximity, reactivity, accessibility and concentration of thiolate groups with accessibility of thiol groups to the intermediate species being the most important. ${ }^{[69,70]}$ Additionally, the relative position of cysteine residues of peptides determine the kinetic of folding, namely those furthest away from each other slow down the folding process the most. ${ }^{[71]}$ In order to obtain the native peptide in good yields different conditions have to be tested for each disulphide-rich peptide e. g. changing temperature, concentration of the peptide, ionic strength of the solvent, $\mathrm{pH}$, electron-accepting reagent or redox species, and folding additives (e. g. surfactants or organic cosolvents). ${ }^{[67]}$ Nevertheless, random oxidative folding is mostly applied for natural peptides and has the disadvantage of the formation of different disulphide connectivities leading to several products being hard to purify. ${ }^{[72]}$

\subsubsection{Regioselective oxidation using different protecting groups}

To overcome the problem of having products with different disulphide connectivities, regioselective oxidation is employed. Therefore, the peptide is protected with orthogonal protecting groups for each disulphide bridge permitting a stepwise formation of cystines. The disulphide bridges are formed either on solid support using the pseudo-dilution effect preferring intramolecular disulphide bridges, or by a mixture of formation on solid support and in solution, or by forming all disulphide bridges in solution applying different protecting groups. During all steps of deprotection and disulphide bridging it is highly important to keep a slightly acidic $\mathrm{pH}$ to prevent thiol-disulphide exchange reactions leading to reshuffling and scrambling of the disulphide bridges. ${ }^{[47]}$

As the field of different cysteine protecting groups is immense, only an outline of most common protecting groups and those utilised in this work is given below (see Table 1). Most of the thiol protecting groups employed today are acid sensitive. Hence, $\mathrm{Fmoc} /{ }^{t} \mathrm{Bu}$ rather than Boc/Bzl strategy is mostly applied to synthesize fully protected peptides. ${ }^{[73]}$ Only the 2-pyridinesulphenyl (SPyr) protecting group is not stable to basic conditions as it activates the cysteine thiol group to facilitate an attack of another free thiol. ${ }^{[74]}$ Thus, this protecting group is implemented into peptides after SPPS to prepare disulphide linkage. For syntheses of multiple disulphide bridges containing peptides the order of cleavage/deprotection of cysteines is highly important. For example the tert-butylthio $\left(S^{t} \mathrm{Bu}\right)$ group is cleaved reductively, therefore the resulting disulphide bridge has to be formed first, as otherwise already formed disulphide bridges will be reduced during this deprotection step. Additionally, 
sensitivity of deprotected functional groups towards sequential deprotection conditions has to be evaluated before considering disulphide bridges formation strategy. For instance, the commonly used Acm group is usually cleaved by iodine which possibly leads to an oxidation of methionine, histidine, tryptophan, or tyrosine residues, or a shift of Acm towards serine or threonine. ${ }^{[47,75,76]}$ To prevent these problems the group of ALBERICIO proposed the new protecting group phenylacetoamidomethyl (Phacm) having the same stability as Acm. However, this protecting group is cleaved using the enzyme penicillin $\mathrm{G}$ acylase (PGA) offering mild deprotection conditions. ${ }^{[77,78]}$ The enzyme is highly specific for the phenylacetyl residue, retaining Acm groups during Phacm cleavage.

Table 1: Thiol protecting groups for peptide synthesis. ${ }^{[78-83]}$

\begin{tabular}{|c|c|c|c|}
\hline Protecting group & Structure & Stability & Removal \\
\hline Triphenylmethyl (Trt) & & $\begin{array}{l}\text { base, } \\
\text { nucleophiles }\end{array}$ & $\begin{array}{l}\text { diluted TFA/scavenger, } \mathrm{I}_{2} \text {, } \\
\mathrm{Ag}(\mathrm{I}), \mathrm{Hg}(\mathrm{II}), \mathrm{Ti}(\mathrm{III}), \mathrm{RSCl}\end{array}$ \\
\hline Dimethoxytrityl (Dmt) & OMe & base & diluted TFA/scavenger \\
\hline Acetoamidomethyl (Acm) & & $\begin{array}{l}\text { TFA, } \mathrm{HF}\left(0^{\circ} \mathrm{C}\right) \text {, } \\
\text { base }\end{array}$ & $\begin{array}{l}\mathrm{I}_{2}, \mathrm{Hg}(\mathrm{II}), \mathrm{Ag}(\mathrm{I}), \mathrm{Ti}(\mathrm{III}), \mathrm{RSCl}, \\
\mathrm{Ph}_{2} \mathrm{SO} / \mathrm{MeSiCl}_{3}\end{array}$ \\
\hline tert-Butylthio $\left(\mathrm{S}^{t} \mathrm{Bu}\right)$ & & $\begin{array}{l}\text { TFA, HF (partial), } \\
\text { base, } \mathrm{RSCl}\end{array}$ & $\mathrm{RSH}, \mathrm{Bu}_{3} \mathrm{P},\left(\mathrm{HOOCCH}_{2} \mathrm{CH}_{2}\right)_{3} \mathrm{P}$ \\
\hline tert-Butyl ( $\left.{ }^{t} \mathrm{Bu}\right)$ & & $\begin{array}{l}\text { TFA, HF }\left(0^{\circ} \mathrm{C}\right), \\
\operatorname{Ag}(\mathrm{I}), \mathrm{I}_{2}\end{array}$ & $\begin{array}{l}\mathrm{HF}\left(20^{\circ} \mathrm{C}\right), \mathrm{Hg}(\mathrm{II}), \mathrm{RSCl} \\
\mathrm{Ph}_{2} \mathrm{SO} / \mathrm{MeSiCl}_{3}\end{array}$ \\
\hline 2-Pyridinesulphenyl (SPyr) & & acid & RSH, thiocarboxylic acid, DTT \\
\hline $\begin{array}{l}\text { Phenylacetoamidomethyl } \\
\text { (Phacm) }\end{array}$ & & TFA, HF, base & $\begin{array}{l}\text { penicillin aminohydrolase, } \\
\mathrm{Hg}(\mathrm{II}), \mathrm{Ti}(\mathrm{III}), \mathrm{I}_{2}\end{array}$ \\
\hline 4-Methylbenzyl (Mbzl) & & $\begin{array}{l}\text { TFA, Ag(I), base, } \\
\text { RSCl }\end{array}$ & $\begin{array}{l}\mathrm{HF}\left(0^{\circ} \mathrm{C}\right), \mathrm{Ti}(\mathrm{III}), \\
\mathrm{Ph}_{2} \mathrm{SO} / \mathrm{MeSiCl}_{3}\end{array}$ \\
\hline
\end{tabular}

The disulphide bridge formation strategies being mostly applied are shown in Table 2 . The first disulphide bridge is protected using either Trt or $S^{t} B u$ offering the possibility to decide whether to purify the peptide prior to regioselective oxidation $\left(S^{t} \mathrm{Bu}\right)$. Furthermore, the $\mathrm{Acm},{ }^{t} \mathrm{Bu}$ and $\mathrm{Mbz}$ groups are common protecting groups for the $2^{\text {nd }}$ and $3^{\text {rd }}$ disulphide bridge formation. To carry regioselective 
oxidation to the extreme CUTHBERTSON et al. synthesized an $\alpha$-conotoxin dimer peptide containing four disulphide bridges using Trt, Acm, ${ }^{t} \mathrm{Bu}$ and Mbzl successively. This is the first example of using four distinct protecting groups to produce conotoxin analogues. ${ }^{[84]}$

Table 2: Common regioselective oxidation protocols for peptides containing 1-3 disulphide bridges using Fmoc/ ${ }^{t} \mathrm{Bu}$ strategy. ${ }^{[73]}{ }^{1}$ Deprotection and cleavage from the resin using TFA. ${ }^{2} \mathrm{I}_{2} / \mathrm{AcOH} / \mathrm{H}_{2} \mathrm{O}, \mathrm{Cys}(\mathrm{Acm})$ and Cys(Trt) are oxidized in different rates in chloroform, dichloromethane and 2,2,2-trifluorethanol. ${ }^{3}$ Phosphinemediated reductive cleavage. ${ }^{4} \mathrm{DMSO} / \mathrm{TFA}$ at $\mathrm{rt}$ or PheS(O)Phe/MeSiCl $3 / \mathrm{TFA} .{ }^{5} \mathrm{DMSO} / \mathrm{TFA}$ at $60{ }^{\circ} \mathrm{C}$.

\begin{tabular}{|l|l|l|}
\hline $1^{\text {st }}$ disulphide & $2^{\text {nd }}$ disulphide & $3^{\text {rd }}$ disulphide \\
\hline $\mathrm{Trt}^{1}$ & $\mathrm{Acm}{ }^{2}$ & \\
\hline $\mathrm{S}^{t} \mathrm{Bu}^{3}$ & $\mathrm{Acm}{ }^{2}$ & \\
\hline $\mathrm{S}^{t} \mathrm{Bu}^{3}$ & $\mathrm{Trt}^{2}$ & $\mathrm{Acm}^{2}$ \\
\hline $\mathrm{Trt}^{1}$ & $\mathrm{Acm}^{2}$ & ${ }^{t} \mathrm{Bu}^{4}$ \\
\hline $\mathrm{Trt}^{1}$ & ${ }^{t} \mathrm{Bu}^{4}$ & $\mathrm{Mbz}^{5}$ \\
\hline
\end{tabular}

In addition to the influence of employing different protecting groups, the distribution of these groups along a peptide sequence strongly affects the outcome of the synthesis. ${ }^{[85,86]}$ Despite the regioselectivity of sequentially synthesized disulphide rich peptides the formation of multiple products is still possible. For instance, two topological isomers are isolated during the synthesis of enterotoxin with the incorrectly folded isomer being completely converted into native conformation using redox reagents (e. g. glutathione). The folding of the topological isomer appears to be regulated by the last disulphide bond formation defining the conformation of final product which is either a right-handed (native isomer) or left-handed spiral (topological isomer). ${ }^{[87,88]}$ In addition to using different protecting groups regioselectivity is reached by the introduction of modifications, e. g. selenocysteines. This topic will be discussed further in the next chapter.

\subsubsection{Synthetic modifications of conotoxins}

Due to the drug potential of conotoxins many modifications are investigated to increase their stability and activity. Until now the peptidomimetic strategy, developing a rational design of organic scaffolds and thereby topographically mimicking key binding elements of native conotoxins, resulted in losses of activity. ${ }^{[89]}$ Another commonly used technique is to slightly alter native conotoxins to improve their properties as drugs (see an overview in Figure 3). Owing to high lability of cystine frameworks to reducing environment disulphide isosters, such as diselenide, dicarba, cystathionine as well as lactam bridges were introduced instead of disulphide bridges. ${ }^{[00-93]}$ Especially the selenoconotoxins are being widely used as these analogues showed an improved stability to reductive conditions. ${ }^{\left[{ }^{[4]}\right.}$ 


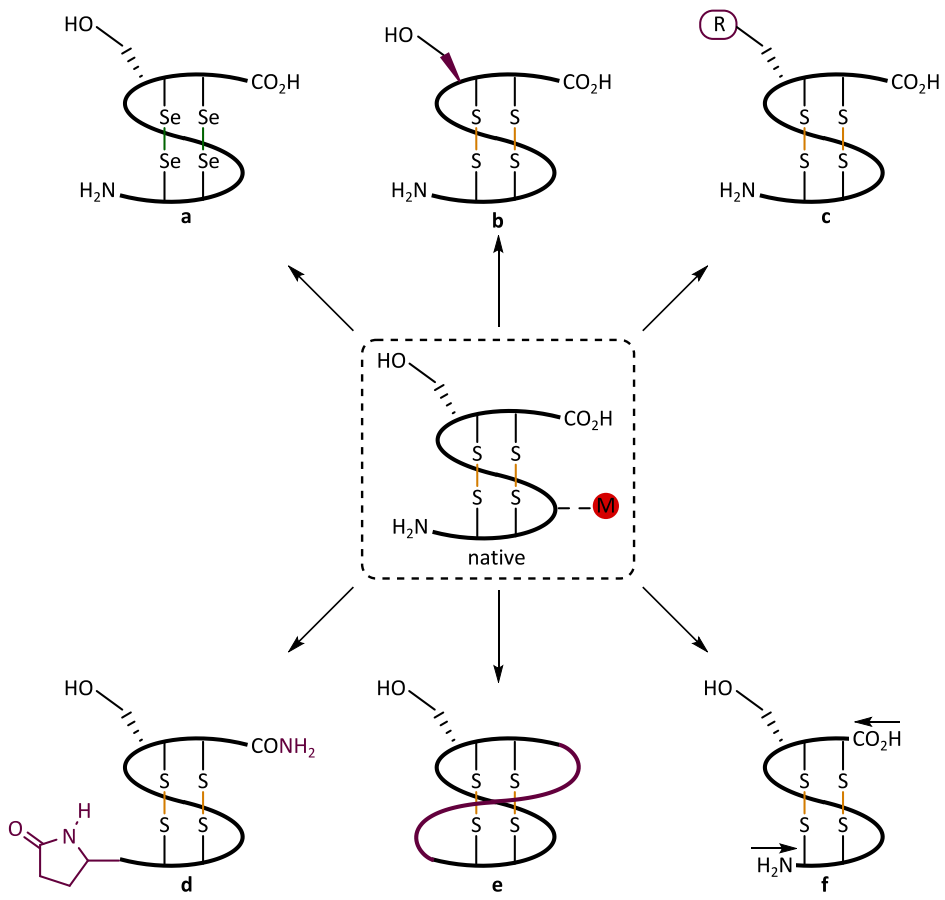

Figure 3: Overview of synthetic modifications applied to conotoxins. Unstable residues such as methionine (M), which is easily oxidized in nature, are substituted in modified peptides. a) cystine isosters (e. g. selenocystine) b) inversion of selected residues c) side chain modification d) $\mathbf{N}$ - and $\boldsymbol{C}$-terminal capping e) backbone cyclization $\mathrm{f}$ ) truncation of $\boldsymbol{N}$ - and $\boldsymbol{C}$-termini. ${ }^{\text {[95] }}$

Another way of increasing stability is sequence modification. Several amino acids such as methionine or arginine residues are easily degraded (e. g. by oxidation); hence, these residues are being replaced if possible. ${ }^{[96,97]}$ Additional attempts to reduce proneness towards proteolytic degradation are the substitution of L- versus D-amino acids, being employed for $\omega$-conotoxins MVIIA and CVID. ${ }^{[98,99]}$ Further approaches include side chain modifications such as adding lipid tags or introducing additional posttranslational modifications either on the side chains or the $\mathrm{C}$ - and $\mathrm{N}$-termini improving bioavailability and stability. ${ }^{[100-104]}$ Besides, the structure is simplified e. g. by inserting flexible spacer as backbone replacement or truncation of the peptide sequence. ${ }^{[105-107]}$ The stability of conotoxins towards degradation may be improved by cyclization joining the $C$ - and $N$-termini using amino acid linker. ${ }^{[108,109]}$ To conclude, many modifications of conotoxins are known today to increase stability of these peptides. For every peptide evaluations have to be made of the influence on potency, as some modifications might reduce, increase or modulate the affinity towards special targets.

\subsection{Synthesis of labelled $\mu$-conotoxin SIIIA}

The main target of this thesis was the synthesis of labelled $\mu$-conotoxin SIIIA (short $\mu$-SIIIA) which is one of the $\mu$-conotoxins selectively inhibiting voltage-gated sodium channels (VGSC). VGSCs are responsible for the influx of sodium ions during action potentials. ${ }^{[110]}$ The recent determination of 
crystal structures of bacterial VGSCs offers the opportunity for simulations of mammalian VGSCs leading to molecular dynamics studies of binding of $\mu$-conotoxins. ${ }^{[111-115]}$ Exemplarily, the docking of $\mu$-GIIIA to VGSC Nav1.4 directly blocking the pore of the channel is shown below (Figure 4). The outer pore of VGSCs mostly consists of electronegative residues such as aspartic acid or glutamic acid, which are addressed by positively charged residues like lysine or arginine of the $\mu$-conotoxin. In contrast to potassium channels where one lysine is sufficient to block the channel at least two basic residues are required to achieve the same in sodium channels. ${ }^{[116]}$ In comparison to non-peptidic toxins blocking the VGSCs, like saxitoxin (STX) or tetrodotoxin (TTX), $\mu$-conotoxins distinguish between the different subtypes of VGSCs and are modifiable by introducing different amino acid residues thereby inducing different selectivities. ${ }^{[117-119]}$ This difference in selectivity is due to the fact that the binding sites of TTX and $\mu$-conotoxins overlap only partially and more residues of the VGSCs are involved in the binding of $\mu$-conotoxins (additional to the four residues shown here for $\mu$-GIIIA). ${ }^{[119]}$ Furthermore, ZHANG et al. discovered conotoxin $\mu$-KIIIA and TTX binding simultaneously to VGSC Nav1.2 with $\mu$-KIIIA having higher off-rates in presence of TTX due to a repulsive interaction of positively charged residues offering even further applications for labelled $\mu$-conotoxins. ${ }^{[120]}$
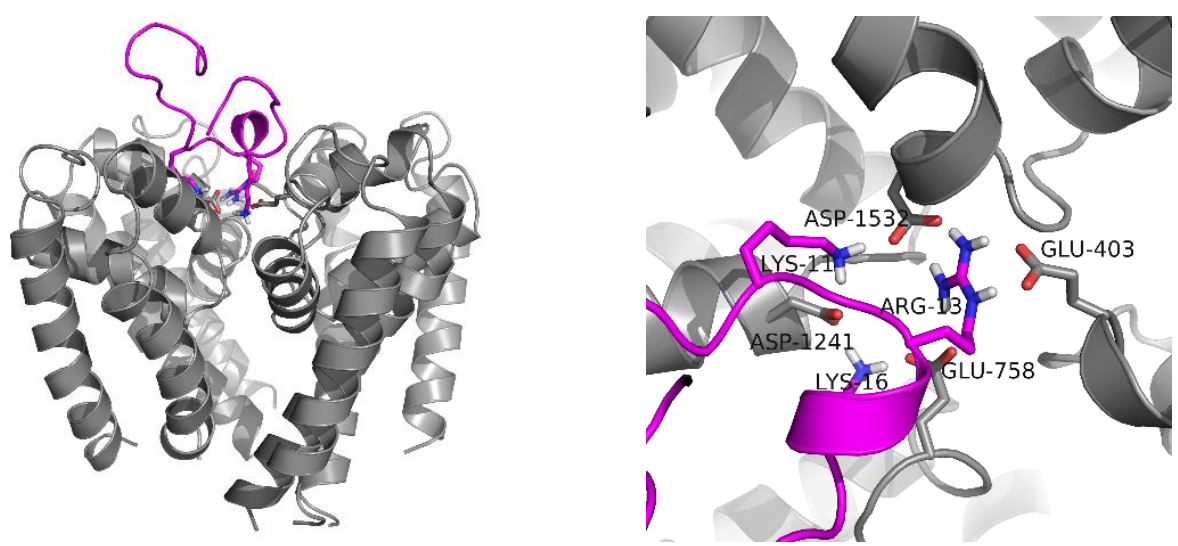

Figure 4: Docking of conotoxin $\mu$-GIIIA (purple) to a homology model of Nav1.4 (grey): side view (left) and top view zoomed in on the binding site (right). The interacting residues of $\mu$-GIIIA (R13, K11, K16) and Nav1.4 (E403, E758, D1241, D1532) are presented as sticks (PDB file provided by MAHDAVI et al.). ${ }^{[16]}$

One of the smallest conotoxins and thereby a good target for labelling is conotoxin $\mu$-SIIIA, comparable with $\mu$-KIIIA it displays a strong selectivity towards mammalian neuronal sodium channel Nav1.2 leading to nearly irreversible blocking of the channel. In addition, it blocks skeletal muscle subtype Nav1.4 (reversible blocking) and neuronal Nav1.6 (partially reversible). ${ }^{[121]} \mu$-KIIIA and $\mu$-SIIIA differ only in a few residues, with $\mu$-SIIIA having four additional residues. These findings implicate that the additional residues do not disturb the overall activity and might be easily used for modification and labelling. 


\subsubsection{Structural and functional analysis of $\mu$-conotoxin SIIIA}

Conotoxin $\mu$-SIIIA is a short conotoxin, 20 amino acids in length, containing three posttranslational modifications: $N$-terminal cyclization forming pyroglutamate, $C$-terminal amidation, and disulphide bridging. Pyroglutamate (pGlu) causes $N$-terminal blockage of peptides protecting them from enzymatic digestion by exopeptidases. ${ }^{[122]}$ Comparable to the $N$-terminal pyroglutamate the $C$-terminal amidation affects the overall isoelectric point and overall charge state (net charge of $\mu$-SIIIA $=+2$ ), which may influence three-dimensional structure and is important for binding to the negative surface of VGSC. ${ }^{[123,124]}$ Additionally, amidation protects $\mu$-SIIIA against carboxypeptidase activity. ${ }^{[125]}$ Three disulphide bridges are formed which are buried in the core of the molecule. The structure is further defined by an $\alpha$-helix including residues $11-16$ determining the arrangement of side chains along this motif (see Figure 5).

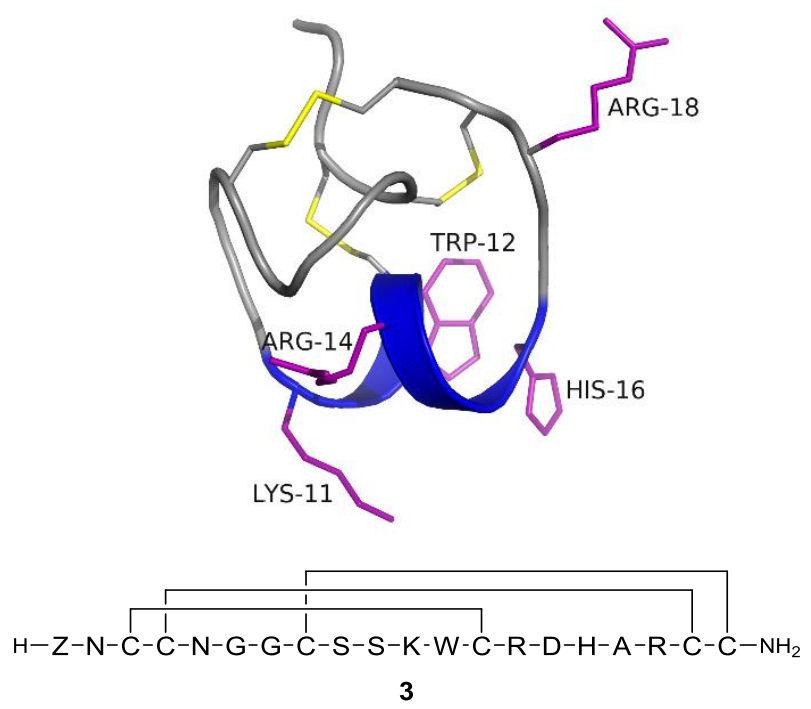

Figure 5: Average ribbon structure of $\mu$-conotoxin SIIIA (top): The $\alpha$-helical motif is seen across residues 11-16. The three disulphide bonds are highlighted in yellow. The important residues for the affinity are highlighted in purple. See BMRB accession code 20025. ${ }^{[126]}$ One letter code of $\mu$-conotoxin SIIIA (3) (bottom): $Z=p G l u$, the $C$-terminus is amidated.

The key binding determinants are distributed across this motif (Lys11, Trp12 and Arg14) and along it (Arg18). Each is contributing similarly to the binding affinity of $\mu$-SIIIA. ${ }^{[126]}$ Furthermore, substitution of His16 by alanine leads to a strong decrease in affinity, with $\alpha H$-chemical shifts changes indicating perturbation of backbone structure. ${ }^{[126]}$ YAO et al. conducted further temperature dependent backbone dynamic calculations revealing high flexibility of pGlu1, Asn2 and Ser9. ${ }^{[127]}$ Additionally, a substitution of Asn5, Ser9 and Ser10 of the related $\mu$-KIIIA does not change blockage of the

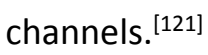




\subsubsection{Modifications of $\mu$-conotoxin SIIIA and their influence on activity}

In order to develop possible positions for labelling preliminary considerations have to be made based on already existing modifications known for $\mu$-SIIIA and related compounds ( $\mu$-KIIIA, truncated $\mu$-SIIIA missing pGlu1, Asn2, Gly6 and Gly7; and $\mu$-SIIIB, differing in two residues: Lys14 and Gly15 compared to Arg14 and Asp15 for $\mu$-SIIIA). ${ }^{[45,46]}$ Many investigations have been carried out to improve the synthesis of $\mu$-SIIIA and related compounds. To stabilize the structure of $\mu$-SIIIA and enhance the oxidative folding rate WALEWSKA et al. and STEINER et al. installed diselenide bridges instead of disulphide bridges replacing either $\mathrm{C} 3-\mathrm{C} 13, \mathrm{C} 4-\mathrm{C} 19$ or $\mathrm{C} 8-\mathrm{C} 20$ disulphide bridge. The oxidative folding is enhanced using this method but a small decrease in overall blocking is observed. ${ }^{[128,129]}$ Comparable results are obtained for modified $\mu$-KIIIA, removing one disulphide bridge and substituting another disulphide bridge with a diselenide bridge does not lead to an enhanced affinity. ${ }^{[130,131]}$ In contrast, deletion of one single disulphide bridge leads to significantly larger off-rates when compared to native $\mu$-KIIIA. ${ }^{[132]}$ Besides, disulphide depletion and $N$-terminal truncation of $\mu$-KIIIA stabilizing the $\alpha$-helical motif by one lactam bridge results in similar structures and good binding affinities for the lactam between positions Asp9 and Lys13. However, the high binding affinities of natural $\mu$-KIIIA are not reproduced. ${ }^{[133]}$ Another approach, namely backbone prosthesis, was applied by GREEN et al. to $\mu$-SIIIA substituting non-essential residues such as the two Gly residues in the first loop or the $N$-terminal Asn and pGlu by non-peptidic spacers like amino-3-oxapentanoic acid or 6-aminohexanoic acid. Structural analysis reveals similar structural conformations of these analogues and activity essays are promising. ${ }^{[105]}$ In contrast, replacing pGlu with Glu in $\mu$-SIIIB reduces affinity of Nav1.2 compared with natural $\mu$-SIIIB. ${ }^{[134]}$ [pGlu1Arg]- $\mu$-SIIIA has slightly increased VGSC affinity, with a change in selectivity from Nav1.2 to Nav1.4. SCHROEDER et al. synthesized even more $N$ - and $C$-terminal extended $\mu$-SIIIA and $\mu$-SIIIB. $C$-terminal elongation of $\mu$-SIIIA using Ala residues as well as $N$-terminal elongation of $\mu$-SIIIB using Glu does not change the potency strongly. Furthermore, an increase in potency and neuronal selectivity is seen for $\mu$-SIIIA substituting Asp15 by an alanine. ${ }^{[134]}$ Based on this finding AKONDI et al. reengineered loop 1 using the [Asp15Ala]-mutant altering the overall charge and size of this loop. An increase in affinity is seen for the [Asn5Lys]-mutant being truncated at the $\mathrm{N}$-terminus. Additionally, the deletion of Gly6 does not influence the affinity strongly. ${ }^{[135]}$

STEVENS et al. synthesized a number of very small (13 residues) $\mu$-KIIIA $/ \mu$-BullIC analogues having the first disulphide bridge and one of the Ser residues deleted. Even though an $\alpha$-helix is not observed, the analogue has nearly similar potency as the native peptide. ${ }^{[136]} A$ totally different approach is the design of organic scaffolds topographically mimicking key binding elements of native peptides, which is employed for $\mu$-KIIIA. ${ }^{[89]}$ BRADY et al. synthesized a diketopiperazine carboxamide scaffold 
functionalized with Lys, Trp and His and a benzamide functionalized twice with Arg; both showing only very small sodium channel affinities. ${ }^{[89,137]}$

\subsubsection{Synthesis and labelling of alkyne modified $\mu$-conotoxin SIIIA}

Following this detailed analysis of $\mu$-conotoxin analogous a strategy for labelling $\mu$-SIIIA was proposed. The sequence of native $\mu$-SIIIA contains acid, amine and thiol functionalities, hence, introduction of a label could only be accomplished employing an orthogonal reaction or an elaborate protecting scheme. As previously described (see section 2.2 ) the copper(I)-catalysed azide-alkyne cycloaddition (CUAAC) provides this kind of orthogonally. Following this approach an azide or alkyne moiety should be introduced into the peptide. As a result of the introduction of an azide into peptides might possibly be the reduction to the corresponding amine during cleavage, an alkyne moiety should be incorporated into $\mu$-SIIIA. ${ }^{[138]}$ As truncated analogues of $\mu$-SIIIA mainly show smaller affinities and adding residues to already very short analogues may have a great impact on overall structural properties, native $\mu$-SIIIA should be modified bearing an alkyne moiety. As described in literature, the alkyne moiety was introduced by side chain propargylation of Boc protected serine $\mathbf{4}$ using sodium hydride and propargyl bromide, followed by Boc-deprotection and Fmoc-protection of $\mathbf{5}$ to form Fmoc-L-Ser(2'-propyne)-OH (6) in good yields (see Scheme 5). ${ }^{[139-141]}$ Providing an alkyne in a position far away from the backbone should allow CuAAC to take place even in folded peptides. Additionally, the polar side chain of serine prevents formation of aggregates during peptide synthesis. ${ }^{[141]}$

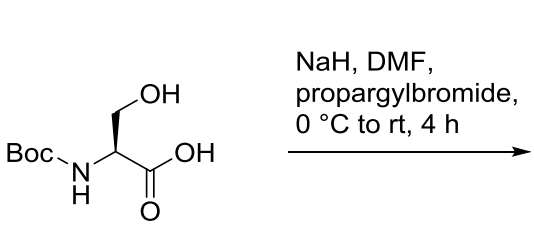

4

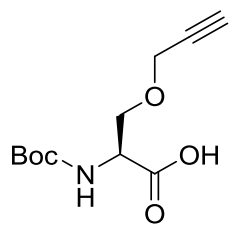

5

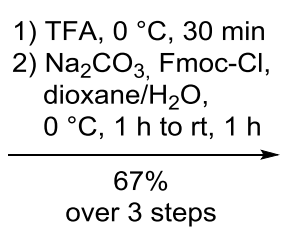

over 3 steps

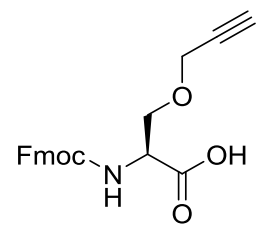

6

Scheme 5: Synthesis of Fmoc-L-Ser(2'-propyne)-OH (6).

By analysing $\mu$-SIIIA analogous possible modifiable positions were ascertained. As mentioned above the $C$-terminal and $N$-terminal extensions of $\mu$-SIIIA/B do not change the ability to bind to VGSCs. ${ }^{[134]}$ Additionally, Gly6 and Ser9 are removed without a strong decrease in affinity. ${ }^{[135,136]}$ Therefore, four peptides were postulated for synthesis (7-10, see Figure 6). 


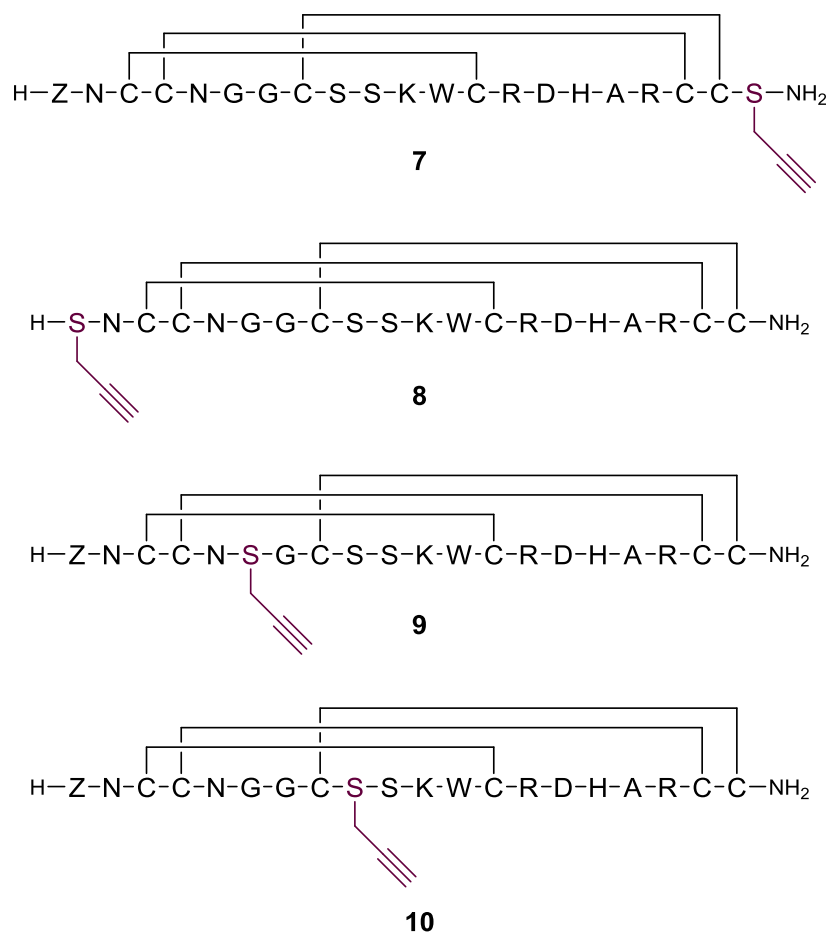

Figure 6: Alkyne modified peptides postulated for synthesis. $Z=p G l u$, the $C$-terminus is amidated.

First of all, direct oxidative folding was performed as described before (see 3.1.1) using trityl protecting group for cysteine residues. As described by BULAJ et al., the linear precursor was synthesized on rink amide MBHA resin as solid support preloaded with Fmoc-L-Cys(Trt)-OH according to Fmoc based SPPS protocols providing a $C$-terminal amide after cleavage. ${ }^{[110]}$ Artificial amino acids Fmoc-L-Ser(2'-propyne)-OH (6) as well as H-L-pGlu-OH were coupled using lower temperatures and longer reaction times, as racemisation rates were unknown. Initial occurrence of aspartimide formation $(m / z=-18)$ was circumvented by adding $0.1 \mathrm{M}$ 1-hydroxybenzotriazole (HOBt) to the deprotection solution. ${ }^{[142]}$ The racemisation of cysteine and histidine was suppressed using lower reaction temperatures $\left(50^{\circ} \mathrm{C}\right)$ during coupling. This reduces the amount of $\mathrm{D}$-amino acid from $>8.00 \%$ to $1.59 \%$ for histidine and $>3.96 \%$ to $3.16 \%$ for cysteine respectively. ${ }^{[143]}$ Linear [Gly6Ser(2'-propyne)]$\mu$-SIIIA and [Ser9Ser(2'-propyne)]- $\mu$-SIIIA precursor were obtained in good yields and purity. Direct oxidative folding of native $\mu$-SIIIA using different reagents has been covered in literature. The following methods were tested for the alkyne modified $\mu$-SIIIA analogues:

- Linear $\mu$-SIIIA was dissolved in high dilution in aqueous solution of $0.1 \mathrm{M}$ Tris/ $\mathrm{HCl}$ solution, $1 \mathrm{~mm}$ oxidized and $1 \mathrm{~mm}$ reduced glutathione and $0.1 \mathrm{mM}$ EDTA ( $\mathrm{pH} 7.5$ ).

- Linear $\mu$-SIIIA was dissolved in high dilution in aqueous $\mathrm{NH}_{4} \mathrm{HCO}_{3}$-solution (pH 9.1).

- Linear $\mu$-SIIIA was dissolved in high dilution in aqueous $\mathrm{NH}_{4} \mathrm{HCO}_{3}$-solution, $1 \mathrm{~mm}$ oxidized and $1 \mathrm{mM}$ reduced glutathione and $0.1 \mathrm{mM}$ EDTA $(\mathrm{pH} 7.1)$.

- Linear M-SIIIA was dissolved in high concentrations in an ionic liquid. 
The first method was described by GREEN et al. and STEINER et al. testing different reaction times, $\mathrm{pH}$-values, molar ratios of glutathione in the oxidized and reduced form and different temperatures. ${ }^{[105,144]}$ The high dilution is necessary to prevent polymerization and aggregation. Herein, the described conditions were used differing reaction times and work-ups. The reaction mixtures were either directly subjected to freeze-drying or water was removed using rotary evaporator. Diverse efforts were made to desalinate crude products using either reverse phase column chromatography or dialysis membranes with different pore sizes (molecular weight cut of: 100-500 D or 500-1000 D). Albeit obtaining small amounts of desired product HPLC diagrams showed a scrambling indicating formation of multiple disulphide bond and topological isomers. The second method was previously performed by AVRUTINA to fold cystine-knot microproteins and the third method was a combination of the first and second method. ${ }^{[145]}$ An advantage of using ammonium bicarbonate as buffer solution is its removability by freeze-drying making extensive desalination steps superfluous. By these two methods no product was obtained. Applying the fourth method renders the need to use high dilution obsolete as MILOSLAVINA et al. found 1-ethyl-3-methylimidazolium acetate [ $\left.\mathrm{C}_{2} \mathrm{mim}\right]$ [OAc] to be able to solubilise and stabilise secondary structure by providing hydrogen bonds between anions of imidazolium salt and hydroxyl groups of the solute. ${ }^{[146]}$ Thereby, the formation of correctly folded product is favoured and amount of misfolded peptides reduced. Even though correct mass was detected, a separation of ionic liquid from the peptide was impossible. A recent investigation by HEIMER et al. scaling up the previously performed reaction resulted in a significant loss of inhibiting effect on Nav1.4 channels, attributed to an adherence of ions from $\left[\mathrm{C}_{2} \mathrm{mim}\right][\mathrm{OAc}]$ to peptides, with connectivity of disulphide bridges and HPLC profile being in accordance to conventionally oxidized $\mu$-SIIIA versions. ${ }^{[147]}$ Due to the formation of multiple isomers using glutathione in Tris buffer another strategy was applied for the synthesis of labelled $\mu$-SIIIA. Although previously described regioselective oxidation (see section 3.1.2) of three disulphide bridges might be time-consuming it has the advantage of selectively formed bridges reducing the amount of different isomers to a few topological isomers. ${ }^{[148]}$

Regioselective oxidation of $\mu$-SIIIA was based on a strategy proposed by LINDNER et al. in 2012 (see Scheme 6). ${ }^{[81]}$ Peptides are synthesized on 2-chlorotrityl chloride resin using RAMAGE-linker providing $C$-terminal amides. ${ }^{[149]}$ Thereby, peptides can be cleaved from the resin using very low acidic conditions before deprotecting side chain protecting groups. As the first disulphide bridge usually is the hardest to form a method previously exercised in interchain disulphide bridge formation is used to increase the yield; the first cysteine residue is activated for subsequent reaction with the second cysteine. ${ }^{[65]}$ Thiols are activated by introducing an electron-withdrawing substituent e. g. 2-thiopyridine. This residue is introduced using 2,2'-dithiodipyridine. In order to have a good activation of thiols using mixed disulphides a deactivated leaving group is highly important to prevent thiol/disulphide exchange 
reactions; in the case of SPyr the leaving group is 2-thiopyridine which immediately tautomerizes to inactive 2-thiopyridone. ${ }^{[150,151]}$ As the cysteine activation group SPyr is not stable during coupling conditions $S^{t} B u$ is introduced into the peptide being cleaved of using 2-mercaptoethanol followed by a reaction with 2,2'-dithiodipyridine. After cleavage from the resin the fully protected peptide containing activated thiol then reacts with a second thiol, which has been Dmt protected beforehand. Following the formation of the first disulphide bridge, all protecting groups are deprotected including Trt protected cysteine. LINDNER et al. proposed a one-pot iodine oxidation forming the second disulphide bridge, deprotecting Acm-groups and forming the third disulphide bridge. ${ }^{[81]}$ The advantages of this regioselective strategy by LINDNER et al. are:

- High dilution during formation of the first disulphide bridges prevents polymerization reaction.

- Unprotected peptide containing one disulphide bridge and the following steps are handled in acidic medium preventing shuffling of the disulphide bridges.

- Regioselective disulphide bridge formation in acceptable yields.
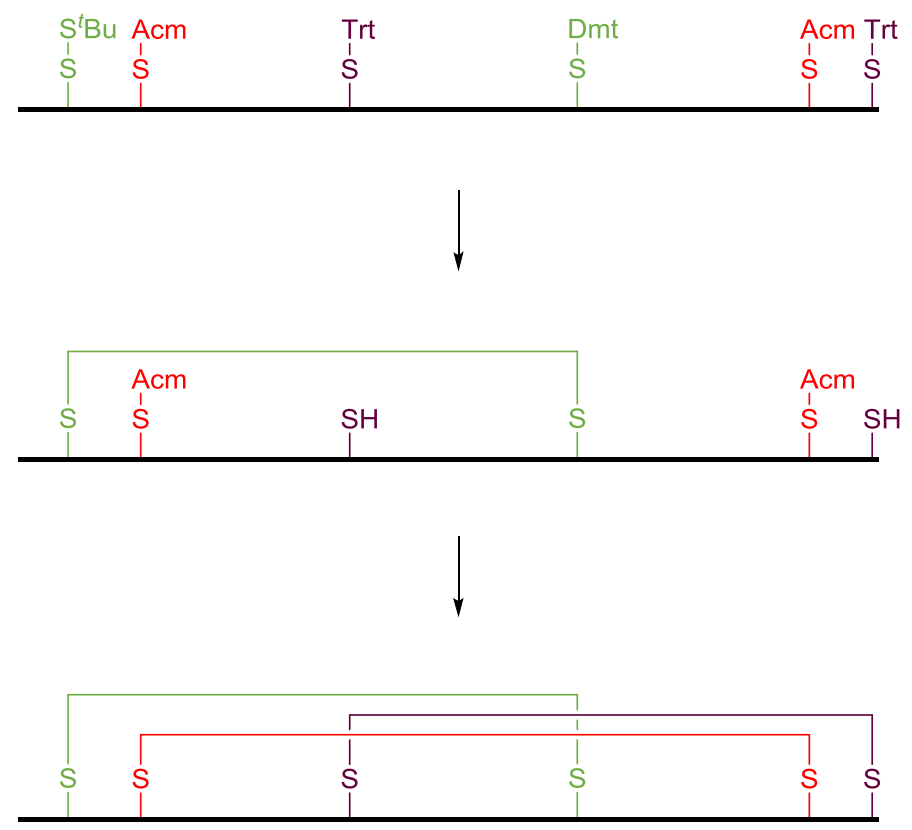

Scheme 6: Regioselective approach proposed for $\mu$-SIIIA as described by LINDNER et al. ${ }^{\text {[81] }}$

As Fmoc-L-Cys(Dmt)-OH (11) is not commercially available, it was synthesized in two steps following a procedure of LINDNER et al. (see Scheme 7). ${ }^{[81]}$ Unprotected cysteine (12) was treated with 4,4'-dimethoxytrityl chloride to form a thioether (13) followed by $\mathrm{N}$-terminal Fmoc-protection using Fmoc-Cl. Flash chromatography was carried out quickly and without acid to prevent Dmt-deprotection on the slightly acidic silica yielding the product (11) in good yields. 


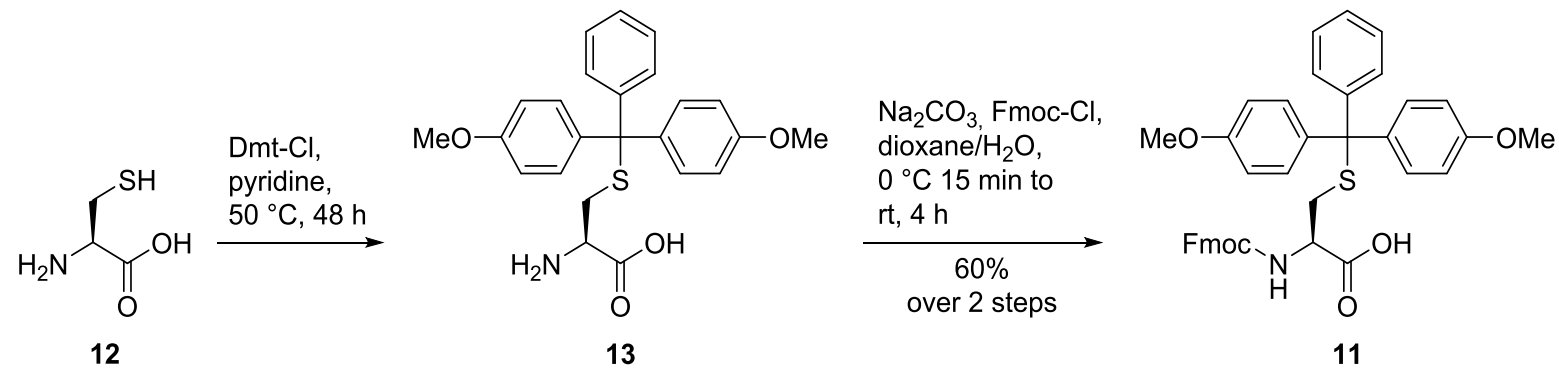

Scheme 7: Synthesis of Fmoc-L-Cys(Dmt)-OH (11).

2-Chlorotrityl chloride resin was then preloaded with the Fmoc protected RAMAGE-linker using DIPEA for activation. An excess of 2-chlorotrityl chloride resin, reduced reaction times and capping with methanol and DIPEA were necessary to reduce the loading density from $1.5 \mathrm{mmol} / \mathrm{g}$ for 2-chlorotrityl chloride resin to $0.30-0.40 \mathrm{mmol} / \mathrm{g}$ of preloaded resin. A low loading density was used to prevent aggregation during solid phase peptide synthesis. After Fmoc deprotection the first amino acid Fmoc-L-Cys(Trt)-OH was coupled using $N, N^{\prime}$-diisopropylcarbodiimide (DIC) and HOBt, thereby preventing base-catalysed racemisation during activation and coupling of Trt protected cysteine. ${ }^{[152,153]}$ Furthermore, linear $C$-terminal modified $\mu$-SIIIA-[Ser(2'-propyne)] precursor 14 was synthesized according to Fmoc based SPPS protocols reducing the temperature as 2-chlorotrityl chloride resin is sensitive to high temperatures. As previously described the $S^{t} B u$ protecting group was cleaved by $20 \%$ 2-mercaptoethanol as the reducing agent. Subsequent reaction with 2,2'-dithiodipyridine yielded the activated disulphide bridged Cys(SPyr) derivative 15. Cleavage from the resin was performed using mild acidic conditions yielding 16 (see Scheme 8). 


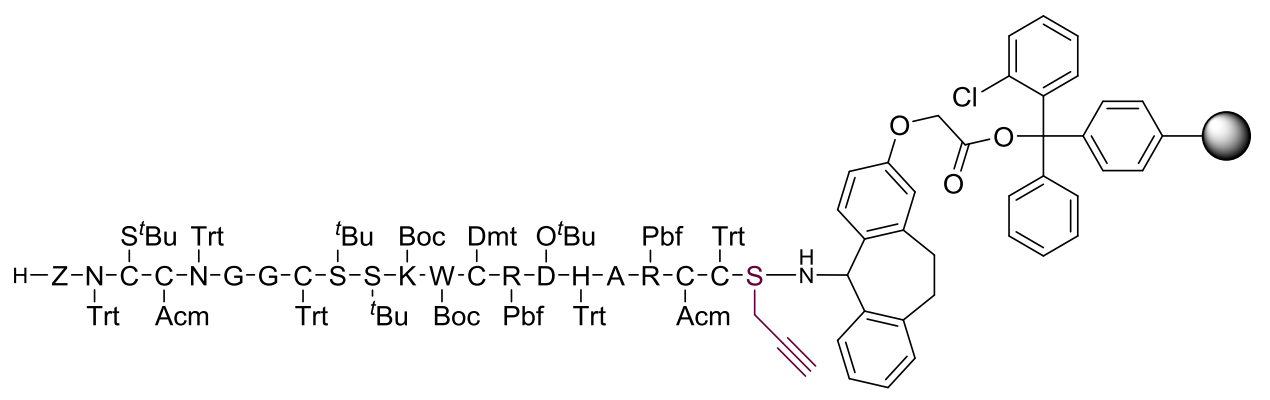

14

1) $20 \% 2$-mercaptoethanol, $1 \% \mathrm{DBU}, \mathrm{DMF}$,

rt, $3 \times 20 \mathrm{~min}$

2) 2,2'-dithiodipyridine, DCM, $\mathrm{rt}, 3 \times 20 \mathrm{~min}$

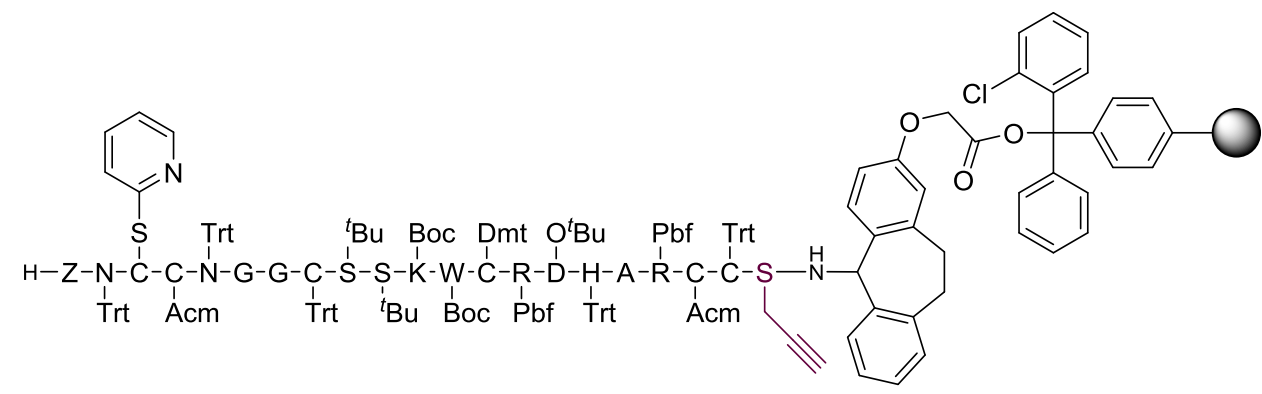

15

$10 \% \mathrm{AcOH}, 20 \%$ TFE, DCM, rt, $3 \times 15 \mathrm{~min}$

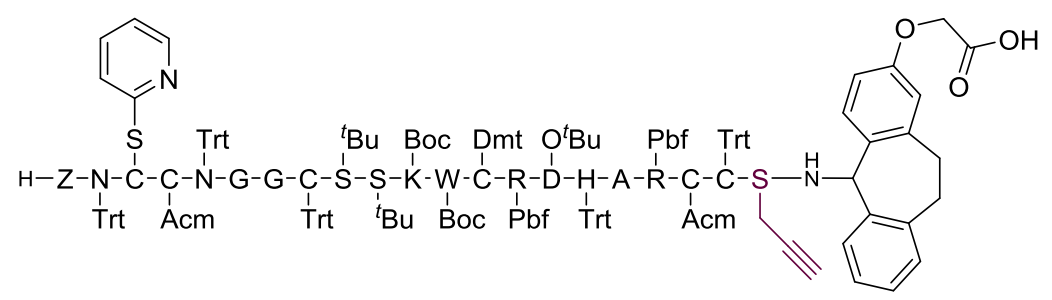

16

Scheme 8: First deprotection steps performed on linear $\mu$-SIIIA-[Ser(2'-propyne)] precursor 14: $S^{t} B^{\prime} u$ deprotection was followed by activation of the free thiol to Cys(SPyr) and subsequent cleavage from the resin yielding peptide $16 . \mathrm{Z}=$ pGlu.

Further acidification under high dilution using low concentrations of TFA yielded Dmt deprotected peptide which was transferred to a solution of triethylamine (10\%) to form the first disulphide bridged peptide 17 by deprotonating the free thiol group which then reacted with activated Cys(SPyr). After precipitation the crude product was directly deprotected utilising triisopropylsilane (TIS) and water as scavengers obtaining crude peptide 18 in an overall yield of 64\% (see Scheme 9). Neither deletion 
sequences nor disulphide depleted side products were detected by mass analysis. The Acm protecting group remained stable under these conditions.

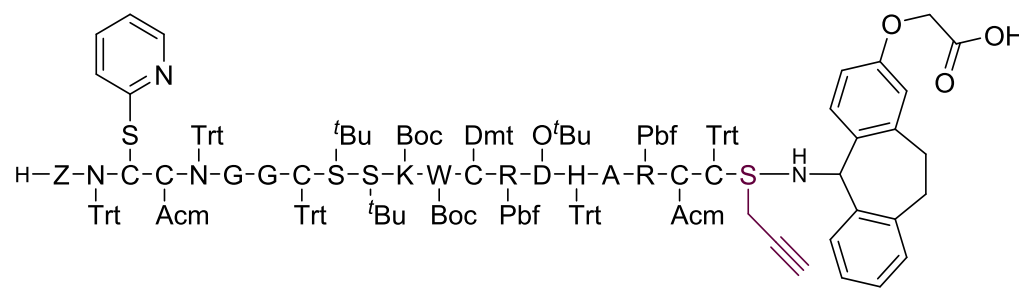

16

1) $0.1 \%$ TFA, $0.2 \%$ TES, DCM, rt, o/n

2) $10 \% \mathrm{NEt}_{3}, \mathrm{DCM}, \mathrm{rt}, 30 \mathrm{~min}$

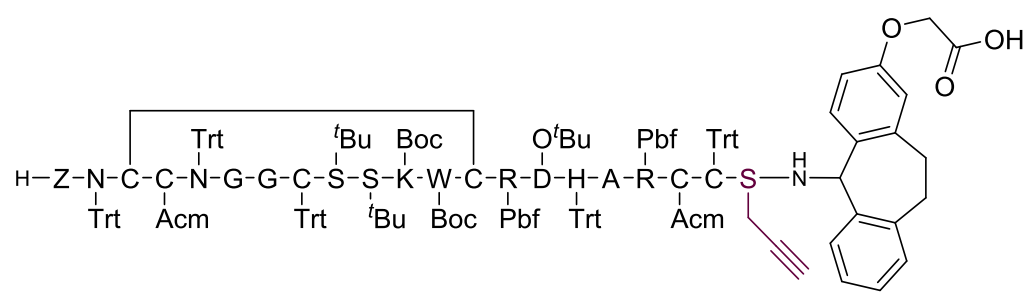

17

\begin{tabular}{c|c}
$64 \%$ & over 6 steps
\end{tabular} 95\% TFA, 2.5\% TIS, 2.5\% $\mathrm{H}_{2} \mathrm{O}, \mathrm{rt}, 2 \mathrm{~h}$

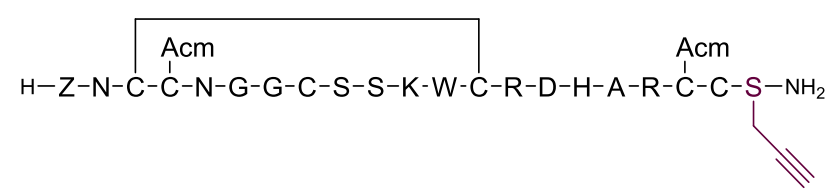

18

Scheme 9: Formation of the first disulphide bridge of $\mu$-SIIIA-[Ser(2'-propyne)] followed by deprotection of all side chain protecting groups except the Acm group. $Z=p G l u$, the $C$-terminus is amidated.

The one-pot oxidation proposed by LINDNER et al. for native $\mu$-SIIIA did not lead to any product formation in the following steps of disulphide formation, Acm deprotection and disulphide formation of Acm deprotected thiols. ${ }^{[81]}$ Therefore, a stepwise procedure was undertaken firstly to form the $2^{\text {nd }}$ disulphide bridge and secondly to deprotect the Acm groups and to generate the $3^{\text {rd }}$ disulphide bridge. Alternatively to oxidation by atmospheric oxygen being a relatively slow process or by mild oxidizing agents such as potassium ferricyanide which may lead to side products such as oxidation of Met and Trp residues and has an additional step of removing the oxidizing reagent, DMSO-promoted oxidation is frequently utilised. ${ }^{[65,154,155]}$ It can be applied over an extended $\mathrm{pH}$ range of 1 to $8 .{ }^{[156]}$ In general, acidic media induces faster oxidation rates and it also prevents shuffling of already formed bridges. 
However, low $\mathrm{pH}(\mathrm{pH}<3)$ accelerates oxidation of other side chains, such as methionine. Following a procedure of TAM et al. disulphide formation to peptide 19 was carried out at pH 6 with $20 \%$ DMSO in high yields (see Scheme 10). ${ }^{[156]}$

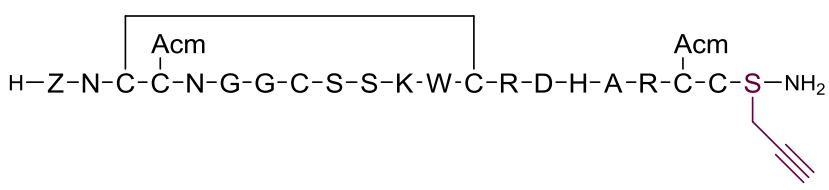

18

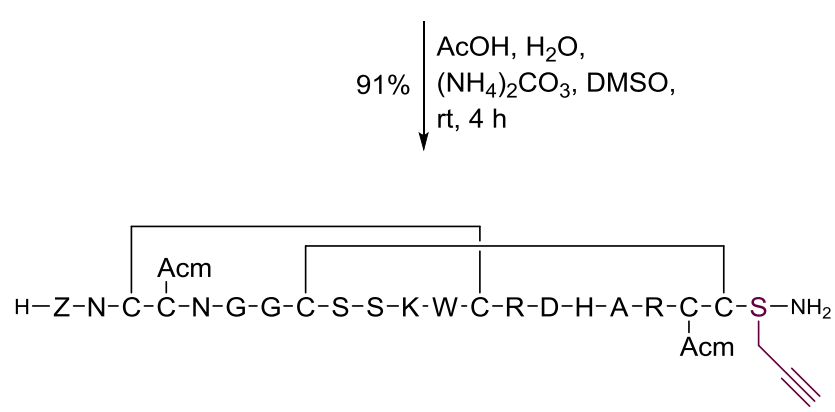

19

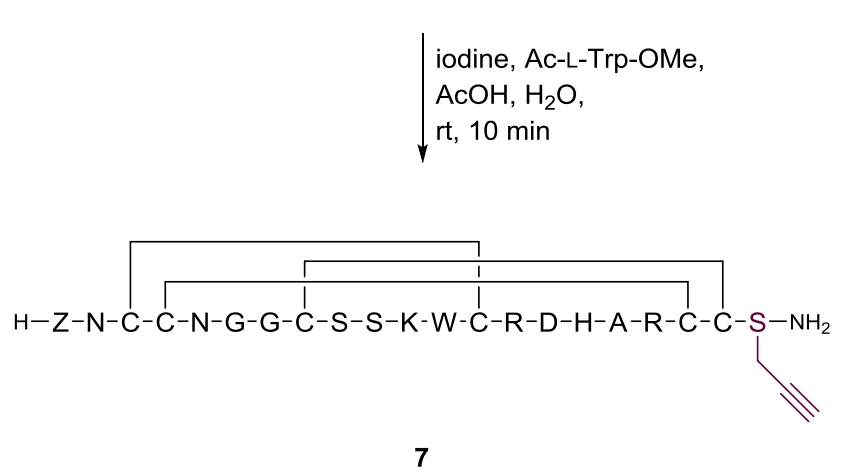

Scheme 10: Formation of the second and third disulphide bridge of $\mu$-SIIIA-[Ser(2'-propyne)] (7). $Z=p G l u$, the C-terminus is amidated.

For the deprotection of Acm groups and simultaneous disulphide bridge formation a method described by LINDNER et al. was first applied utilising iodine in a solution of acetic acid/water with anisole as scavenger for $2 \mathrm{~h}$ leading to no product formation. ${ }^{[81]}$ As oxidation by iodine is known to cause serious side reactions on several amino acids such as Tyr, Met, His and Trp extensive efforts have been made in the past to optimize reaction conditions. ${ }^{[75]}$ To prevent side reactions with Trp residues Ac-L-Trp-OMe is added as scavenger. ${ }^{[157,158]}$ Additionally, disulphide exchange reactions may occur by an electrophilic attack of sulphenyl iodide, which usually reacts with free cysteines to produce the desired disulphide, on preformed disulphides. This will lead to shuffling und scrambling of disulphide bridges. Although, KAMBER et al. described this reaction to be a minor side reaction ( $5 \%$ side product after $4 \mathrm{~h}$ ) being reduced by reduction of reaction time. ${ }^{[75]}$ In this thesis, additional tests were performed 
to analyse the stability of the alkyne moiety to the conditions of LINDNER et al. taking the Fmoc protected amino acid as starting material which resulted in the formation of diiodated product. To gain knowledge whether Acm deprotection and disulphide formation or iodination occurred first or if these reactions happened at the same time, LC-MS was performed. Thus, the reaction mixture (acetic acid/water, Ac-L-Trp-OMe, iodine) was quenched with aqueous ascorbic acid solution after 0, 5, 10, $20,30,40,50$ and $60 \mathrm{~min}$. The desired product 7 was already seen when the reaction mixture was quenched directly after iodine addition $(0 \mathrm{~min})$. After $5 \mathrm{~min}$ the starting material 19 was consumed and first traces of iodated side product were seen after $20 \mathrm{~min}$. Therefore, this reaction was carried out for $10 \mathrm{~min}$ to have a complete conversion to the desired product 7.

In a second approach deprotection was analysed using silver(I) trifluoroacetate followed by oxidation with 10\% DMSO in $1 \mathrm{M}$ hydrochloric acid. By this approach the formation of oxidised and iodated products should be minimised. With this method no product was obtained, possibly due to problematic destruction of the silver-peptide complex using DMSO in hydrochloric acid as described by HARRIS et $a{ }^{\left[{ }^{[159]}\right.}$ Other possible methods to release peptides would also reduce already formed disulphide bridges.

Therefore, the previously described iodine method, followed by a direct purification of the quenched reaction mixtures on preparative HPLC, was utilised. HPLC purification yielded three main products having the same mass but different retention times (see Figure 7). Due to the regioselective formation of disulphide bridges different products could only be topological isomers (see section 3.1.2). Because of small amounts of obtained product no NMR analysis was performed which would give detailed information about the structure of each isomer. Instead, collected peaks were directly given for analysis by whole-cell patch-clamp but were not measured yet.

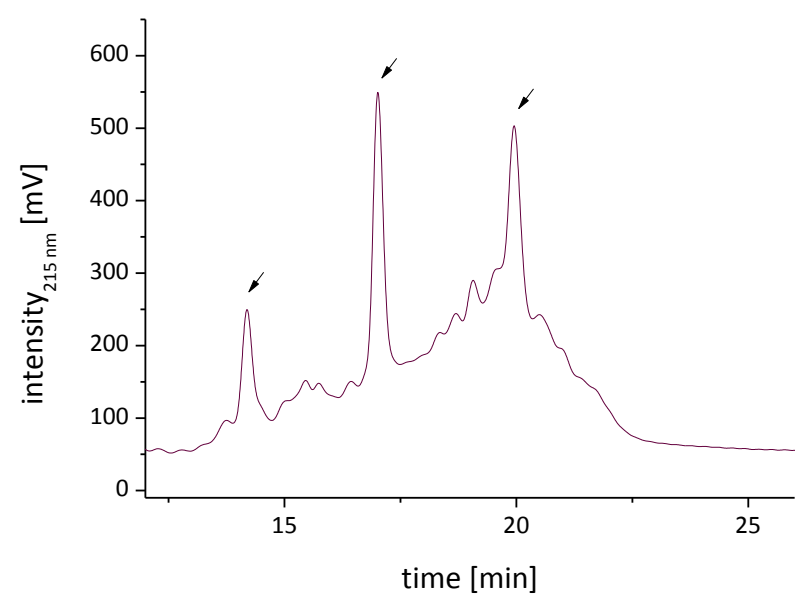

Figure 7: HPLC trace of crude $\mu$-SIIIA-[Ser(2'-propyne)] (7). Three topological isomers (marked by an arrow) will be analysed by whole-cell patch-clamp. 
The whole sequence of reactions was repeated to synthesize [pGlu1Ser(2'propyne)]- $\mu$-SIIIA (8). The first and second disulphide bridged peptide was obtained in good yields $\left(1^{\text {st }} 46 \%, 2^{\text {nd }} 67 \%\right.$ ) but formation of the third disulphide bridge gave four topological isomers. Two of them could be purified in an adequate amount and inhibition rates are now being measured using patch-clamp.

[Gly6Ser(2'-propyne)]- $\mu$-SIIIA (9) was prepared using the same reaction method yielding $75 \%$ crude product for the formation of the $1^{\text {st }}$ disulphide bridge and $98 \%$ crude product for the $2^{\text {nd }}$ disulphide bridge. Formation of the $3^{\text {rd }}$ disulphide bridge yielded three topological isomers which were analysed using patch-clamp experiments ${ }^{1}$. Inhibition studies were conducted at $1 \mu \mathrm{M}$ in HEK293 cells that expressed voltage dependent sodium channels from rat, rNav1.2. The two DNA-plasmids encoding green fluorescent protein (GFP) and rNav1.2 (ratio 1:3), respectively, were delivered into cells by electroporation. During inhibition tests cells were held at $-60 \mathrm{mV}$. Every $10 \mathrm{~s}$ sodium channel availability was monitored with a pulse, consisting of a brief hyperpolarization to $-100 \mathrm{mV}$ and a depolarization to $0 \mathrm{mV}$. Maximal block of sodium current observed for [Gly6Ser(2'-propyne)]- $\mu$-SIIIA (9) was $90 \%$ (see Figure 8). The other topological isomers showed no visible inhibition.

Therefore, labelling was performed with this isomer. As pure peptide was only obtained in yields of a few nanomoles, labelling studies were initially made with one of the isomers formed during direct oxidative folding. After consulting with the ENDERLEIN research group Alexa Fluor ${ }^{\circledast} 647$ azide was used as the fluorophore. CuAAC was investigated utilising different methods. In comparison to CuAAC using small molecules CUAAC with peptides generates several problems as prolonged reaction times are needed. To preserve catalytic active copper(I) species during long reaction times reactions must be conducted under exclusion of oxygen and reducing agent, furthermore, copper (I) stabilizing agents such as tris[(1-benzyl-1H-1,2,3-triazol-4-yl)methyl]amine (TBTA) need to be applied. ${ }^{[141]}$ First of all a method by CORTEKAR, namely using copper(I) (as copper(I) iodide (Cul) or copper(I) iodide-triethyl phosphite $\left.\left(\mathrm{CuIP}(\mathrm{OEt})_{3}\right)\right)$ together with TBTA and 2,6-lutidine in DMF to couple cysteine knot microproteines to cyclic $\beta$-peptides, was tested. ${ }^{[141]}$

\footnotetext{
${ }^{1}$ All patch-clamp experiments of $\mu$-conotoxin derivatives were conducted by TING WANG, PhD student in the BCCN group (Biophysics of neural computation), supervised by ANDREAS NEEF.
} 


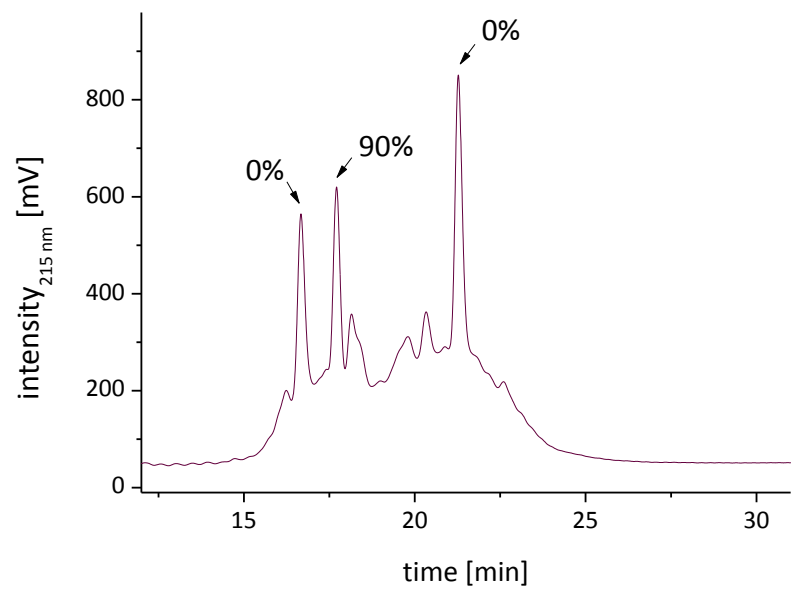

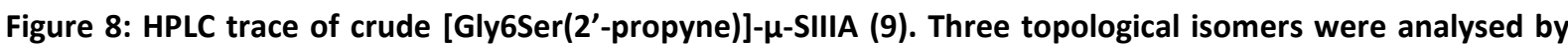
whole-cell patch-clamp (block levels of each isomer is assigned with an arrow).

Reactions of modified, folded conotoxin and fluorophore using these methods were analysed after 3 , 4 and 5 days by LC-MS showing no product formation. Furthermore, these reaction conditions were unsuccessfully applied to the reaction of Fmoc-L-Ser(2'propyne)-OH (6) with the fluorophore. As these shortcomings might also be due to misfolding of peptides, which might reduce accessibility of alkyne, or solubility problems in case of the single amino acid, further CuAAC studies were made on [Gly6Ser(2'-propyne)]- $\mu$-SIIIA (9) (90\% block). The following methods for CuAAC were investigated to attach Alexa Fluor ${ }^{\circledast} 647$ azide or Alexa Fluor ${ }^{\circledast} 647$ picolyl azide, respectively:

- Copper(I) iodide, sodium ascorbate in DMF.

- Copper(II) sulphate pentahydrate, ascorbic acid, ethylenediaminetetraacetic acid (EDTA) in phosphate buffer.

- Pentamethylcyclopentadienylbis(triphenylphosphine)ruthenium(II) chloride in dioxane.

- Click-iT ${ }^{\circledR}$ Plus Alexa Fluor ${ }^{\circledR} 647$ Picolyl Azide Toolkit including Alexa Fluor ${ }^{\circledR} 647$ picolyl azide, copper(II) sulphate pentahydrate, copper protectant and reaction buffer.

The first method was recently used by PANSE linking two different peptide strands together having alkyne and azide moieties. ${ }^{[160]}$ Due to the fact that thiols have a high affinity for copper two other methods were tested $\left(2^{\text {nd }}\right.$ and $3^{\text {rd }}$ in the list). The second method was utilised by LI et al. for linkage of azide modified bovine serum albumin (BSA, containing 17 disulphide bridges) to alkyne modified monomethyl poly(ethylene glycol) and the third method included employment of a ruthenium catalyst leading to 1,5- instead of 1,4-disubstituted 1,2,3-triazoles. ${ }^{[161,162]}$ In contrast to CuAAC ruthenium(II)catalysed alkyne-azide cycloaddition (RuAAC) allows a wide range of alkynes and is even performed with internal alkynes. The fourth method investigated was to utilise an activated azide, namely picolyl azide, containing an internal copper-chelating moiety, which raises the effective copper concentration 
at the reaction side. ${ }^{[163]}$ As these four methods were unsuccessful a $5^{\text {th }}$ method was investigated: the use of DIPEA to overcome difficulties forming the active copper acetylide complex (see Scheme 11). Addition of base to increase formation of copper acetylide complex is usually applied in case of reactions in organic solvents, where this formation is unfavourable and deprotonation is required. ${ }^{[164]}$ Recently, KOLMAR et al. described a method for CUAAC using DIPEA in water as well, which was employed herein. ${ }^{[165]}$

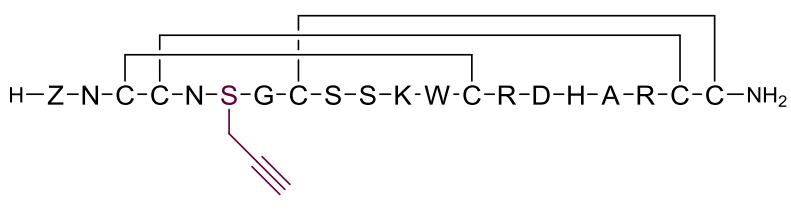

9

Alexa Fluor ${ }^{\circledR} 647$ azide triethylammonium salt,

$18 \% \mathrm{CuSO}_{4} \cdot 5 \mathrm{H}_{2} \mathrm{O}$, sodium ascorbate, DIPEA, $\downarrow \mathrm{rt}, 2 \mathrm{~d}$

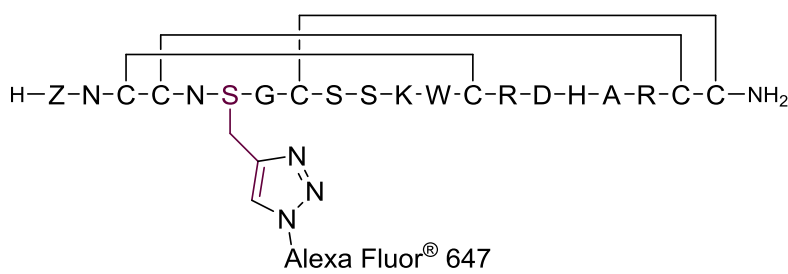

20

Scheme 11: Synthesis of labelled [Gly6Ser(2'-propyne)]- $\mu$-SIIIA 20 by addition of DIPEA. $Z=$ pGlu, the C-terminus is amidated.

After two days the formation of labelled [Gly6Ser(2'-propyne)]- $\mu$-SIIIA 20 was seen albeit incomplete (see Figure 9). Due to small amounts of starting material an optimization of reaction conditions were not done, the alkyne was recovered and the reaction repeated. 


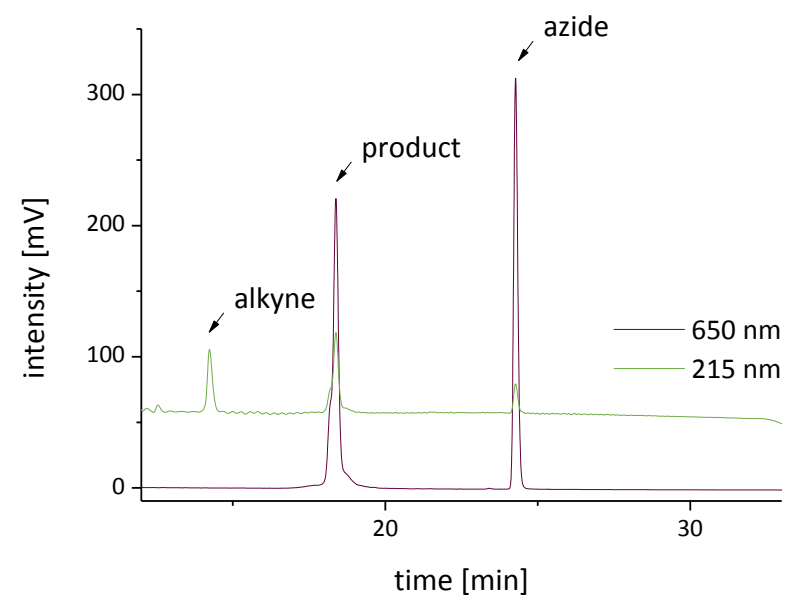

Figure 9: HPLC traces (intensity at $650 \mathrm{~nm}$ and $215 \mathrm{~nm}$ ) of crude reaction mixture of Alexa Fluor ${ }^{\circledR} 647$ labelled

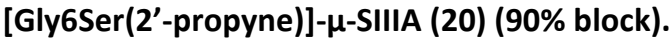

Labelled [Gly6Ser(2'-propyne)]- $\mu$-SIIIA 20 was analysed using patch-clamp experiments as aforementioned. Depolarization-activated sodium currents were measured before and after toxin application showing a strong decrease in sodium current within seconds (see Figure 10).
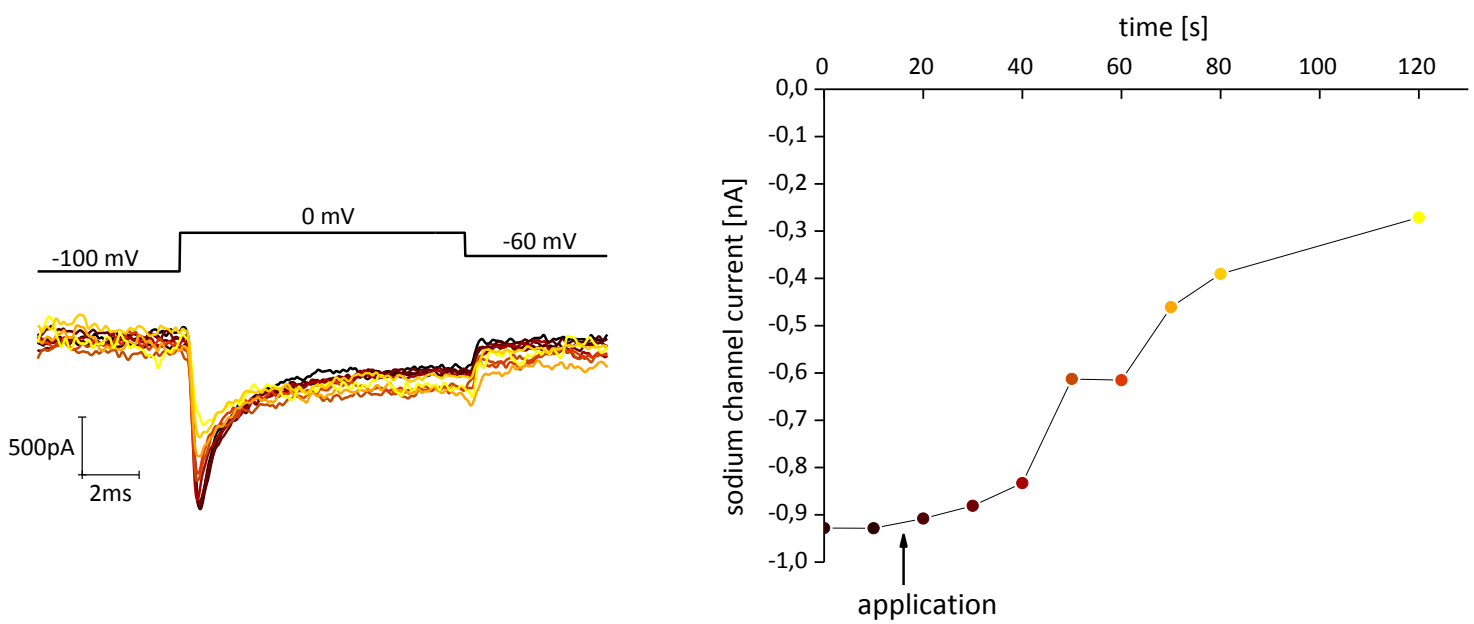

Figure 10: Inhibition of rNav1.2 by Alexa Fluor ${ }^{\circledR} 647$ labelled [Gly6Ser(2'-propyne)]- $\mu$-SIIIA (20). Superimposed depolarization-activated sodium currents in the absence and presence of labelled toxin. HEK293 cells were held at $-60 \mathrm{mV}$; every $10 \mathrm{~s}$ sodium channel availability was monitored with a pulse (hyperpolarisation to $-100 \mathrm{mV}$ and depolarisation to $0 \mathrm{mV}$ ). Application of $1 \mu \mathrm{M}$ toxin induces a decrease in sodium channel current.

[Ser9Ser(2'-propyne)]- $\mu$-SIIIA (10) was synthesized following the previously described method obtaining the $1^{\text {st }}$ disulphide bridge in $72 \%$ (crude peptide) and the $2^{\text {nd }}$ in $97 \%$ yield (crude peptide). Synthesis of the $3^{\text {rd }}$ disulphide bridge yielded three topological isomers which were analysed by patchclamp experiments. Maximal block of sodium current (85\%) was observed for the isomer having a retention time of $16.9 \mathrm{~min}$. Labelling according to the previously described method yielded two 
products (see Figure 11 (left)) having the same mass (analysis by MALDI). These were separated, obtained in good purity (see Figure 11 (right)) and will be analysed by patch-clamp experiments.
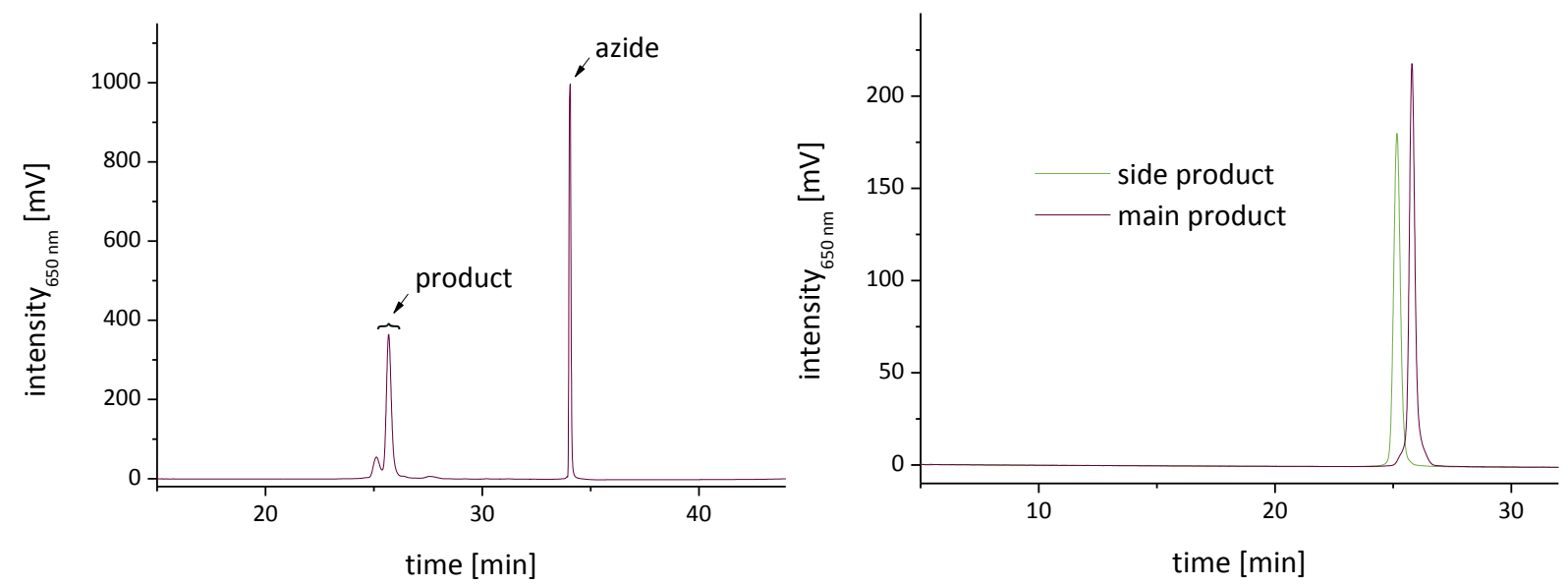

Figure 11: HPLC traces of crude reaction mixture (left) and purified products (right) of Alexa Fluor ${ }^{\circledR} 647$ labelled [Ser9Ser(2'-propyne)]- $\mu$-SIIIA (21) (85\% block) (for the structure of 21 see Figure 27).

To conclude, labelled $\mu$-SIIIA was synthesized by introducing an amino acid modified with an alkyne moiety into the peptide sequence, which was subsequently labelled with a fluorophore bearing an azide moiety. Additional patch-clamp experiments are currently under investigation to further analyse the properties of labelled $\mu$-SIIIA and imaging experiments will be conducted in near future.

\subsubsection{Synthesis of thiol modified $\mu$-conotoxin SIIIA}

Owing to small yields in forming the last disulphide bridge using an alkyne moiety another method was executed introducing a further cysteine, which might later on react with a maleimide activated fluorophore, protected by the Mbzl group (see chapter 3.1.2), which might be cleaved after the three disulphide bridges were formed. The Mbzl group is often used in Boc/Bzl strategy to protect cysteine. The group is usually cleaved by hydrofluoric acid (HF) but can also be cleaved using milder conditions, e. g. tetrafluoroboric acid in triflouroacetic acid or hydroboric acid in acetic acid eliminating the need of special HF apparatuses. ${ }^{[166-168]} \mathrm{Mbzl}$ protected cysteine was introduced as beforehand in Gly6 position and alternatively an $\mathrm{N}$-terminal polyethylene glycol (PEG) linker was utilised to further attach one $\mathrm{Mbzl}$ protected cysteine at the $\mathrm{N}$-terminus directing away from the active binding site. In contrast to $N$-terminal elongated alkyne modified $\mu$-SIIIA 8 the $N$-terminal pGlu was preserved, to protect peptides from proteolytic digestion. The linear precursor of [Gly6Cys(Mbzl)]- $\mu$-SIIIA 22 was synthesized using previously described method, followed by sequential synthesis to the mono- and two-disulphide bridge containing peptide $\mathbf{2 3}$ and $\mathbf{2 4}$, in good yields. In the absence of an alkyne moiety quenching was unnecessary during the last step, therefore, it was conducted for a prolonged time and peptide $\mathbf{2 5}$ was obtained by precipitation rather than direct HPLC purification (see Scheme 12). Similar conditions were 
applied in the synthesis of $\mathrm{N}$-terminal elongated peptide $\mathbf{2 6}$ (see Figure 12). In comparison with alkyne modified $\mu$-SIIIA several topological isomers were seen on HPLC.

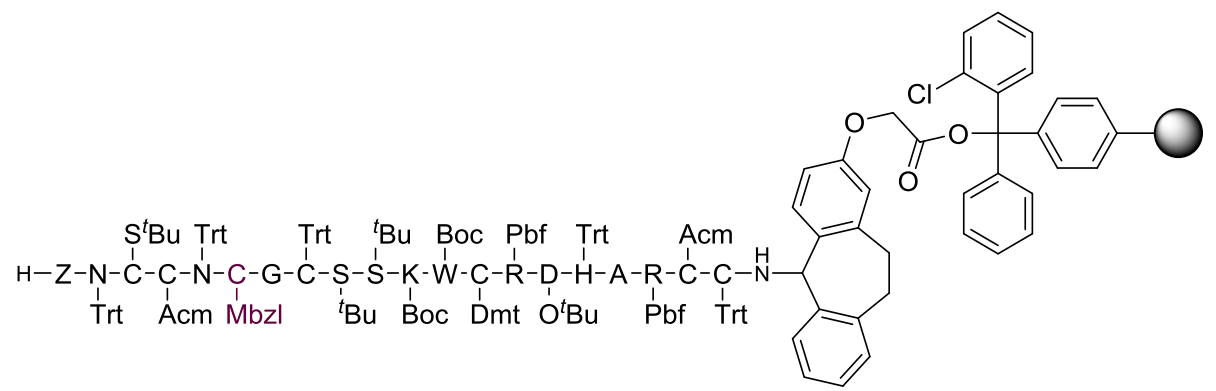

22

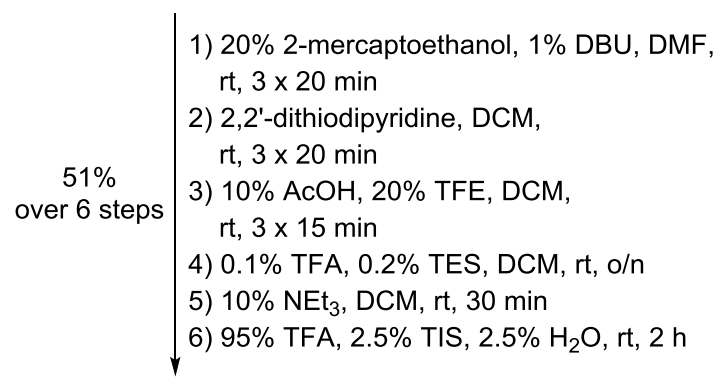

$\mathrm{H}-\mathrm{Z}-\mathrm{N}-\mathrm{C}-\mathrm{C}-\mathrm{N}-\mathrm{C}-\mathrm{G}-\mathrm{C}-\mathrm{S}-\mathrm{S}-\mathrm{K}-\mathrm{W}-\mathrm{C}-\mathrm{R}-\mathrm{D}-\mathrm{H}-\mathrm{A}-\mathrm{R}-\mathrm{C}-\mathrm{C}-\mathrm{C}-\mathrm{NH}_{2}$
A cm Mbzl
Acm
Acm

23

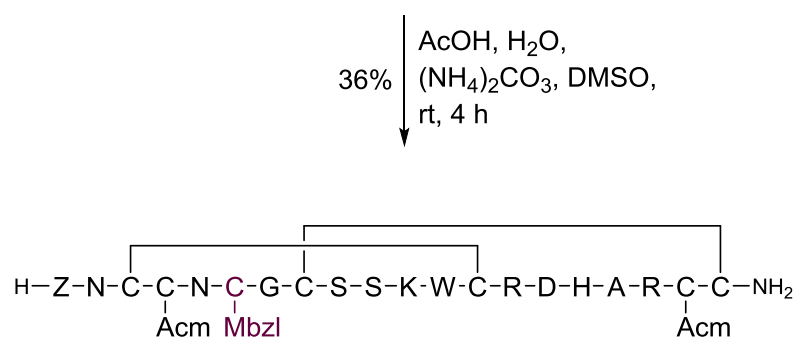

24

$$
22 \% \mid \begin{aligned}
& \text { iodine, } \mathrm{Ac} \text {-L-Trp-OMe } \\
& \mathrm{AcOH}, \mathrm{H}_{2} \mathrm{O}
\end{aligned}
$$

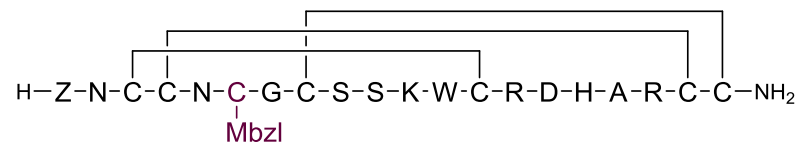

25

Scheme 12: Synthesis of [Gly6Cys(Mbzl)]- $\mu$-SIIIA (25). Z = pGlu, the $C$-terminus is amidated. 


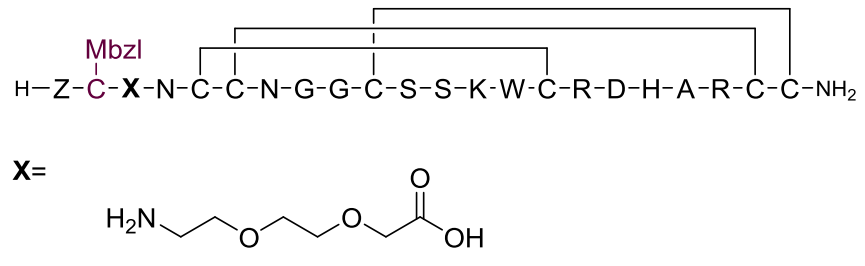

26

Figure 12: Synthesized $N$-terminal elongated Cys(Mbzl) modified $\mu$-SIIIA 26. $Z=p G l u, X$ as described, the C-terminus is amidated.

Deprotection of crude or purified peptide was investigated firstly using hydroboric acid in acetic acid containing pentamethylbenzene and thioanisole as scavengers. These reaction conditions were unsuccessfully applied to these peptides. A deprotection of Fmoc protected amino acid also showed only a small amount of deprotected amino acid. Further investigation on the deprotection of Fmoc protected amino acid using boiling triflouroacetic acid with anisole as a scavenger did not lead to the desired compound. Good turnover was seen applying tetrafluoroboric acid diethyl ether complex with thioanisole in trifluoroacetic acid. However, reinvestigating this method with synthesized modified peptides did not yield desired unprotected products. Due to successful inhibition studies of labelled alkyne modified $\mu$-SIIIA no further investigations were made on the introduction of a seventh cysteine residue for labelling.

\subsection{Validation of folding pattern of $\mu$-conotoxin SIIIA}

Due to the fact that recent studies on $\mu$-SIIIA related $\mu$-KIIIA presented by POPPE et al. and KHOO et al. suggested a different disulphide connectivity (1-5/2-4/3-6) compared to previously published data by KHOO et al. (1-4/2-5/3-6), the disulphide pattern of $\mu$-SIIIA was validated in this thesis. ${ }^{[132,169,170]}$ This validation is important to prove that the amount of different topological isomers formed is not caused by wrong disulphide connectivity. Reevaluation of disulphide bridged peptides such as $\mu$-KIIIA is performed on the on hand, by an NMR based methodology, where disulphide connectivities are obtained by applying BAYESIAN rules of inference to the local topology of cysteine residues. ${ }^{[169]}$ On the other hand, direct mass spectrometric collision-induced dissociation (CID) fragmentation is utilised, where the peptides are firstly digested by trypsin followed by a thorough mass analysis of formed tryptic peptides. ${ }^{[170]}$ Previously, structures were derived by NMR spectroscopy including distance restraints on disulphide bridges based on an alignment with closely related $\mu$-conotoxins, which was also done by YAO et al. for $\mu$-SIIIA . ${ }^{[127]}$ Even though SCHROEDER et al. probably included no distance restraints evaluating $\mu$-SIIIA by NMR; the close relation of $\mu$-SIIIA to $\mu$-KIIIA suggests a similar disulphide connectivity. Comparison of the structure of $\mu$-SIIIA (connectivity 1-4/2-5/3-6) by SCHROEDER et al. with the reevaluated structure of $\mu$-KIIIA (connectivity 1-5/2-4/3-6) by KHOO et al. shows high similarity for 
the $\alpha$-helical motif and for important residues (see Figure 13); additionally, high inhibition rates are seen for both. ${ }^{[126,170]}$
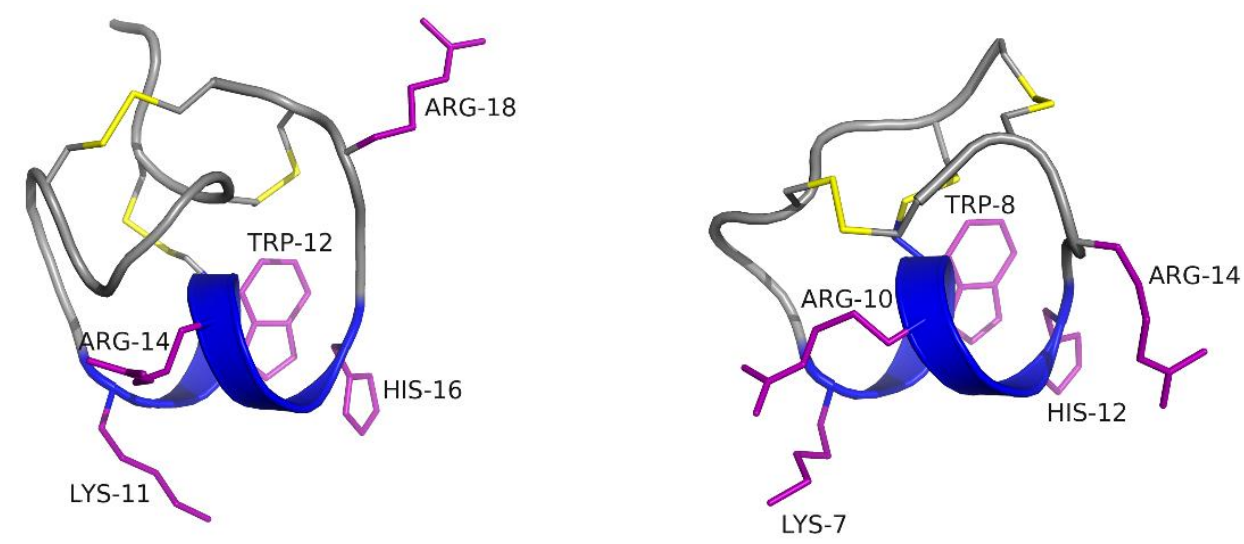

Figure 13: Comparison of average ribbon structure of $\mu$-SIIIA (left) (disulphide pattern 1-4/2-5/3-6) and $\mu$-KIIIA (right) (disulphide pattern 1-5/2-4/3-6) showing the $\alpha$-helical motif across residues 11-16. The three disulphide bonds are highlighted in yellow. The important residues for the affinity are highlighted in purple. See BMRB accession code 20025 and PDB code 2 LXG, respectively. ${ }^{[126,170]}$

Due to the uncertainty of structure of $\mu$-SIIIA two peptides were synthesized by the previously described method with distinct disulphide pattern 1-4/2-5/3-6 (3) and 1-5/2-4/3-6 (27) (see Figure 14). Yields were comparable to previous syntheses and formation of different topological isomers was detected by HPLC (see Figure 15). Two main isomers were isolated for the 1-5/2-4/3-6 disulphide pattern and three for the 1-4/2-5/3-6 pattern. These results prove distinct isomer formation was not due to the modification of $\mu$-SIIIA, but resulted from the disulphide formation using the regioselective approach. Comparison to commercially available $\mu$-SIIIA, which should have the same retention time as native $\mu$-SIIIA, did not lead to conclusions about disulphide pattern as one isomer of each pattern co-eluted with commercially available $\mu$-SIIIA. Therefore, these two isomers were analysed by patchclamp experiments as described beforehand showing $65 \%$ of sodium current to be blocked for $\mu$-SIIIA 27 having 1-5/2-4/3-6 disulphide pattern and 80-100\% for $\mu$-SIIIA 3 having 1-4/2-5/3-6 pattern.

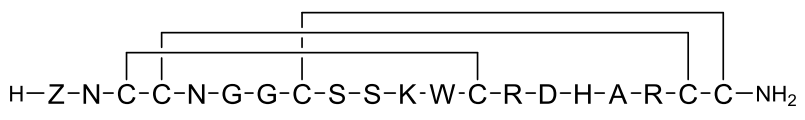

3

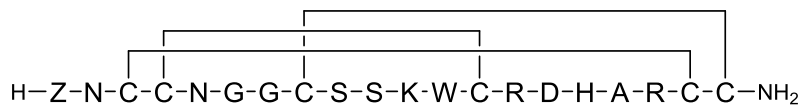

27

Figure 14: Synthesized $\mu$-SIIIA with 1-4/2-5/3-6 (3) and 1-5/2-4/3-6 (27) disulphide pattern. 


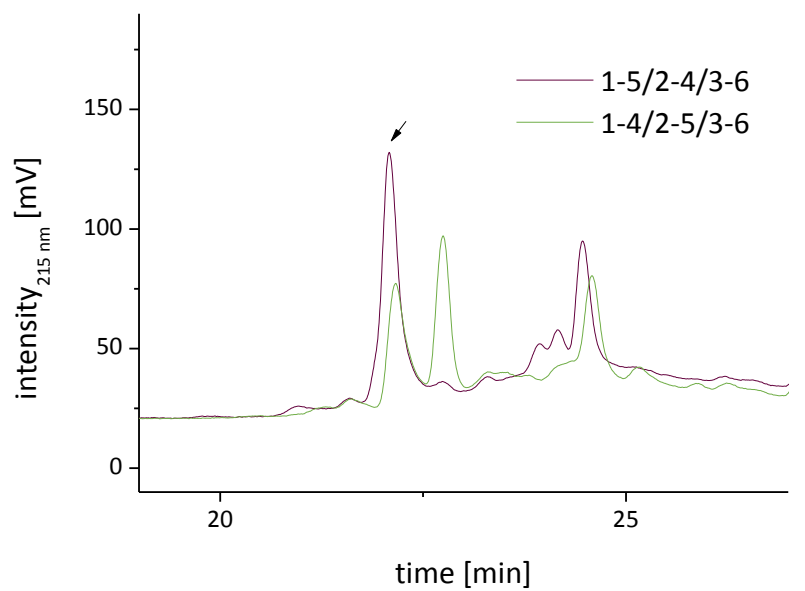

Figure 15: HPLC trace of $\mu$-SIIIA with 1-4/2-5/3-6 (3) and 1-5/2-4/3-6 (27) disulphide pattern. Diverse set of topological isomers were formed. Isomers having same retention time on the HPLC as commercially available $\mu$-SIIIA (highlighted with an arrow) were analysed by patch-clamp.

These results supported previous assessments of disulphide bridges of $\mu$-SIIIA indicating 1-4/2-5/3-6 disulphide pattern to be the native conformation comparable to longer $\mu$-conotoxins such as $\mu$-conotoxin BullIB (disulphide connectivity determined through direct mass spectrometric CID fragmentation) ${ }^{[171]}$

\subsection{Synthesis of caged $\mu$-conotoxin SIIIA}

In addition to the synthesis of labelled $\mu$-SIIIA, a modified $\mu$-SIIIA was synthesized bearing a photoremovable protecting group (PPG) on a residue important for binding to sodium channels. This caged molecule might be used for consecutive cell-attached patch-clamp experiments measuring the current before (no inhibition) and after (inhibition of Nav1.2) uncaging.

\subsubsection{Characteristics and applications of photolabile compounds}

Photoremovable protecting groups are utilised to temporarily block a number of functionalities e. g. acids, alcohols or amines. ${ }^{[172]}$ Their characteristic feature is the spatially and temporally controlled cleavage upon photo-irradiation excluding the need for additional reagents which may interact with sensitive groups present in a molecule. ${ }^{[173]}$ PPGs are commonly applied to explore diverse biological processes: biologically active molecules are rendered inactive by masking their functional groups with PPGs (leading to a caged compound) and subsequent photo-excitation results in an uncaging releasing the active compound with free functional groups. ${ }^{[174]}$ KAPLAN et al. synthesized and analysed the first so called "caged molecule": a phosphate PPG protected adenosine triphosphate (ATP) derivative. ${ }^{[175]}$ Protected ATP does not act as a substrate of renal $\mathrm{Na} / \mathrm{K}$-ATPase, whereas after irradiation unprotected ATP regains its property of activating the $\mathrm{Na} / \mathrm{K}$-pump. In addition to small caged molecules this concept 
has been extended to peptides and proteins. Photocaged amino acids are introduced either by SPPS or by genetically encoding using evolved aminoacyl-tRNA synthetase-tRNA ${ }_{c U A}$ pairs. ${ }^{[176]}$ PPGs have already been broadly applied in the field of neural sciences and many photoactivable derivatives of neurotransmitters and neurotransmitter agonists are available. Thereby, precise analysis of the kinetics and mechanism of chemical synaptic transmission is possible. An example is the induction of whole cell current in HEK293 cells upon photolysis of nitrobenzyl $\mathrm{N}$-protected glycine acting as a neurotransmitter in its uncaged form. ${ }^{[177]}$

\subsubsection{Photolabile nitrobenzyl protecting groups: mechanism and derivatives}

The photoremovable protecting groups mostly applied are based on the 2-nitrobenzyl PPG (NB). The mechanism of its cleavage has been widely studied using different spectroscopic tools. ${ }^{[178-183]}$ Initially, photo-irradiation of $\mathbf{2 8}$ converts the nitro group into its excited state 29. Intramolecular hydrogen abstraction of the benzylic hydrogen by the excited nitro group then leads to the formation of the acinitro intermediate 30, being resonance stabilized. Successive cyclization to $\mathbf{3 1}$ and ring opening results in the formation of hemiacetal $\mathbf{3 2}$ being hydrolysed to form the aldehyde or ketone $\mathbf{3 3}$ (depending on the residue) and releases the target molecule (TM) (see Scheme 13). A diverse range of target molecules can be used e. g. phosphates, carboxylates, carbonates, carbamates, thiolates and phenolates. Alcohols and amines are protected as a carbonate or carbamate; consecutive decarboxylation leads to liberated alkoxides or amines. ${ }^{[184]}$ Substituents in the benzylic positions might be introduced to prevent reactions of formed aldehydes $(R=H)$ with amines forming imines. An additional problem concerning the nitroso byproduct is its strong absorbance above $300 \mathrm{~nm}$, which decreases the photoreaction efficiency. ${ }^{[179]}$<smiles>[R]C([M])c1ccccc1[N+](=O)[O-]</smiles>

28

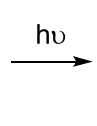<smiles>[R]C([M])c1ccccc1[N+](=O)[O-]</smiles>

29<smiles>[R]C([M])c1ccccc1[N+](=O)[O-]</smiles>

30

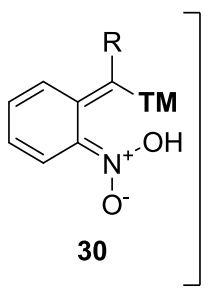<smiles>[R]C1([R])ON(O)c2ccccc21</smiles>

31<smiles>[R]C([R])(O)c1ccccc1[N+](=O)[O-]</smiles>

32 $+\quad \mathrm{TM}-\mathrm{H}$<smiles>[R]C(=O)c1ccccc1[N+](=O)[O-]</smiles>

33

Scheme 13: Photo-induced uncaging of the 2-nitrobenzyl protecting group. TM $=$ target molecule. ${ }^{[184,185]}$ 
Various modifications of the aromatic ring are reported in literature, which are employed to improve the photochemical properties (quantum yield, cleavage efficiency and cleavage wavelength). The most frequently used NB analogues 6-nitroveratryl (also named 3,5-dimethoxy-o-nitrobenzyl = DMNB) and 6-nitroveratryloxycarbonyl (NVOC) have two additional methoxy groups, which are added to shift the absorption maxima from 265 to $365 \mathrm{~nm} \cdot{ }^{[186]}$ Under these conditions even the most light-sensitive amino acid, tryptophan, is not effected. ${ }^{[185]}$ Due to the wide applicability of these groups they were used in this work.

\subsubsection{Structural analysis of $\mu$-conotoxin SIIIA regarding the introduction of a caging group}

In the structural analysis of $\mu$-SIIIA (see section 3.2.1 and 3.2.2) the important residues for binding, namely Lys11, Trp12, Arg14 and Arg18, were already described. The most frequently employed and easiest synthesizable caged amino acid out of this three is Fmoc-L-Lys(NVOC)-OH (34). Commonly used caged arginine is not incorporated into the peptide sequence by means of SPPS. Instead, an ornithine is integrated into the peptide sequence, which is guanylated by a special reagent, prepared from $S$-methylisothiourea and 6-nitroveratryl chloroformate, yielding an arginine after uncaging. ${ }^{[187]}$ Owing to the fact that this guanylation reagent is reactive towards amines, it also reacts with unprotected lysine, and subsequently gives an arginine in this position after uncaging. Additionally, SCHROEDER et al. detected an enhanced affinity by substituting Asp15 with alanine, whereby the substitution of Asp15 by either lysine (positive charge) or tyrosine (aromatic residue) strongly decreases the affinity towards Nav1.2. ${ }^{[126]}$ These results suggest that only a small side chain is preferred in this position making it an optimal target for caging. Furthermore, the [His16Ala] substitution of $\mu$-SIIIA drastically lowers the affinity to Nav1.2, which is probably due to structural changes. Therefore, histidine should not be caged, as a cage in this position might also influence the overall structure formation. Following this structural analysis two peptides were postulated for synthesis: one bearing a caged lysine and the other one bearing a caged aspartic acid (see Figure 16). 


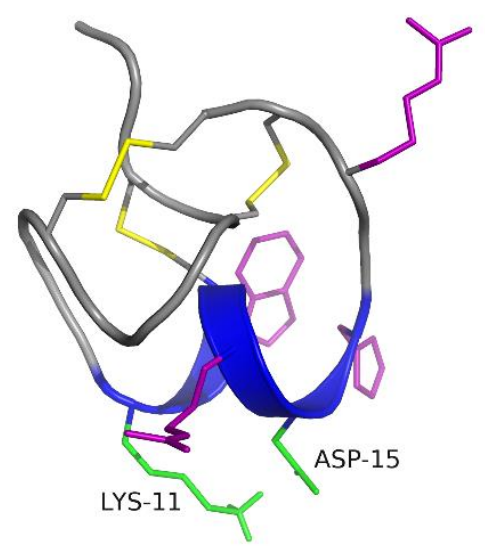

Figure 16: Average ribbon structure of $\mu$-conotoxin SIIIA showing the $\alpha$-helical motif across residues 11-16. The three disulphide bonds are highlighted in yellow. The important residues for the affinity are highlighted in purple, the residues available for modification are shown in green, respectively. See BMRB accession code 20025. ${ }^{[126]}$

\subsubsection{Synthesis of caged $\mu$-conotoxin SIIIA}

For the synthesis of caged lysine, 4-nitrophenyl chloroformate (35) was reacted with 4,5-dimethoxy-2nitrobenzyl alcohol (36) to form an activated carbonate ester $\mathbf{3 7}$ as described by FoMINA et al. ${ }^{[188]}$ In the following reaction with Fmoc protected lysine, previously described by DE GRACIA LUX et al., caged lysine 34 containing a carbamate function was obtained (see Scheme 14). ${ }^{[189]}$<smiles>O=C(Cl)Oc1ccc([N+](=O)[O-])cc1</smiles>

35<smiles>COc1cc(CO)c([N+](=O)[O-])cc1OC</smiles>

36

$$
58 \% \begin{aligned}
& \text { DIPEA, } \\
& \text { DCM, } \\
& r t, o / n
\end{aligned}
$$<smiles>COc1cc(COC(=O)Oc2ccc([N+](=O)[O-])cc2)c([N+](=O)[O-])cc1OC</smiles>

37

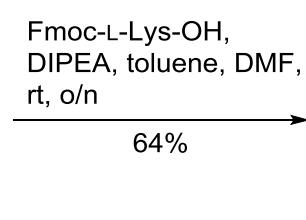<smiles>COc1cc(COC(=O)NCCCC[C@H](NCF)C(=O)O)c([N+](=O)[O-])cc1OC</smiles>

34

Scheme 14: Synthesis of Fmoc-L-Lys(NVOC)-OH (34).

Synthesis of caged aspartic acid $\mathbf{3 8}$ was accomplished based on a procedure described by BOURGAULT et al. starting from Fmoc and ${ }^{t} \mathrm{Bu}$ protected aspartic acid 39. [190] Instead of 1,3-dicyclohexylcarbodiimide (DCC) 1-ethyl-3-(3-dimethylaminopropyl)carbodiimide (EDC) was used 
as the carboxyl activating agent as separation of byproduct $N, N^{\prime}$-dicyclohexylurea (DCU) was not possible either by precipitation or column chromatography. Byproducts of esterification with EDC were easily separated as these were water soluble. ${ }^{[191]}$ Subsequent deprotection of the ${ }^{{ }^{t} \mathrm{Bu}}$ protected carboxylic acid $\mathbf{4 0}$ by trifluoroacetic acid resulted in the caged aspartic acid $\mathbf{3 8}$ (see Scheme 15).

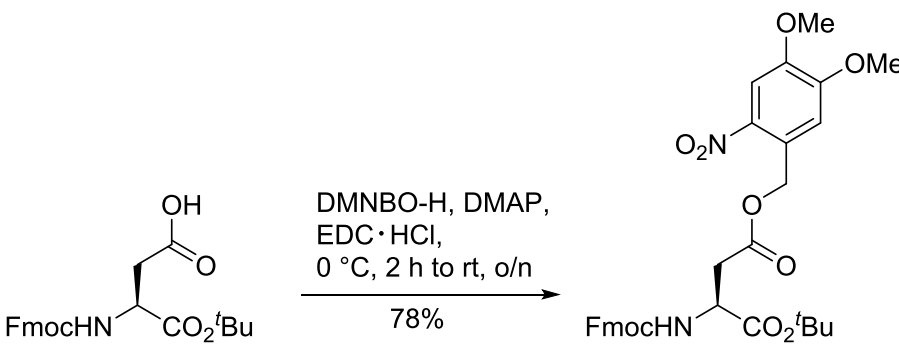

39

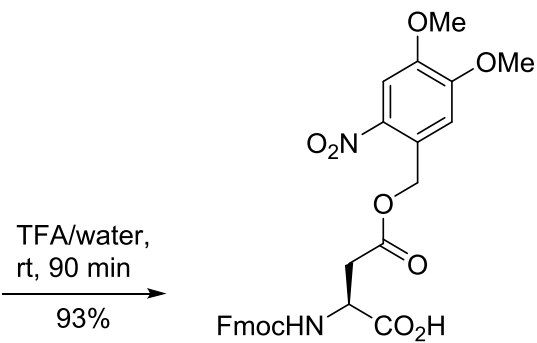

38

Scheme 15: Synthesis of Fmoc-L-Asp(ODMNB)-OH (38).

After preparation of the caged amino acids, they were integrated into the peptide sequence of $\mu$-SIIIA as described earlier (see chapter 3.2.3). Test cleavage of linear peptide 41 containing caged lysine proved that the integration of this amino acid was successful. Formation of the $1^{\text {st }}$ and $2^{\text {nd }}$ disulphide bridge was accomplished in good yields (64\% and 70\% crude peptide $\mathbf{4 2}$ and $\mathbf{4 3}$, see Scheme 16). Purification of crude peptide $\mathbf{4 3}$ by HPLC was necessary after the formation of the $2^{\text {nd }}$ disulphide bridge yielding one major product. As previously described, the $3^{\text {rd }}$ disulphide bridge was synthesized using iodine but stirring was continued for $2 \mathrm{~h}$ due to the absence of a reactive alkyne moiety. Precipitation yielded the crude product $\mathbf{4 4}$, which was purified by HPLC. As the yield of the formation of the $3^{\text {rd }}$ disulphide bridge was very poor (8\%), another protecting strategy was investigated employing the enzyme labile cysteine protecting group Phacm instead of Acm (see chapter 3.1.2). Even though peptide synthesis and formation of the $1^{\text {st }}$ and $2^{\text {nd }}$ disulphide bridges were accomplished, the $3^{\text {rd }}$ disulphide bridge was not formed by applying resin bound PGA as previously described by GónGORABENITEZ et al. ${ }^{[77]}$

Additionally, caged aspartic acid $\mathbf{3 8}$ was incorporated into the peptide sequence of $\mu$-SIIIA. The peptide was synthesized as previously mentioned (see chapter 3.2.3). Mass analysis after a test cleavage of the resulting peptide did show a mass difference $(m / z=-213)$, which corresponds to an aspartimide of uncaged peptide. Even though this was prevented for $\mathrm{O}^{t} \mathrm{Bu}$ protected aspartic acid by applying $\mathrm{HOBt}$ into the deprotection solution, this reaction could not be prevented for the good leaving group ODMNB. However, BOURGAULT et al. observed problems with this protecting group for aspartic acid as well, directing the need for aspartimide suppressing conditions, which were used here. ${ }^{[190]}$ As these conditions did not reduce aspartimide formation, future protection of aspartic acid should be 
conducted using 3-(4,5-dimethoxy-2-nitrophenyl)-2-butyl (DMNPB), which is stable during coupling/ deprotection conditions. ${ }^{[192,193]}$

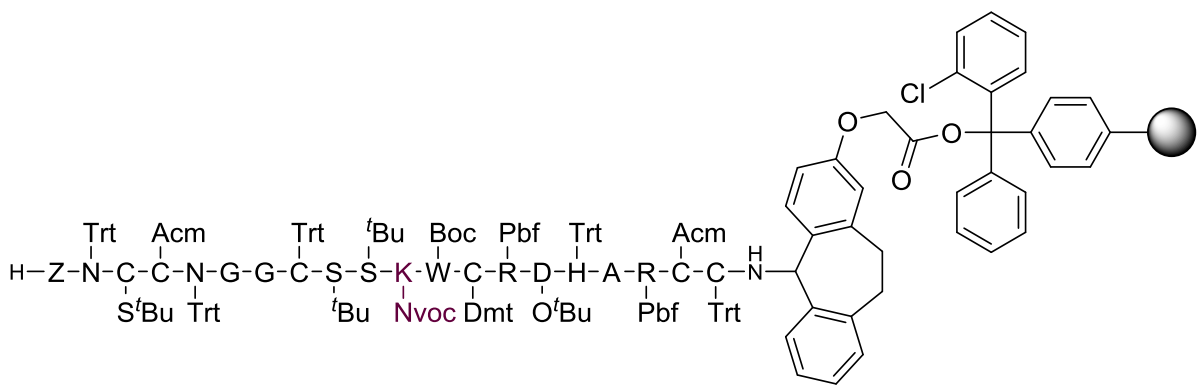

41

\begin{tabular}{l|l}
$64 \%$ & 1) $20 \%$ 2-mercaptoethanol, $1 \% \mathrm{DBU}, \mathrm{DMF}$ \\
2) 2,2 -dithiopyridine, DCM \\
3) $10 \% \mathrm{AcOH}, 20 \% \mathrm{TFE}, \mathrm{DCM}$ \\
4) $0.1 \% \mathrm{TFA}, 0.2 \% \mathrm{TES}, \mathrm{DCM}$ \\
5) $10 \% \mathrm{NEt}_{3}, \mathrm{DCM}$ \\
6) $95 \% \mathrm{TFA}, 2.5 \% \mathrm{TIS}, 2.5 \% \mathrm{H}_{2} \mathrm{O}$
\end{tabular}

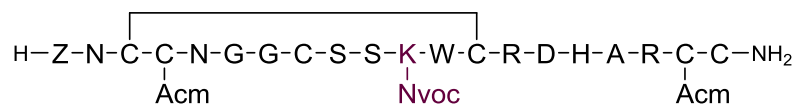

42

$70 \% \mid \begin{aligned} & \mathrm{AcOH}, \mathrm{H}_{2} \mathrm{O} \\ & \left(\mathrm{NH}_{4}\right)_{2} \mathrm{CO}_{3}, \mathrm{DMSO} \\ & \mathrm{rt}, 4 \mathrm{~h}\end{aligned}$

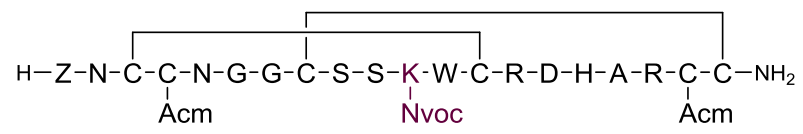

43

$8 \% \mid \begin{aligned} & \text { iodine, Ac-L-Trp-OMe } \\ & \mathrm{AcOH}, \mathrm{H}_{2} \mathrm{O} \\ & \mathrm{rt}, 2 \mathrm{~h}\end{aligned}$

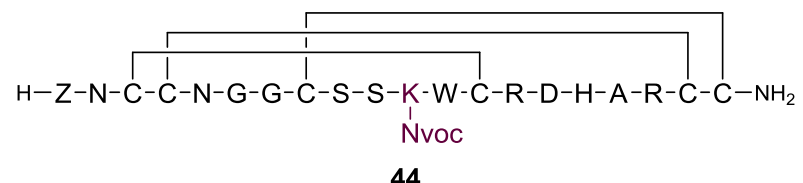

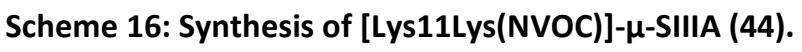

Initial uncaging experiments of $\mu$-SIIIA 44 containing caged lysine were conducted in a mixture of acetonitrile/water by applying a $1000 \mathrm{~W} \mathrm{Hg(Xe)} \mathrm{lamp} \mathrm{as} \mathrm{UV} \mathrm{light} \mathrm{source} \mathrm{and} \mathrm{irradiating} \mathrm{at} 650 \mathrm{~W}$ at 
300-400 $\mathrm{nm}$ as previously described by PANSE. ${ }^{[160]}$ Probes were taken after 1,2 and $3 \mathrm{~min}$ and analysed by HPLC indicating a reduction of starting material but no product formation. Therefore, a milder light source, specifically a transilluminator for visualizing DNA bands in gels, was utilised, which was used beforehand by MÜLLER and PANSE for uncaging. ${ }^{[160,194]}$ UV light with a wavelength of $365 \mathrm{~nm}$ was applied for $90 \mathrm{~min}$. Every $15 \mathrm{~min}$ a probe was taken and analysed by LC-MS. Similar conditions were applied to uncage Fmoc-L-Lys(NVOC)-OH (34), which was completely deprotected after $30 \mathrm{~min}$, and to native $\mu$-SIIIA. For native $\mu$-SIIIA, the formation of an additional peak at longer retention times was observed after $60 \mathrm{~min}(\mathrm{~m} / \mathrm{z}=+2)$, which was probably due to the destruction of one disulphide bridge. Photolysis of disulphide bonds were already described by ZHOU et al. for a lower wavelength of $254 \mathrm{~nm} \cdot{ }^{[195]}$ For caged $\mu$-SIIIA first uncaging was observed after $30 \mathrm{~min}$ and after $75 \mathrm{~min}$ the starting material was consumed. Even though no product peak formation was detected by LC-MS at $215 \mathrm{~nm}$ after the uncaging process, the correct mass was seen at an earlier retention time compared to caged peptide. As these long cleavage times are incompatible with cell-attached measurements further investigations have to be made in the future. Possible side reactions such as destruction of disulphide bridges or imine side product formation might be prevented by changing the caging group. Furthermore, patchclamp experiments need to be conducted with caged $\mu$-SIIIA 44 to investigate whether the introduction of a caged lysine impedes its binding affinity. Otherwise an option would be the introduction of several caged amino acids in one $\mu$-SIIIA. Currently, investigations are carried out by JUNIUS synthesizing a caged arginine, which might possibly be integrated in the synthesis of caged $\mu$-SIIIA. 


\section{Labelling of pompilidotoxin}

\subsection{Characteristics and applications of pompilidotoxin}

Pompilidotoxins (Pmtxs) are toxins derived from the venoms of the spider wasps (Pompilidae) Anoplius samariensis ( $\alpha$-Pmtx) and Batozonellus maculifrons ( $\beta$-Pmtx), which paralyse their prey instead of killing it, in order to feed their larvae with living prey. ${ }^{[40]}$ After their first identification by KoNNO et al., pompilidotoxins have been widely applied on different tissues to analyse their impact on ion channels. ${ }^{[196,197]}$ SAHARA et al. discovered a slowing of the sodium channel inactivation process in TTXsensitive voltage-gated sodium channels (VGSCs) of rat trigeminal neurons by PMTX. ${ }^{[198]}$ Further studies proved its selectivity to target rNav1.2 over rNav1.5 (rat sodium channels), showing its preference of neuronal over cardiac sodium channels. ${ }^{[199]}$ Additionally, SCHIAVON et al. analysed its effect on eight different VGSC isoforms for their selective response to Pmtx. ${ }^{[40]} \mathrm{Nav1.2}$ and Nav1.6 are the isoforms with the highest affinity, followed by Nav1.7 and Nav1.3. Nav1.4 and Nav1.5 does not induce any effect. The described absence of affinity for Nav1.4 and Nav1.5 is attributed to a Glu $\rightarrow$ Gln mutation between segment 3 and 4 of domain IV of the sodium channel, where the active binding site of Pmtx is incorporated.

\subsection{Structural analysis of pompilidotoxin}

$\alpha$-Pmtx as well as $\beta$-Pmtx are composed of 13 amino acids, which differ only at position 12 , where $\alpha$-Pmtx has a lysine and $\beta$-Pmtx an arginine residue (see Figure 17). This small change induces a fivefold higher potency for $\beta$-Pmtx over $\alpha$-Pmtx. Structure-activity relationships of synthetic analogues of $\alpha$-Pmtx were conducted by SAHARA et $a{ }^{\left[{ }^{[198]}\right.}{ }^{[1}$ Deletion of the $C$-terminal amidation, or the first five or last four amino acids leads to a loss of activity. Furthermore, a [Ile2Phe] or [Phe7Tyr] replacement abolishes the activity. Additionally, 23 analogues were synthesized by KonNo et al. and compared to $\alpha$ - and $\beta$-Pmtx. ${ }^{[200]}$ Substitution of basic amino acids of $\alpha$-Pmtx such as lysine or arginine (forming mutants [Arg1Lys]- $\alpha$-Pmtx or [Lys3Arg]- $\alpha$-Pmtx) causes an increased activity comparable to that of $\beta$-Pmtx. However, double or triple mutants (based on $\alpha$-Pmtx) do not have an increased potency compared to $\beta$-Pmtx. Modification of the position of the basic residues, such as a shift of lysine in 
position 3 to position 4 or 5 leads to a loss of activity. Only the [Ser11Ala]- $\alpha$-Pmtx mutant does not show a decrease in affinity.

$$
\begin{array}{l|l}
\alpha-P m t x & \text { RIKIGLFDQLSKL* } \\
\beta \text {-Pmtx } & \text { RIKIGLFDQLSRL* }
\end{array}
$$

Figure 17: One letter code of $\alpha-P m t x$ and $\beta$-Pmtx for comparison. The difference in position 12 is highlighted in green. The important residues for the affinity are highlighted in purple. The $C$-terminus is amidated (indicated by an asterisk).

\subsection{Synthesis of modified and labelled pompilidotoxin}

Following this detailed structural analysis, two alternatives were proposed in order to label $\beta$-pompilidotoxin (having higher activity than $\alpha$-Pmtx): substitution of the serine at position 11 and elongation of the $\mathrm{N}$-terminus, as there were no results on an elongation in this position. Introduction of a label in these positions might be accomplished either by a substitution with cysteine, which offers the opportunity to use a maleimide functionalized fluorophore, or with serine( $2^{\prime}$-propyne), which can react with an azide functionalized fluorophore via CUAAC. Fmoc-L-Ser(2'-propyne)-OH (6) was synthesized according to the previously mentioned method (see Scheme 5). Syntheses of four peptides bearing either alkyne substituted serine or a cysteine in position 0 or 11 were performed on rink amide MBHA resin as solid support preloaded with Fmoc-L-Leu-OH according to Fmoc based SPPS protocols providing a $C$-terminal amide after cleavage (see Figure 18). In a first approach, aspartimide formation was reduced by adding $0.1 \mathrm{M}$ 1-hydroxybenzotriazole (HOBt) to the deprotection solution, but standard coupling conditions $\left(75^{\circ} \mathrm{C}\right)$ were utilised. ${ }^{2}$ As aspartimide formation was still detected $(m / z=-18)$, the temperature for all steps was reduced to $50^{\circ} \mathrm{C}$. Test cleavages of all protected peptides confirmed the formation of peptides 45-48.

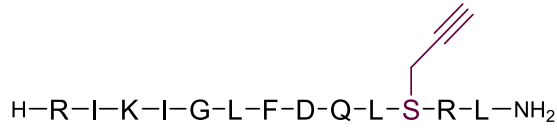

45

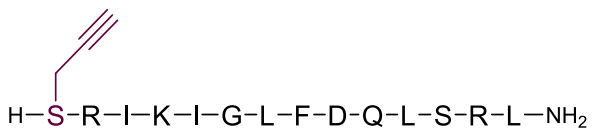

47

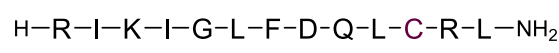

46

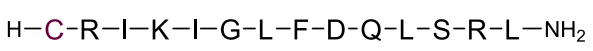

48

Figure 18: Synthesized alkyne or cysteine modified $\beta$-pompilidotoxins 45-48.

\footnotetext{
${ }^{2}$ SPPS of 45 and 47 applying standard coupling conditions $\left(75^{\circ} \mathrm{C}\right)$ were carried out by SELDA KABATAS.
} 
Alkyne modified peptide 45, resin loaded and fully protected, was subjected to copper(I)-catalysed azide-alkyne cycloaddition (CuAAC). Conversion with copper(I) iodide, sodium ascorbate as reducing agent and Alexa Flour ${ }^{\circledast} 488$ azide, which was used in agreement with the SCHILD research group, was followed by cleavage and subsequent HPLC purification. Even though product was detected, it was obtained in a mixture with unreacted alkyne, which was not separable via HPLC. Therefore, the unlabelled alkyne modified peptides $\mathbf{4 5}$ and $\mathbf{4 7}$ were only submitted to patch-clamp analysis. The advantage of an alkyne moiety instead of a cysteine moiety for patch-clamp analysis was the avoidance of side effects, which might occur due to dimerization via disulphide bond formation in case of cysteine modified $\beta$-Pmtx. After deprotection of peptides $\mathbf{4 6}$ and $\mathbf{4 8}$, they were purified by HPLC. Subsequent conversion to labelled $\beta$-pompilidotoxins was achieved by reaction with Alexa Fluor ${ }^{\circledR} 488 \mathrm{C} 5$ maleimide at a neutral pH (see Scheme 17). Tris(2-carboxyethyl)phosphine (TCEP) was utilised to reduce existing disulphide bridged compounds. Labelled peptides $\mathbf{4 9}$ and $\mathbf{5 0}$ were purified by HPLC in yields of $34 \%$ and $10 \%$, respectively. Synthesized Alexa Fluor ${ }^{\circledR} 488$ labelled $\beta$-pompilidotoxins were than analysed by GUOBIN BAO in the SCHILD research group to investigate sodium channels in olfactory receptor neurons (ORNs).

$$
\text { H-R-I-K-I-G-L-F-D-Q-L-C-R-L- } \mathrm{NH}_{2}
$$

46

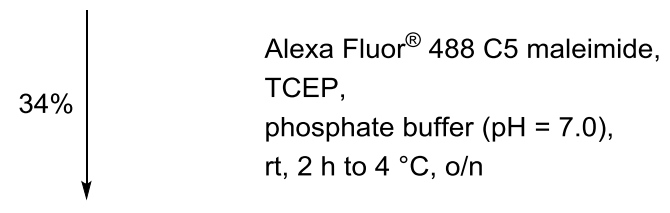

$$
\text { H-C-R-I-K-I-G-L-F-D-Q-L-S-R-L- } \mathrm{NH}_{2}
$$

48

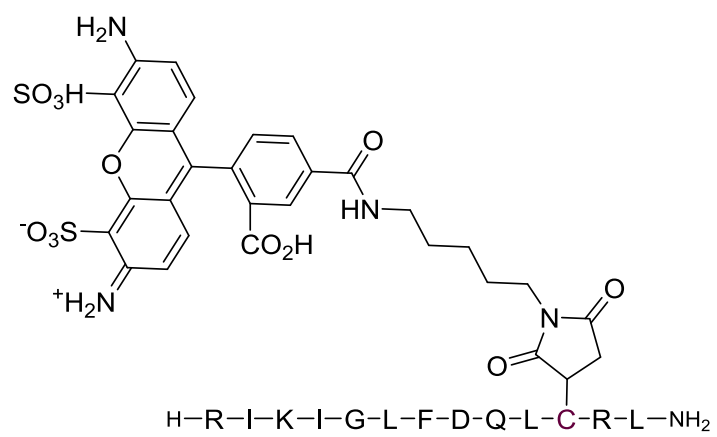

49

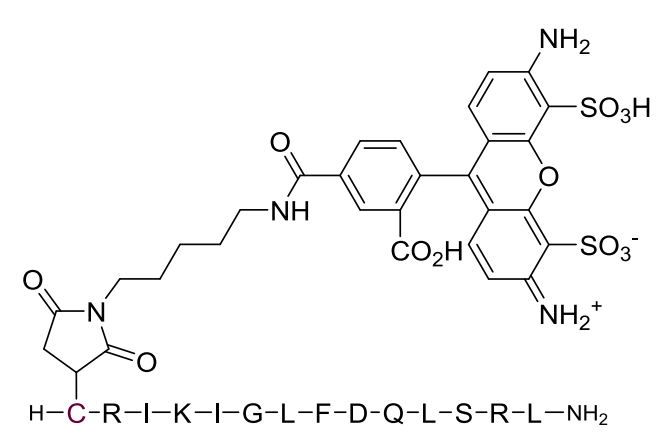

50

Scheme 17: Syntheses of Alexa Fluor ${ }^{\circledR} 488$ labelled $\beta$-pompilidotoxins 49 and 50. 


\subsection{Analysis of modified and labelled pompilidotoxin}

Firstly, unlabelled alkyne modified peptide $\mathbf{4 5}$ was studied by patch-clamp experiments. ${ }^{3}$ Without toxin application sodium current was detected at depolarisation pulses of $-30 \mathrm{mV}$ and above. Even though the first sodium current for $\beta$-Pmtx was seen with a depolarisation pulse of $-30 \mathrm{mV}$ as well, the amplitude for $-30 \mathrm{mV}$ was increased compared to the control experiment, indicating an inhibition of sodium channel inactivation by $\beta$-Pmtx. Similar results were obtained by modified peptide 45, suggesting that the modified $\beta$-Pmtx was also able to inhibit or slow down sodium channel inactivation (see Figure 19).

A

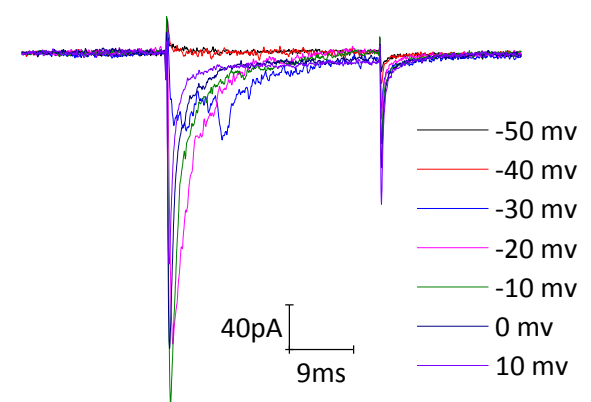

C

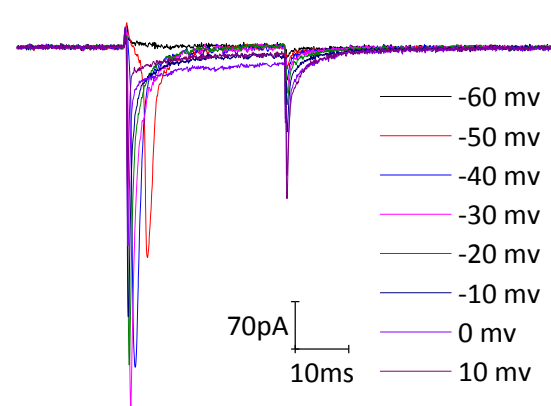

B

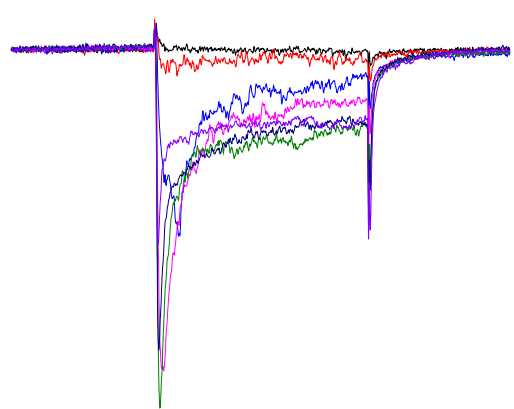

D

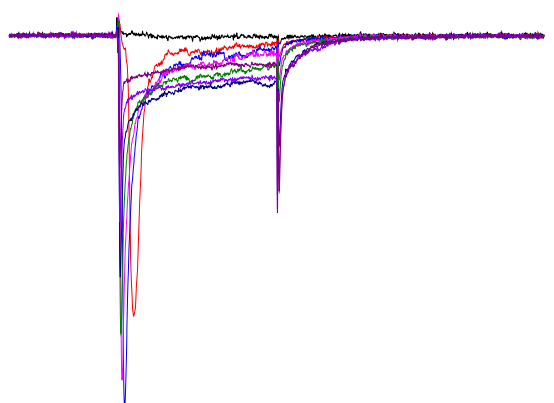

Figure 19: Inhibition of sodium channels of ORNs by unmodified $\beta$-Pmtx and modified $\beta$-Pmtx 45 . In the whole cell configuration patch-clamp recording was conducted with ORN cells, which were held at $-70 \mathrm{mV}$ and depolarized to $-60-10 \mathrm{mV}$. Sodium currents were measured before ( $A$ and $C$ ) and after treatment with unmodified $\beta$-Pmtx (B) or modified $\beta$-Pmtx 45 (D). Application of $50 \mu \mathrm{M}$ toxin induces a slowed inactivation.

The effect of the toxins in terms of the additional current during depolarization with different voltages was further analysed with additional channel current/voltage (IV) curves before and after treatment. As shown in Figure 20 (left), after $\mathbf{4 5}$ treatment, sodium channel inactivation slows down, which

${ }^{3}$ All patch-clamp experiments of $\beta$-pompilidotoxin derivatives were conducted by GUOBIN BAO in the SCHILD research group. 
resulted in an additional current during the different depolarisation pulses. For 45 , the additional sodium current was seen even at low depolarisation pulses (start at $-50 \mathrm{mV}$ ) compared to natural $\beta$-Pmtx (see Figure 20 (right)), which showed the same effect after depolarisation pulses of $-30 \mathrm{mV}$. A complete wash-out of $\mathbf{4 5}$ was detected after $3 \mathrm{~min}$. However, $\mathbf{4 7}$ as well as related labelled pompilidotoxin $\mathbf{5 0}$ did not have any effect on the sodium current (see Figure 20 (right)).
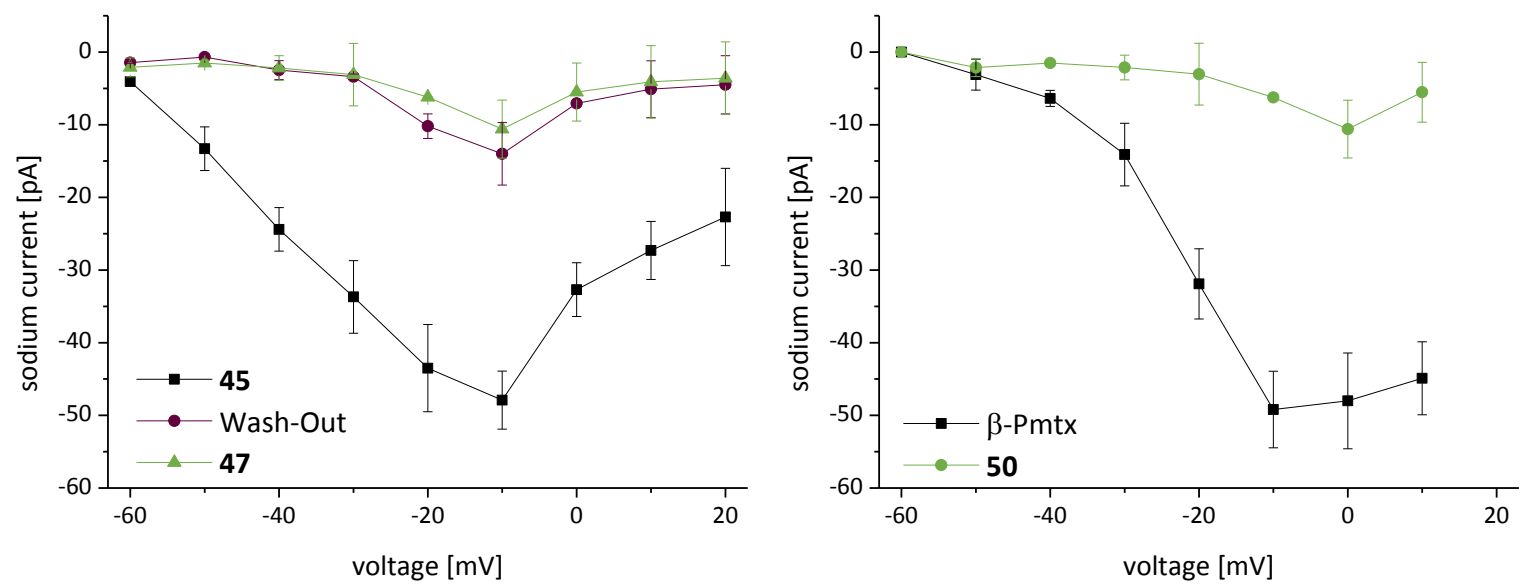

Figure 20: Sodium current/voltage curves for natural and modified $\beta$-Pmtx. Curves for modified $\beta$-Pmtx 45, after wash-out for $3 \mathrm{~min}$ and for modified $\beta$-Pmtx 47 are seen in the left diagram. A comparison of unmodified $\beta$-Pmtx and fluorophore labelled $\beta$-Pmtx 50 is shown in the right diagram.

Initial fluorescence staining of ORN was conducted by GUOBIN BAO with fluorophore labelled $\beta$-Pmtx 49 (see Figure 21). In the first image the autofluorescence of the cell is seen, in which two surface dead cells show a high autofluorescence. The second and third image shows the staining after three and ten minutes, respectively, whereas an accumulation of Alexa Fluor ${ }^{\circledR} 488$ at the cell membrane was detected. A five minutes wash was performed as a control experiment, which removed staining by Alexa Fluor ${ }^{\circledast}$ 488. Therefore, only the autofluorescence was detected after wash-out.
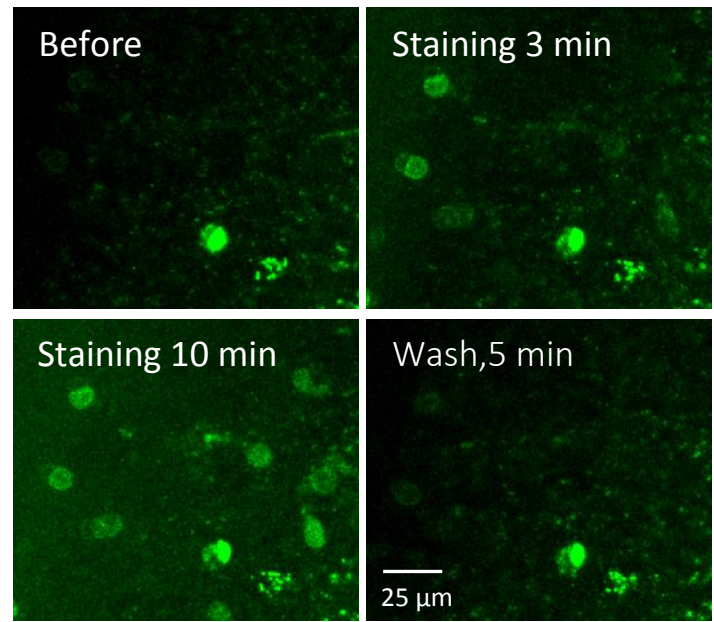

Figure 21: Staining sodium channels with 49 in ORN at a low concentration of $10 \mu \mathrm{M}$. Maximum intensity projection in $\mathrm{Z}$ is shown. Images were taken before and after staining for three and ten minutes. After washing for five minutes, only the autofluorescence was observed. 



\section{Labelling of iberiotoxin}

\subsection{Characteristics and applications of iberiotoxin}

Since the first isolation of iberiotoxin (Ibtx) in 1990 from the venom of the scorpion Buthus tamulus by GALVEZ et al., it has become an interesting target for addressing calcium-activated potassium channels (BK channels). ${ }^{[201]}$ Ibtx is composed of 37 amino acids containing three disulphide bridges. In comparison with charibdotoxin (Chtx), another scorpion-derived BK channel blocker having 68\% sequence homology with Ibtx, Ibtx is more selective for BK channels. In contrast to Chtx, iberiotoxin distinguishes between BK channels and other voltage-gated ion channels, especially other potassium channels. ${ }^{[202]}$ Ibtx binds to the external vestibule of the channel interacting with surface charges located there. ${ }^{[202]}$

Owing to its high selectivity, several labels have been introduced to Ibtx. First labelling was performed by KNAUS et al. introducing a radiolabel utilising $N$-[ $\left.{ }^{3} \mathrm{H}\right]$ ethylmaleimide to react with recombinant [Asp19Cys]lbtx. ${ }^{[203]}$ In comparison, the double mutant [Asp19Tyr/Tyr36Phe]lbtx, where tyrosine is specifically labelled with ${ }^{125}$ I, has improved radiolabel properties displaying high specific activity. ${ }^{[204]}$ Therein, double mutation is necessary because direct labelling of Tyr36 reduces the binding affinity. This radiolabel method provides the tool to detect the coassembly of BK channels and L-type voltagegated calcium channels in rat brain. ${ }^{[205]}$ The introduction of a fluorophore is accomplished on the one hand, by labelling free amines of Ibtx with rhodamine red $^{\mathrm{TM}}$ succinimidyl ester to analyse Xenopus neurons in different embryonic stages. ${ }^{[36]}$ On the other hand, recombinant [Asp19Cys]lbtx is labelled with Alexa Fluor ${ }^{\circledR} 488$ maleimide in order to directly visualize localisation of BK channels in mammalian cochlear hair cells. ${ }^{[206]}$ The synthesis of a biotin derivative of Ibtx and its binding to Alexa Fluor $^{\circledR} 488$ streptavidin conjugate was accomplished by BINGHAM et al. to image the surface distribution of BK channels on a transfected human cell line, revealing a patch-like surface distribution. ${ }^{[207]}$ The positioning of labels on Ibtx was clearly dependent on the structural analysis of iberiotoxin, which will be discussed in the next section. 


\subsection{Structural analysis of iberiotoxin}

Structural analysis of Chtx as well as Ibtx reveals, that the 37 amino acids form a short triple-stranded $\beta$-sheet (residues 1-3, 26-29, 32-35), an $\alpha$-helix (residues 10-19), and an extended fragment (residues 5-7) (see Figure 22). These motifs are linked together by three disulphide bridges. A hydrophobic cluster is formed in the centre of the molecule by two groups of well-defined, low-accessible side chains (Thr3, Val5, Val16, Leu20, Cys33 and Leu2, His21, Thr23, Cys17 and Cys35) stabilizing the overall structure. ${ }^{[208]}$ MILLER et al. provided further insights into the structure-activity relationship by point mutation of a number of amino acids for Chtx. ${ }^{[209,210]}$ While mutation of certain charged residues has only small impact on the binding affinity (Lys11, Glu12, Arg19, His21, Lys31, Lys32), eight residues are highly important (Ser10, Trp14, Arg25, Lys27, Met29, Asn30, Arg34, Tyr36). These residues are located on the surface of the $\beta$-sheet. Even though, most point mutations induce a decrease in binding affinity, [Thr8Ser]Chtx has an increased binding affinity with twofold reduction in off-rate. However, iberiotoxin, which has a thirteenfold lower off-rate than Chtx, contains a serine in this position.

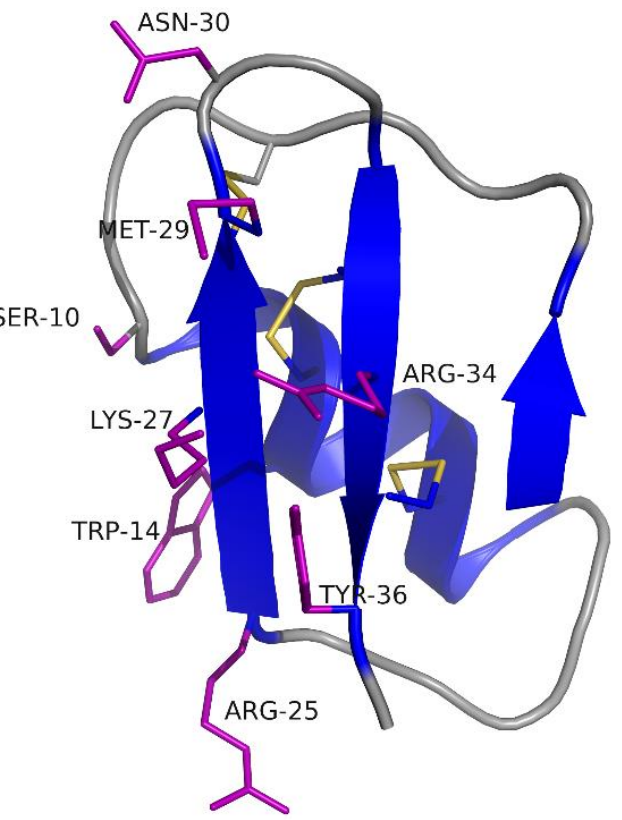

Chtx $\quad$ ZFTNVSCTTSKECWSVCQRLHNTSRGKCMNKKCRCYS*

Ibtx ZFTDVDCSVSKECWSVCKDLFGVDRGKCMGKKCRCYQ*

Figure 22: Average ribbon structure of iberiotoxin related charybdotoxin (top): The three disulphide bonds are highlighted in yellow. The important residues for the affinity are highlighted in purple. See PDB code 2CRD. ${ }^{[208]}$ One letter code of Chtx and Ibtx for comparison (bottom): $Z=p G l u$, the $C$-terminus is amidated (indicated by an asterisk). 
Further differences between these two toxins are the presence of four additional negatively charged amino acids in iberiotoxin inducing a net charge of +1 (if Lys, Arg, Asp and Glu are ionised) in contrast to +5 of Chtx. These differences may be responsible for a fivefold lower on-rate compared to Chtx as the pore of the channel has a negative charge. The increase in off-rates must therefore be due to electrostatic asymmetry, Ibtx has a larger dipole moment because of the asymmetrical substitution of four additional aspartates, or specific interactions between residues. ${ }^{[211]}$

\subsection{Synthesis of labelled iberiotoxin}

As previously described (see section 5.1), many labelled iberiotoxins have already been researched. Even though solid phase peptide synthesis of Ibtx is possible and can be improved by applying NATIVE CHEMICAL LIGATION, most of the applied iberiotoxins are gained by recombinant expression. ${ }^{[212]}$ Described labels are usually attached in the Arg19 position, as this residue is located in the $\alpha$-helical motif, on the side of the molecule opposite to the binding site. Introducing a label in this position requires a change in amino acid backbone, usually a cysteine is introduced to have a target for maleimide reagents. A much simpler approach is the labelling of free amines of commercial available Ibtx with the fluorophore succinimidyl ester (see chapter 5.1). Even though Lys27 is highly important for the inhibition, specific labelling of ion channels is possible after labelling lbtx with eight equivalents of rhodamine red $^{\mathrm{TM}}$ succinimidyl ester. ${ }^{[36]}$ Therefore, this method is applied in the SCHILD research group to label iberiotoxin. The amount of labels per Ibtx is estimated to be three to four labels per Ibtx (see section 2.3). ${ }^{[42]}$ In this thesis, a tool for the exact quantification of BK channels was developed utilising commercially available recombinant lbtx (51), missing cyclization at the $N$-terminus, which as stated by ALOMONE LABS does not have an influence on inhibition (see Scheme 18). Mono-labelling to 52 was accomplished by utilising 0.7 eq. of Alexa Fluor ${ }^{\circledR} 546$ carboxylic acid succinimidyl ester and was confirmed by mass analysis after HPLC purification. Further quantifications studies on BK channels forming clusters with VGCCs are yet to be made by BAO in the SCHILD research group. 


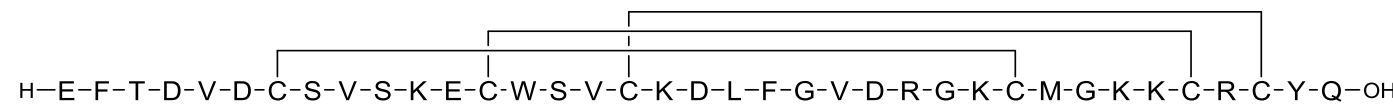

51

Alexa Fluor ${ }^{\circledR} 546$ carboxylic acid succinimidyl ester, $\mathrm{NEt}_{3}, \mathrm{rt}, \mathrm{o} / \mathrm{n}$
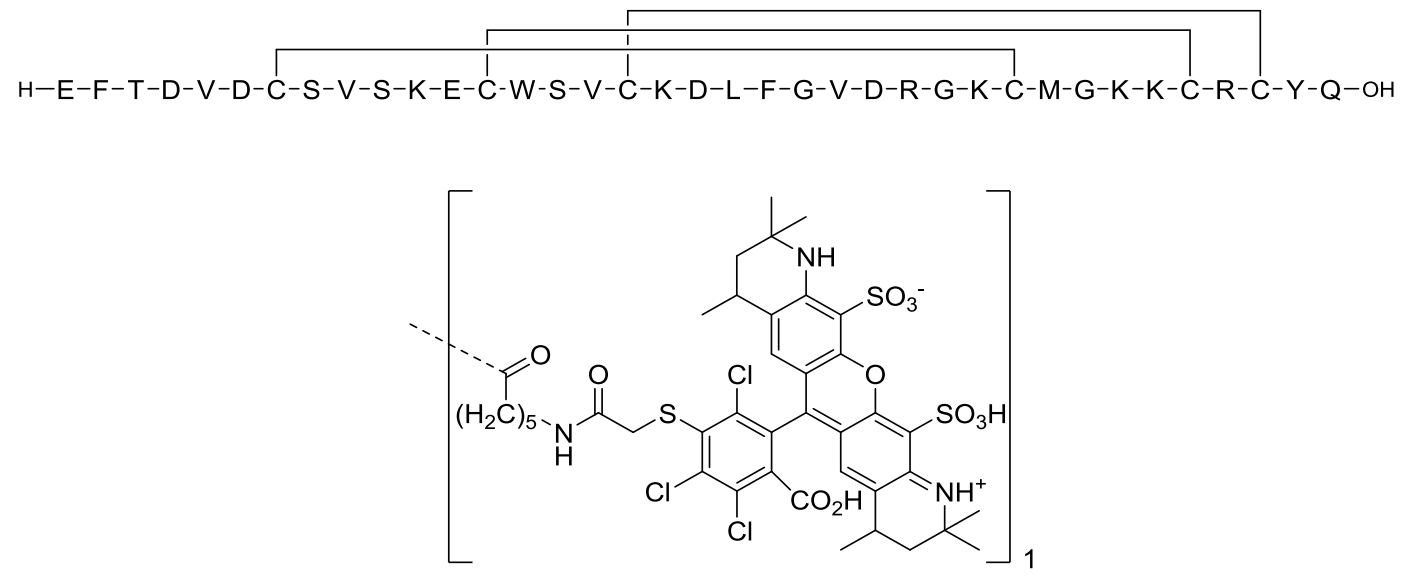

52

Scheme 18: Synthesis of mono-labelled Alexa Fluor ${ }^{\circledast} 546$ iberiotoxin (52). The fluorophore was attached to one of the lysine residues or the $\mathrm{N}$-terminus. 


\section{Labelling of cyclic adenosine-3',5'- monophosphate}

\subsection{Role of cyclic adenosine-3',5'-monophosphate in the chemotaxis of Dictyostelium discoideum}

Chemotaxis is defined as the directed migration of cells in chemical gradients. ${ }^{[213]}$ It plays an important role in many eukaryotic processes, e. g. the healing process of wounds, which is facilitated by neutrophils (white blood cells) removing bacteria from the wound. ${ }^{[214]}$ Furthermore, in cancer metastasis malignant cells move away from the tumour and towards blood vessels, directed by gradients of growth factors. ${ }^{[215]}$ A widely applied model system for eukaryotic chemotaxis is the migration of the amoeboid Dictyostelium discoideum. ${ }^{[216]} D$. discoideum is an organism possessing a social cycle, where it is able to switch between proliferating as single amoeba and when starved aggregating into a cellular slime mould existing of approximately $10^{5}$ cells. ${ }^{[217]}$ This aggregation is driven by a spontaneous production and emission of cyclic adenosine-3', $5^{\prime}$-monophosphate (cAMP), which acts as a signal for neighbouring cells. Due to the fact, that $D$. discoideum cells are chemotactic towards CAMP, they come into close contact and aggregate. ${ }^{[218]}$ Aggregation is followed by several morphological changes leading to the formation of a fruiting body, with stalk cells that carry spore cells, which survive unfavourable conditions. Following the release of the spore cells, they spread and the cycle is closed when they reach the amoeboid stage again. ${ }^{[219]}$

The response of $D$. discoideum to CAMP is initiated by CAMP receptors (CAR), which are linked to a heterotrimeric G-protein. ${ }^{[216]}$ A downstream signalling cascade eventually leads to a polarisation of the cell with an actin polymerisation in the front and a contracting acto-myosin network at the back of the cell. ${ }^{[220]}$ For the quantification and visualization of cAMP concentration during experiments concerning the motility of $D$. discoideum, labelled CAMP is of great interest for researchers. Already, UEDA et al. utilised labelled CAMP to reveal the binding of individual CAMP receptors on the surface of living cells by single-molecule imaging techniques. ${ }^{[221]}$ 


\subsection{Structural analysis of cyclic adenosine-3',5'-monophosphate with regard to the binding to CAMP receptors of $D$. discoideum cells}

Binding studies of a number of cAMP derivatives to the surface of $D$. discoideum cells give a hint about the important functions involved in the interaction with CAR. ${ }^{[222-224]}$ The binding affinity is strongly reduced when the CAMP derivative is no longer able to form hydrogen bonds at $N^{6}$ or at $3^{\prime} O$ (see Figure 23). Though, substitution of $N^{6} \mathrm{H}_{2}$ by chlorine has a stronger influence on affinity than a substitution with benzylamine, indicating that one hydrogen in this position is sufficient for hydrogen bond formation. Furthermore, the activation of the receptor requires a stereospecific interaction between CAR and the phosphate moiety of cAMP. Modifications at the $2^{\prime} \mathrm{O}$ - or $5^{\prime} \mathrm{O}$-position, preventing hydrogen bonds in these positions, reduces the binding affinity only slightly.

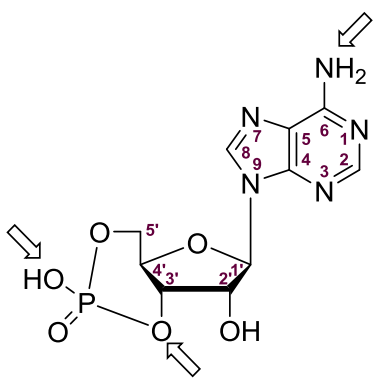

53

Figure 23: Structure of cyclic adenosine-3',5'-monophosphate (53). Residues, important for binding to the CAMP receptor of $D$. discoideum cells, are indicated with an arrow.

Resulting from these findings and synthetic considerations, two positions were proposed for labelling. On the one hand modification on $N^{6}$, while preserving one hydrogen for the hydrogen bond, or on the other hand modification at the 2'O-position.

\subsection{Syntheses of labelled cyclic adenosine-3',5'-monophosphates}

Labelling was performed utilising the bioorthogonal copper(I)-catalysed azide-alkyne cycloaddition (CuAAC). This will offer the possibility of further applications of functionalized cAMP, which will be discussed at the end of this chapter. For the synthesis of an $N^{6}$-labelled cAMP a procedure described by KATAOKA et al., published in 1988, was followed. ${ }^{[225]}$ Therein, a series of $N^{6}$-alkyladenosine- $3^{\prime}, 5^{\prime}$-cyclic phosphates are synthesized via a single step reductive alkylation starting from cAMP and the corresponding aldehydes. In this thesis, an aldehyde and an alkyne functionality were combined in one molecule, as this was needed for the CuAAC with an azide functionalized fluorophore. Therefore, commercially available 5 -hexynol (54) was oxidized to 5 -hexynal (55) by pyridinium chlorochromate 
(PCC) as described by KocsIs et al. (see Scheme 19). ${ }^{[226]}$ Application of DESS-MARTIN periodinane instead of PCC did not increase the yield of the reaction. The small yield was probably a result of the low melting point of 55, leading to an evaporation during purification. For the following reaction with cAMP the tri-n-butylammonium salt of CAMP (56) was prepared according to the procedure of KATAOKA et al. to increase its solubility. ${ }^{[225]}$ The product $\mathbf{5 7}$ of the following reductive amination was purified by HPLC utilising aqueous triethylammonium acetate solution as the solvent (see Scheme 19).

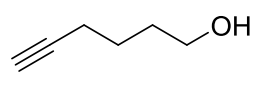

54

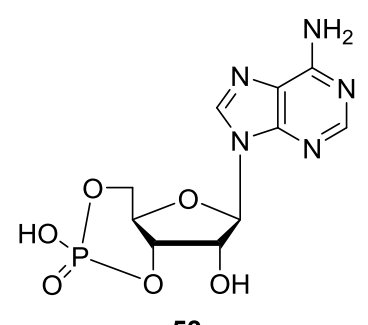

53

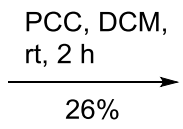

$\mathrm{NBu}_{3}, \mathrm{H}_{2} \mathrm{O}$,

$\mathrm{EtOH}$,

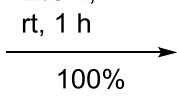

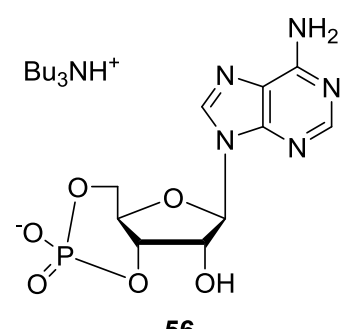

56

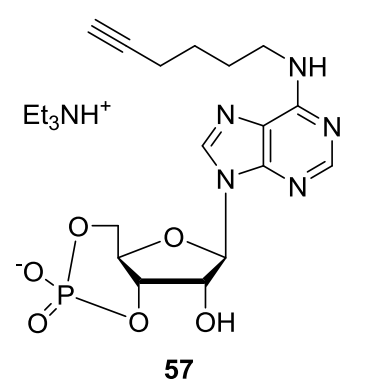

Scheme 19: Syntheses of $N^{6}$-hex-5-yn-1-yladenosine-3', $5^{\prime}$-cyclic monophosphate tri- $n$-butylammonium salt (57).

The $N^{6}$-alkyne functionalized cAMP 57 was labelled with Alexa Fluor ${ }^{\circledast} 488$ azide, in agreement with our cooperation partner MARCO TARANTOLA. The reaction was performed based on a procedure by SEELA et al. performing CuAAC on functionalized nucleosides, and the manual for Alexa Fluor ${ }^{\circledR} 488$ azide (see Scheme 20). ${ }^{[227]} N^{6}$-Labelled cAMP 58 was purified by HPLC and verified by mass analysis. 


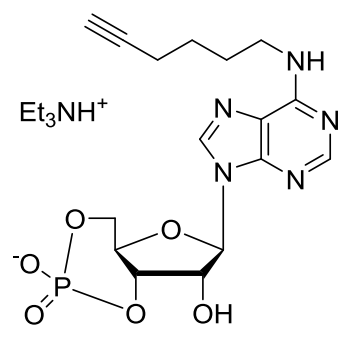

57
Alexa Fluor ${ }^{\circledR} 488$ azide $\cdot 2\left(\mathrm{Et}_{3} \mathrm{~N}\right)$, DMF, NaAsc, $\mathrm{CuSO}_{4} \cdot 5 \mathrm{H}_{2} \mathrm{O}$, $\mathrm{rt}, 16 \mathrm{~h}$

$12 \%$<smiles>CCCCCCNC(=O)c1cc(C(=O)NCC)ccc1-c1c2ccc(=[NH2+])c(S(=O)(=O)O)c-2oc2c(S(=O)(=O)O)c(N)ccc12</smiles>

58

Scheme 20: Synthesis of $\boldsymbol{N}^{6}$-labelled cAMP 58.

Chemotaxis assays, conducted with $N^{6}$-labelled cAMP 58, did not show any directed migration of D. discoideum upon the application of $58 .{ }^{4}$ The bulky fluorophore in $N^{6}$-position probably hindered the development of the hydrogen bond, which is necessary for the receptor binding.

For the labelling of cAMP in 2'O-position, a synthetic pathway was considered, which included ester formation followed by an amide bond formation based on an approach by UEDA et al. (see Scheme 21). ${ }^{[221]}$ In the first step, CAMP (53) was reacted with succinic anhydride at a pH of 9.6 to form $\mathbf{5 9}$. The reaction was performed in both, water or aqueous sodium bicarbonate solution, while adjusting the $\mathrm{pH}$ with an aqueous sodium hydroxide solution. The reaction could not be conducted to completion and starting material $\mathbf{5 3}$ was not separable from the product by HPLC purification. In a subsequent conversion of the mixed products with 3-butyn-1-amine utilising 1-ethyl-3(3-dimethylaminopropyl)carbodiimide (EDC) as the carboxyl activating reagent, desired product 60 was only found in traces during mass analysis. Consequentially, this synthetic pathway was no longer pursued.

\footnotetext{
${ }^{4}$ All chemotaxis assays of Dictyostelium discoideum are based on gradient-mixer microfluidic devices and were performed under linear CAMP gradients by either NICK SCHOLAND or CHRISTOPH BLUM, both co-supervised by MARCO TARANTOLA and EBERHARD BODENSCHATZ.
} 
<smiles>C#CCCNC(=O)CCC(=O)OC1C2COP(=O)(O)OC1C(n1cnc3c(N)ncnc31)O2</smiles>

60

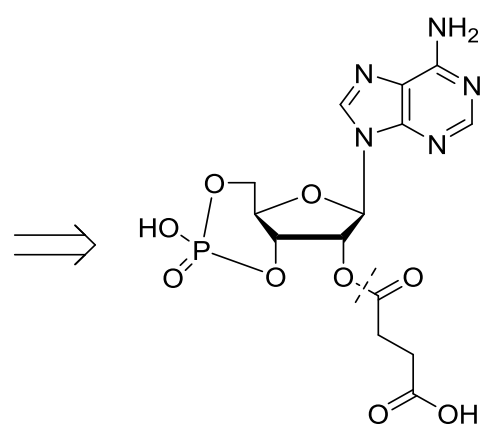

59

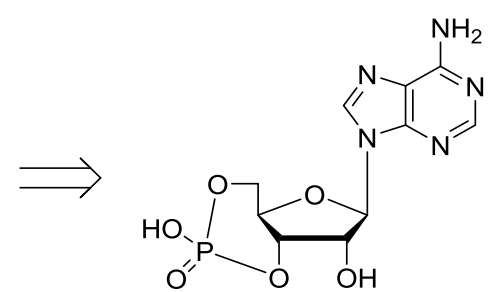

53

Scheme 21: Retrosynthetic analysis of 2'O-modified CAMP 60 based on a procedure of UEDA et al. ${ }^{[221]}$

The 2'O-labelling of cAMP was therefore not based on esterification but on nucleophilic substitution, leading to a more flexible attachment of the linker. Additionally, this procedure has the advantage of being a one-step reaction. Published in 1990, KATAOKA et al. prepared 2'O-alkyl cAMP derivatives by reacting CAMP with alkyl bromides in the presence of potassium hydroxide and 18-crown-6 in a water/dioxane mixture. ${ }^{[228]}$ The $2^{\prime} \mathrm{O}$ over $N^{6}$-selectivity of the reaction can be seen by ${ }^{1} \mathrm{H}-\mathrm{NMR}$ and by determination of the absorption maximum, which is not changed in the case of the 2'O-derivative compared to unsubstituted cAMP.

Firstly, the reaction was conducted utilising commercially available 4-bromo-1-butyne, which should give 2'O-modified cAMP 61. Because this reaction was unsuccessful, probably due to the neighbouring alkyne, and the introduction of a longer alkyne chain would be more comparable to the synthesized $N^{6}$-modified CAMP 57, 6-bromo-1-hexyne was synthesized according to a procedure of SHARMA and OEHLSCHLAGER. ${ }^{[229]}$ Subsequent reaction with CAMP (53) under the reaction conditions discussed above, yielded the 2'O-alkyne functionalized cAMP 62 in 50\% (see Scheme 22). The product was purified by HPLC, leading to the tri- $n$-ethylammonium salt, and the product formation verified by NMR and mass analysis. The absorption maximum of 2'O-alkyne functionalized cAMP 62 was comparable to unmodified cAMP 53 (258 nm). 

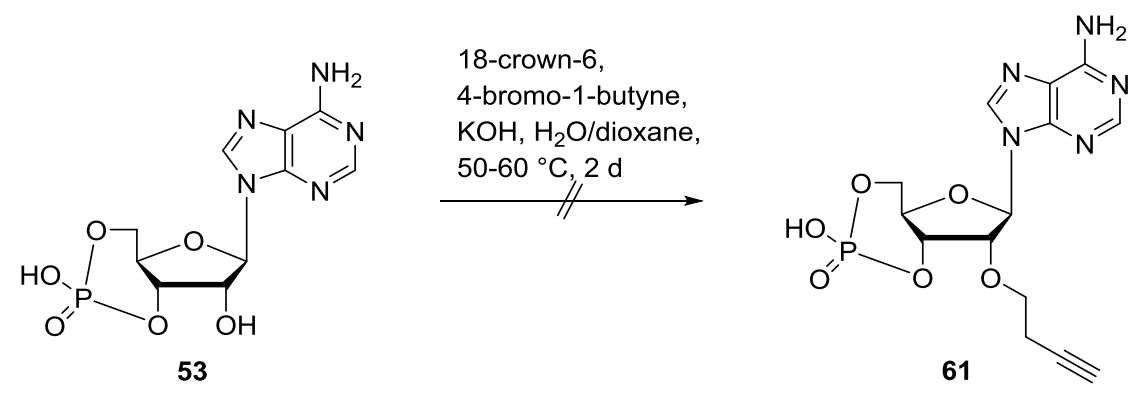

$$
55 \% \mid \begin{aligned}
& \text { 18-crown-6, } \\
& 6 \text {-bromo-1-hexyne, } \\
& \mathrm{KOH}, \mathrm{H}_{2} \mathrm{O} / \text { dioxane } \\
& 50-60^{\circ} \mathrm{C}, 2 \mathrm{~d}
\end{aligned}
$$

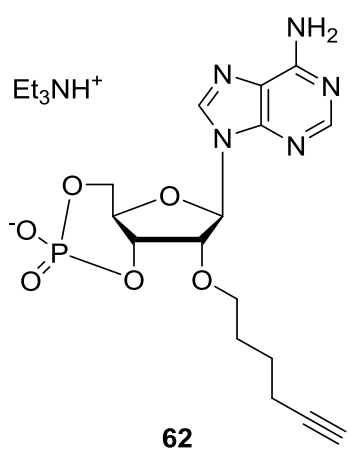

Scheme 22: Synthesis of 2'O-hex-5-yn-1-yladenosine-3',5'-cyclic monophosphate tri-n-ethylammonium salt (62).

The subsequent copper(I)-catalysed azide-alkyne cycloaddition of $\mathbf{6 2}$ was performed similar to the previous CUAAC labelling $N^{6}$-alkyne functionalized cAMP 57. HPLC purification yielded the desired 2'O-labelled cAMP as the tri- $n$-ethylammonium salt 63 (see Scheme 23). In Figure 24, showing the corresponding HPLC traces, the good separability of the 2'O-alkyne functionalized CAMP 62 and the product 63 is shown.

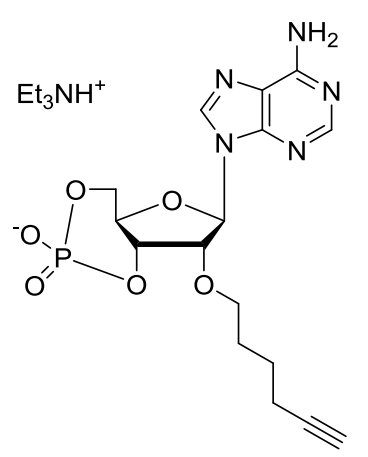

62

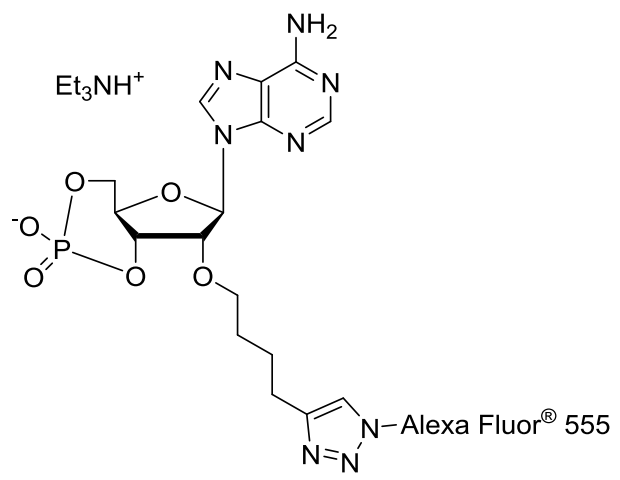

63

Scheme 23: Synthesis of 2'O-labelled cAMP 63. 


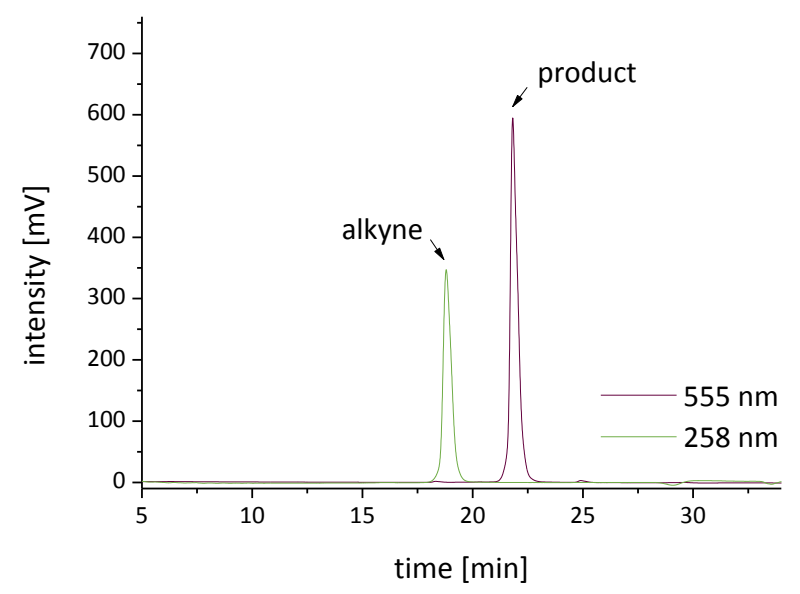

Figure 24: HPLC traces (intensity at $258 \mathrm{~nm}$ and $555 \mathrm{~nm}$ ) of purified unlabelled (62) and labelled 2'O-alkyne functionalized cAMP (63).

Chemotaxis assays by NICK SCHOLAND and CHRISTOPH BLUM, conducted with 2'O-labelled CAMP 63, did show directed migration of $D$. discoideum upon application of 63 . The chemotactic index $(\mathrm{Cl})$, which is a measurement of the directness of a cell towards the chemoattractant, for $\mathbf{6 3}$ was comparable to the $\mathrm{Cl}$ when applying unmodified cAMP. In Figure 25 the directed migration of $D$. discoideum cells towards the side with highest concentration of 2'O-labelled cAMP was visualized by showing the trajectories over time. The successful synthesis of 2'O-labelled cAMP clears the way to new applications. Recently, WESTENDORF et al. utilised a caged CAMP, which, upon irradiation with a laser beam, releases CAMP, to analyse chemotaxis of $D$. discoideum. ${ }^{[230]}$ A combination of this approach with a modified labelling approach (where the label bears a caging unit as well), will offer the opportunity to have modified CAMP, that is activated by a laser beam and at the same time the fluorescence is released.

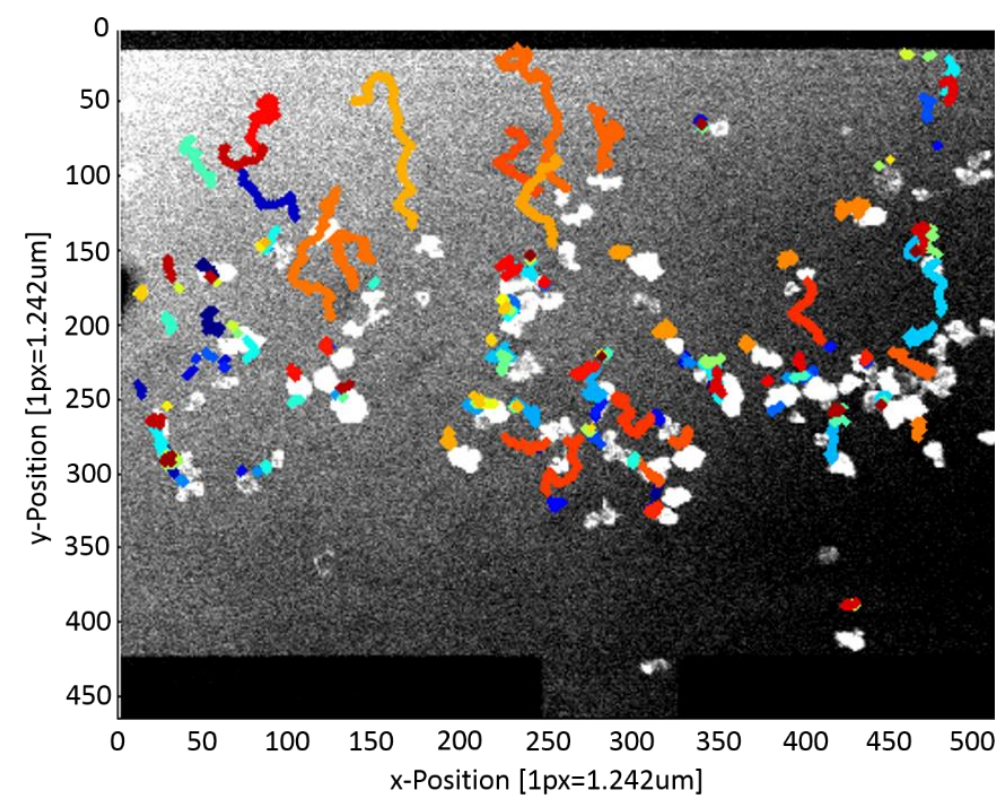

Figure 25: Trajectories of $D$. discoideum over time, when 2'O-labelled cAMP 63 is applied. The distribution of 63 is seen by the difference in background brightness (highest concentration in the upper-left corner). 



\section{Conclusion}

The development of new methods and tools for in vivo/in vitro labelling helps to elucidate structures, localisation and distinct processes of biomolecules in their native environment. Fluorescence labelling and detection provides researchers with a highly sensitive, non-destructive method to visualize biomolecules even on the nanometre scale. This thesis comprises two different approaches for fluorescent labelling. The first approach includes the indirect labelling of ion channels, in which ion channels are addressed by specific binding fluorescently labelled neurotoxins. The second project comprises a direct labelling approach, where a nucleotide is functionalized with a fluorophore for direct investigation of its concentration and localisation.

Ion channels are membrane proteins, which are substantial for the signal translation and propagation in excitable cells by generating and shaping action potentials. ${ }^{[7]}$ Although, the patch-clamp technique allows the monitoring of channel activity in localised regions of plasma membranes, limitations occur in the assignment of the distribution of ion channels in whole cell membranes of living cells. ${ }^{[30]}$ Therefore, fluorescent labelling is applied by addressing ion channels with specifically binding neurotoxins, which, in comparison to most antibody labelling approaches, have high selectivity for the ion channel extracellular domains distinguishing between different ion channels and their subtypes. ${ }^{[31]}$ The first neurotoxin labelled in this study was $\mu$-conotoxin SIIIA, a disulphide rich peptide. The disulphide bridges were established by a consecutive approach. To validate the disulphide connectivity of native $\mu$-conotoxin SIIIA, two isomers, discussed in literature, were synthesized (see Figure 26). ${ }^{[127,170]}$ Isomer 3 with a 1-4/2-5/3-6 disulphide pattern induced highest inhibition during patchclamp analysis by TING WANG.
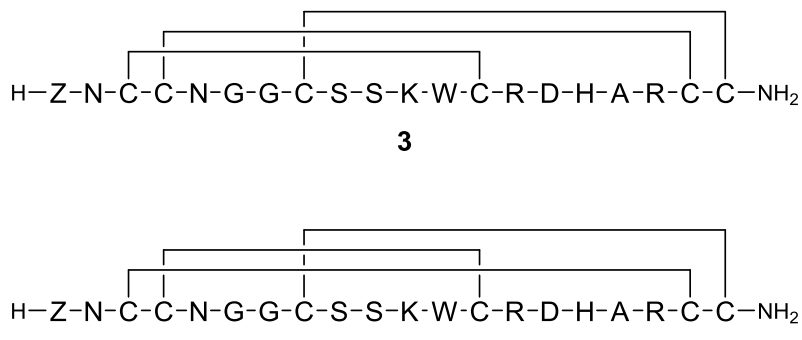

27

Figure 26: Synthesized disulphide bridge variations of $\mu$-conotoxin SIIIA. 
Four analogues of $\mu$-conotoxin SIIIA were synthesized by the introduction of artificial H-L-Ser(2'-propyne)-OH in four different positions. Different topological isomers were isolated of each analogue and those modified in position Gly6 and Ser9 were already analysed by TING WANG on sodium channels determining two isomers with good binding affinities. In the key step, these were labelled via copper(I)catalysed azide-alkyne cycloaddition (CUAAC) with DIPEA as an additive (forming $\mathbf{2 0}$ and $\mathbf{2 1}$, see Figure

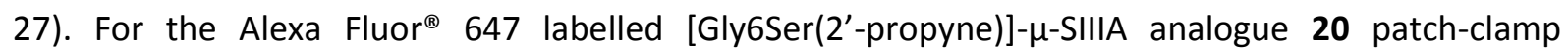
experiments were conducted, proving its strong remaining activity after labelling. In the near future, further analysis of its labelling properties will be followed by imaging experiments. In addition to the synthesis of labelled $\mu$-conotoxin SIIIA a caged compound was presented, bearing the photocleavable protection group 6-nitroveratryloxycarbonyl (NVOC) on the $\varepsilon$-amine of lysine (see Figure 27, 44). Uncaging was accomplished only after illumination for a long time with a mild light source. Supplementary studies of the uncaging process and patch-clamp experiments of caged compound will reveal its potency as a light-sensitive inhibitory switch for sodium channels. Additionally, the caging group may be changed from an aldehyde to a ketone releasing, thereby avoiding the imine formation by the reaction of free aldehydes of the caging group (upon uncaging) with free amine groups present in $\mu$-conotoxin SIIIA. Furthermore, multiple caging groups may be incorporated to facilitate a greater reduction of activity before uncaging.

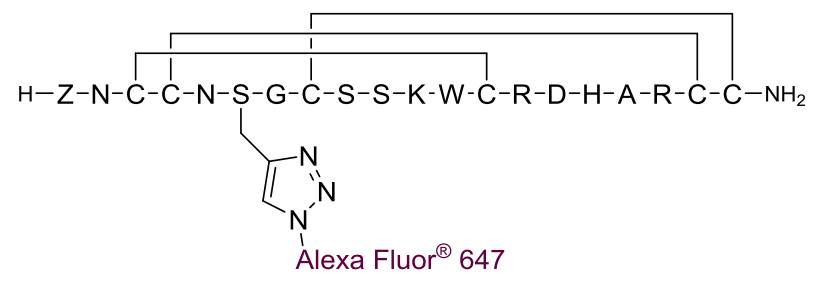

20

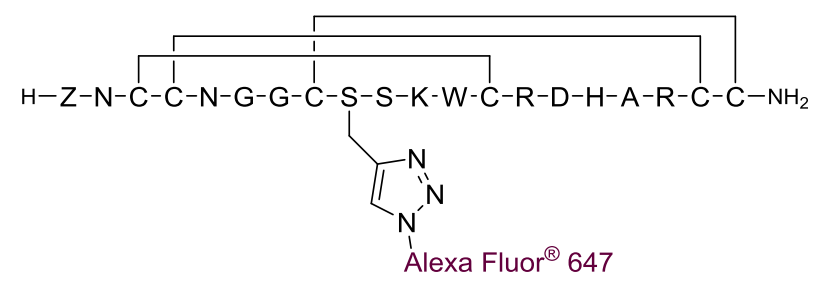

21

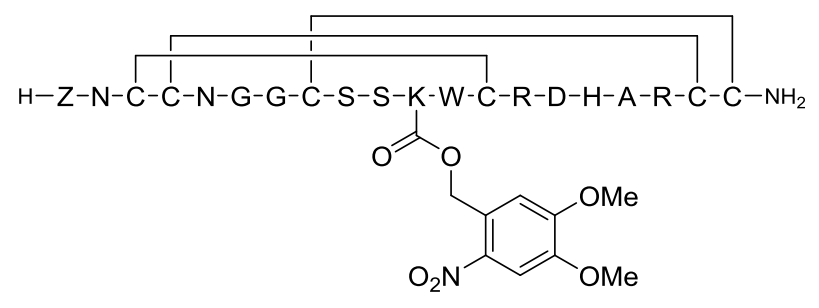

44

Figure 27: Synthesized labelled analogues of $\mu$-conotoxins SIIIA modified in position Gly6 (20) and Ser9 (21) and the caged $\mu$-conotoxin SIIIA 44, modified in position Lys11. 
The functionalization of two other neurotoxins, $\beta$-pompilidotoxin and iberiotoxin, with fluorescent labels was successfully developed. While $\beta$-pompilidotoxin slows the inactivation of voltage-gated sodium channels, iberiotoxin blocks calcium-activated potassium channels. ${ }^{[4,41]}$ Structural analysis led to the successful labelling of linear $\beta$-pompilidotoxin on the $N$-terminus and at position Ser11, since a [Ser11Ala] modification has no influence on the overall activity (see Figure 28, 49 and 50). Bioorthogonal linkage was accomplished by the use of the cysteine/maleimide reaction. Patch-clamp experiments with unlabelled $\mathbf{4 9}$ and imaging experiments with labelled $\mathbf{4 9}$ conducted by GUOBIN BAO of the SCHILD research group indicated this compound to be a good tool for labelling sodium channels. The task of labelling iberiotoxin was approached by the amine/succinimidyl ester reaction. To avoid consecutive disulphide bridge formation, commercially available iberiotoxin was labelled directly. Mono-labelling was successfully achieved by applying an excess of iberiotoxin in the reaction (see Figure 28, 52). Subsequent co-localisation and quantification studies with voltage-gated calcium channels in olfactory receptor neurons will be conducted in the near future.

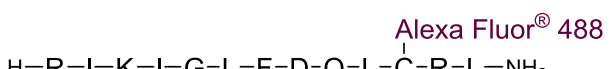

49

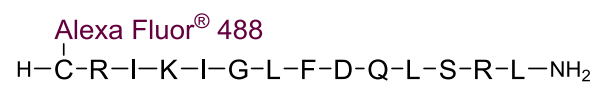

50

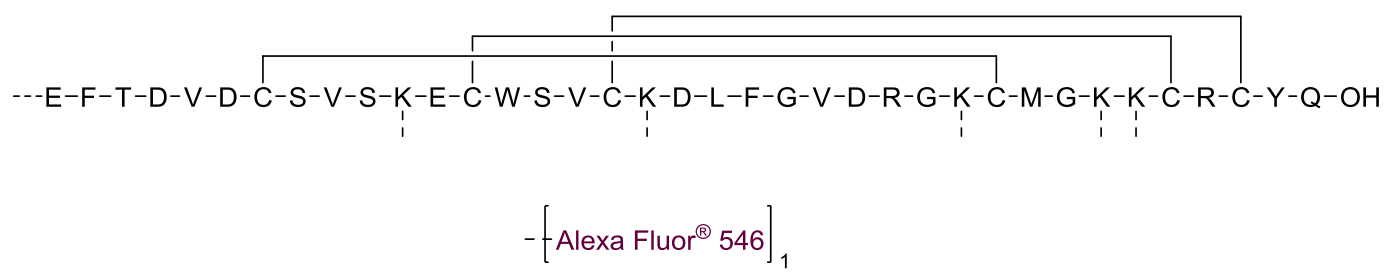

52

Figure 28: Structural conformation of novel Alexa Fluor ${ }^{\circledR} 488$ labelled pompilidotoxins $(49,50)$ and Alexa Fluor ${ }^{\circledR}$ 546 labelled iberiotoxin (52).

A further approach was the labelling of cyclic adenosine- $3^{\prime}, 5^{\prime}$-monophosphate (cAMP), which acts as a chemoattractant for the amoeboid Dictyostelium discoideum, to investigate cAMP concentration dependent migration of these amoeboids. CUAAC was utilised for the linkage of fluorescent probes in the $N^{6}$ - and $2^{\prime} O$-position (forming 58 and 63 , Figure 29), offering, with the alkyne modified cAMP, a tool for further applications. The 2'O-labelled cAMP 63 was successfully employed for migration studies of $D$. discoideum, while $N^{6}$-labelled cAMP 58 did not induce migration. In the future, a combination of this labelling approach and the caging approach described by WESTENDORF et al. might be conducted. ${ }^{[230]}$ Therefore, a caging compound will be attached to the phosphate or $N^{6}$-position 
suppressing its binding to the CAMP receptor and additionally, a caging moiety will be introduced to the fluorophore, quenching its fluorescence. Upon uncaging, this would lead to a fluorescent cAMP, which regains its activity to induce migration of amoeboids.

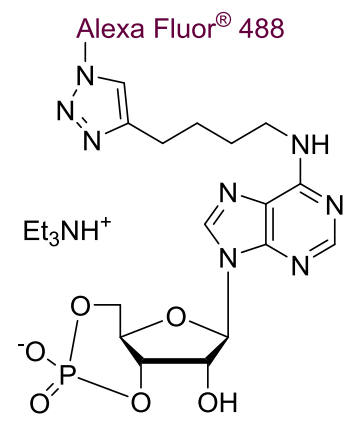

58

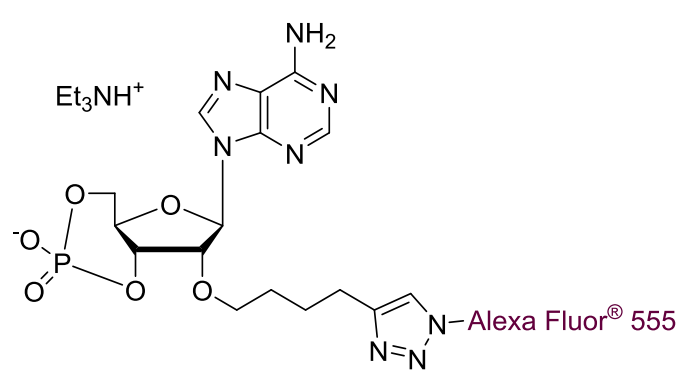

63

Figure 29: Synthesized $N^{6}$ - and 2'O-labelled cyclic adenosine-3',5'-monophosphates $(58,63)$. 


\section{Experimental part}

\subsection{General}

\section{Solvents}

Technical solvents were purified by distillation prior to use. Solvents of analytical or HPLC grade were used as supplied from FLUKA, FISHERSCIENTIFIC GMBH, SIGMA ALDRICH, VWR INTERNATIONAL, ROTH and ACROS ORGANICS. Dry solvents were stored over molecular sieves (4 Å). Ultra-pure water was obtained by purifying distilled water with the purification device SIMPLICITY (MILLIPORE).

\section{Reagents}

All reagents were of highest grade available and used as supplied. Amino acids and amino acid derivatives as well as resins, linker and coupling reagents for solid phase synthesis were obtained from NoVABIOCHEM, IRIS BIOTECH, GL BIOCHEM, BACHeM, MERCK, VWR INTERNATIONAL, ROTH and SIGMA ALDRICH. All other chemicals were purchased from fiSHER SCIENTIFIC GMBH, ALOMONE LABS, SPRIN-TECHNOLOGIES, ALFA Aesar, Sigma Aldrich, Merck, Acros Organics, Roth, Riedel-de HaËn, Iris Biotech, Fluka and VWr INTERNATIONAL.

\section{Reactions}

Air and/or water sensitive reactions were carried out under argon atmosphere using standard SCHLENKtechnique. The glass apparatus was heated with a heat gun under reduced pressure and flushed with $\operatorname{argon}(3 \mathrm{x})$.

\section{Freeze-drying}

Lyophilisation from aqueous solutions and aqueous mixtures containing minor amounts of acetonitrile or tert-butanol was performed using a CHRIST Alpha-2-4 lyophiliser equipped with a high vacuum pump. Small samples were lyophilized using an evacuable CHRIST RVC 2-18 centrifuge connected to the Iyophilisation device. 


\section{Thin layer chromatography (TLC)}

Analytical TLC was performed on MERCK silica gel $60 \mathrm{~F}_{254}$ (layer thickness $0.25 \mathrm{~mm}$ ) aluminium backed plates. The plates were visualized under UV fluorescence $(254 \mathrm{~nm})$ or developed using ninhydrin (0.30 g ninhydrin, $100 \mathrm{~mL}$ EtOH) and charring to detect amines.

\section{Column chromatography}

Flash column chromatography was carried out using MERCK silica gel $60(40-63 \mu \mathrm{m})$ at 0.4-1.0 bar. Columns were packed with wet silica gel (50-100 fold weight excess) and the sample loaded onto silica or loaded as a concentrated solution.

\section{High performance liquid chromatography (HPLC)}

Reverse Phase (RP)-HPLC analyses were performed using a system from JASCO equipped with two pumps PU-2080Plus, a multi wavelength detector MD-2010Plus either with an analytical or preparative cell, a 3-line degasser DG-2080-53 and interface LC-Net II/ADC. Substances were analysed or purified with a linear gradient of $A$ (water or triethylammonium acetate (TEAA) buffer) to $B$ (solvent containing mainly MeCN) using the following columns:

- Analytical: MN Nucleodur ${ }^{\circledast} 100-5-\mathrm{C} 18,250 \mathrm{~mm} \times 4.6 \mathrm{~mm}, 5 \mu \mathrm{m}$, flow rate: $1 \mathrm{~mL} / \mathrm{min}$.

- Semipreparative: MN Nucleodur ${ }^{\circledast} 100-5-\mathrm{C} 18,250 \mathrm{~mm} \times 10 \mathrm{~mm}, 5 \mu \mathrm{m}$, flow rate: $3 \mathrm{~mL} / \mathrm{min}$.

- Preparative: $\mathrm{MN}$ Nucleodur ${ }^{\circledR} 100-5-\mathrm{C} 18,250 \mathrm{~mm} \times 21.0 \mathrm{~mm}, 5 \mu \mathrm{m}$, flow rate: $10 \mathrm{~mL} / \mathrm{min}$.

\section{Liquid chromatography-mass spectrometry (LC-MS)}

For LC-MS analyses the mass spectrometer from FINNIGAN (LCQ), the detector from FINNIGAN (Surveyor PDA), pumps from FLUX INSTRUMENTS (rheos 400), the degasser from KONTRON (degasser 3492) and the auto-sampler from JASCO (AS-1555) were used. A C-18 column (MN Nucleodur ${ }^{\circledR} 100 \mathrm{~mm} \times 2 \mathrm{~mm}$, S$3 \mu \mathrm{m}, 11 \mathrm{~nm}$, flow $0.3 \mathrm{~mL} / \mathrm{min}$ ) was utilised using a linear gradient of $A$ ( $99.95 \%$ water $+0.05 \%$ formic acid) to $\mathrm{B}(99.95 \% \mathrm{MeOH}+0.05 \%$ formic acid).

\section{Solid phase peptide synthesis (SPPS)}

Manual SPPS was conducted on solid support using PE-frit equipped BD discardit syringes as reaction vessel and the "Discover" microwave (CEM). Peptides were automatically synthesized using the "Liberty" microwave peptide synthesizer (CEM) equipped with a "Discover" microwave reaction cavity (CEM). 


\subsection{Characterisation}

\section{Nuclear magnetic resonance spectroscopy (NMR)}

NMR spectra were recorded on a VARIAN spectrometer (Unity 300, Mercury 300, Mercury-Vx 300, VNMRS-300, Inova 500, and Inova 600). The sample temperature was $298 \mathrm{~K}$ except stated otherwise. The chemical shift are quoted in ppm downfield on a $\delta$-scale. As internal standards the resonances of the residual protons of the deuterated solvents were used. ${ }^{[231]}$ The abbreviations for the multiplets are: $\mathrm{s}=$ singlet, $\mathrm{d}=$ doublet $\mathrm{t}=$ triplet $\mathrm{q}=$ quartet, $\mathrm{m}=$ multiplet, $\mathrm{br}=$ broad. Coupling constants are ${ }^{n} J_{X, Y}$ in Hertz $(\mathrm{Hz})$ where $n$ is the order of coupling and $X$ and $Y$ the coupling partners. ${ }^{13} \mathrm{C}-$ spectra and ${ }^{31} \mathrm{P}$-spectra were measured as ${ }^{1} \mathrm{H}$-broadband decoupled or as APT-spectra $\left({ }^{13} \mathrm{C}\right.$ only).

\section{Mass spectrometry}

Electrospray-ionisation (ESI) and high resolution ESI (HR-MS (ESI)) spectra were obtained with BRUKER devices (maXis or MicrOTOF). Matrix assisted laser desorption/ionisation (MALDI) spectra were obtained with BRUKER devices (MALDI-TOF) using 2,5-dihydroxybenzoic acid as the matrix.

\section{UV/Vis spectroscopy}

UV spectra for estimation of occupancy were measured using the JASCO UV/Vis spectrophotometer V550. Peptide concentrations were estimated using a THERMO SCIENTIFIC nanodrop ND-2000c spectrophotometer and calculated by using LAMBERT-BEER's law (for extinction coefficients see Table 3). The molecular absorption coefficients were calculated by summation of the single coefficients at a set wavelength. For fluorescently labelled molecules the absorption was measured for the maximum absorption of the labels.

Table 3: Extinction coefficients for tryptophan (Trp) and disulphide bonds (average values in folded proteins), caged lysine and of Alexa Fluor ${ }^{\circledast}$ dyes. ${ }^{[232-234]}$

\begin{tabular}{|c|c|c|}
\hline & $\begin{array}{c}\text { Absorption Max } \\
{[\mathrm{nm}]}\end{array}$ & $\begin{array}{l}\text { Extinction Coefficient } \\
\qquad\left[\mathrm{cm}^{-1} \mathrm{M}^{-1}\right]\end{array}$ \\
\hline $\operatorname{Trp}$ & 280 & 5500 \\
\hline S-S & 280 & 125 \\
\hline Caged lysine & 350 & 5485 \\
\hline Alexa Fluor ${ }^{\circledR} 488$ & 495 & 73000 \\
\hline Alexa Fluor ${ }^{\circledR} 546$ & 556 & 112000 \\
\hline Alexa Fluor ${ }^{\circledR} 555$ & 555 & 155000 \\
\hline Alexa Fluor ${ }^{\circledR} 647$ & 650 & 270000 \\
\hline
\end{tabular}




\subsection{Standard operating procedures (SOPs)}

\subsubsection{SOP1: Preloading resin with linker}

2-Chlorotrityl chloride resin (385 mg, $0.58 \mathrm{mmol}, 100-200$ mesh, $1.50 \mathrm{mmol} / \mathrm{g}$ ) was swollen in a BD discardit syringe with PE frit in dry DCM $(6 \mathrm{~mL})$ for 2 h. RAMAGE-linker (176 mg, $348 \mu \mathrm{mol}, 0.60$ eq.) and DIPEA (237 $\mu \mathrm{L}, 1.39 \mathrm{mmol}, 2.40$ eq.) were dissolved in dry DCM (4 mL), a small amount of dry DMF was added to dissolute the acid. This solution was added to the resin and the mixture shaken for $30 \mathrm{~min}$. The resin was washed with DCM/MeOH/DIPEA (17:2:1, v/v/v, $3 \times 6 \mathrm{~mL}), \mathrm{DCM}(3 \times 6 \mathrm{~mL}), \mathrm{DMF}(2 \times 6 \mathrm{~mL})$, $\operatorname{DCM}(2 \times 6 \mathrm{~mL})$ and dried under reduced pressure.

\subsubsection{SOP2: Loading resin with first amino acid}

Either 2-chlorotrityl chloride or rink amide MBHA resin were used in this work. Loading of the resins is described here exemplarily for the rink amide MBHA resin. The rink amide MBHA resin $(345 \mathrm{mg}$, $0.10 \mathrm{mmol}, 1.00$ eq., $0.29 \mathrm{mmol} / \mathrm{g}$ ) was swollen in DCM (6 mL) for $2 \mathrm{~h}$. The Fmoc-protecting group was cleaved microwave assisted $\left(30 \mathrm{~s}, 50^{\circ} \mathrm{C}, 25 \mathrm{~W}\right)$ by $20 \%$ piperidine in NMP $(4 \mathrm{~mL})$. The resin was washed with NMP $(5 \mathrm{~mL})$ and the second cleavage ( $20 \%$ piperidine in NMP) was performed using a microwave $\left(3 \mathrm{~min}, 50^{\circ} \mathrm{C}, 25 \mathrm{~W}\right)$. After washing with NMP $(3 \times 5 \mathrm{~mL}), \mathrm{DCM}(5 \times 5 \mathrm{~mL})$ and NMP $(5 \times 5 \mathrm{~mL})$ coupling of the first amino acid cysteine was performed using Fmoc-L-Cys(Trt)-OH (293 mg, $0.50 \mathrm{mmol}$, 5.00 eq.), DIC (76.0 $\mu \mathrm{L}, 4.90 \mathrm{mmol}, 4.90$ eq.), HOBt (66.2 mg, $4.90 \mathrm{mmol}, 4.90$ eq.) in NMP ( $3 \mathrm{~mL})$ for $10 \mathrm{~min}$ at $40^{\circ} \mathrm{C}$ and $20 \mathrm{~W}$. Final washing was performed using NMP $(3 \times 5 \mathrm{~mL}), \mathrm{DCM}(5 \times 5 \mathrm{~mL}), \mathrm{NMP}$ $(5 \times 5 \mathrm{~mL})$ and $\mathrm{DCM}(3 \times 5 \mathrm{~mL})$ and the resin was dried under reduced pressure.

\subsubsection{SOP3: Determination of the occupancy}

The resin load was estimated using UV absorption measurements. To a small amount of resin (approximately $5 \mu \mathrm{mol}$ with respect to Fmoc) in a graduated flask (10 mL) 2\% DBU in DMF $(2 \mathrm{~mL}$ ) were added. After agitating for $30 \mathrm{~min}$ the solution was diluted (to $10 \mathrm{~mL}$ ) with $\mathrm{MeCN}$. Another dilution with acetonitrile (1/12.5) was applied before UV absorption was recorded in a $1 \mathrm{~cm}$ cuvette. The absorption was measured at $304 \mathrm{~nm}$, as reference solution everything was performed without addition of the resin. Fmoc loading was estimated using following equation: ${ }^{[235]}$

$$
\text { Fmoc loading }\left[\frac{\mathrm{mmol}}{\mathrm{g}}\right]=\frac{\left(\mathrm{Abs}_{\text {sample }}-\mathrm{Abs}_{\mathrm{ref}}\right) \cdot 16.4 \mathrm{mmol}}{\mathrm{m}_{\text {resin }}[\mathrm{g}] \cdot 1000}
$$

\subsubsection{SOP4: Automated SPPS}

Peptides were synthesized by standard $\mathrm{Fmoc} /{ }^{\mathrm{B}} \mathrm{Bu}$ peptide synthesis on solid support. Side chain protection groups were tert-butyl ( $\left.{ }^{t} \mathrm{Bu}\right)$ for Asp and Ser; tert-butyloxycarbonyl (Boc) for Lys and Trp; 
trityl for Asn, Gln and His; 2,2,4,6,7-pentamethyldihydrofurane-5-sulphonyl (Pbf) for Arg and trityl, $\mathrm{S}^{t} \mathrm{Bu}$, acetylaminomethyl (Acm), dimethoxytrityl (Dmt), 4-methylbenzyl (Mbzl) and phenylacetylaminomethyl (Phacm) for Cys. NMP was used as the solvent. The resin $(0.10 \mathrm{mmol})$ was swollen in DMF ( $4 \mathrm{~mL}$ ) for $2 \mathrm{~h}$ prior usage. Deprotection was performed using piperidine (20\% in NMP $+0.10 \mathrm{M} \mathrm{HOBt}, 2 \times 2.5 \mathrm{~mL}, 3 \mathrm{~min}, 50^{\circ} \mathrm{C}, 20 \mathrm{~W} \rightarrow 3 \mathrm{~min}, 50^{\circ} \mathrm{C}, 35 \mathrm{~W}$ ). Fmoc protected amino acids were used as a $0.20 \mathrm{M}$ solution in NMP except for Fmoc-L-Cys(Dmt)-OH, Fmoc-L-Cys(StBu)-OH, Fmoc-L-Cys(Acm)-OH, H-L-pGlu-OH, Fmoc-L-Ser(2'-propyne)-OH, Fmoc-L-Lys(NVOC)-OH and Fmoc-L-Asp(ODMNB)-OH, which were dissolved in DMF. Double coupling was conducted microwaveassisted (all amino acids: $10 \mathrm{~min}, 40^{\circ} \mathrm{C}, 20 \mathrm{~W}$; $\mathrm{Arg}: 25 \mathrm{~min}, \mathrm{rt}, 0 \mathrm{~W} \rightarrow 10 \mathrm{~min}, 40{ }^{\circ} \mathrm{C}, 20 \mathrm{~W}$; His: $1 \mathrm{~h}, \mathrm{rt}$, $0 \mathrm{~W}$ ) using activation with HBTU/HOBt (0.5 M/0.45 $\mathrm{M}$ in DMF) and DIPEA (2.00 $\mathrm{M}$ in NMP). After the synthesis was completed the resin was transferred into a BD discardit syringe with PE frit, washed with NMP ( $3 \times 6 \mathrm{~mL}), \mathrm{DCM}(3 \times 6 \mathrm{~mL}), \mathrm{DMF}(3 \times 6 \mathrm{~mL})$ and $\mathrm{DCM}(3 \times 6 \mathrm{~mL})$ and dried under reduced pressure.

\subsubsection{SOP5: Manual SPPS}

The peptides were synthesized using the same protection groups as for the automated SPPS. The preloaded resin $(0.10 \mathrm{mmol})$ was swollen in NMP $(6 \mathrm{~mL})$ for $2 \mathrm{~h}$. The Fmoc-protecting group was cleaved microwave assisted $\left(30 \mathrm{~s}, 50{ }^{\circ} \mathrm{C}, 25 \mathrm{~W}\right.$ ) by $20 \%$ piperidine, $0.10 \mathrm{M} \mathrm{HOBt}$ in DMF ( $4 \mathrm{~mL}$ ). The resin was washed with NMP $(5 \mathrm{~mL})$ and the second cleavage (20\% piperidine, $0.10 \mathrm{M} \mathrm{HOBt}$ in DMF, $4 \mathrm{~mL}$ ) was performed on a microwave $\left(3 \mathrm{~min}, 50^{\circ} \mathrm{C}, 25 \mathrm{~W}\right)$. After washing with NMP $(3 \times 5 \mathrm{~mL})$, DCM $(5 \times 5 \mathrm{~mL})$ and NMP $(5 \times 5 \mathrm{~mL})$ coupling of the first amino acid was performed using a solution of the amino acid in NMP $(0.20 \mathrm{M}, 2.50 \mathrm{~mL}), \mathrm{HBTU} / \mathrm{HOBt}(0.50 \mathrm{M} / 0.45 \mathrm{M}$ in DMF, $1 \mathrm{~mL})$ and DIPEA (2.00 $\mathrm{M}$ in NMP, $0.50 \mathrm{~mL})$ for $10 \mathrm{~min}$ at $40^{\circ} \mathrm{C}$ and $20 \mathrm{~W}$. After washing with NMP $(3 \times 5 \mathrm{~mL}), \mathrm{DCM}(5 \times 5 \mathrm{~mL})$ and NMP $(5 \times 5 \mathrm{~mL})$ the coupling was repeated followed by the next Fmoc-deprotection. Final washing was performed using NMP ( $3 \times 5 \mathrm{~mL}), \mathrm{DCM}(5 \times 5 \mathrm{~mL}), \mathrm{NMP}(5 \times 5 \mathrm{~mL})$ and DCM $(3 \times 5 \mathrm{~mL})$ and the resin was dried under reduced pressure.

\subsubsection{SOP6: Cleavage}

Cleavage from resin and simultaneous removal of most side chains (depending on the protecting strategy) was performed using $A$ (reagent $\mathrm{K}$ (TFA/ $\mathrm{H}_{2} \mathrm{O} / 1$,2-ethanedithiol/phenol/thioanisole 82.5:5:2.5:5:5 v/v/v/v, $10 \mathrm{~mL} / \mathrm{g}$ resin) or $\mathrm{B}$ (TFA/ $\mathrm{H}_{2} \mathrm{O} / \mathrm{TIS}$ 95:2.5:2.5, v/v/v, $10 \mathrm{~mL} / \mathrm{g}$ resin) and shaking for $2 \mathrm{~h}$. After cleavage the solution was concentrated under nitrogen stream. The crude peptide was precipitated from $-20^{\circ} \mathrm{C}$ cold diethyl ether, isolated by centrifugation (9000 rpm, $2.5 \mathrm{~min},-10{ }^{\circ} \mathrm{C}$ ), washed three times with cold diethyl ether followed by centrifugation and dried overnight under reduced pressure. 


\subsubsection{SOP7: Synthesis of $\mu$-conotoxin SIIIA: formation of the first disulphide bridge and deprotection of acid-labile protecting groups}

The resin was swollen in DMF ( $6 \mathrm{~mL}$ ) for $2 \mathrm{~h}$. Then following steps were performed (exemplarily shown for $6 \mathrm{~mL}$ in steps 1-4, $205 \mathrm{~mL}$ in step 4 and $100 \mathrm{~mL}$ in step 5):

1. The $S^{t} \mathrm{Bu}$-protecting group of cysteine was cleaved using $20 \% 2$-mercaptoethanol and $1 \%$ DBU in DMF ( $6 \mathrm{~mL}, 3 \times 2 \mathrm{~mL}, 20 \mathrm{~min}$ each) followed by washing with DMF ( $3 \times 6 \mathrm{~mL}), \mathrm{DCM}(2 \times 6 \mathrm{~mL})$, DMF $(2 \times 6 \mathrm{~mL})$ and DCM $(3 \times 6 \mathrm{~mL})$.

2. The free thiol was activated using $2,2^{\prime}$ dipyridyl disulphide (135 mg, $\left.0.61 \mathrm{mmol}\right)$ in DCM (6 mL) $(6 \mathrm{~mL}, 3 \times 2 \mathrm{~mL}, 20 \mathrm{~min}$ each) followed by washing with DCM ( $3 \times 6 \mathrm{~mL})$, DMF ( $3 \times 6 \mathrm{~mL})$ and $\operatorname{DCM}(3 \times 6 \mathrm{~mL})$.

3. Cleavage from the resin was performed using $10 \% \mathrm{AcOH}$ and $20 \%$ TFE in DCM $(6 \mathrm{~mL}, 3 \times 2 \mathrm{~mL}$, 20 min each).

4. Under argon atmosphere this solution $(6 \mathrm{~mL})$ was added dropwise to a solution of $0.1 \%$ TFA $(205 \mu \mathrm{L})$ and $0.2 \%$ TES $(410 \mu \mathrm{L})$ in DCM $(204 \mathrm{~mL})$. The reaction mixture was stirred overnight at rt.

5. Under argon atmosphere this solution was added dropwise over $1 \mathrm{~h}$ to a solution of $10 \% \mathrm{NEt}_{3}$ $(10 \mathrm{~mL})$ in DCM $(90 \mathrm{~mL})$. The solution was concentrated to $10 \mathrm{~mL}$ under reduced pressure. The peptide was precipitated from $-20^{\circ} \mathrm{C}$ cold diethyl ether $(50 \mathrm{~mL})$, isolated by centrifugation (9000 rpm, $10 \mathrm{~min},-10^{\circ} \mathrm{C}$ ), washed three times with cold diethyl ether followed by centrifugation and dried overnight under reduced pressure.

6. Deprotection of acid-labile protecting groups was performed for $2 \mathrm{~h}$ using TFA/ $\mathrm{H}_{2} \mathrm{O} / \mathrm{TIS}$ $(95: 2.5: 2.5, \mathrm{v} / \mathrm{v} / \mathrm{v})(6 \mathrm{~mL})$. The solution was concentrated under nitrogen stream. The crude peptide was precipitated from $-20^{\circ} \mathrm{C}$ cold diethyl ether, isolated by centrifugation ( $9000 \mathrm{rpm}$, $10 \mathrm{~min},-10^{\circ} \mathrm{C}$ ), washed three times with cold diethyl ether followed by centrifugation and dried overnight under reduced pressure to yield a colourless solid.

\subsubsection{SOP8: Synthesis of $\mu$-conotoxin SIIIA: formation of the second disulphide bridge}

Based on a procedure of TAM et al., crude peptide $(23.4 \mu \mathrm{mol})$ was added to a solution of $5 \%$ acetic acid $(2.50 \mathrm{~mL})$ in water $(47.5 \mathrm{~mL})\left(\mathrm{pH}\right.$ was adjusted with $\left(\mathrm{NH}_{4}\right)_{2} \mathrm{CO}_{3}$ to $\left.\mathrm{pH} 6\right) \cdot{ }^{[156]}$ DMSO $(12.5 \mathrm{~mL})$ was added and the solution was stirred for $4 \mathrm{~h}$ at $\mathrm{rt}$, the solvent was removed under reduced pressure and co-evaporated with DMF. The crude peptide was dissolved in a small amount of TFA and precipitated with cold diethyl ether, isolated by centrifugation (9000 rpm, $2.5 \mathrm{~min},-10^{\circ} \mathrm{C}$ ), washed three times 
with $-20^{\circ} \mathrm{C}$ cold diethyl ether followed by centrifugation and dried overnight under reduced pressure to yield a colourless solid. 


\subsection{Syntheses}

\subsubsection{Syntheses of the unnatural amino acids}

\section{Boc-L-Ser(2'-propyne)-OH (5)}

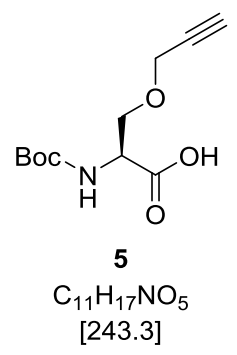

According to the procedure of CORTEKAR, NaH $(921 \mathrm{mg}, 23.0 \mathrm{mmol}, 2.70$ eq., $60 \%$ dispersion in mineral oil) was suspended in dry DMF $(7 \mathrm{~mL})$ under argon atmosphere and cooled to $0^{\circ} \mathrm{C}$, followed by addition of Boc-L-Ser-OH (4) (1.75 g, $8.54 \mathrm{mmol}, 1.00$ eq.) dissolved in DMF (28 mL). ${ }^{[141]}$ After $10 \mathrm{~min}$ propargylbromide ( $1.58 \mathrm{~g}, 10.7 \mathrm{mmol}, 1.25$ eq., $80 \%$ in toluene) was added dropwise to the mixture and the reaction stirred for $4 \mathrm{~h}$ at $\mathrm{rt}$. The reaction was quenched with water and evaporated under reduced pressure. The resulting residue was dissolved in water $(70 \mathrm{~mL})$ and the reaction mixture adjusted to $\mathrm{pH}=3$ with $12 \mathrm{M} \mathrm{HCl}$, extracted with EtOAc $(3 \times 50 \mathrm{~mL})$, dried over $\mathrm{MgSO}_{4}$ and evaporated under reduced pressure. The crude product was purified by flash column chromatography (EtOAc/MeOH/AcOH 8.5:1.5:0.1, v/v/v) to yield the product 5 as a yellow oil (2.07 g, $8.52 \mathrm{mmol}, 99 \%)$. The NMR data is in accordance to the literature. ${ }^{[236]}$

TLC (EtOAc/MeOH/AcOH 8.5:1.5:0.1, v/v/v): $\mathrm{R}_{f}=0.68$.

${ }^{1} \mathrm{H}-\mathrm{NMR}\left(300 \mathrm{MHz}, \mathrm{CDCl}_{3}\right): \delta_{H}(\mathrm{ppm})=1.42\left(\mathrm{~s}, 9 \mathrm{H}, \mathrm{C}\left(\mathrm{CH}_{3}\right)_{3}\right), 2.45\left(\mathrm{t},{ }^{4} J_{\mathrm{H}, \mathrm{H}}=2.4 \mathrm{~Hz}, 1 \mathrm{H}, \mathrm{CCH}\right), 3.78-4.01$ $\left(\mathrm{m}, 2 \mathrm{H}, \beta-\mathrm{CH}_{2}\right), 4.12-4.19\left(\mathrm{~m}, 2 \mathrm{H}, \mathrm{OCH}_{2}\right), 4.43-4.45(\mathrm{~m}, 1 \mathrm{H}, \alpha-\mathrm{CH}), 5.46\left(\mathrm{~d},{ }^{3} J_{\mathrm{H}, \mathrm{H}}=8.2 \mathrm{~Hz}, 1 \mathrm{H}, \mathrm{NH}\right), 11.03$ (s, $1 \mathrm{H}, \mathrm{COOH})$.

${ }^{13} \mathrm{C}-\mathrm{NMR}\left(126 \mathrm{MHz}, \mathrm{CDCl}_{3}\right): \delta_{c}(\mathrm{ppm})=28.2\left(\mathrm{C}\left(\mathrm{CH}_{3}\right)_{3}\right), 53.6(\alpha-\mathrm{CH}), 58.6\left(\mathrm{OCH}_{2}\right), 69.5\left(\beta-\mathrm{CH}_{2}\right), 75.2(\mathrm{CCH})$, $78.8\left(\mathrm{CH}_{2} \mathrm{CCH}\right), 80.2\left(\mathrm{C}\left(\mathrm{CH}_{3}\right)_{3}\right), 155.6$ (Fmoc- $\left.\mathrm{CO}\right), 174.2\left(\mathrm{CO}_{2} \mathrm{H}\right)$.

HR-MS (ESI): calc. for $\left[\mathrm{C}_{11} \mathrm{H}_{17} \mathrm{NNaO}_{5}\right]^{+}\left([\mathrm{M}+\mathrm{Na}]^{+}\right): 266.0999$, found: 266.1001 ; calc. for $\left[\mathrm{C}_{11} \mathrm{H}_{16} \mathrm{NO}_{5}\right]^{-}$ ([M-H] $\left.]^{-}\right): 242.1034$, found: 242.1036. 
Fmoc-L-Ser(2'-propyne)-OH (6)

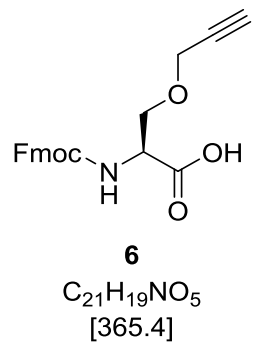

According to the procedure of CORTEKAR, TFA (16 mL) was added to Boc-L-Ser(2'-propyne)-OH (5) ( $2.07 \mathrm{~g}, 8.52 \mathrm{mmol}, 1.00 \mathrm{eq}$.) at $0{ }^{\circ} \mathrm{C}$, stirred for $30 \mathrm{~min}$ and evaporated under reduced pressure. ${ }^{[141]}$ The resulting residue was dissolved in $10 \% \mathrm{Na}_{2} \mathrm{CO}_{3}(\mathrm{aq})(23 \mathrm{~mL})$ at $0{ }^{\circ} \mathrm{C}$. 9-Fluorenylmethoxycarbonyl chloride ( $2.43 \mathrm{~g}, 9.39 \mathrm{mmol}, 1.10 \mathrm{eq}$.) dissolved in dioxane $(20 \mathrm{~mL})$ was added to the solution and the mixture stirred for $1 \mathrm{~h}$ at $0{ }^{\circ} \mathrm{C}, 1 \mathrm{~h}$ at $\mathrm{rt}$ and quenched with water $(21 \mathrm{~mL})$. The reaction mixture was washed with diethyl ether $(2 \times 40 \mathrm{~mL})$, the aqueous phase was adjusted to $\mathrm{pH}=1$ with $12 \mathrm{M} \mathrm{HCl}$, extracted with EtOAc $(2 \times 60 \mathrm{~mL})$ and the combined organic phases were evaporated under reduced pressure. The crude product was purified by flash column chromatography (pentane/EtOAc/AcOH 6:4:0.1, v/v/v) to yield the product 6 as a colourless solid $(2.08 \mathrm{~g}, 5.70 \mathrm{mmol}, 67 \%)$. The NMR data is in accordance to the literature. ${ }^{[141]}$

TLC (Pentane/EtOAc/AcOH 6:4:0.1, v/v/v): $\mathrm{R}_{f}=0.20$.

${ }^{1} \mathrm{H}-\mathrm{NMR}\left(300 \mathrm{MHz},\left[\mathrm{D}_{6}\right] \mathrm{DMSO}\right): \delta_{H}(\mathrm{ppm})=3.43\left(\mathrm{t},{ }^{4} \mathrm{~J}_{\mathrm{H}, \mathrm{H}}=2.4 \mathrm{~Hz}, 1 \mathrm{H}, \mathrm{CCH}\right), 3.72\left(\mathrm{~d},{ }^{3} \mathrm{~J}_{\mathrm{H}, \mathrm{H}}=5.4 \mathrm{~Hz}, 2 \mathrm{H}\right.$, $\left.\beta-\mathrm{CH}_{2}\right), 4.16\left(\mathrm{~d},{ }^{4} \mathrm{~J}_{\mathrm{H}, \mathrm{H}}=2.4 \mathrm{~Hz}, 2 \mathrm{H}, \mathrm{OCH}_{2}\right), 4.19-4.30(\mathrm{~m}, 4 \mathrm{H}, \alpha-\mathrm{CH}$, Fmoc-CH, Fmoc-CH), 7.33 (dt, $\left.{ }^{3,4} J_{H, H}=7.4,1.3 \mathrm{~Hz}, 2 \mathrm{H}, \mathrm{Fmoc}-\mathrm{CH}\right), 7.42\left(\mathrm{dt},{ }^{3,4} J_{\mathrm{H}, \mathrm{H}}=7.5,1.2 \mathrm{~Hz}, 2 \mathrm{H}, \mathrm{Fmoc}-\mathrm{CH}\right), 7.59\left(\mathrm{~d},{ }^{3} J_{\mathrm{H}, \mathrm{H}}=8.2 \mathrm{~Hz}, 1 \mathrm{H}\right.$, $\mathrm{NH}), 7.74\left(\mathrm{~d},{ }^{3} \mathrm{~J}_{\mathrm{H}, \mathrm{H}}=7.4 \mathrm{~Hz}, 2 \mathrm{H}, \mathrm{Fmoc}-\mathrm{CH}\right), 7.89\left(\mathrm{~d},{ }^{3} \mathrm{~J}_{\mathrm{H}, \mathrm{H}}=7.5 \mathrm{~Hz}, 2 \mathrm{H}, \mathrm{Fmoc}-\mathrm{CH}\right), 12.72\left(\mathrm{~s}, 1 \mathrm{H}, \mathrm{CO}_{2} \mathrm{H}\right)$.

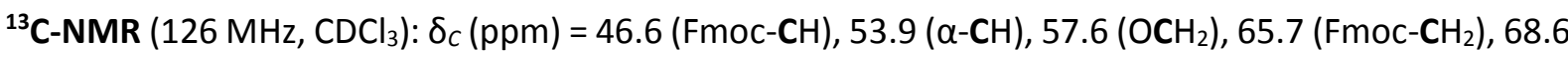
$\left(\beta-\mathrm{CH}_{2}\right), 77.3(\mathrm{CCH}), 79.8(\mathrm{CCH}), 119.9,125.1,126.9,127.4$ (Fmoc-CH), 140.5, 143.6 (Fmoc-C), 155.8 (Fmoc-CO), $171.1\left(\mathrm{CO}_{2} \mathrm{H}\right)$.

HR-MS (ESI): calc. for $\left[\mathrm{C}_{21} \mathrm{H}_{19} \mathrm{NNaO}_{5}\right]^{+}\left([\mathrm{M}+\mathrm{Na}]^{+}\right): 388.1155$, found: 388.1150 ; calc. for $\left[\mathrm{C}_{21} \mathrm{H}_{18} \mathrm{NO}_{5}\right]^{]}$ ([M-H] $): 364.1190$, found: 364.1189 . 
Fmoc-L-Cys(Dmt)-OH (11)

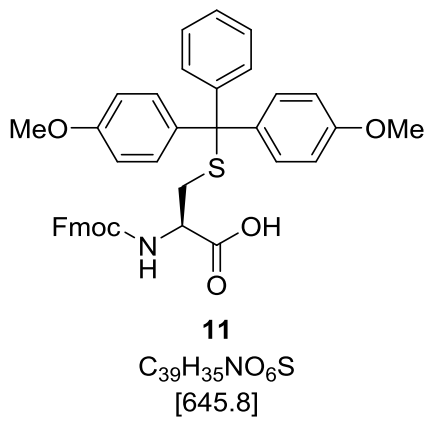

According to the procedure of LINDNER, H-L-Cys-OH. $\mathrm{H}_{2} \mathrm{O} \cdot \mathrm{HCl}(1.00 \mathrm{~g}, 5.69 \mathrm{mmol}, 1.00 \mathrm{eq}$.$) was co-$ evaporated with pyridine $(3 \times 4 \mathrm{~mL})$ and dissolved in pyridine $(4 \mathrm{~mL})$ under argon atmosphere. ${ }^{[81]}$ After addition of 4,4'-dimethoxytrityl chloride ( $1.83 \mathrm{~g}, 5.41 \mathrm{mmol}, 0.95 \mathrm{eq}$.) the reaction mixture was stirred for $48 \mathrm{~h}$ at $50^{\circ} \mathrm{C}$ and the reaction process monitored by TLC (DCM/MeOH 10:0.2, v/v). The solvent was evaporated under reduced pressure. The resulting residue was suspended in $20 \% \mathrm{Na}_{2} \mathrm{CO}_{3}$ (aq) (12.5 mmol, $6.63 \mathrm{~mL}, 2.20$ eq.) at $0{ }^{\circ} \mathrm{C}$. (9-Fluorenylmethoxycarbonyloxy)succinimide (1.73 g, $5.12 \mathrm{mmol}, 0.90$ eq.) dissolved in dioxane $(6 \mathrm{~mL})$ was added to the solution and the mixture stirred for $15 \mathrm{~min}$ at $0^{\circ} \mathrm{C}$, followed by $4 \mathrm{~h}$ at $\mathrm{rt}$. The mixture was adjusted to $\mathrm{pH}=5$ with citric acid, extracted with EtOAc $(3 \times 10 \mathrm{~mL})$ and the combined organic phases were evaporated under reduced pressure. The crude product was purified by flash column chromatography (DCM/MeOH 10:0.2 $\rightarrow$ 10:0.5, v/v) to yield the product 11 as a yellow solid $(2.20 \mathrm{~g}, 3.41 \mathrm{mmol}, 60 \%)$.

$\operatorname{TLC}(\mathrm{DCM} / \mathrm{MeOH} 10: 0.5, \mathrm{v} / \mathrm{v} / \mathrm{v}): \mathrm{R}_{f}=0.33$.

${ }^{1} \mathrm{H}-\mathrm{NMR}\left(600 \mathrm{MHz},\left[\mathrm{D}_{6}\right] \mathrm{DMSO}\right): \delta_{H}(\mathrm{ppm})=2.48-2.56\left(\mathrm{~m}, 2 \mathrm{H}, \beta-\mathrm{CH}_{2}\right), 3.71\left(\mathrm{~s}, 6 \mathrm{H}, \mathrm{OCH}_{3}\right), 3.88-3.91(\mathrm{~m}$, $1 \mathrm{H}, \alpha-\mathrm{CH}), 4.21-4.28\left(\mathrm{~m}, 3 \mathrm{H}, \mathrm{Fmoc}-\mathrm{CH}, \mathrm{Fmoc}-\mathrm{CH}_{2}\right), 6.85\left(\mathrm{~d}, 3_{\mathrm{H}, \mathrm{H}}=8.5 \mathrm{~Hz}, 4 \mathrm{H}, \mathrm{Dmt}-\mathrm{CH}\right), 7.18(\mathrm{~d}$, $\left.3 J_{H, H}=8.5 \mathrm{~Hz}, 4 \mathrm{H}, \mathrm{Dmt}-\mathrm{CH}\right), 7.19-7.31(\mathrm{~m}, 8 \mathrm{H}, \mathrm{Dmt}-\mathrm{CH}, \mathrm{Fmoc}-\mathrm{CH}, \mathrm{NH}), 7.38-7.41(\mathrm{~m}, 2 \mathrm{H}, \mathrm{Fmoc}-\mathrm{CH}), 7.73$ (d, ${ }^{3} J_{H, H}=7.5 \mathrm{~Hz}, 2 \mathrm{H}$, Fmoc-CH), $7.88\left(\mathrm{~d},{ }^{3} \mathrm{~J}_{\mathrm{H}, \mathrm{H}}=7.5 \mathrm{~Hz}, 2 \mathrm{H}\right.$, Fmoc-CH).

${ }^{13} \mathrm{C}-\mathrm{NMR}\left(126 \mathrm{MHz}, \mathrm{CDCl}_{3}\right): \delta_{C}(\mathrm{ppm})=34.1\left(\beta-\mathrm{CH}_{2}\right)$, $46.6(\mathrm{Fmoc}-\mathrm{CH}), 54.1(\alpha-\mathrm{CH}), 55.0\left(\mathrm{OCH}_{2}\right), 65.6$ (Fmoc-CH ${ }_{2}$ ), 113.1 (Dmt-CH), 120.0, 125.2 (Fmoc-CH), 126.4 (Dmt-CH), 127.0, 127.5 (Fmoc-CH), 127.8, 128.9, 130.2 (Dmt-CH), 136.7 (Dmt-C), 140.6, 143.7 (Fmoc-C), 145.2 (Dmt-C), 155.5 (Fmoc-CO), 157.6 (Dmt-C), $172.6\left(\mathrm{CO}_{2} \mathrm{H}\right)$.

HR-MS (ESI): calc. for $\left[\mathrm{C}_{39} \mathrm{H}_{39} \mathrm{~N}_{2} \mathrm{O}_{6} \mathrm{~S}\right]^{+}\left(\left[\mathrm{M}+\mathrm{NH}_{4}\right]^{+}\right): 663.2523$, found: 663.2500 ; calc. for $\left[\mathrm{C}_{39} \mathrm{H}_{34} \mathrm{NO}_{6} \mathrm{~S}\right]^{-}$ ([M-H] $)$ : 644.2112, found: 644.2105 . 


\section{4,5-Dimethoxy-2-nitrobenzyl(4-nitrophenyl)carbonate (37)}

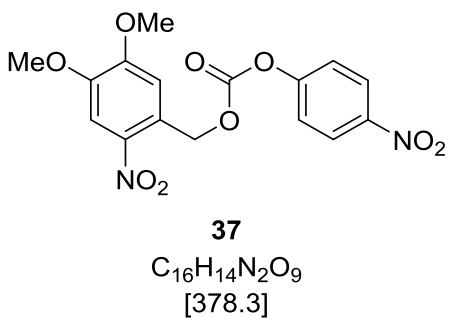

According to the procedure of FomINA et al., 4,5-dimethoxy-2-nitrobenzyl alcohol (36) (2.50 g, $11.7 \mathrm{mmol}, 1.00$ eq.) and 4-nitrophenyl chloroformate (35) (PNPCl) $(4.70 \mathrm{~g}, 23.5 \mathrm{mmol}, 2.00$ eq.) were dissolved in DCM $(25 \mathrm{~mL})$ under argon atmosphere and exclusion of light. ${ }^{[188]}$ DIPEA $(4.18 \mathrm{~mL}$, $23.5 \mathrm{mmol}, 2.00$ eq.) and DCM ( $25 \mathrm{~mL})$ were added and the solution stirred overnight at $\mathrm{rt}$. The solvent was removed under reduced pressure, the resulting residue washed with hot EtOH $(3 \times 20 \mathrm{~mL})$ and dried under reduced pressure to yield the product 37 as a yellow solid ( $2.56 \mathrm{~g}, 6.77 \mathrm{mmol}, 58 \%)$. The NMR data is in accordance to the literature. ${ }^{[188,237]}$

${ }^{1} \mathrm{H}-\mathrm{NMR}\left(300 \mathrm{MHz}, \mathrm{CDCl}_{3}\right): \delta_{H}(\mathrm{ppm})=3.99\left(\mathrm{~s}, 3 \mathrm{H}, \mathrm{OCH}_{3}\right), 4.02\left(\mathrm{~s}, 3 \mathrm{H}, \mathrm{OCH}_{3}\right), 5.71\left(\mathrm{~s}, 2 \mathrm{H}, \mathrm{CH}_{2}\right), 7.11(\mathrm{~s}$, $1 \mathrm{H}, \mathrm{DMNB}-\mathrm{H} 6), 7.41\left(\mathrm{~d}, 3^{3} \mathrm{JH}_{\mathrm{H}}=9.2 \mathrm{~Hz}, 2 \mathrm{H}, \mathrm{PNP}-\mathrm{H} 2, \mathrm{H} 6\right), 7.77(\mathrm{~s}, 1 \mathrm{H}, \mathrm{DMNB}-\mathrm{H} 3), 8.30\left(\mathrm{~d},{ }^{3} \mathrm{~J}_{\mathrm{H}, \mathrm{H}}=9.2 \mathrm{~Hz}\right.$, 2H, PNP-H3,H5).

${ }^{13} \mathrm{C}-\mathrm{NMR}\left(126 \mathrm{MHz}, \mathrm{CDCl}_{3}\right): \delta_{\mathrm{C}}(\mathrm{ppm})=56.6\left(\mathrm{OCH}_{3}\right), 56.7\left(\mathrm{OCH}_{3}\right), 67.9\left(\mathrm{CH}_{2}\right), 108.6(\mathrm{DMNB}-\mathrm{C} 3), 110.8$ (DMNB-C6), 121.9 (PNP-C2,C6), 125.2 (DMNB-C1), 125.5 (PNP-C3,C5), 140.2 (DMNB-C2), 145.7 (PNP-C1), 149.0 (DMNB-C5), 152.2 (CO), 153.8 (DMNB-C4), 155.5 (PNP-C4).

HR-MS (ESI): calc. for $\left[\mathrm{C}_{16} \mathrm{H}_{14} \mathrm{~N}_{2} \mathrm{NaO}_{9}\right]^{+}\left([\mathrm{M}+\mathrm{Na}]^{+}\right): 401.0592$, found: 401.0578 . 


\section{Fmoc-L-Lys(NVOC)-OH (34)}

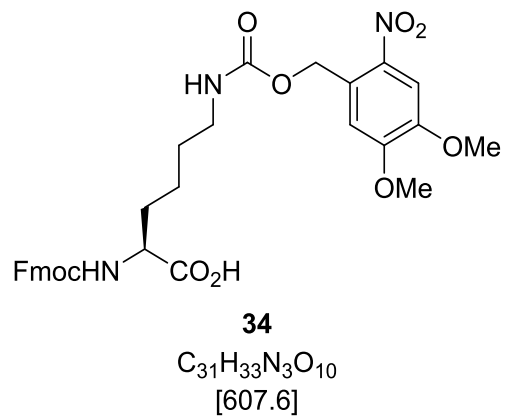

According to the procedure of DE GRACIA LUX et al., Fmoc-L-Lys-OH (2.50 g, $6.79 \mathrm{mmol}, 1.00$ eq.) was dissolved in toluene (122 $\mathrm{mL})$ and added to a suspension of 4,5-dimethoxy2-nitrobenzyl(4-nitrophenyl)carbonate (37) (2.56 g, $6.79 \mathrm{mmol}, 1.00$ eq.) and DIPEA (24.4 mL) in DMF $(41 \mathrm{~mL})$ under argon atmosphere and exclusion of light. ${ }^{[189]}$ The reaction mixture was stirred overnight at $\mathrm{rt}$ and the solvent removed under reduced pressure. The resulting yellow oil was purified by flash column chromatography $(\mathrm{DCM} / \mathrm{MeOH} / \mathrm{AcOH}$ 10:0.5:0.1 $\rightarrow$ 10:1:0.1, v/v/v) to yield the product 34 as a slightly yellow solid $(2.64 \mathrm{~g}, 4.34 \mathrm{mmol}, 64 \%)$. The NMR data is in accordance to the literature. ${ }^{[189]}$

$\operatorname{TLC}\left(\mathrm{DCM} / \mathrm{MeOH} / \mathrm{AcOH}\right.$ 10:0.5:0.1, v/v/v): $\mathrm{R}_{f}=0.19$.

${ }^{1} \mathrm{H}-\mathrm{NMR}\left(300 \mathrm{MHz},\left[\mathrm{D}_{6}\right] \mathrm{DMSO}\right): \delta_{H}(\mathrm{ppm})=1.26-1.49\left(\mathrm{~m}, 4 \mathrm{H}, \delta-\mathrm{CH}_{2}, \mathrm{\gamma}-\mathrm{CH}_{2}\right), 1.59-1.72\left(\mathrm{~m}, 2 \mathrm{H}, \beta-\mathrm{CH}_{2}\right)$, 2.98-3.05 (m, 2H, $\left.\varepsilon-\mathrm{CH}_{2}\right), 3.84\left(\mathrm{~s}, 3 \mathrm{H}, \mathrm{OCH}_{3}\right), 3.87\left(\mathrm{~s}, 3 \mathrm{H}, \mathrm{OCH}_{3}\right), 3.89-3.95(\mathrm{~m}, 1 \mathrm{H}, \mathrm{Fmoc}-\mathrm{CH}), 4.17-4.29$ $\left(\mathrm{m}, 3 \mathrm{H}, \alpha-\mathrm{CH}, \mathrm{Fmoc}-\mathrm{CH}_{2}\right), 5.31\left(\mathrm{~s}, 2 \mathrm{H}, \mathrm{DMNB}-\mathrm{CH}_{2}\right), 7.14(\mathrm{~s}, 1 \mathrm{H}, \mathrm{DMNB}-\mathrm{H} 6), 7.30\left(\mathrm{t},{ }^{3} \mathrm{~J}_{\mathrm{H}, \mathrm{H}}=7.3 \mathrm{~Hz}, 2 \mathrm{H}\right.$, Fmoc-CH), $7.39\left(\mathrm{t},{ }^{3} \mathrm{~J}_{\mathrm{H}, \mathrm{H}}=7.3 \mathrm{~Hz}, 2 \mathrm{H}, \mathrm{Fmoc}-\mathrm{CH}\right), 7.53\left(\mathrm{~d},{ }^{3} \mathrm{~J}_{\mathrm{H}, \mathrm{H}}=7.9 \mathrm{~Hz}, 1 \mathrm{H}, \mathrm{NH}\right), 7.66(\mathrm{~s}, 1 \mathrm{H}, \mathrm{DMNB}-\mathrm{H} 3)$, $7.69\left(\mathrm{~d},{ }^{3} J_{\mathrm{H}, \mathrm{H}}=7.3 \mathrm{~Hz}, 2 \mathrm{H}, \mathrm{Fmoc}-\mathrm{CH}\right), 7.85\left(\mathrm{~d},{ }^{3} \mathrm{H}_{\mathrm{H}, \mathrm{H}}=7.3 \mathrm{~Hz}, 2 \mathrm{H}\right.$, Fmoc-CH).

${ }^{13} \mathrm{C}-\mathrm{NMR}\left(126 \mathrm{MHz},\left[\mathrm{D}_{6}\right] \mathrm{DMSO}\right): \delta_{c}(\mathrm{ppm})=23.0\left(\gamma-\mathrm{CH}_{2}\right), 29.0\left(\delta-\mathrm{CH}_{2}\right), 30.5\left(\beta-\mathrm{CH}_{2}\right), 40.1\left(\varepsilon-\mathrm{CH}_{2}\right), 46.8$ (Fmoc-CH), $53.9\left(\alpha-\mathrm{CH}_{2}\right), 56.2,56.3\left(\mathrm{OCH}_{3}\right), 62.3\left(\mathrm{DMNB}^{\left.-\mathrm{CH}_{2}\right)}, 65.7\left(\mathrm{Fmoc}-\mathrm{CH}_{2}\right), 108.3\right.$ (DMNB-C3), 110.6 (DMNB-C6), 120.1, 125.3, 127.1, 127.7 (Fmoc-CH), 128.0 (DMNB-C1), 139.4 (DMNB-C2), 140.8, 143.9 (Fmoc-C), 147.8 (DMNB-C5), 153.4 (DMNB-C4), 155.8, 156.3 (CO), $174.0\left(\mathrm{CO}_{2} \mathrm{H}\right)$.

HR-MS (ESI): calc. for $\left[\mathrm{C}_{31} \mathrm{H}_{33} \mathrm{~N}_{3} \mathrm{NaO}_{10}\right]^{+}\left([\mathrm{M}+\mathrm{Na}]^{+}\right): 630.2058$, found: 630.2039 ; calc. for $\left[\mathrm{C}_{31} \mathrm{H}_{32} \mathrm{~N}_{3} \mathrm{O}_{10}\right]^{-}$ ([M-H] $\left.]^{-}\right): 606.2093$, found: 606.2097. 
Fmoc-L-Asp(ODMNB)-O'Bu (40)

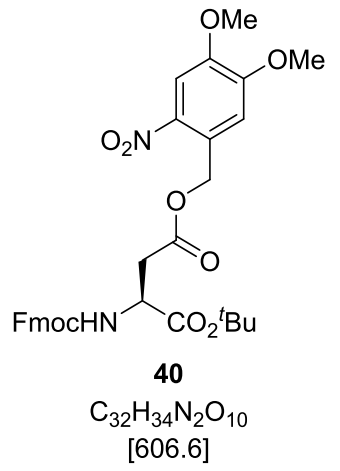

Fmoc-L-Asp-Ot Bu (39) (912 mg, 2.20 mmol, 1.00 eq.), 4-(dimethylamino)pyridine (156 mg, 1.10 mmol, 0.50 eq.), 4,5-dimethoxy-2-nitrobenzyl alcohol (562 mg, $2.64 \mathrm{mmol}, 1.20$ eq.) was dissolved in DCM $(30 \mathrm{~mL})$ under argon atmosphere and exclusion of light. The reaction mixture was stirred for $10 \mathrm{~min}$ at $0{ }^{\circ} \mathrm{C}$ and $N$-(3-dimethylaminopropyl)- $N$ '-ethylcarbodiimide hydrochloride $(460 \mathrm{mg}, 2.40 \mathrm{mmol}$, 1.09 eq.) were added. Further stirring for $2 \mathrm{~h}$ at $0{ }^{\circ} \mathrm{C}$ and overnight at $\mathrm{rt}$ was followed by solvent removal under reduced pressure. The resulting residue was dissolved in EtOAc $(25 \mathrm{~mL})$ and water $(5 \mathrm{~mL})$. The organic phase was washed with saturated $\mathrm{NaHCO}_{3}(\mathrm{aq})(2 \times 15 \mathrm{~mL})$, water $(2 \times 15 \mathrm{~mL})$, dried over $\mathrm{Na}_{2} \mathrm{SO}_{4}$ and the solvent removed under reduced pressure. The resulting yellow oil was purified by flash column chromatography (pentane/EtOAc 2:1, v/v) to yield the product 40 as a yellow solid (1.04 g, $1.71 \mathrm{mmol}, 78 \%)$.

TLC (pentane/EtOAc 2:1, v/v): $R_{f}=0.60$.

${ }^{1} \mathrm{H}-\mathrm{NMR}\left(600 \mathrm{MHz},\left[\mathrm{D}_{6}\right] \mathrm{DMSO}\right): \delta_{H}(\mathrm{ppm})=1.36\left(\mathrm{~s}, 9 \mathrm{H}, \mathrm{C}\left(\mathrm{CH}_{3}\right)_{3}\right), 2.78-2.82\left(\mathrm{~m}, 2 \mathrm{H}, \beta-\mathrm{CH}_{2}\right), 3.85(\mathrm{~s}, 3 \mathrm{H}$, $\left.\mathrm{OCH}_{3}\right), 3.90\left(\mathrm{~s}, 3 \mathrm{H}, \mathrm{OCH}_{3}\right), 4.20\left(\mathrm{t},{ }^{3} \mathrm{~J}_{\mathrm{H}, \mathrm{H}}=7.0 \mathrm{~Hz}, 1 \mathrm{H}, \mathrm{Fmoc}-\mathrm{CH}\right), 4.30-4.32\left(\mathrm{~m}, 2 \mathrm{H}, \mathrm{Fmoc}-\mathrm{CH}_{2}\right), 4.37-4.41$ (m, 1H, $\alpha-C H), 5.43$ (s, 2H, DMNB-CH $), 7.17$ (s, 1H, DMNB-H6), 7.29-7.32 (m, 2H, Fmoc-CH), 7.40 (t, $\left.{ }^{3} J_{H, H}=7.5 \mathrm{~Hz}, 2 \mathrm{H}, \mathrm{Fmoc}-\mathrm{CH}\right), 7.67-7.69(\mathrm{~m}, 3 \mathrm{H}, \mathrm{DMNB}-\mathrm{H} 3, \mathrm{Fmoc}-\mathrm{CH}), 7.75\left(\mathrm{~d},{ }^{3} \mathrm{~J}_{\mathrm{H}, \mathrm{H}}=8.4 \mathrm{~Hz}, 1 \mathrm{H}, \mathrm{NH}\right)$, $7.87\left(\mathrm{~d},{ }^{3} \mathrm{~J}_{\mathrm{H}, \mathrm{H}}=7.5 \mathrm{~Hz}, 2 \mathrm{H}\right.$, Fmoc-CH).

${ }^{13} \mathrm{C}-\mathrm{NMR}\left(126 \mathrm{MHz},\left[\mathrm{D}_{6}\right] \mathrm{DMSO}\right): \delta_{c}(\mathrm{ppm})=27.4\left(\mathrm{C}\left(\mathrm{CH}_{3}\right)\right), 35.9\left(\beta-\mathrm{CH}_{2}\right), 46.6(\mathrm{Fmoc}-\mathrm{CH}), 51.0(\alpha-\mathrm{CH})$, $56.0\left(\mathrm{OCH}_{3}\right), 56.1\left(\mathrm{OCH}_{3}\right), 62.8\left(\mathrm{DMNB}-\mathrm{CH}_{2}\right), 65.7\left(\mathrm{Fmoc}-\mathrm{CH}_{2}\right), 81.1\left(\mathrm{C}\left(\mathrm{CH}_{3}\right)\right), 108.1$ (DMNB-C3), 111.2 (DMNB-C6), 120.0, 125.0 (Fmoc-CH), 125.9 (DMNB-C1), 126.9, 127.5 (Fmoc-CH), 139.6 (DMNB-C2), 140.6, 143.7 (Fmoc-CH), 147.9 (DMNB-C5), 153.2 (DMNB-C4), 155.8 (Fmoc-CO), 169.6, 169.7 (CO).

HR-MS (ESI): calc. for $\left[\mathrm{C}_{32} \mathrm{H}_{34} \mathrm{~N}_{2} \mathrm{NaO}_{10}\right]^{+}\left([\mathrm{M}+\mathrm{Na}]^{+}\right): 629.2106$, found: 629.2107 . 


\section{Fmoc-L-Asp(ODMNB)-OH (38)}

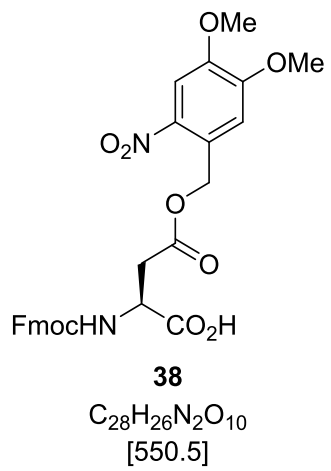

According to the procedure of BOURGaUlt et al., Fmoc-L-Asp(ODMNB)-O ${ }^{\mathrm{t} B u}(\mathbf{4 0})(1.02 \mathrm{~g}, 1.69 \mathrm{mmol})$ was dissolved in TFA/water (36 mL, 19:1, v/v) and stirred for $90 \mathrm{~min}^{[190]}$ The solvent was removed under reduced pressure, the resulting residue was dissolved in DCM $(50 \mathrm{~mL})$, washed with $5 \% \mathrm{KHSO}_{4}$ (aq) $(3 \times 20 \mathrm{~mL})$ and dried over $\mathrm{Na}_{2} \mathrm{SO}_{4}$. The solvent was removed under reduced pressure and the resulting yellow oil was purified by flash column chromatography (DCM/MeOH/AcOH 9:1:0.1, v/v/v) to yield the product 38 as a yellow solid ( $863 \mathrm{mg}, 1.57 \mathrm{mmol}, 93 \%)$. The NMR data is in accordance to the literature. ${ }^{[190]}$

TLC (DCM/MeOH/AcOH 9:1:0.1, v/v/v): $\mathrm{R}_{f}=0.69$.

${ }^{1} \mathrm{H}-\mathrm{NMR}\left(300 \mathrm{MHz},\left[\mathrm{D}_{6}\right] \mathrm{DMSO}\right): \delta_{H}(\mathrm{ppm})=2.77-3.00\left(\mathrm{~m}, 2 \mathrm{H}, \beta-\mathrm{CH}_{2}\right), 3.85\left(\mathrm{~s}, 3 \mathrm{H}, \mathrm{OCH}_{3}\right), 3.90(\mathrm{~s}, 3 \mathrm{H}$, $\left.\mathrm{OCH}_{3}\right), 4.17-4.21(\mathrm{~m}, 1 \mathrm{H}, \mathrm{Fmoc}-\mathrm{CH}), 4.27-4.30\left(\mathrm{~m}, 2 \mathrm{H}, \mathrm{Fmoc}-\mathrm{CH}_{2}\right), 4.41-4.48(\mathrm{~m}, 1 \mathrm{H}, \alpha-\mathrm{CH}), 5.42(\mathrm{~s}, 2 \mathrm{H}$, DMNB-CH $\left.{ }_{2}\right), 7.16(\mathrm{~s}, 1 \mathrm{H}, \mathrm{DMNB}-\mathrm{H} 6), 7.30\left(\mathrm{t},{ }^{3} \mathrm{~J}_{\mathrm{H}, \mathrm{H}}=7.5 \mathrm{~Hz}, 2 \mathrm{H}, \mathrm{Fmoc}-\mathrm{CH}\right), 7.40\left(\mathrm{t},{ }^{3} \mathrm{~J}_{\mathrm{H}, \mathrm{H}}=7.5 \mathrm{~Hz}, 2 \mathrm{H}\right.$, Fmoc-CH), 7.66-7.71 (m, 4H, DMNB-H3, Fmoc-CH, NH), 7.87 (d, ${ }^{3} J_{\mathrm{H}, \mathrm{H}}=7.5 \mathrm{~Hz}, 2 \mathrm{H}, \mathrm{Fmoc}-\mathrm{CH}$ ).

${ }^{13} \mathrm{C}-\mathrm{NMR}\left(126 \mathrm{MHz},\left[\mathrm{D}_{6}\right] \mathrm{DMSO}\right): \delta_{C}(\mathrm{ppm})=36.0\left(\beta-\mathrm{CH}_{2}\right), 46.6(\mathrm{Fmoc}-\mathrm{CH}), 50.5(\alpha-\mathrm{CH}), 56.0\left(\mathrm{OCH}_{3}\right), 56.3$ $\left(\mathrm{OCH}_{3}\right), 62.7$ (DMNB-CH 2 ), 65.7 (Fmoc-CH ${ }_{2}$ ), 108.1 (DMNB-C3), 110.9 (DMNB-C6), 120.0, 125.1 (FmocCH), 126.3 (DMNB-C1), 127.0, 127.6 (Fmoc-CH), 139.5 (DMNB-C2), 140.7, 143.7 (Fmoc-CH), 147.9 (DMNB-C5), 153.4 (DMNB-C4), 155.8 (Fmoc-CO), 169.9 ( $(-\mathrm{CO}), 172.3\left(\mathrm{CO}_{2} \mathrm{H}\right)$.

HR-MS (ESI): calc. for $\left[\mathrm{C}_{28} \mathrm{H}_{26} \mathrm{~N}_{2} \mathrm{NaO}_{10}\right]^{+}\left([\mathrm{M}+\mathrm{Na}]^{+}\right): 573.1480$, found: 573.1471 ; calc. for $\left[\mathrm{C}_{28} \mathrm{H}_{25} \mathrm{~N}_{2} \mathrm{O}_{10}\right]^{-}$ ([M-H] $\left.]^{-}\right)$: 549.1515, found: 549.1517. 


\subsubsection{Syntheses of $\mu$-conotoxin SIIIA derivatives}

Synthesis of a linear $\mu$-conotoxin SIIIA-[Ser(2'propyne)] (disulphide connectivity: 1-4/2-5/3-6) precursor (14)

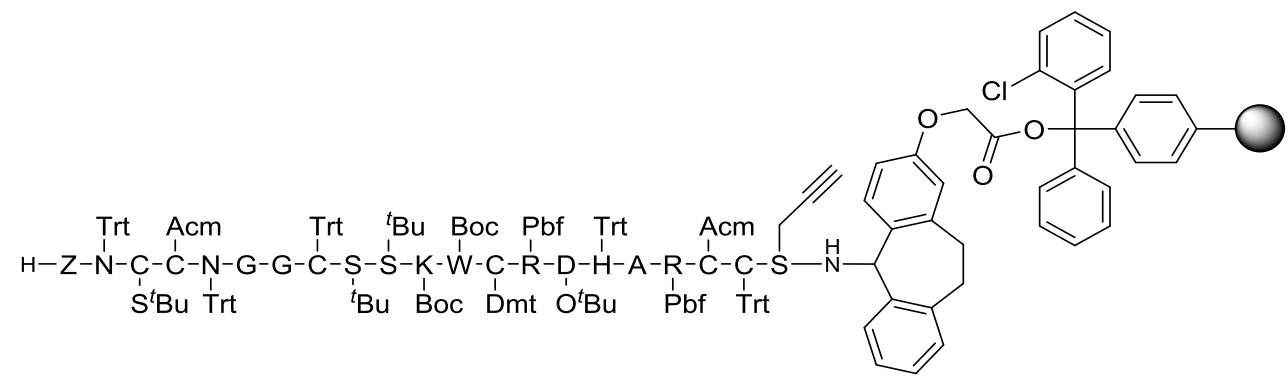

14

2-Chlorotrityl chloride resin $(0.70 \mathrm{~g}, 0.70 \mathrm{mmol}, 1-1.50 \mathrm{mmol} / \mathrm{g})$ was preloaded following SOP1. The occupancy was tested following SOP3 and determined to be $0.29 \mathrm{mmol} / \mathrm{g}$. The resin $(345 \mathrm{mg}$, $0.10 \mathrm{mmol}$ ) was loaded with the first amino acid Fmoc-L-Ser(2'propyne)-OH following SOP2. The peptide was synthesized following SOP4. Test cleavage was performed using SOP6/A yielding the Acm and $S^{t} B u$ protected peptide 64 .

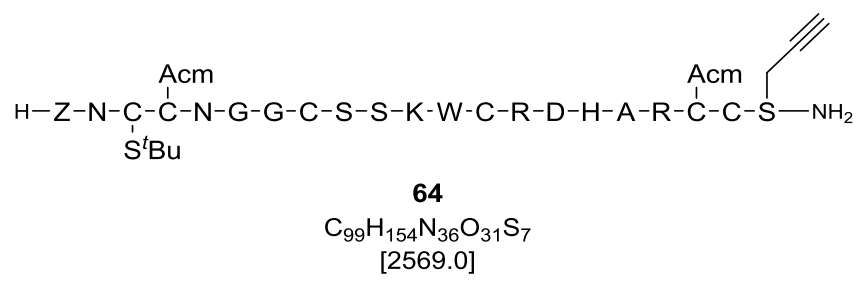

HR-MS (ESI): calc. for $\left[\mathrm{C}_{99} \mathrm{H}_{156} \mathrm{~N}_{36} \mathrm{O}_{31} \mathrm{~S}_{7}\right]^{2+}\left([\mathrm{M}+2 \mathrm{H}]^{2+}\right)$ : 1284.4886, found: 1284.4881; calc. for $\left[\mathrm{C}_{99} \mathrm{H}_{157} \mathrm{~N}_{36} \mathrm{O}_{31} \mathrm{~S}_{7}\right]^{3+}\left([\mathrm{M}+3 \mathrm{H}]^{3+}\right): 856.6615$, found: 856.6629 . 
Synthesis of $\mu$-conotoxin SIIIA-[Ser(2'propyne)] (disulphide connectivity: 1-4/2-5/3-6): formation of the first disulphide bridge and deprotection of acid-labile protecting groups

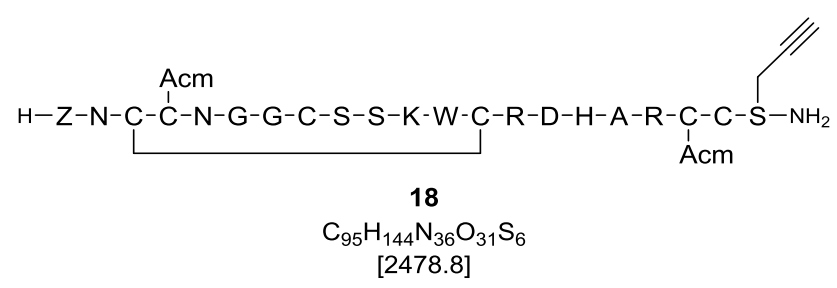

The formation of the first disulphide bridge using the linear precursor 14 (279 mg, $34.2 \mu \mathrm{mol})$ was performed following SOP7 (24 mL in steps $1-3,820 \mathrm{~mL}$ in step 4, $400 \mathrm{~mL}$ in step 5) yielding the product 18 as a colourless solid (54.2 mg, $21.9 \mu \mathrm{mol}, 64 \%$ ).

HR-MS (ESI): calc. for $\left[\mathrm{C}_{95} \mathrm{H}_{146} \mathrm{~N}_{36} \mathrm{O}_{31} \mathrm{~S}_{6}\right]^{2+}\left([\mathrm{M}+2 \mathrm{H}]^{2+}\right)$ : 1239.4634, found: 1239.4627 ; calc. for $\left[\mathrm{C}_{95} \mathrm{H}_{147} \mathrm{~N}_{36} \mathrm{O}_{31} \mathrm{~S}_{6}\right]^{3+}\left([\mathrm{M}+3 \mathrm{H}]^{3+}\right): 826.6447$, found: 826.6437.

Synthesis of $\mu$-conotoxin SIIIA-[Ser(2'propyne)] (disulphide connectivity: 1-4/2-5/3-6): formation of the second disulphide bridge

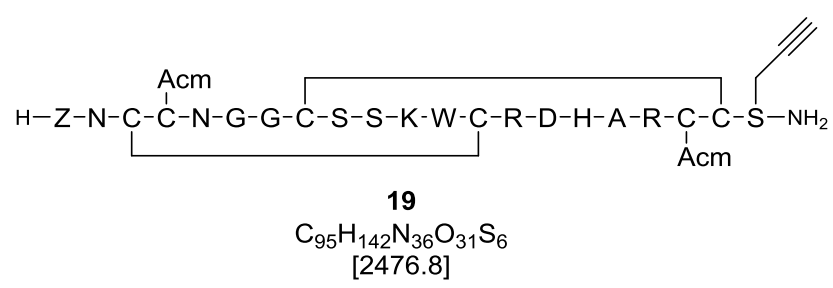

The second disulphide bridge using the crude peptide 18 (54.4 mg, $21.9 \mu \mathrm{mol})$ was performed following SOP8 yielding the product 19 as a colourless solid (49.3 mg, $19.9 \mu \mathrm{mol}, 91 \%)$.

HR-MS (ESI): calc. for $\left[\mathrm{C}_{95} \mathrm{H}_{144} \mathrm{~N}_{36} \mathrm{O}_{31} \mathrm{~S}_{6}\right]^{2+}\left([\mathrm{M}+2 \mathrm{H}]^{2+}\right)$ : 1238.4556 , found: 1238.4532 ; calc. for $\left[\mathrm{C}_{95} \mathrm{H}_{145} \mathrm{~N}_{36} \mathrm{O}_{31} \mathrm{~S}_{6}\right]^{3+}\left([\mathrm{M}+3 \mathrm{H}]^{3+}\right): 825.9728$, found: 825.9725 . 
Synthesis of $\mu$-conotoxin SIIIA-[Ser(2'propyne)] (7) (disulphide connectivity: 1-4/2-5/3-6): formation of the third disulphide bridge

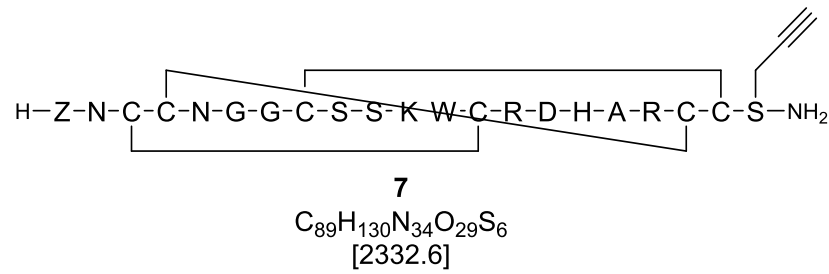

The Acm-groups were removed and the last disulphide bridge formed by dissolving the crude peptide 19 (31.8 mg, $12.8 \mu \mathrm{mol}, 1.00$ eq.) in AcOH/water (2:1, v/v, $9.6 \mathrm{~mL}$ ), adding Ac-L-Trp-OMe (33.3 mg, $128 \mu \mathrm{mol}, 10.0$ eq.) and a solution of iodine (162 mg, $640 \mu \mathrm{mol}, 50.0$ eq.) dissolved in acetic acid $(6.4 \mathrm{~mL})$ and stirring for $15 \mathrm{~min}$. The reaction was quenched using a solution of L-ascorbic acid in water (495 mg in $1.5 \mathrm{~mL}$ water) and directly purified by preparative HPLC yielding four differently folded peptides 7.

HPLC (preparative, A $\left(99.9 \% \mathrm{H}_{2} \mathrm{O}, 0.10 \%\right.$ TFA), B (79.9\% MeCN, $20.0 \% \mathrm{H}_{2} \mathrm{O}, 0.10 \%$ TFA), gradient $0-40 \% \mathrm{~B}, 30 \mathrm{~min}$ ) was utilised for all products.

1. Colourless solid $(63.1 \mu \mathrm{g}, 27.1 \mathrm{nmol})$.

HPLC: $\mathrm{R}_{\mathrm{t}}=22.3 \mathrm{~min}$.

HR-MS (ESI): calc. for $\left[\mathrm{C}_{89} \mathrm{H}_{132} \mathrm{~N}_{34} \mathrm{O}_{29} \mathrm{~S}_{6}\right]^{2+}\left([\mathrm{M}+2 \mathrm{H}]^{2+}\right): 1166.4106$, found: 1166.4111 ; calc. for $\left[\mathrm{C}_{89} \mathrm{H}_{133} \mathrm{~N}_{34} \mathrm{O}_{29} \mathrm{~S}_{6}\right]^{3+}\left([\mathrm{M}+3 \mathrm{H}]^{3+}\right): 777.9428$, found: 777.9435; calc. for $\left[\mathrm{C}_{89} \mathrm{H}_{134} \mathrm{~N}_{34} \mathrm{O}_{29} \mathrm{~S}_{6}\right]^{4+}$ $\left([\mathrm{M}+4 \mathrm{H}]^{4+}\right): 583.7090$, found: 583.7091 .

2. Colourless solid $(95.0 \mu \mathrm{g}, 40.7 \mathrm{nmol})$.

HPLC: $R_{t}=23.4 \mathrm{~min}$

HR-MS (ESI): calc. for $\left[\mathrm{C}_{89} \mathrm{H}_{132} \mathrm{~N}_{34} \mathrm{O}_{29} \mathrm{~S}_{6}\right]^{2+}\left([\mathrm{M}+2 \mathrm{H}]^{2+}\right): 1166.4106$, found: 1166.4094 ; calc. for $\left[\mathrm{C}_{89} \mathrm{H}_{133} \mathrm{~N}_{34} \mathrm{O}_{29} \mathrm{~S}_{6}\right]^{3+}\left([\mathrm{M}+3 \mathrm{H}]^{3+}\right): 777.9428$, found: 777.9431 ; calc. for $\left[\mathrm{C}_{89} \mathrm{H}_{134} \mathrm{~N}_{34} \mathrm{O}_{29} \mathrm{~S}_{6}\right]^{4+}$ $\left([\mathrm{M}+4 \mathrm{H}]^{4+}\right): 583.7090$, found: 583.7098 .

3. Colourless solid $(143 \mu \mathrm{g}, 61.4 \mathrm{nmol})$.

HPLC: $\mathrm{R}_{\mathrm{t}}=24.1 \mathrm{~min}$

HR-MS (ESI): calc. for $\left[\mathrm{C}_{89} \mathrm{H}_{132} \mathrm{~N}_{34} \mathrm{O}_{29} \mathrm{~S}_{6}\right]^{2+}\left([\mathrm{M}+2 \mathrm{H}]^{2+}\right): 1166.4106$, found: 1166.4113 ; calc. for $\left[\mathrm{C}_{89} \mathrm{H}_{133} \mathrm{~N}_{34} \mathrm{O}_{29} \mathrm{~S}_{6}\right]^{3+}\left([\mathrm{M}+3 \mathrm{H}]^{3+}\right): 777.9428$, found: 777.9438; calc. for $\left[\mathrm{C}_{89} \mathrm{H}_{134} \mathrm{~N}_{34} \mathrm{O}_{29} \mathrm{~S}_{6}\right]^{4+}$ $\left([\mathrm{M}+4 \mathrm{H}]^{4+}\right): 583.7090$, found: 583.7095 .

4. Colourless solid (106 $\mu \mathrm{g}, 45.5 \mathrm{nmol})$.

HPLC: $R_{t}=25.9$ min 
HR-MS (ESI): calc. for $\left[\mathrm{C}_{89} \mathrm{H}_{132} \mathrm{~N}_{34} \mathrm{O}_{29} \mathrm{~S}_{6}\right]^{2+}\left([\mathrm{M}+2 \mathrm{H}]^{2+}\right): 1166.4106$, found: 1166.4113 ; calc. for $\left[\mathrm{C}_{89} \mathrm{H}_{133} \mathrm{~N}_{34} \mathrm{O}_{29} \mathrm{~S}_{6}\right]^{3+}\left([\mathrm{M}+3 \mathrm{H}]^{3+}\right): 777.9428$, found: 777.9441 ; calc. for $\left[\mathrm{C}_{89} \mathrm{H}_{134} \mathrm{~N}_{34} \mathrm{O}_{29} \mathrm{~S}_{6}\right]^{4+}$ $\left([\mathrm{M}+4 \mathrm{H}]^{4+}\right): 583.7090$, found: 583.7109 .

Synthesis of a linear [pGlu1Ser(2'propyne)]- $\mu$-conotoxin SIIIA (disulphide connectivity: 1-4/2-5/3-6) precursor (65)

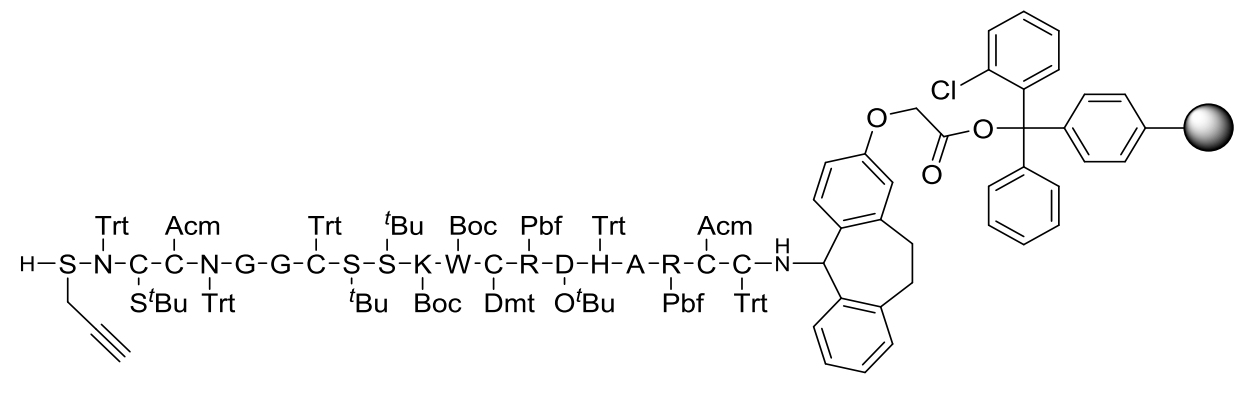

65

2-Chlorotrityl chloride resin $(0.70 \mathrm{~g}, 0.70 \mathrm{mmol}, 1-1.50 \mathrm{mmol} / \mathrm{g})$ was preloaded following SOP1. The occupancy was tested following SOP3 and determined to be $0.29 \mathrm{mmol} / \mathrm{g}$. The resin $(345 \mathrm{mg}$, $0.10 \mathrm{mmol}$ ) was loaded with the first amino acid Fmoc-L-Cys(Trt)-OH following SOP2. The peptide was synthesized following SOP4. Test cleavage was performed using SOP6/A yielding the Acm and $S^{t} B u$ protected peptide 66.

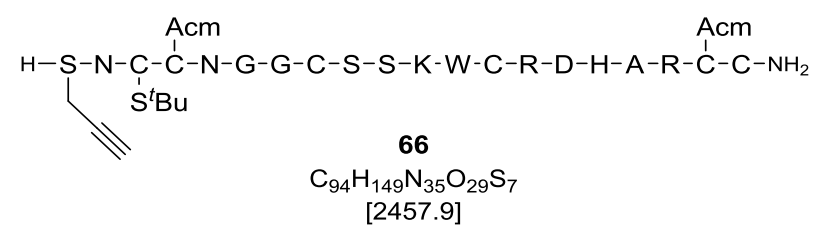

HR-MS (ESI): calc. for $\left[\mathrm{C}_{94} \mathrm{H}_{151} \mathrm{~N}_{35} \mathrm{O}_{29} \mathrm{~S}_{7}\right]^{2+}\left([\mathrm{M}+2 \mathrm{H}]^{2+}\right)$ : 1228.9725 , found: 1228.9698 ; calc. for $\left[\mathrm{C}_{94} \mathrm{H}_{152} \mathrm{~N}_{35} \mathrm{O}_{29} \mathrm{~S}_{7}\right]^{3+}\left([\mathrm{M}+3 \mathrm{H}]^{3+}\right): 819.6508$, found: 819.6502 ; calc. for $\left[\mathrm{C}_{94} \mathrm{H}_{153} \mathrm{~N}_{35} \mathrm{O}_{29} \mathrm{~S}_{7}\right]^{4+}\left([\mathrm{M}+4 \mathrm{H}]^{4+}\right)$ : 614.9899, found: 614.9899 . 


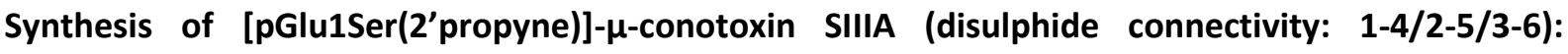
formation of the first disulphide bridge and deprotection of acid-labile protecting groups

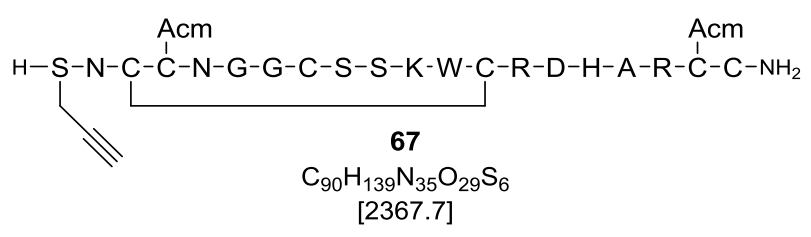

The formation of the first disulphide bridge using the linear precursor 65 (279 $\mathrm{mg}, 34.7 \mu \mathrm{mol})$ was performed following SOP7 ( $24 \mathrm{~mL}$ in steps $1-3,820 \mathrm{~mL}$ in step 4, $400 \mathrm{~mL}$ in step 5) yielding the product 67 as a colourless solid ( $38.3 \mathrm{mg}, 16.1 \mu \mathrm{mol}, 46 \%)$.

HR-MS (ESI): calc. for $\left[\mathrm{C}_{90} \mathrm{H}_{141} \mathrm{~N}_{35} \mathrm{O}_{29} \mathrm{~S}_{6}\right]^{2+}\left([\mathrm{M}+2 \mathrm{H}]^{2+}\right)$ : 1183.9474 , found: 1183.9471 ; calc. for $\left[\mathrm{C}_{90} \mathrm{H}_{142} \mathrm{~N}_{35} \mathrm{O}_{29} \mathrm{~S}_{6}\right]^{3+}\left([\mathrm{M}+3 \mathrm{H}]^{3+}\right): 789.6340$, found: 789.6346 .

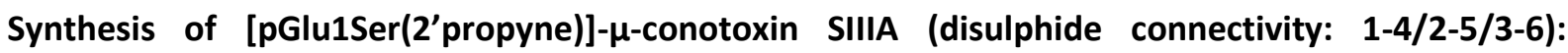
formation of the second disulphide bridge

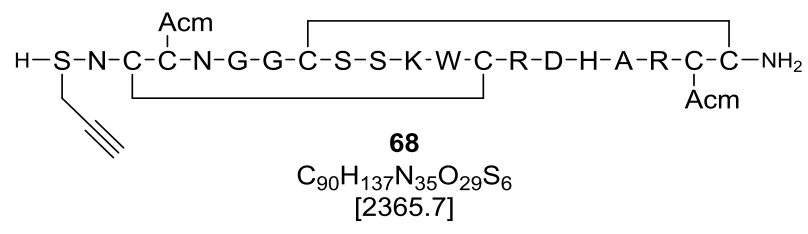

The second disulphide bridge using the crude peptide $67(38.3 \mathrm{mg}, 16.1 \mu \mathrm{mol})$ was performed following SOP8 yielding the product 68 as a colourless solid ( $25.5 \mathrm{mg}, 10.8 \mu \mathrm{mol}, 67 \%)$.

HR-MS (ESI): calc. for $\left[\mathrm{C}_{90} \mathrm{H}_{139} \mathrm{~N}_{35} \mathrm{O}_{29} \mathrm{~S}_{6}\right]^{2+}\left([\mathrm{M}+2 \mathrm{H}]^{2+}\right)$ : 1182.9396, found: 1182.9393; calc. for $\left[\mathrm{C}_{90} \mathrm{H}_{140} \mathrm{~N}_{35} \mathrm{O}_{29} \mathrm{~S}_{6}\right]^{3+}\left([\mathrm{M}+3 \mathrm{H}]^{3+}\right)$ : 788.9621, found: 788.9623 . 


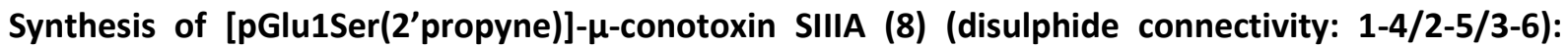
formation of the third disulphide bridge

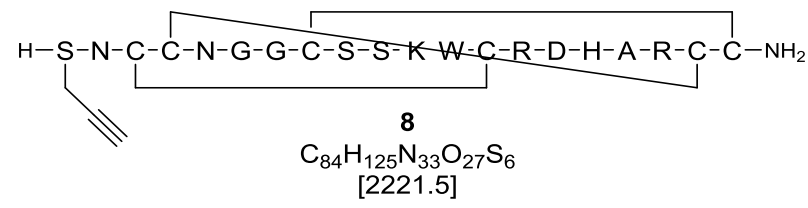

The Acm-groups were removed and the last disulphide bridge formed by dissolving the crude peptide 68 (20.9 mg, $8.83 \mu \mathrm{mol}, 1.00$ eq.) in AcOH/water (2:1, v/v, $6 \mathrm{~mL}$ ), adding Ac-L-Trp-OMe (23.0 mg, $88.3 \mu \mathrm{mol}, 10.0$ eq.) and a solution of iodine (112 mg, $442 \mu \mathrm{mol}, 50.0$ eq.) dissolved in acetic acid ( $4 \mathrm{~mL})$ and stirring for $15 \mathrm{~min}$. The reaction was quenched using a solution of L-ascorbic acid in water (495 $\mathrm{mg}$ in $1.5 \mathrm{~mL}$ water) and directly purified by preparative HPLC yielding four differently folded peptides 8 .

HPLC (preparative, A $\left(99.9 \% \mathrm{H}_{2} \mathrm{O}, 0.10 \%\right.$ TFA), B (79.9\% $\mathrm{MeCN}, 20.0 \% \mathrm{H}_{2} \mathrm{O}, 0.10 \%$ TFA), gradient $0-40 \%$ B, $30 \mathrm{~min}$ ) was utilised for all products.

1. Colourless solid $(92.6 \mu \mathrm{g}, 41.7 \mathrm{nmol})$.

HPLC: $\mathrm{R}_{\mathrm{t}}=22.4 \mathrm{~min}$.

HR-MS (ESI): calc. for $\left[\mathrm{C}_{84} \mathrm{H}_{127} \mathrm{~N}_{33} \mathrm{O}_{27} \mathrm{~S}_{6}\right]^{2+}\left([\mathrm{M}+2 \mathrm{H}]^{2+}\right): 1110.8946$, found: 1110.8938 ; calc. for $\left[\mathrm{C}_{84} \mathrm{H}_{128} \mathrm{~N}_{33} \mathrm{O}_{27} \mathrm{~S}_{6}\right]^{3+}\left([\mathrm{M}+3 \mathrm{H}]^{3+}\right): 740.9322$, found: 740.9323; calc. for $\left[\mathrm{C}_{84} \mathrm{H}_{129} \mathrm{~N}_{33} \mathrm{O}_{27} \mathrm{~S}_{6}\right]^{4+}$ $\left([\mathrm{M}+4 \mathrm{H}]^{4+}\right)$ : 555.9509, found: 555.9498 .

2. Colourless solid $(148 \mu \mathrm{g}, 66.7 \mathrm{nmol})$.

HPLC: $R_{t}=23.5 \mathrm{~min}$.

HR-MS (ESI): calc. for $\left[\mathrm{C}_{84} \mathrm{H}_{127} \mathrm{~N}_{33} \mathrm{O}_{27} \mathrm{~S}_{6}\right]^{2+}\left([\mathrm{M}+2 \mathrm{H}]^{2+}\right): 1110.8946$, found: 1110.8936 ; calc. for $\left[\mathrm{C}_{84} \mathrm{H}_{128} \mathrm{~N}_{33} \mathrm{O}_{27} \mathrm{~S}_{6}\right]^{3+}\left([\mathrm{M}+3 \mathrm{H}]^{3+}\right): 740.9322$, found: 740.9325 ; calc. for $\left[\mathrm{C}_{84} \mathrm{H}_{129} \mathrm{~N}_{33} \mathrm{O}_{27} \mathrm{~S}_{6}\right]^{4+}$ $\left([\mathrm{M}+4 \mathrm{H}]^{4+}\right): 555.9509$, found: 555.9508 .

3. Colourless solid $(115 \mu \mathrm{g}, 51.7 \mathrm{nmol})$.

HPLC: $\mathrm{R}_{\mathrm{t}}=24.2 \mathrm{~min}$.

HR-MS (ESI): calc. for $\left[\mathrm{C}_{84} \mathrm{H}_{127} \mathrm{~N}_{33} \mathrm{O}_{27} \mathrm{~S}_{6}\right]^{2+}\left([\mathrm{M}+2 \mathrm{H}]^{2+}\right): 1110.8946$, found: 1110.8938 ; calc. for $\left[\mathrm{C}_{84} \mathrm{H}_{128} \mathrm{~N}_{33} \mathrm{O}_{27} \mathrm{~S}_{6}\right]^{3+}\left([\mathrm{M}+3 \mathrm{H}]^{3+}\right): 740.9322$, found: 740.9300 .

4. Colourless solid (131 $\mu \mathrm{g}, 58.8 \mathrm{nmol})$.

HPLC: $R_{t}=24.7 \mathrm{~min}$.

HR-MS (ESI): calc. for $\left[\mathrm{C}_{84} \mathrm{H}_{127} \mathrm{~N}_{33} \mathrm{O}_{27} \mathrm{~S}_{6}\right]^{2+}\left([\mathrm{M}+2 \mathrm{H}]^{2+}\right): 1110.8946$, found: 1110.8938 ; calc. for $\left[\mathrm{C}_{84} \mathrm{H}_{128} \mathrm{~N}_{33} \mathrm{O}_{27} \mathrm{~S}_{6}\right]^{3+}\left([\mathrm{M}+3 \mathrm{H}]^{3+}\right): 740.9322$, found: 740.9319 ; calc. for $\left[\mathrm{C}_{84} \mathrm{H}_{129} \mathrm{~N}_{33} \mathrm{O}_{27} \mathrm{~S}_{6}\right]^{4+}$ $\left([\mathrm{M}+4 \mathrm{H}]^{4+}\right): 555.9509$, found: 555.9497 . 


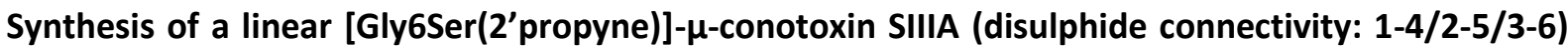
precursor (69)

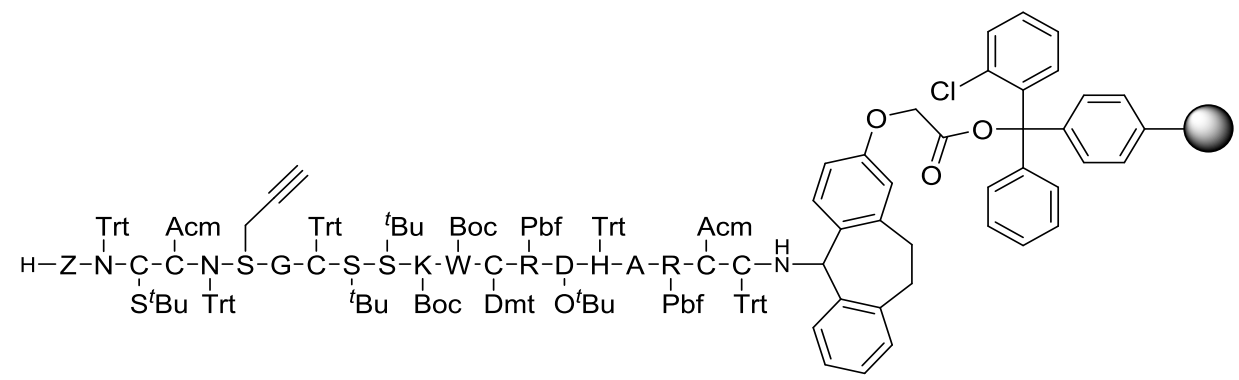

69

2-Chlorotrityl chloride resin $(0.70 \mathrm{~g}, 0.70 \mathrm{mmol}, 1-1.50 \mathrm{mmol} / \mathrm{g})$ was preloaded following SOP1. The occupancy was tested following SOP3 and determined to be $0.38 \mathrm{mmol} / \mathrm{g}$. The resin $(263 \mathrm{mg}$, $0.10 \mathrm{mmol}$ ) was loaded with the first amino acid Fmoc-L-Cys(Trt)-OH following SOP2. The peptide was synthesized following SOP4. Test cleavage was performed using SOP6/A yielding the Acm and $\mathrm{S}^{t} \mathrm{Bu}$ protected peptide $\mathbf{7 0}$.

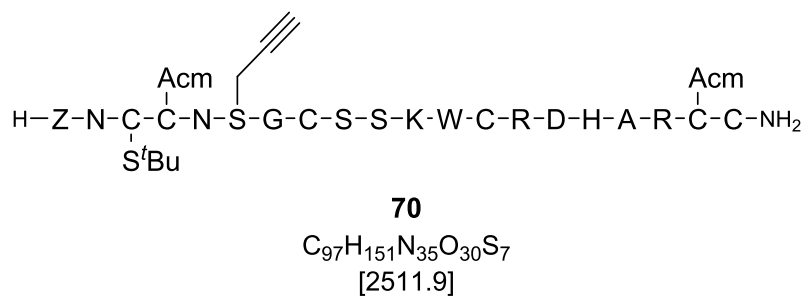

HR-MS (ESI): calc. for $\left[\mathrm{C}_{97} \mathrm{H}_{153} \mathrm{~N}_{35} \mathrm{O}_{30} \mathrm{~S}_{7}\right]^{2+}\left([\mathrm{M}+2 \mathrm{H}]^{2+}\right)$ : 1255.9778 , found: 1255.9778 ; calc. for $\left[\mathrm{C}_{97} \mathrm{H}_{154} \mathrm{~N}_{35} \mathrm{O}_{30} \mathrm{~S}_{7}\right]^{3+}\left([\mathrm{M}+3 \mathrm{H}]^{3+}\right): 837.6543$, found: 837.6546 . 


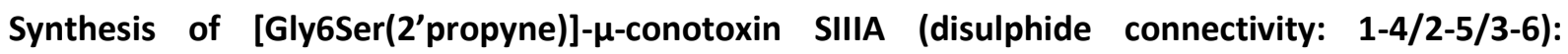
formation of the first disulphide bridge and deprotection of acid-labile protecting groups

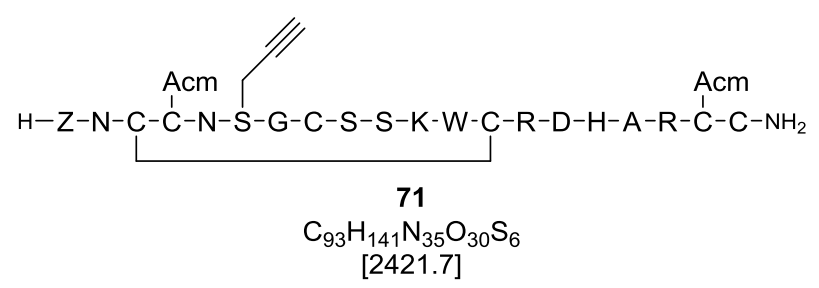

The formation of the first disulphide bridge using the linear precursor 69 (213 $\mathrm{mg}, 30.9 \mu \mathrm{mol})$ was performed following SOP7 (24 mL in steps $1-3,820 \mathrm{~mL}$ in step 4, $400 \mathrm{~mL}$ in step 5) yielding the product 71 as a colourless solid (56.3 mg, $23.2 \mu \mathrm{mol}, 75 \%$ ).

HR-MS (ESI): calc. for $\left[\mathrm{C}_{93} \mathrm{H}_{143} \mathrm{~N}_{35} \mathrm{O}_{30} \mathrm{~S}_{6}\right]^{2+}\left([\mathrm{M}+2 \mathrm{H}]^{2+}\right)$ : 1210.9527, found: 1210.9523; calc. for $\left[\mathrm{C}_{93} \mathrm{H}_{144} \mathrm{~N}_{35} \mathrm{O}_{30} \mathrm{~S}_{6}\right]^{3+}\left([\mathrm{M}+3 \mathrm{H}]^{3+}\right): 807.6375$, found: 807.6379 .

Synthesis of [Gly6Ser(2'propyne)]- $\mu$-conotoxin SIIIA (disulphide connectivity: 1-4/2-5/3-6): formation of the second disulphide bridge

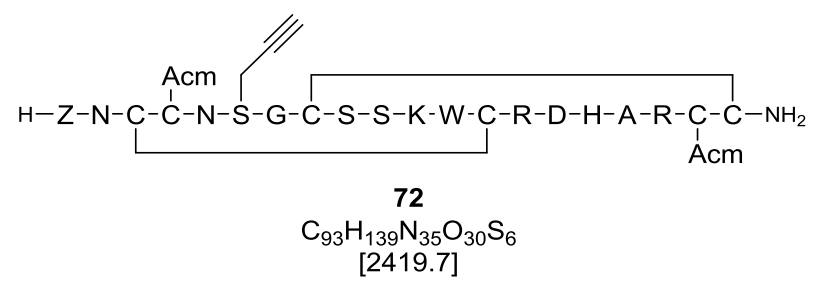

The second disulphide bridge using the crude peptide 71 ( $56.3 \mathrm{mg}, 23.2 \mu \mathrm{mol})$ was performed following SOP8 yielding the product 72 as a colourless solid (55.1 mg, $22.8 \mu \mathrm{mol}, 98 \%)$.

HR-MS (ESI): calc. for $\left[\mathrm{C}_{93} \mathrm{H}_{141} \mathrm{~N}_{35} \mathrm{O}_{30} \mathrm{~S}_{6}\right]^{2+}\left([\mathrm{M}+2 \mathrm{H}]^{2+}\right)$ : 1209.9448 , found: 1209.9414 ; calc. for $\left[\mathrm{C}_{93} \mathrm{H}_{142} \mathrm{~N}_{35} \mathrm{O}_{30} \mathrm{~S}_{6}\right]^{3+}\left([\mathrm{M}+3 \mathrm{H}]^{3+}\right): 806.9657$, found: 806.9669 . 


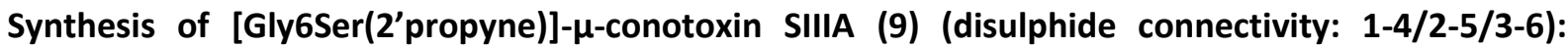
formation of the third disulphide bridge

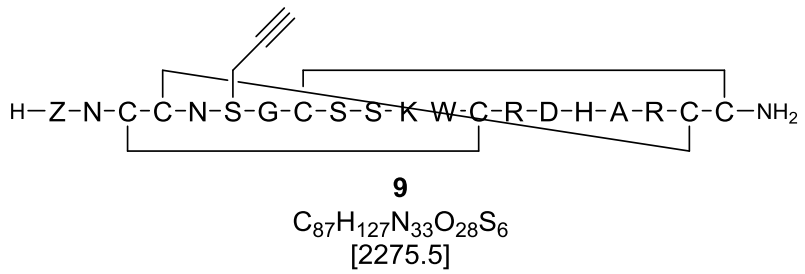

The Acm-groups were removed and the last disulphide bridge formed by dissolving the crude peptide 72 (21.3 mg, $8.80 \mu \mathrm{mol}, 1.00$ eq.) in AcOH/water (2:1, v/v, $6 \mathrm{~mL}$ ), adding Ac-L-Trp-OMe (22.9 mg, $88.0 \mu \mathrm{mol}, 10.0$ eq.) and a solution of iodine (112 mg, $440 \mu \mathrm{mol}, 50.0$ eq.) dissolved in acetic acid ( $4 \mathrm{~mL})$ and stirring for $15 \mathrm{~min}$. The reaction was quenched using a solution of L-ascorbic acid in water (495 $\mathrm{mg}$ in $1.5 \mathrm{~mL}$ water) and directly purified by preparative HPLC yielding three differently folded peptides 9 .

HPLC (preparative, A $\left(99.9 \% \mathrm{H}_{2} \mathrm{O}, 0.10 \% \mathrm{TFA}\right), \mathrm{B}\left(79.9 \% \mathrm{MeCN}, 20.0 \% \mathrm{H}_{2} \mathrm{O}, 0.10 \% \mathrm{TFA}\right)$, gradient $0-40 \% \mathrm{~B}, 30 \mathrm{~min}$ ) was utilised for all products.

1. Colourless solid $(219 \mu \mathrm{g}, 96.1 \mathrm{nmol})$.

HPLC: $R_{t}=23.7$ min.

HR-MS (ESI): calc. for $\left[\mathrm{C}_{87} \mathrm{H}_{129} \mathrm{~N}_{33} \mathrm{O}_{28} \mathrm{~S}_{6}\right]^{2+}\left([\mathrm{M}+2 \mathrm{H}]^{2+}\right): 1137.8999$, found: 1137.8996 ; calc. for $\left[\mathrm{C}_{87} \mathrm{H}_{130} \mathrm{~N}_{33} \mathrm{O}_{28} \mathrm{~S}_{6}\right]^{3+}\left([\mathrm{M}+3 \mathrm{H}]^{3+}\right): 758.9357$, found: 758.9366 ; calc. for $\left[\mathrm{C}_{87} \mathrm{H}_{131} \mathrm{~N}_{33} \mathrm{O}_{28} \mathrm{~S}_{6}\right]^{4+}$ $\left([\mathrm{M}+4 \mathrm{H}]^{4+}\right): 569.4536$, found: 569.4546 .

2. Colourless solid $(204 \mu \mathrm{g}, 89.6 \mathrm{nmol})$.

HPLC: $\mathrm{R}_{\mathrm{t}}=24.5 \mathrm{~min}$.

HR-MS (ESI): calc. for $\left[\mathrm{C}_{87} \mathrm{H}_{129} \mathrm{~N}_{33} \mathrm{O}_{28} \mathrm{~S}_{6}\right]^{2+}\left([\mathrm{M}+2 \mathrm{H}]^{2+}\right): 1137.8999$, found: 1137.9006; calc. for $\left[\mathrm{C}_{87} \mathrm{H}_{130} \mathrm{~N}_{33} \mathrm{O}_{28} \mathrm{~S}_{6}\right]^{3+}\left([\mathrm{M}+3 \mathrm{H}]^{3+}\right): 758.9357$, found: 758.9371 ; calc. for $\left[\mathrm{C}_{87} \mathrm{H}_{131} \mathrm{~N}_{33} \mathrm{O}_{28} \mathrm{~S}_{6}\right]^{4+}$ $\left([\mathrm{M}+4 \mathrm{H}]^{4+}\right): 569.4536$, found: 569.4554 .

3. Colourless solid $(484 \mu \mathrm{g}, 213 \mathrm{nmol})$.

HPLC: $\mathrm{R}_{\mathrm{t}}=26.5 \mathrm{~min}$.

HR-MS (ESI): calc. for $\left[\mathrm{C}_{87} \mathrm{H}_{129} \mathrm{~N}_{33} \mathrm{O}_{28} \mathrm{~S}_{6}\right]^{2+}\left([\mathrm{M}+2 \mathrm{H}]^{2+}\right): 1137.8999$, found: 1137.9003 ; calc. for $\left[\mathrm{C}_{87} \mathrm{H}_{130} \mathrm{~N}_{33} \mathrm{O}_{28} \mathrm{~S}_{6}\right]^{3+}\left([\mathrm{M}+3 \mathrm{H}]^{3+}\right): 758.9357$, found: 758.9369; calc. for $\left[\mathrm{C}_{87} \mathrm{H}_{131} \mathrm{~N}_{33} \mathrm{O}_{28} \mathrm{~S}_{6}\right]^{4+}$ $\left([M+4 H]^{4+}\right): 569.4536$, found: 569.4552 . 


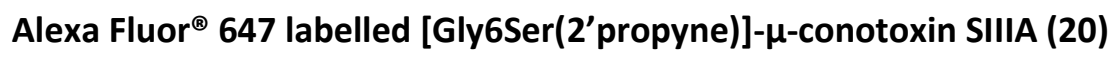

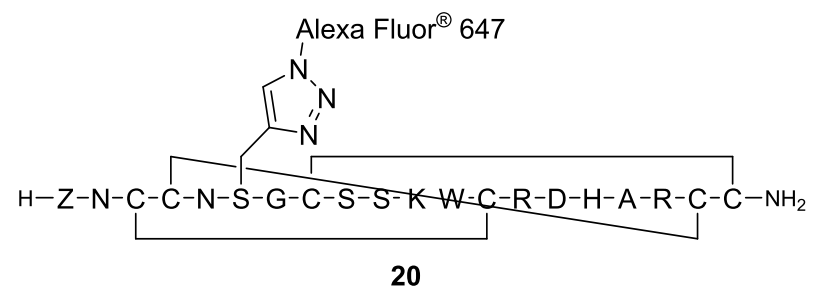

Based on the procedure of EMPTING et al., to [Gly6Ser(2'propyne)]- $\mu$-SIIIA (9) $\left(R_{t}=24.5 \mathrm{~min}, 12.5 \mu \mathrm{g}\right.$, $5.50 \mathrm{nmol}, 1.00$ eq.) and Alexa Fluor ${ }^{\circledR} 647$ azide triethylammonium salt ( $4.68 \mu \mathrm{L}, 5.50 \mathrm{nmol}, 1.00$ eq., $0.50 \mathrm{mg}$ in $500 \mu \mathrm{L}$ degassed and argon-flushed water) the catalyst solution $(27.5 \mu \mathrm{L}, 1.90 \mathrm{~mL}$ degassed and argon-flushed water, $0.40 \mathrm{mg}$ copper (II) sulphate pentahydrate (final amount: $189 \mathrm{nmol}, 4.00 \mathrm{eq}$. ), $100 \mu \mathrm{L} 4 \mathrm{~mm}$ sodium ascorbate solution (final amount: $5.50 \mathrm{nmol}, 1.00$ eq.), $0.55 \mu \mathrm{L}$ DIPEA (final amount: $378 \mathrm{nmol}, 8.00 \mathrm{eq}$.)) was added and the reaction mixture shaken at $\mathrm{rt}$ for $2 \mathrm{~d}$. The reaction mixture was directly purified via analytical HPLC yielding the product 20 as a colourless solid (1.00 nmol, 18\%).

HPLC (analytical, A $\left(99.9 \% \mathrm{H}_{2} \mathrm{O}, 0.10 \% \mathrm{TFA}\right), \mathrm{B}\left(79.9 \% \mathrm{MeCN}, 20.0 \% \mathrm{H}_{2} \mathrm{O}, 0.10 \% \mathrm{TFA}\right)$, gradient $0-100 \% \mathrm{~B}, 30 \mathrm{~min}): \mathrm{R}_{t}=14.4 \mathrm{~min}$.

MS (ESI): calc. for $\left([\mathrm{M}+3 \mathrm{H}]^{3+}\right)$ : 1014.4 (based on the Alexa Fluor ${ }^{\circledR} 647$ azide HR-MS(ESI) $\left.([\mathrm{M}-1 \mathrm{H}]]^{-}\right)$: 765.3), found: 1014.4 ; calc. for $\left([\mathrm{M}+2 \mathrm{H}+\mathrm{Na}]^{3+}\right)$ : 1021.7, found: 1021.7 .

Synthesis of a linear [Ser9Ser(2'propyne)]- $\mu$-conotoxin SIIIA (disulphide connectivity: 1-4/2-5/3-6) precursor (73)

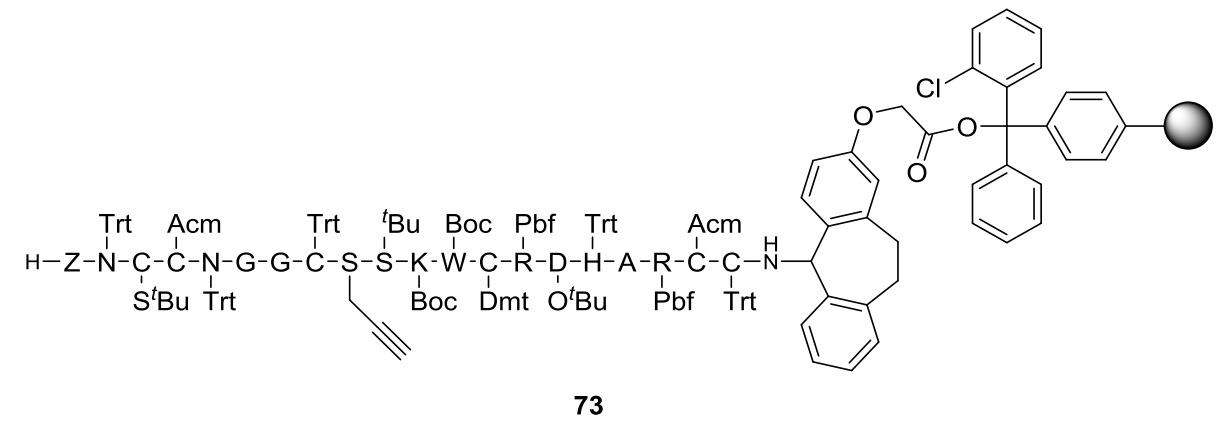

2-Chlorotrityl chloride resin $(0.70 \mathrm{~g}, 0.70 \mathrm{mmol}, 1-1.50 \mathrm{mmol} / \mathrm{g})$ was preloaded following SOP1. The occupancy was tested following SOP3 and determined to be $0.38 \mathrm{mmol} / \mathrm{g}$. The resin $(263 \mathrm{mg}$, $0.10 \mathrm{mmol}$ ) was loaded with the first amino acid Fmoc-L-Cys(Trt)-OH following SOP2. The peptide was 
synthesized following SOP4. Test cleavage was performed using SOP6/A yielding the Acm and $S^{t} B u$ protected peptide 74 .

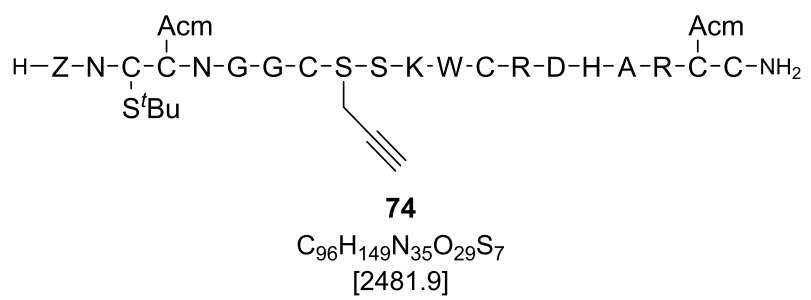

HR-MS (ESI): calc. for $\left[\mathrm{C}_{96} \mathrm{H}_{151} \mathrm{~N}_{35} \mathrm{O}_{29} \mathrm{~S}_{7}\right]^{2+}\left([\mathrm{M}+2 \mathrm{H}]^{2+}\right)$ : 1240.9725 , found: 1240.9721 ; calc. for $\left[\mathrm{C}_{96} \mathrm{H}_{152} \mathrm{~N}_{35} \mathrm{O}_{29} \mathrm{~S}_{7}\right]^{3+}\left([\mathrm{M}+3 \mathrm{H}]^{3+}\right): 827.6508$, found: 827.6512 .

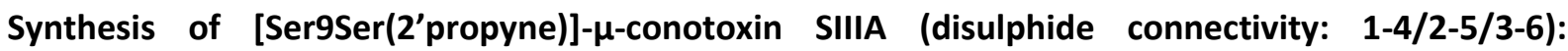
formation of the first disulphide bridge and deprotection of acid-labile protecting groups

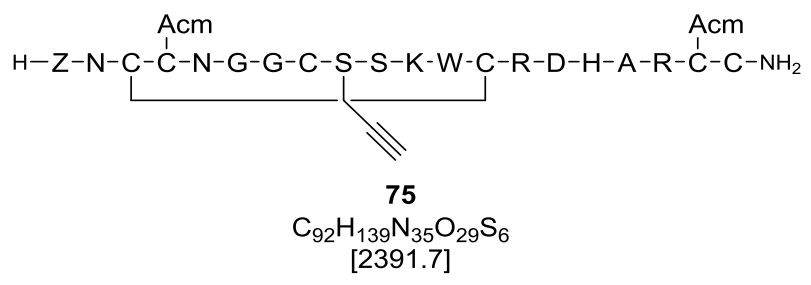

The formation of the first disulphide bridge using the linear precursor $73(213 \mathrm{mg}, 31.3 \mu \mathrm{mol})$ was performed following SOP7 (24 mL in steps $1-3,820 \mathrm{~mL}$ in step 4, $400 \mathrm{~mL}$ in step 5) yielding the product 75 as a colourless solid (53.6 mg, $22.4 \mu \mathrm{mol}, 72 \%)$.

HR-MS (ESI): calc. for $\left[\mathrm{C}_{92} \mathrm{H}_{141} \mathrm{~N}_{35} \mathrm{O}_{29} \mathrm{~S}_{6}\right]^{2+}\left([\mathrm{M}+2 \mathrm{H}]^{2+}\right)$ : 1195.9474 , found: 1195.9463 ; calc. for $\left[\mathrm{C}_{92} \mathrm{H}_{142} \mathrm{~N}_{35} \mathrm{O}_{29} \mathrm{~S}_{6}\right]^{3+}\left([\mathrm{M}+3 \mathrm{H}]^{3+}\right): 797.6340$, found: 797.6350 . 


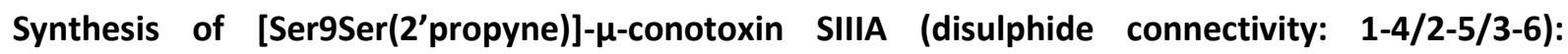
formation of the second disulphide bridge

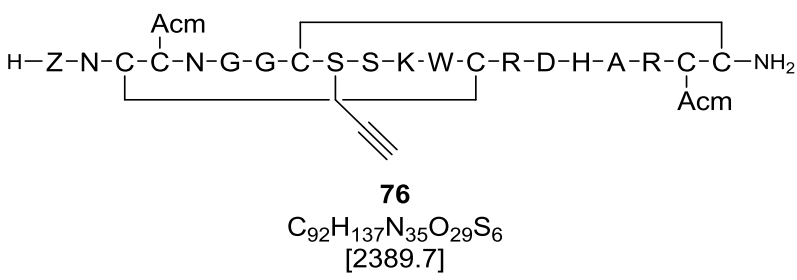

The second disulphide bridge using the crude peptide 75 (53.6 mg, $22.4 \mu \mathrm{mol})$ was performed following SOP8 yielding the product 76 as a colourless solid ( $52.2 \mathrm{mg}, 21.8 \mu \mathrm{mol}, 97 \%)$.

HR-MS (ESI): calc. for $\left[\mathrm{C}_{92} \mathrm{H}_{139} \mathrm{~N}_{35} \mathrm{O}_{29} \mathrm{~S}_{6}\right]^{2+}\left([\mathrm{M}+2 \mathrm{H}]^{2+}\right)$ : 1194.9396, found: 1194.9381; calc. for $\left[\mathrm{C}_{92} \mathrm{H}_{140} \mathrm{~N}_{35} \mathrm{O}_{29} \mathrm{~S}_{6}\right]^{3+}\left([\mathrm{M}+3 \mathrm{H}]^{3+}\right):$ 796.9621, found: 796.9619 .

Synthesis of [Ser9Ser(2'propyne)]- $\mu$-conotoxin SIIIA (10) (disulphide connectivity: 1-4/2-5/3-6): formation of the third disulphide bridge

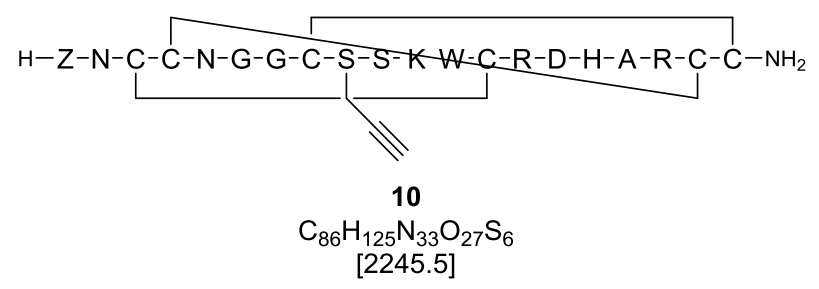

The Acm-groups were removed and the last disulphide bridge formed by dissolving the crude peptide 76 (20.3 mg, $8.49 \mu \mathrm{mol}, 1.00$ eq.) in AcOH/water (2:1, v/v, $6 \mathrm{~mL}$ ), adding Ac-L-Trp-OMe (22.1 mg, $84.9 \mu \mathrm{mol}, 10.0$ eq.) and a solution of iodine (108 mg, $425 \mu \mathrm{mol}, 50.0$ eq.) dissolved in acetic acid ( $4 \mathrm{~mL})$ and stirring for $15 \mathrm{~min}$. The reaction was quenched using a solution of L-ascorbic acid in water (495 $\mathrm{mg}$ in $1.5 \mathrm{~mL}$ water) and directly purified by preparative HPLC yielding three differently folded peptides 10.

HPLC (preparative, A $\left(99.9 \% \mathrm{H}_{2} \mathrm{O}, 0.10 \%\right.$ TFA), B (79.9\% $\mathrm{MeCN}, 20.0 \% \mathrm{H}_{2} \mathrm{O}, 0.10 \%$ TFA), gradient $0-40 \% \mathrm{~B}, 30 \mathrm{~min}$ ) was utilised for all products.

1. Colourless solid ( $371 \mu \mathrm{g}, 165 \mathrm{nmol})$. HPLC: $R_{t}=23.9 \min$. 
HR-MS (ESI): calc. for $\left[\mathrm{C}_{86} \mathrm{H}_{127} \mathrm{~N}_{33} \mathrm{O}_{27} \mathrm{~S}_{6}\right]^{2+}\left([\mathrm{M}+2 \mathrm{H}]^{2+}\right): 1122.8946$, found: 1122.8946 ; calc. for $\left[\mathrm{C}_{86} \mathrm{H}_{128} \mathrm{~N}_{33} \mathrm{O}_{27} \mathrm{~S}_{6}\right]^{3+}\left([\mathrm{M}+3 \mathrm{H}]^{3+}\right): 748.9322$, found: 748.9334; calc. for $\left[\mathrm{C}_{86} \mathrm{H}_{129} \mathrm{~N}_{33} \mathrm{O}_{27} \mathrm{~S}_{6}\right]^{4+}$ $\left([\mathrm{M}+4 \mathrm{H}]^{4+}\right): 561.9509$, found: 561.9524 .

2. Colourless solid $(497 \mu \mathrm{g}, 221 \mathrm{nmol})$.

HPLC: $R_{t}=24.1 \mathrm{~min}$.

HR-MS (ESI): calc. for $\left[\mathrm{C}_{86} \mathrm{H}_{127} \mathrm{~N}_{33} \mathrm{O}_{27} \mathrm{~S}_{6}\right]^{2+}\left([\mathrm{M}+2 \mathrm{H}]^{2+}\right): 1122.8946$, found: 1122.8946 ; calc. for $\left[\mathrm{C}_{86} \mathrm{H}_{128} \mathrm{~N}_{33} \mathrm{O}_{27} \mathrm{~S}_{6}\right]^{3+}\left([\mathrm{M}+3 \mathrm{H}]^{3+}\right): 748.9322$, found: 748.9337; calc. for $\left[\mathrm{C}_{86} \mathrm{H}_{129} \mathrm{~N}_{33} \mathrm{O}_{27} \mathrm{~S}_{6}\right]^{4+}$ $\left([M+4 H]^{4+}\right): 561.9509$, found: 561.9526 .

3. Colourless solid (499 $\mu \mathrm{g}, 222 \mathrm{nmol})$.

HPLC: $R_{t}=26.2 \mathrm{~min}$.

HR-MS (ESI): calc. for $\left[\mathrm{C}_{86} \mathrm{H}_{127} \mathrm{~N}_{33} \mathrm{O}_{27} \mathrm{~S}_{6}\right]^{2+}\left([\mathrm{M}+2 \mathrm{H}]^{2+}\right): 1122.8946$, found: 1122.8950; calc. for $\left[\mathrm{C}_{86} \mathrm{H}_{128} \mathrm{~N}_{33} \mathrm{O}_{27} \mathrm{~S}_{6}\right]^{3+}\left([\mathrm{M}+3 \mathrm{H}]^{3+}\right): 748.9322$, found: 748.9333; calc. for $\left[\mathrm{C}_{86} \mathrm{H}_{129} \mathrm{~N}_{33} \mathrm{O}_{27} \mathrm{~S}_{6}\right]^{4+}$ $\left.([\mathrm{M}+4 \mathrm{H}]]^{4+}\right): 561.9509$, found: 561.9527 .

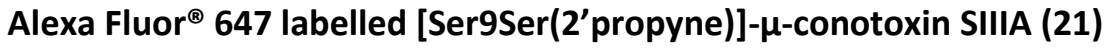

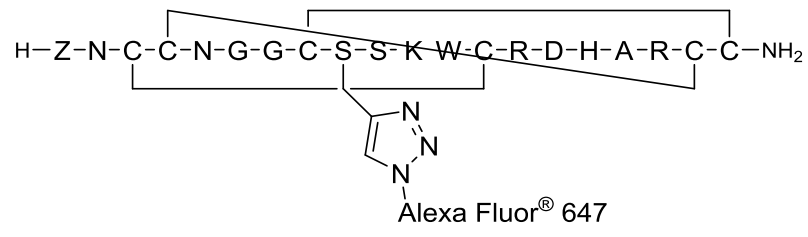

21

Based on the procedure of EMPTING et al., to [Ser9Ser(2'propyne)]- $\mu$-SIIIA (10) $\left(R_{t}=23.9 \mathrm{~min}, 106 \mu \mathrm{g}\right.$, $47.3 \mathrm{nmol}, 1.00$ eq.) and Alexa Fluor ${ }^{\circledR} 647$ azide triethylammonium salt ( $40.2 \mu \mathrm{L}, 47.3 \mathrm{nmol}, 1.00$ eq., $0.50 \mathrm{mg}$ in $500 \mu \mathrm{L}$ degassed and argon-flushed water) the catalyst solution $(237 \mu \mathrm{L}, 1.90 \mathrm{~mL}$ degassed and argon-flushed water, $0.40 \mathrm{mg}$ copper (II) sulphate pentahydrate (final amount: $189 \mathrm{nmol}, 4.00$ eq.), $100 \mu \mathrm{L} 4 \mathrm{mM}$ sodium ascorbate solution (final amount: $47.3 \mathrm{nmol}, 1.00$ eq.), $0.55 \mu \mathrm{L}$ DIPEA (final amount: $378 \mathrm{nmol}, 8.00$ eq.)) was added and the reaction mixture shaken at $\mathrm{rt}$ for $2 \mathrm{~d}$. The reaction mixture was directly purified via analytical HPLC yielding two products $\mathbf{2 1}$ with identical mass.

1. Blue solid (1.18 nmol, $3 \%)$.

HPLC (analytical, A (99.9\% $\left.\mathrm{H}_{2} \mathrm{O}, 0.10 \% \mathrm{TFA}\right)$, B (79.9\% MeCN, 20.0\% $\left.\mathrm{H}_{2} \mathrm{O}, 0.10 \% \mathrm{TFA}\right)$, gradient $10-40 \%$ B, $30 \mathrm{~min}): R_{t}=25.2 \mathrm{~min}$.

MS (MALDI): calc. for $\left([\mathrm{M}+\mathrm{H}]^{+}\right)$: 3011.1 (based on the Alexa Fluor ${ }^{\circledast} 647$ azide HR-MS(ESI) ([M-1H] $\left.]^{-}\right)$: 765.3), found: 3011.2 . 
2. Blue solid (4.03 nmol, $9 \%)$.

HPLC (analytical, A (99.9\% $\left.\mathrm{H}_{2} \mathrm{O}, 0.10 \% \mathrm{TFA}\right), \mathrm{B}\left(79.9 \% \mathrm{MeCN}, 20.0 \% \mathrm{H}_{2} \mathrm{O}, 0.10 \%\right.$ TFA), gradient $10-40 \% \mathrm{~B}, 30 \mathrm{~min}): \mathrm{R}_{t}=25.8 \mathrm{~min}$.

MS (MALDI): calc. for $\left([\mathrm{M}+\mathrm{H}]^{+}\right)$: 3011.1 (based on the Alexa Fluor ${ }^{\circledR} 647$ azide HR-MS(ESI) ([M-1H]'): 765.3), found: 3011.2 .

Synthesis of a linear [Gly6Cys(Mbzl)]- $\mu$-conotoxin SIIIA (disulphide connectivity: 1-4/2-5/3-6) precursor (22)

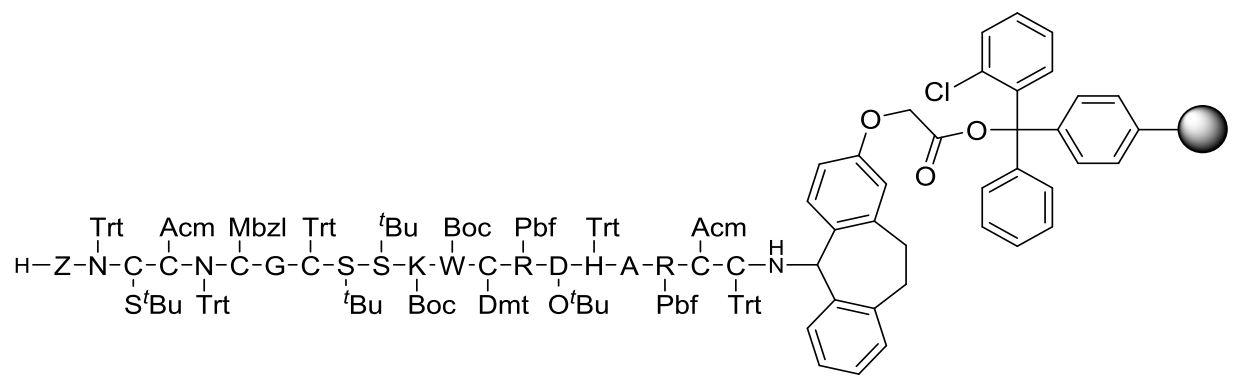

22

2-Chlorotrityl chloride resin $(0.70 \mathrm{~g}, 0.70 \mathrm{mmol}, 1-1.50 \mathrm{mmol} / \mathrm{g})$ was preloaded following SOP1. The occupancy was tested following SOP3 and determined to be $0.47 \mathrm{mmol} / \mathrm{g}$. The resin $(213 \mathrm{mg}$, $0.10 \mathrm{mmol}$ ) was loaded with the first amino acid Fmoc-L-Cys(Trt)-OH following SOP2. The peptide was synthesized following SOP4. Product $\mathbf{2 2}$ was directly used for the next step.

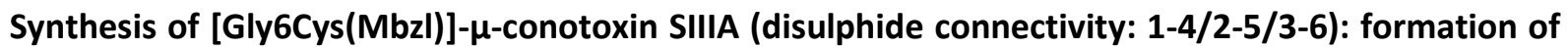
the first disulphide bridge and deprotection of acid-labile protecting groups

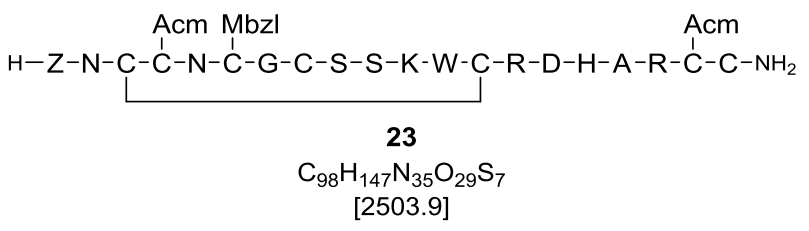

The formation of the first disulphide bridge using the linear precursor $22(172 \mathrm{mg}, 26.6 \mu \mathrm{mol})$ was performed following SOP7 (24 mL in steps $1-3,820 \mathrm{~mL}$ in step 4, $400 \mathrm{~mL}$ in step 5) yielding the product 23 as a colourless solid ( $33.7 \mathrm{mg}, 13.5 \mu \mathrm{mol}, 51 \%)$. 
HR-MS (ESI): calc. for $\left[\mathrm{C}_{98} \mathrm{H}_{149} \mathrm{~N}_{35} \mathrm{O}_{29} \mathrm{~S}_{7}\right]^{2+}\left([\mathrm{M}+2 \mathrm{H}]^{2+}\right): 1251.9647$, found: 1251.9641 ; calc. for $\left[\mathrm{C}_{98} \mathrm{H}_{150} \mathrm{~N}_{35} \mathrm{O}_{29} \mathrm{~S}_{7}\right]^{3+}\left([\mathrm{M}+3 \mathrm{H}]^{3+}\right): 834.9789$, found: 834.9802; calc. for $\left[\mathrm{C}_{98} \mathrm{H}_{151} \mathrm{~N}_{35} \mathrm{O}_{29} \mathrm{~S}_{7}\right]^{4+}\left([\mathrm{M}+4 \mathrm{H}]^{4+}\right)$ : 626.4860 , found: 626.4871 .

Synthesis of [Gly6Cys(Mbzl)]- $\mu$-conotoxin SIIIA (disulphide connectivity: 1-4/2-5/3-6): formation of the second disulphide bridge

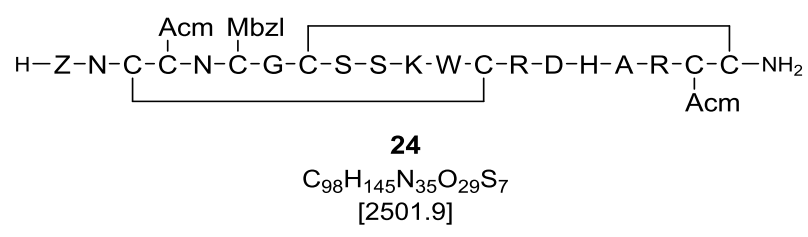

The second disulphide bridge using the crude peptide $23(67.4 \mathrm{mg}, 26.9 \mu \mathrm{mol})$ was performed following SOP8 yielding the product 24 as a colourless solid ( $24.1 \mathrm{mg}, 9.63 \mu \mathrm{mol}, 36 \%$ ).

HR-MS (ESI): calc. for $\left[\mathrm{C}_{98} \mathrm{H}_{147} \mathrm{~N}_{35} \mathrm{O}_{29} \mathrm{~S}_{7}\right]^{2+}\left([\mathrm{M}+2 \mathrm{H}]^{2+}\right)$ : 1250.9569, found: 1250.9569; calc. for $\left[\mathrm{C}_{98} \mathrm{H}_{148} \mathrm{~N}_{35} \mathrm{O}_{29} \mathrm{~S}_{7}\right]^{3+}\left([\mathrm{M}+3 \mathrm{H}]^{3+}\right): 834.3070$, found: 834.3081 .

Synthesis of [Gly6Cys(Mbzl)]- $\mu$-conotoxin SIIIA (25) (disulphide connectivity: 1-4/2-5/3-6): formation of the third disulphide bridge

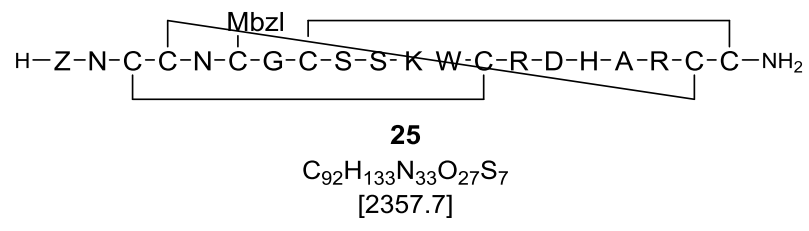

The Acm-groups were removed and the last disulphide bridge formed by dissolving the crude peptide 24 (10.0 mg, $4.00 \mu \mathrm{mol}, 1.00$ eq.) in AcOH/water (2:1, v/v, $3 \mathrm{~mL}$ ), adding Ac-L-Trp-OMe (10.4 mg, $40.0 \mu \mathrm{mol}, 10.0$ eq.) and a solution of iodine ( $50 \mathrm{mg}, 200 \mu \mathrm{mol}, 50.0$ eq.) dissolved in acetic acid ( $2 \mathrm{~mL})$ and stirring for $1 \mathrm{~h}$ at $\mathrm{rt}$. The solvent was removed under reduced pressure. The crude peptide was dissolved in a small amount of TFA and precipitated with cold diethyl ether, isolated by centrifugation (9000 rpm, $2.5 \mathrm{~min},-10^{\circ} \mathrm{C}$ ), washed three times with cold diethyl ether followed by centrifugation and dried overnight under reduced pressure to yield the crude product $\mathbf{2 5}$ as a colourless solid $(2.11 \mathrm{mg}$, $0.89 \mu \mathrm{mol}, 22 \%)$.

HR-MS (ESI): calc. for $\left[\mathrm{C}_{92} \mathrm{H}_{135} \mathrm{~N}_{33} \mathrm{O}_{27} \mathrm{~S}_{7}\right]^{2+}\left([\mathrm{M}+2 \mathrm{H}]^{2+}\right)$ : 1178.9120, found: 1178.9124; calc. for $\left[\mathrm{C}_{92} \mathrm{H}_{136} \mathrm{~N}_{33} \mathrm{O}_{27} \mathrm{~S}_{7}\right]^{3+}\left([\mathrm{M}+3 \mathrm{H}]^{3+}\right):$ 786.2771, found: 786.2783 . 
Synthesis of a linear $C$-terminal elongated $\mu$-conotoxin SIIIA (disulphide connectivity: 1-4/2-5/3-6) precursor (77)

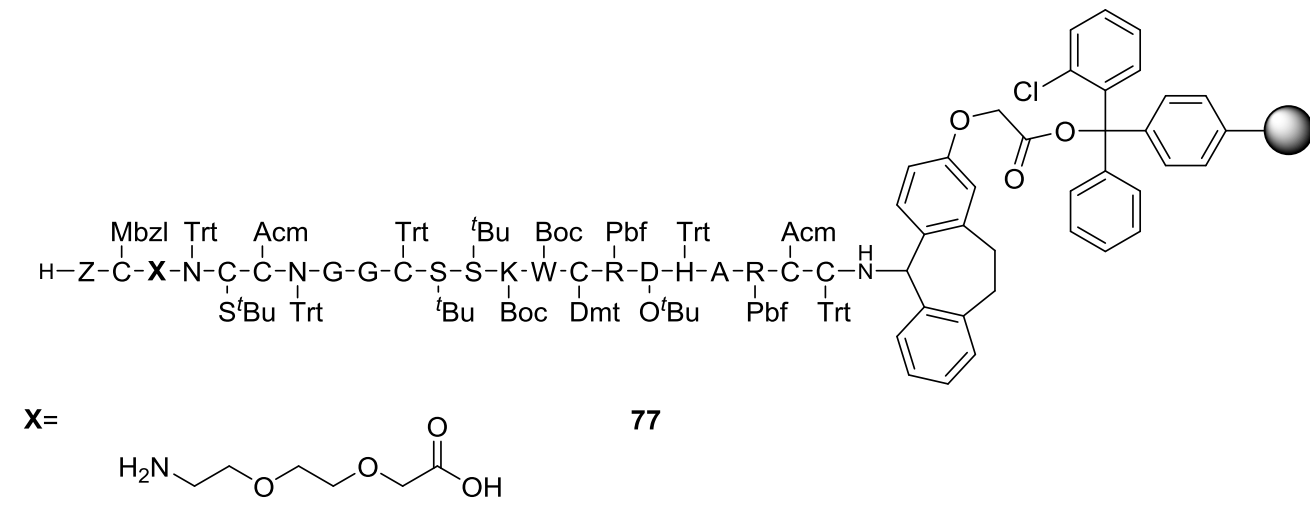

2-Chlorotrityl chloride resin $(0.70 \mathrm{~g}, 0.70 \mathrm{mmol}, 1-1.50 \mathrm{mmol} / \mathrm{g})$ was preloaded following SOP1. The occupancy was tested following SOP3 and determined to be $0.47 \mathrm{mmol} / \mathrm{g}$. The resin $(213 \mathrm{mg}$, $0.10 \mathrm{mmol}$ ) was loaded with the first amino acid Fmoc-L-Cys(Trt)-OH following SOP2. The peptide was synthesized following SOP4. Product $\mathbf{7 7}$ was directly used for the next step.

Synthesis of $C$-terminal elongated $\mu$-conotoxin SIIIA (disulphide connectivity: 1-4/2-5/3-6): formation of the first disulphide bridge and deprotection of acid-labile protecting groups

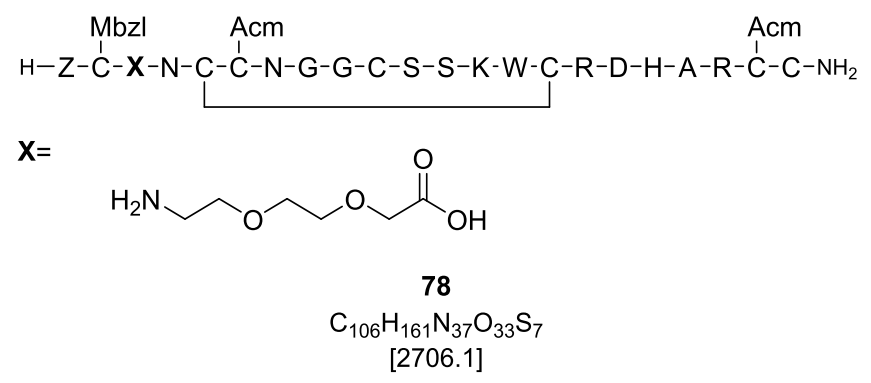

The formation of the first disulphide bridge using the linear precursor $77(279 \mathrm{mg}, 34.7 \mu \mathrm{mol})$ was performed following SOP7 (24 mL in steps $1-3,820 \mathrm{~mL}$ in step 4, $400 \mathrm{~mL}$ in step 5) yielding the product 78 as a colourless solid (50.4 mg, $18.6 \mu \mathrm{mol}, 54 \%$ ), which was directly used for the next step. 
Synthesis of $C$-terminal elongated $\mu$-conotoxin SIIIA (disulphide connectivity: 1-4/2-5/3-6): formation of the second disulphide bridge

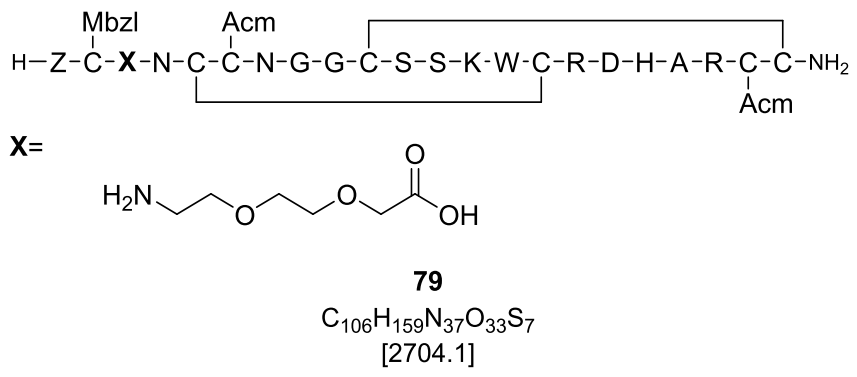

The second disulphide bridge using the crude peptide 78 (101 mg, $37.3 \mu \mathrm{mol})$ was performed following SOP8 yielding the product 79 as a colourless solid ( $8.20 \mathrm{mg}, 3.47 \mu \mathrm{mol}, 9 \%)$.

HR-MS (ESI): calc. for $\left[\mathrm{C}_{106} \mathrm{H}_{161} \mathrm{~N}_{37} \mathrm{O}_{33} \mathrm{~S}_{7}\right]^{2+}\left([\mathrm{M}+2 \mathrm{H}]^{2+}\right)$ : 1352.0046, found: 1352.0041; calc. for $\left[\mathrm{C}_{106} \mathrm{H}_{162} \mathrm{~N}_{37} \mathrm{O}_{33} \mathrm{~S}_{7}\right]^{3+}\left([\mathrm{M}+3 \mathrm{H}]^{3+}\right):$ 901.6721, found: 901.6722 .

Synthesis of $C$-terminal elongated $\mu$-conotoxin SIIIA 26 (disulphide connectivity: 1-4/2-5/3-6): formation of the third disulphide bridge

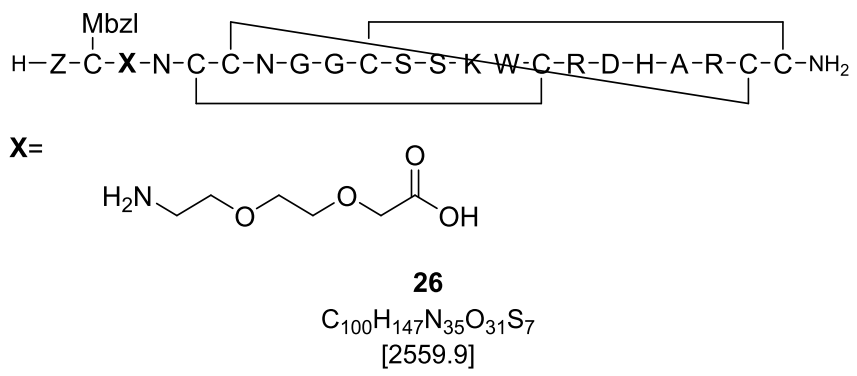

The Acm-groups were removed and the last disulphide bridge formed by dissolving the crude peptide 79 (8.20 mg, $3.03 \mu \mathrm{mol}, 1.00$ eq.) in AcOH/water (2:1, v/v, $4.50 \mathrm{~mL})$, adding Ac-L-Trp-OMe (7.80 mg, $30.3 \mu \mathrm{mol}, 10.0$ eq.) and a solution of iodine $(38.5 \mathrm{mg}, 150 \mu \mathrm{mol}, 50.0$ eq.) dissolved in acetic acid $(3 \mathrm{~mL}$ ) and stirring for $15 \mathrm{~min}$. The solvent was removed under reduced pressure. The crude peptide was dissolved in a small amount of TFA and precipitated with cold diethyl ether, isolated by centrifugation (9000 rpm, $2.5 \mathrm{~min},-10^{\circ} \mathrm{C}$ ), washed three times with cold diethyl ether followed by centrifugation and dried overnight under reduced pressure. The crude peptide $\mathbf{2 6}$ was purified by preparative HPLC yielding a colourless solid $(0.10 \mathrm{mg}, 39.1 \mathrm{nmol}, 1 \%)$. 
HPLC (preparative, A $\left(99.9 \% \mathrm{H}_{2} \mathrm{O}, 0.10 \%\right.$ TFA), B (79.9\% $\left.\mathrm{MeCN}, 20.0 \% \mathrm{H}_{2} \mathrm{O}, 0.10 \% \mathrm{TFA}\right)$, gradient $5-50 \% \mathrm{~B}, 30 \mathrm{~min}): \mathrm{R}_{\mathrm{t}}=26.8 \mathrm{~min}$.

HR-MS (ESI): calc. for $\left[\mathrm{C}_{100} \mathrm{H}_{149} \mathrm{~N}_{35} \mathrm{O}_{31} \mathrm{~S}_{7}\right]^{2+}\left([\mathrm{M}+2 \mathrm{H}]^{2+}\right)$ : 1279.9596, found: 1279.9580 ; calc. for $\left[\mathrm{C}_{100} \mathrm{H}_{150} \mathrm{~N}_{35} \mathrm{O}_{31} \mathrm{~S}_{7}\right]^{3+}\left([\mathrm{M}+3 \mathrm{H}]^{3+}\right): 853.6422$, found: 853.6428 .

Synthesis of a linear $\mu$-conotoxin SIIIA (disulphide connectivity: 1-4/2-5/3-6) precursor (80)

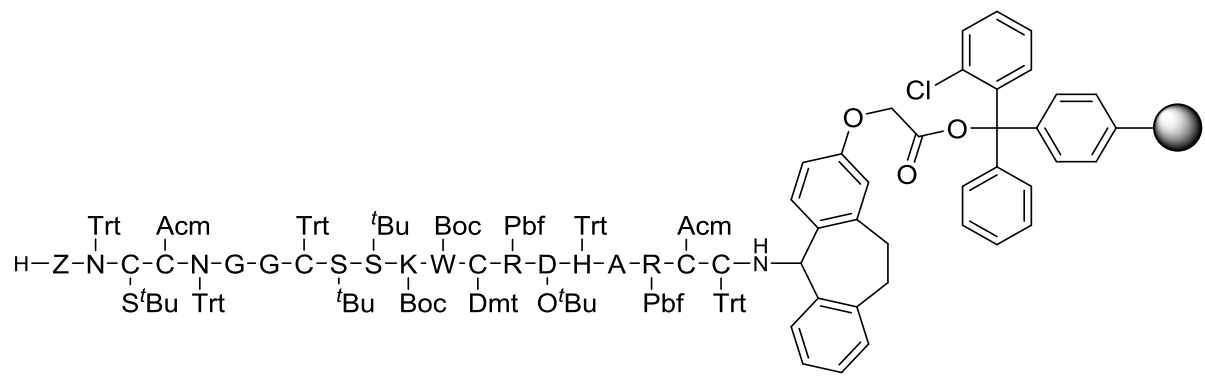

80

2-Chlorotrityl chloride resin $(0.70 \mathrm{~g}, 0.70 \mathrm{mmol}, 1-1.50 \mathrm{mmol} / \mathrm{g})$ was preloaded following SOP1. The occupancy was tested following SOP3 and determined to be $0.36 \mathrm{mmol} / \mathrm{g}$. The resin $(278 \mathrm{mg}$, $0.10 \mathrm{mmol}$ ) was loaded with the first amino acid Fmoc-L-Cys(Trt)-OH following SOP2. The peptide was synthesized following SOP4. Test cleavage was performed using SOP6/A yielding the Acm and $S^{t} B u$ protected peptide $\mathbf{8 1}$.

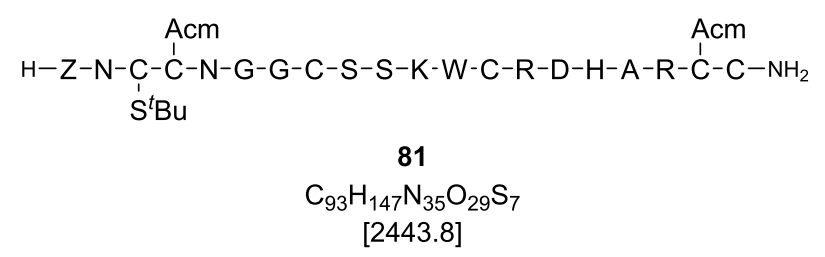

HR-MS (ESI): calc. for $\left[\mathrm{C}_{93} \mathrm{H}_{149} \mathrm{~N}_{35} \mathrm{O}_{29} \mathrm{~S}_{7}\right]^{2+}\left([\mathrm{M}+2 \mathrm{H}]^{2+}\right)$ : 1221.9647, found: 1221.9652; calc. for $\left[\mathrm{C}_{93} \mathrm{H}_{150} \mathrm{~N}_{35} \mathrm{O}_{29} \mathrm{~S}_{7}\right]^{3+}\left([\mathrm{M}+3 \mathrm{H}]^{3+}\right): 814.9789$, found: 814.9795; calc. for $\left[\mathrm{C}_{93} \mathrm{H}_{151} \mathrm{~N}_{35} \mathrm{O}_{29} \mathrm{~S}_{7}\right]^{4+}\left([\mathrm{M}+4 \mathrm{H}]^{4+}\right)$ : 611.4860, found: 611.4863 . 
Synthesis of $\mu$-conotoxin SIIIA (disulphide connectivity: 1-4/2-5/3-6): formation of the first disulphide bridge and deprotection of acid-labile protecting groups

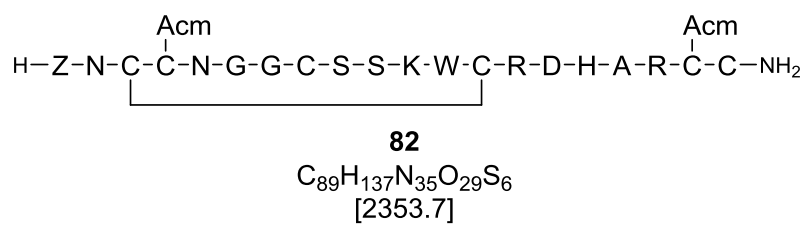

The formation of the first disulphide bridge using the linear precursor 80 (495 mg, $28.9 \mu \mathrm{mol}$ ) was performed following SOP7 (6 mL in steps 1-3, $205 \mathrm{~mL}$ in step 4, $100 \mathrm{~mL}$ in step 5) yielding the product 82 as a colourless solid (55.1 mg, $23.4 \mu \mathrm{mol}, 81 \%)$.

HR-MS (ESI): calc. for $\left[\mathrm{C}_{89} \mathrm{H}_{139} \mathrm{~N}_{35} \mathrm{O}_{29} \mathrm{~S}_{6}\right]^{2+}\left([\mathrm{M}+2 \mathrm{H}]^{2+}\right)$ : 1176.9396 , found: 1176.9403 ; calc. for $\left[\mathrm{C}_{89} \mathrm{H}_{140} \mathrm{~N}_{35} \mathrm{O}_{29} \mathrm{~S}_{6}\right]^{3+}\left([\mathrm{M}+3 \mathrm{H}]^{3+}\right)$ : 784.9621, found: 784.9614 .

Synthesis of $\mu$-conotoxin SIIIA (disulphide connectivity: 1-4/2-5/3-6): formation of the second disulphide bridge

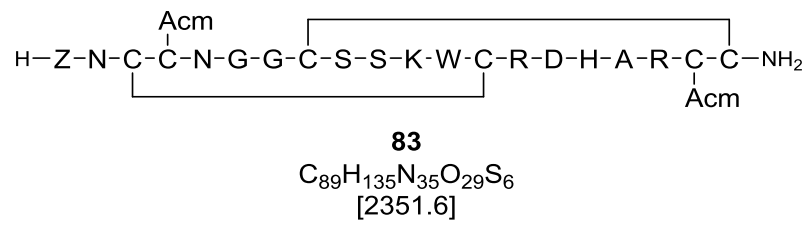

The second disulphide bridge using the crude peptide $82(55.1 \mathrm{mg}, 23.4 \mu \mathrm{mol})$ was performed following SOP8 yielding the product 83 as a colourless solid (40.4 mg, $17.2 \mu \mathrm{mol}, 73 \%$ ).

HR-MS (ESI): calc. for $\left[\mathrm{C}_{89} \mathrm{H}_{137} \mathrm{~N}_{35} \mathrm{O}_{29} \mathrm{~S}_{6}\right]^{2+}\left([\mathrm{M}+2 \mathrm{H}]^{2+}\right)$ : 1175.9317, found: 1175.9323; calc. for $\left[\mathrm{C}_{89} \mathrm{H}_{138} \mathrm{~N}_{35} \mathrm{O}_{29} \mathrm{~S}_{6}\right]^{3+}\left([\mathrm{M}+3 \mathrm{H}]^{3+}\right): 784.2902$, found: 784.2913 ; calc. for $\left[\mathrm{C}_{89} \mathrm{H}_{139} \mathrm{~N}_{35} \mathrm{O}_{29} \mathrm{~S}_{6}\right]^{4+}\left([\mathrm{M}+4 \mathrm{H}]^{4+}\right)$ : 588.4695, found: 588.4698 . 
Synthesis of $\mu$-conotoxin SIIIA 3 (disulphide connectivity: 1-4/2-5/3-6): formation of the third disulphide bridge

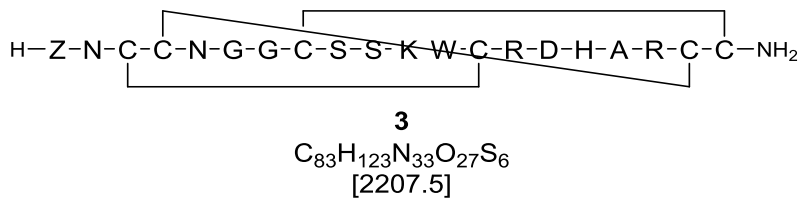

The Acm-groups were removed and the last disulphide bridge formed by dissolving the crude peptide 83 (11.4 mg, $4.85 \mu \mathrm{mol}, 1.00$ eq.) in AcOH/water (2:1, v/v, $3.60 \mathrm{~mL}$ ), adding Ac-L-Trp-OMe (12.5 mg, $48.5 \mu \mathrm{mol}, 10.0$ eq.) and a solution of iodine (60.9 mg, $240 \mu \mathrm{mol}, 50.0$ eq.) dissolved in acetic acid $(2.40 \mathrm{~mL})$ and stirring for $15 \mathrm{~min}$. The reaction was quenched using a solution of L-ascorbic acid in water (495 mg in $1.5 \mathrm{~mL}$ water) and directly purified by preparative HPLC. The peak having the same retention time as commercially available $\mu$-SIIIA was collected yielding the product $\mathbf{3}$ as a colourless solid (0.25 mg, $115 \mathrm{nmol}, 2 \%)$.

HPLC (analytical, A (99.9\% $\left.\mathrm{H}_{2} \mathrm{O}, 0.10 \% \mathrm{TFA}\right), \mathrm{B}\left(79.9 \% \mathrm{MeCN}, 20.0 \% \mathrm{H}_{2} \mathrm{O}, 0.10 \% \mathrm{TFA}\right.$ ), gradient $0-40 \% \mathrm{~B}$, $30 \mathrm{~min}): R_{t}=18.2 \mathrm{~min}$.

HR-MS (ESI): calc. for $\left[\mathrm{C}_{83} \mathrm{H}_{125} \mathrm{~N}_{33} \mathrm{O}_{27} \mathrm{~S}_{6}\right]^{2+}\left([\mathrm{M}+2 \mathrm{H}]^{2+}\right)$ : 1103.8868, found: 1103.8872; calc. for $\left[\mathrm{C}_{83} \mathrm{H}_{126} \mathrm{~N}_{33} \mathrm{O}_{27} \mathrm{~S}_{6}\right]^{3+}\left([\mathrm{M}+3 \mathrm{H}]^{3+}\right): 736.2603$, found: 736.2612 ; calc. for $\left[\mathrm{C}_{83} \mathrm{H}_{127} \mathrm{~N}_{33} \mathrm{O}_{27} \mathrm{~S}_{6}\right]^{4+}\left([\mathrm{M}+4 \mathrm{H}]^{4+}\right)$ : 552.4474 , found: 552.4470 .

Synthesis of a linear $\mu$-conotoxin SIIIA (disulphide connectivity: 1-5/2-4/3-6) precursor (84)

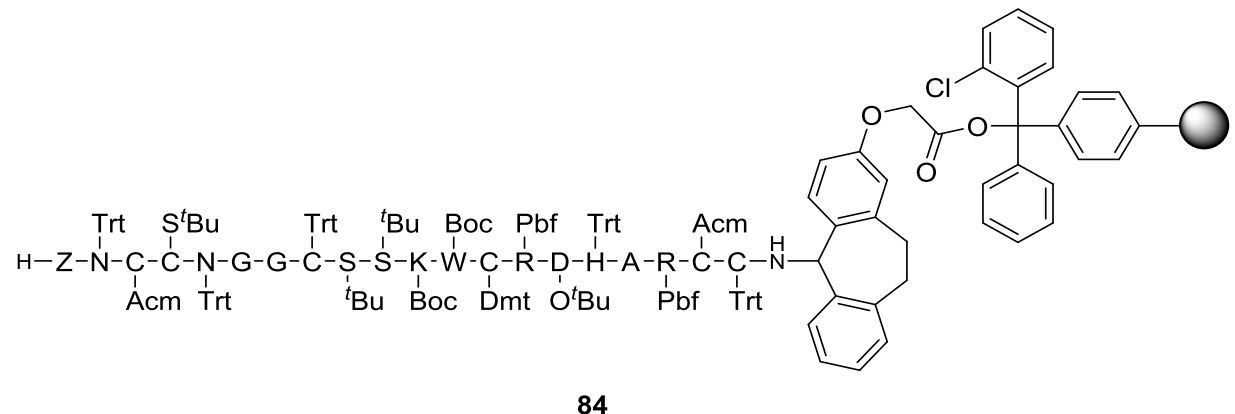

2-Chlorotrityl chloride resin $(0.70 \mathrm{~g}, 0.70 \mathrm{mmol}, 1-1.50 \mathrm{mmol} / \mathrm{g})$ was preloaded following SOP1. The occupancy was tested following SOP3 and determined to be $0.36 \mathrm{mmol} / \mathrm{g}$. The resin $(278 \mathrm{mg}$, $0.10 \mathrm{mmol}$ ) was loaded with the first amino acid Fmoc-L-Cys $(\mathrm{Trt})-\mathrm{OH}$ following SOP2. The peptide was synthesized following SOP4. Test cleavage was performed using SOP6/A yielding the Acm and $\mathrm{S}^{t} \mathrm{Bu}$ protected peptide 85 . 


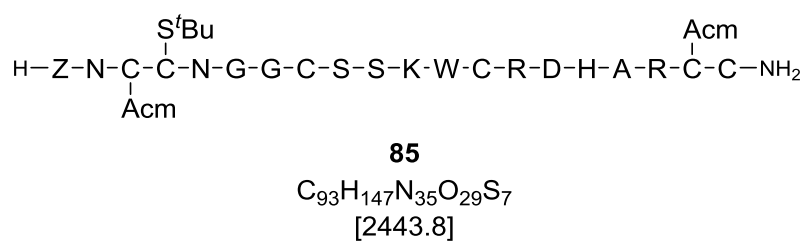

HR-MS (ESI): calc. for $\left[\mathrm{C}_{93} \mathrm{H}_{149} \mathrm{~N}_{35} \mathrm{O}_{29} \mathrm{~S}_{7}\right]^{2+}\left([\mathrm{M}+2 \mathrm{H}]^{2+}\right)$ : 1221.9647, found: 1221.9621; calc. for $\left[\mathrm{C}_{93} \mathrm{H}_{150} \mathrm{~N}_{35} \mathrm{O}_{29} \mathrm{~S}_{7}\right]^{3+}\left([\mathrm{M}+3 \mathrm{H}]^{3+}\right): 814.9789$, found: 814.9779 .

Synthesis of $\mu$-conotoxin SIIIA (disulphide connectivity: 1-5/2-4/3-6): formation of the first disulphide bridge and deprotection of acid-labile protecting groups

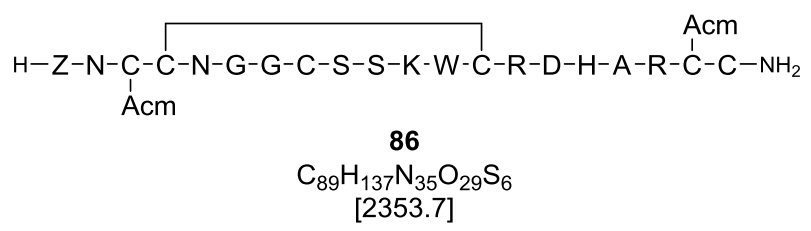

The formation of the first disulphide bridge using the linear precursor 84 (515 mg, $31.6 \mu \mathrm{mol}$ ) was performed following SOP7 (6 mL in steps 1-3, $205 \mathrm{~mL}$ in step 4, $100 \mathrm{~mL}$ in step 5) yielding the product 86 as a colourless solid (53.0 mg, $22.5 \mu \mathrm{mol}, 71 \%$ ).

HR-MS (ESI): calc. for $\left[\mathrm{C}_{89} \mathrm{H}_{139} \mathrm{~N}_{35} \mathrm{O}_{29} \mathrm{~S}_{6}\right]^{2+}\left([\mathrm{M}+2 \mathrm{H}]^{2+}\right)$ : 1176.9396 , found: 1176.9397 ; calc. for $\left[\mathrm{C}_{89} \mathrm{H}_{140} \mathrm{~N}_{35} \mathrm{O}_{29} \mathrm{~S}_{6}\right]^{3+}\left([\mathrm{M}+3 \mathrm{H}]^{3+}\right): 784.9621$, found: 784.9614 .

Synthesis of $\mu$-conotoxin SIIIA (disulphide connectivity: 1-5/2-4/3-6): formation of the second disulphide bridge

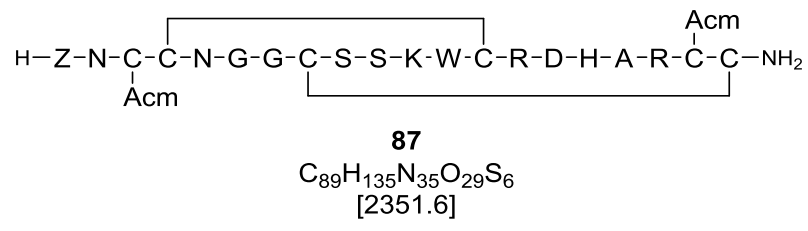

The second disulphide bridge using the crude peptide $86(53.0 \mathrm{mg}, 22.5 \mu \mathrm{mol})$ was performed following SOP8 yielding the product 87 as a colourless solid (39.8 mg, $16.9 \mu \mathrm{mol}, 75 \%)$.

HR-MS (ESI): calc. for $\left[\mathrm{C}_{89} \mathrm{H}_{137} \mathrm{~N}_{35} \mathrm{O}_{29} \mathrm{~S}_{6}\right]^{2+}\left([\mathrm{M}+2 \mathrm{H}]^{2+}\right)$ : 1175.9317, found: 1175.9319; calc. for $\left[\mathrm{C}_{89} \mathrm{H}_{138} \mathrm{~N}_{35} \mathrm{O}_{29} \mathrm{~S}_{6}\right]^{3+}\left([\mathrm{M}+3 \mathrm{H}]^{3+}\right): 784.2902$, found: 784.2909 ; calc. for $\left[\mathrm{C}_{89} \mathrm{H}_{139} \mathrm{~N}_{35} \mathrm{O}_{29} \mathrm{~S}_{6}\right]^{4+}\left([\mathrm{M}+4 \mathrm{H}]^{4+}\right)$ : 588.4695, found: 588.4701 . 
Synthesis of $\mu$-conotoxin SIIIA 27 (disulphide connectivity: 1-5/2-4/3-6): formation of the third disulphide bridge

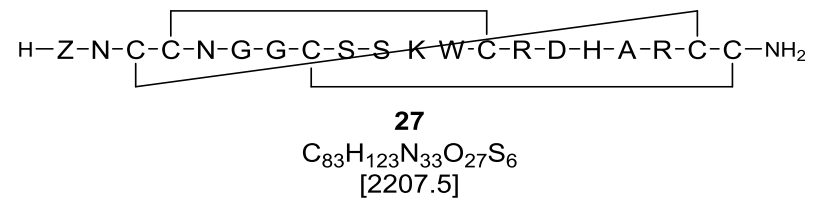

The Acm-groups were removed and the last disulphide bridge formed by dissolving the crude peptide 87 (11.8 mg, $5.02 \mu \mathrm{mol}, 1.00$ eq.) in AcOH/water (2:1, v/v, $3.60 \mathrm{~mL}$ ), adding Ac-L-Trp-OMe (13.1 mg, $50.2 \mu \mathrm{mol}, 10.0$ eq.) and a solution of iodine (63.7 mg, $251 \mu \mathrm{mol}, 50.0$ eq.) dissolved in acetic acid $(2.40 \mathrm{~mL})$ and stirring for $15 \mathrm{~min}$. The reaction was quenched using a solution of L-ascorbic acid in water (495 mg in $1.5 \mathrm{~mL}$ water) and directly purified by preparative HPLC. The peak having the same retention time as commercially available $\mu$-SIIIA was collected yielding the product $\mathbf{2 7}$ as a colourless solid (0.52 mg, $234 \mathrm{nmol}, 5 \%)$.

HPLC (analytical, A (99.9\% $\left.\mathrm{H}_{2} \mathrm{O}, 0.10 \% \mathrm{TFA}\right), \mathrm{B}\left(79.9 \% \mathrm{MeCN}, 20.0 \% \mathrm{H}_{2} \mathrm{O}, 0.10 \% \mathrm{TFA}\right)$, gradient $0-40 \% \mathrm{~B}$, $30 \mathrm{~min}): R_{t}=18.2 \mathrm{~min}$.

HR-MS (ESI): calc. for $\left[\mathrm{C}_{83} \mathrm{H}_{125} \mathrm{~N}_{33} \mathrm{O}_{27} \mathrm{~S}_{6}\right]^{2+}\left([\mathrm{M}+2 \mathrm{H}]^{2+}\right)$ : 1103.8868, found: 1103.8876; calc. for $\left[\mathrm{C}_{83} \mathrm{H}_{126} \mathrm{~N}_{33} \mathrm{O}_{27} \mathrm{~S}_{6}\right]^{3+}\left([\mathrm{M}+3 \mathrm{H}]^{3+}\right): 736.2603$, found: 736.2619 ; calc. for $\left[\mathrm{C}_{83} \mathrm{H}_{127} \mathrm{~N}_{33} \mathrm{O}_{27} \mathrm{~S}_{6}\right]^{4+}\left([\mathrm{M}+4 \mathrm{H}]^{4+}\right)$ : 552.4474, found: 552.4479 .

Synthesis of a linear [Lys11Lys(NVOC)]- $\mu$-conotoxin SIIIA (disulphide connectivity: 1-4/2-5/3-6) precursor (41)

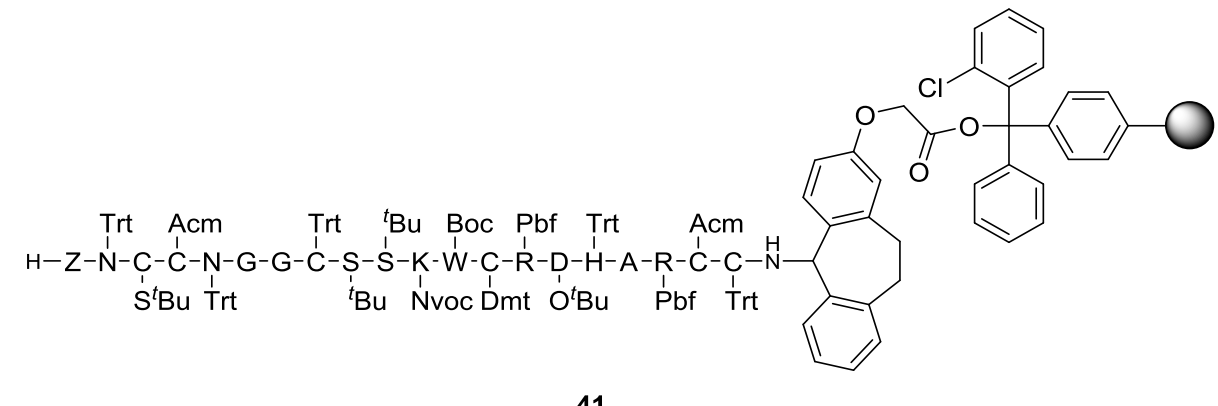

41

2-Chlorotrityl chloride resin $(0.70 \mathrm{~g}, 0.70 \mathrm{mmol}, 1-1.50 \mathrm{mmol} / \mathrm{g})$ was preloaded following SOP1. The occupancy was tested following SOP3 and determined to be $0.39 \mathrm{mmol} / \mathrm{g}$. The resin $(256 \mathrm{mg}$, $0.10 \mathrm{mmol}$ ) was loaded with the first amino acid Fmoc-L-Cys(Trt)-OH following SOP2. The peptide was 
synthesized following SOP4. Test cleavage was performed using SOP6/A yielding the Acm and $\mathrm{S}^{t} \mathrm{Bu}$ protected peptide $\mathbf{8 8}$.

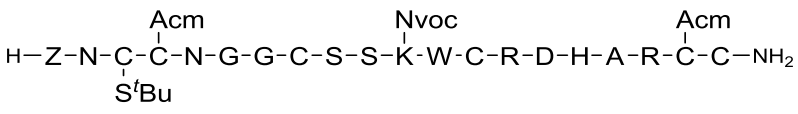

$$
\begin{aligned}
& \begin{array}{c}
\mathbf{8 8} \\
\mathrm{C}_{103} \mathrm{H}_{156} \mathrm{~N}_{36} \mathrm{O}_{35} \mathrm{~S}_{7} \\
{[2683.0]}
\end{array}
\end{aligned}
$$

HR-MS (ESI): calc. for $\left[\mathrm{C}_{103} \mathrm{H}_{158} \mathrm{~N}_{36} \mathrm{O}_{35} \mathrm{~S}_{7}\right]^{2+}\left([\mathrm{M}+2 \mathrm{H}]^{2+}\right)$ : 1341.4862, found: 1341.4878 ; calc. for $\left[\mathrm{C}_{103} \mathrm{H}_{159} \mathrm{~N}_{36} \mathrm{O}_{35} \mathrm{~S}_{7}\right]^{3+}\left([\mathrm{M}+3 \mathrm{H}]^{3+}\right): 894.6599$, found: 894.6607 .

Synthesis of [Lys11Lys(NVOC)]- $\mu$-conotoxin SIIIA (disulphide connectivity: 1-4/2-5/3-6): formation of the first disulphide bridge and deprotection of acid-labile protecting groups

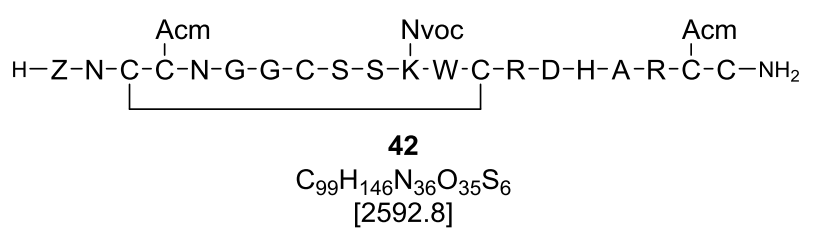

The formation of the first disulphide bridge using the linear precursor 41 (225 mg, $30.8 \mu \mathrm{mol}$ ) was performed following SOP7 (18 mL in steps 1-3, $309 \mathrm{~mL}$ in step 4, $148 \mathrm{~mL}$ in step 5) yielding the product 42 as a colourless solid (51.0 mg, $19.7 \mu \mathrm{mol}, 64 \%)$.

HR-MS (ESI): calc. for $\left[\mathrm{C}_{99} \mathrm{H}_{148} \mathrm{~N}_{36} \mathrm{O}_{35} \mathrm{~S}_{6}\right]^{2+}\left([\mathrm{M}+2 \mathrm{H}]^{2+}\right)$ : 1296.4611, found: 1296.4596; calc. for $\left[\mathrm{C}_{99} \mathrm{H}_{149} \mathrm{~N}_{36} \mathrm{O}_{35} \mathrm{~S}_{6}\right]^{3+}\left([\mathrm{M}+3 \mathrm{H}]^{3+}\right): 864.6431$, found: 864.6418 .

Synthesis of [Lys11Lys(NVOC)]- $\mu$-conotoxin SIIIA (disulphide connectivity: 1-4/2-5/3-6): formation of the second disulphide bridge

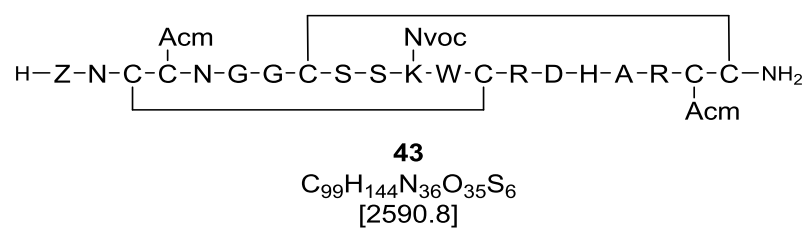

The second disulphide bridge using the crude peptide $42(51.0 \mathrm{mg}, 19.7 \mu \mathrm{mol})$ was performed following SOP8 yielding the product $\mathbf{4 3}$ as a colourless solid (35.6 mg, $13.7 \mu \mathrm{mol}, 70 \%)$. 
HR-MS (ESI): calc. for $\left[\mathrm{C}_{99} \mathrm{H}_{146} \mathrm{~N}_{36} \mathrm{O}_{35} \mathrm{~S}_{6}\right]^{2+}\left([\mathrm{M}+2 \mathrm{H}]^{2+}\right): 1295.4532$, found: 1295.4540 ; calc. for $\left[\mathrm{C}_{99} \mathrm{H}_{147} \mathrm{~N}_{36} \mathrm{O}_{35} \mathrm{~S}_{6}\right]^{3+}\left([\mathrm{M}+3 \mathrm{H}]^{3+}\right): 863.9712$, found: 863.9717.

A small amount of crude peptide was purified by preparative HPLC to yield a colourless solid $(2.4 \mathrm{mg}$, $0.92 \mu \mathrm{mol})$.

HPLC (analytical, A $\left(99.9 \% \mathrm{H}_{2} \mathrm{O}, 0.10 \% \mathrm{TFA}\right), \mathrm{B}\left(79.9 \% \mathrm{MeCN}, 20.0 \% \mathrm{H}_{2} \mathrm{O}, 0.10 \% \mathrm{TFA}\right)$, gradient $10-60 \% \mathrm{~B}, 30 \mathrm{~min}): \mathrm{R}_{t}=19.4 \mathrm{~min}$.

HR-MS (ESI): calc. for $\left[\mathrm{C}_{99} \mathrm{H}_{146} \mathrm{~N}_{36} \mathrm{O}_{35} \mathrm{~S}_{6}\right]^{2+}\left([\mathrm{M}+2 \mathrm{H}]^{2+}\right)$ : 1295.4532, found: 1295.4541; calc. for $\left[\mathrm{C}_{99} \mathrm{H}_{147} \mathrm{~N}_{36} \mathrm{O}_{35} \mathrm{~S}_{6}\right]^{3+}\left([\mathrm{M}+3 \mathrm{H}]^{3+}\right): 863.9712$, found: 863.9713 .

Synthesis of [Lys11Lys(NVOC)]- $\mu$-conotoxin SIIIA (44) (disulphide connectivity: 1-4/2-5/3-6): formation of the third disulphide bridge

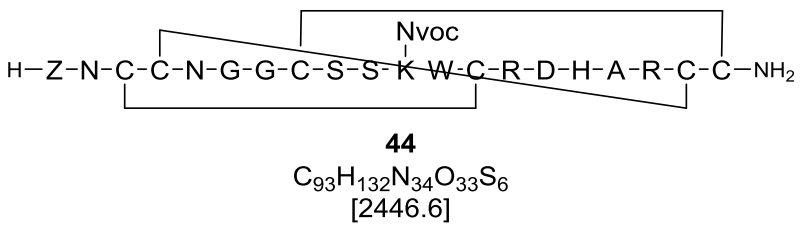

The Acm-groups were removed and the last disulphide bridge formed by dissolving the purified peptide 43 (2.40 mg, $0.93 \mu \mathrm{mol}, 1.00$ eq.) in AcOH/water (2:1, v/v, $696 \mu \mathrm{L})$, adding Ac-L-Trp-OMe ( $2.41 \mathrm{mg}, 9.26 \mu \mathrm{mol}, 10.0$ eq.) and a solution of iodine $(11.8 \mathrm{mg}, 46.3 \mu \mathrm{mol}, 50.0$ eq.) dissolved in acetic acid $(464 \mu \mathrm{L})$ and stirring for $2 \mathrm{~h}$. The solvent was removed under reduced pressure and co-evaporated three times with toluene. The resulting residue was dissolved in a small amount of TFA and precipitated with cold diethyl ether, isolated by centrifugation ( $9000 \mathrm{rpm}, 2.5 \mathrm{~min},-10^{\circ} \mathrm{C}$ ), washed three times with cold diethyl ether followed by centrifugation and dried overnight under reduced pressure. The crude product was purified by preparative HPLC to yield the product 44 as a colourless solid $(187 \mu \mathrm{g}$, $75.5 \mathrm{nmol}, 8 \%)$.

HPLC (preparative, A $\left(99.9 \% \mathrm{H}_{2} \mathrm{O}, 0.10 \%\right.$ TFA), B (79.9\% $\left.\mathrm{MeCN}, 20.0 \% \mathrm{H}_{2} \mathrm{O}, 0.10 \% \mathrm{TFA}\right)$, gradient $10-60 \%$ B, $30 \mathrm{~min}): R_{t}=23.8 \mathrm{~min}$.

HR-MS (ESI): calc. for $\left[\mathrm{C}_{93} \mathrm{H}_{134} \mathrm{~N}_{34} \mathrm{O}_{33} \mathrm{~S}_{6}\right]^{2+}\left([\mathrm{M}+2 \mathrm{H}]^{2+}\right): 1223.4083$, found: 1223.4108 ; calc. for $\left[\mathrm{C}_{93} \mathrm{H}_{135} \mathrm{~N}_{34} \mathrm{O}_{33} \mathrm{~S}_{6}\right]^{3+}\left([\mathrm{M}+3 \mathrm{H}]^{3+}\right):$ 815.9413, found: 815.9428; calc. for $\left[\mathrm{C}_{93} \mathrm{H}_{134} \mathrm{~N}_{34} \mathrm{NaO}_{33} \mathrm{~S}_{6}\right]^{3+}$ $\left([\mathrm{M}+2 \mathrm{H}+\mathrm{Na}]^{3+}\right): 823.2686$, found: 823.2700 . 


\subsubsection{Syntheses of modified pompilidotoxins}

[Ser11Ser(2'-propyne)]-ß3-pompilidotoxin (45)

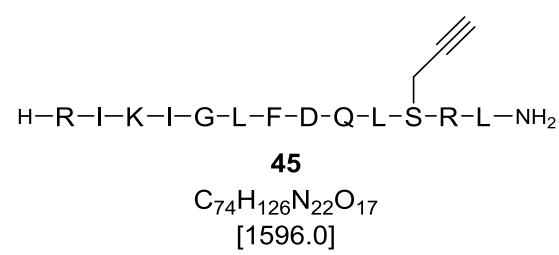

[Ser11Ser(2'-propyne)]- $\beta$-pompilidotoxin (45) was synthesized on rink amide MBHA resin (loading $0.57 \mathrm{mmol} / \mathrm{g}$ ). Therefore, the resin was preloaded following SOP2 using Fmoc-L-Leu-OH as the first amino acid followed by capping with 10\% acetic anhydride in NMP $(3 \times 6 \mathrm{~mL})$. The occupancy was determined by SOP3 $(0.31 \mathrm{mmol} / \mathrm{g})$. The peptide was synthesized with automated SPPS following SOP4. Cleavage was performed following SOP6/B. The crude product was dissolved in water and purified by preparative HPLC to yield the product 45 as a colourless solid ( $22.4 \mathrm{mg}, 14.0 \mu \mathrm{mol}, 14 \%$ ).

HPLC (analytical, A $\left(99.9 \% \mathrm{H}_{2} \mathrm{O}, 0.10 \%\right.$ TFA), B $\left(79.9 \% \mathrm{MeCN}, 20.0 \% \mathrm{H}_{2} \mathrm{O}, 0.10 \%\right.$ TFA), gradient $30-50 \% \mathrm{~B}, 30 \mathrm{~min}): \mathrm{R}_{t}=18.9 \mathrm{~min}$.

HR-MS (ESI): calc. for $\left[\mathrm{C}_{74} \mathrm{H}_{127} \mathrm{~N}_{22} \mathrm{O}_{17}\right]^{+}\left([\mathrm{M}+\mathrm{H}]^{+}\right):$1595.9744, found: 1595.9752; calc. for $\left[\mathrm{C}_{74} \mathrm{H}_{128} \mathrm{~N}_{22} \mathrm{O}_{17}\right]^{2+}\left([\mathrm{M}+2 \mathrm{H}]^{2+}\right): 798.4908$, found: 798.4909; calc. for $\left[\mathrm{C}_{74} \mathrm{H}_{129} \mathrm{~N}_{22} \mathrm{O}_{17}\right]^{3+}\left([\mathrm{M}+3 \mathrm{H}]^{3+}\right)$ : 532.6630, found: 532.6625 .

\section{[Ser11Cys]- $\beta$-pompilidotoxin (46)}

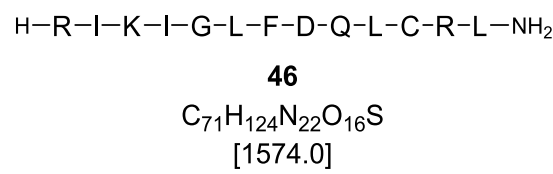

[Ser11Cys]- $\beta$-pompilidotoxin (46) was synthesized on rink amide MBHA resin (loading $0.57 \mathrm{mmol} / \mathrm{g}$ ). Therefore, the resin was preloaded following SOP2 using Fmoc-L-Leu-OH as the first amino acid followed by capping with $10 \%$ acetic anhydride in NMP ( $3 \times 6 \mathrm{~mL})$. The occupancy was determined by SOP3 $(0.31 \mathrm{mmol} / \mathrm{g})$. The peptide was synthesized with automated SPPS following SOP4. Cleavage was performed following SOP6/B. The crude product was dissolved in water and purified by preparative HPLC to yield the product 46 as a colourless solid (15.4 mg, $9.78 \mu \mathrm{mol}, 10 \%)$. 
HPLC (analytical, A $\left(99.9 \% \mathrm{H}_{2} \mathrm{O}, 0.10 \% \mathrm{TFA}\right), \mathrm{B}\left(79.9 \% \mathrm{MeCN}, 20.0 \% \mathrm{H}_{2} \mathrm{O}, 0.10 \% \mathrm{TFA}\right)$, gradient $30-50 \%$ B, $30 \mathrm{~min}): R_{t}=19.5 \mathrm{~min}$.

HR-MS (ESI): calc. for $\left[\mathrm{C}_{71} \mathrm{H}_{125} \mathrm{~N}_{22} \mathrm{O}_{16} \mathrm{~S}\right]^{+}\left([\mathrm{M}+\mathrm{H}]^{+}\right):$1573.9359, found: 1573.9354; calc. for $\left[\mathrm{C}_{71} \mathrm{H}_{126} \mathrm{~N}_{22} \mathrm{O}_{16} \mathrm{~S}\right]^{2+}\left([\mathrm{M}+2 \mathrm{H}]^{2+}\right): 787.4716$, found: 787.4724 ; calc. for $\left[\mathrm{C}_{71} \mathrm{H}_{127} \mathrm{~N}_{22} \mathrm{O}_{16} \mathrm{~S}\right]^{3+}\left([\mathrm{M}+3 \mathrm{H}]^{3+}\right)$ : 525.3168, found: 525.3167 .

\section{Alexa Fluor $^{\circledR} 488$ labelled [Ser11Cys]- $\beta$-pompilidotoxin (49)}

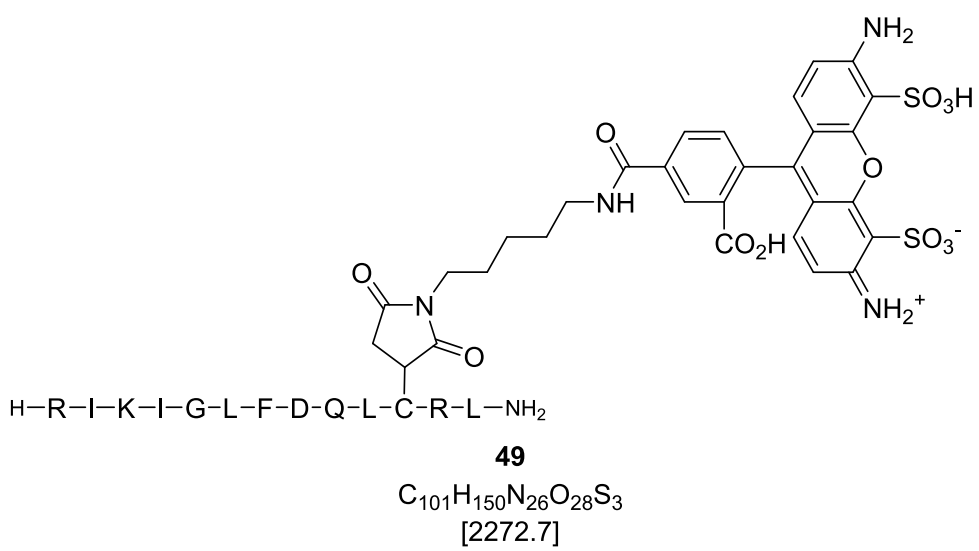

Based on the procedure of LUMIPROBE, [Ser11Cys]- $\beta$-pompilidotoxin (46) (1.97 mg, $1.25 \mu \mathrm{mol}, 0.90$ eq.) was dissolved in $50 \mathrm{mM}$ degassed phosphate buffer $(2.78 \mathrm{~mL}, \mathrm{pH}=7.08)$ under argon atmosphere. ${ }^{[238]}$ TCEP solution ( $77 \mu \mathrm{L}, 10.0 \mu \mathrm{mol}, 8.00$ eq., $0.13 \mathrm{M}$ solution in $50 \mathrm{mM}$ degassed phosphate buffer) was added and the solution stirred for 5 min. Under exclusion of light Alexa Fluor ${ }^{\circledR} 488 C_{5}$ maleimide (139 $\mu \mathrm{L}, 1.39 \mu \mathrm{mol}, 1.00$ eq., $10 \mathrm{mM}$ solution in DMF) was added and the reaction mixture stirred for $2 \mathrm{~h}$ at $\mathrm{rt}$ and stored overnight at $4{ }^{\circ} \mathrm{C}$. The solution was diluted $1: 1$ with acetonitrile and purified by preparative HPLC to yield the product 49 as an orange solid $(0.97 \mathrm{mg}, 426 \mathrm{nmol}, 34 \%$ ).

HPLC (analytical, A $\left(99.9 \% \mathrm{H}_{2} \mathrm{O}, 0.10 \% \mathrm{TFA}\right), \mathrm{B}\left(79.9 \% \mathrm{MeCN}, 20.0 \% \mathrm{H}_{2} \mathrm{O}, 0.10 \% \mathrm{TFA}\right)$, gradient $25-55 \%$ B, $30 \mathrm{~min}): \mathrm{R}_{t}=22.6 \mathrm{~min}$.

HR-MS (ESI): calc. for $\left[\mathrm{C}_{101} \mathrm{H}_{152} \mathrm{~N}_{26} \mathrm{O}_{28} \mathrm{~S}_{3}\right]^{2+}\left([\mathrm{M}+2 \mathrm{H}]^{2+}\right)$ : 1136.5210 , found: 1136.5172 ; calc. for $\left[\mathrm{C}_{101} \mathrm{H}_{153} \mathrm{~N}_{26} \mathrm{O}_{28} \mathrm{~S}_{3}\right]^{3+}\left([\mathrm{M}+3 \mathrm{H}]^{3+}\right):$ 758.0164, found: 758.0153 . 
[Ser(2'-propyne)]-3-pompilidotoxin (47)

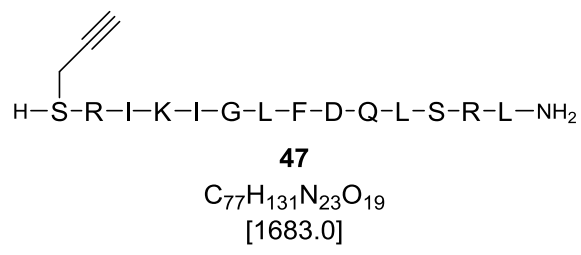

[Ser(2'-propyne)]- $\beta$-pompilidotoxin (47) was synthesized on rink amide MBHA resin (loading $0.57 \mathrm{mmol} / \mathrm{g}$ ). Therefore, the resin was preloaded following SOP2 using Fmoc-L-Leu-OH as the first amino acid followed by capping with $10 \%$ acetic anhydride in NMP $(3 \times 6 \mathrm{~mL})$. The occupancy was determined by SOP3 $(0.31 \mathrm{mmol} / \mathrm{g})$. The peptide was synthesized with automated SPPS following SOP4. Cleavage was performed following SOP6/B. The crude product was dissolved in water and purified by preparative HPLC to yield the product $\mathbf{4 7}$ as a colourless solid (15.1 mg, $8.97 \mu \mathrm{mol}, 9 \%$ ).

HPLC (analytical, A $\left(99.9 \% \mathrm{H}_{2} \mathrm{O}, 0.10 \% \mathrm{TFA}\right), \mathrm{B}\left(79.9 \% \mathrm{MeCN}, 20.0 \% \mathrm{H}_{2} \mathrm{O}, 0.10 \% \mathrm{TFA}\right)$, gradient $30-50 \%$ B, $30 \mathrm{~min}): R_{t}=17.8 \mathrm{~min}$.

HR-MS (ESI): calc. for $\left[\mathrm{C}_{77} \mathrm{H}_{132} \mathrm{~N}_{23} \mathrm{O}_{19}\right]^{+}\left([\mathrm{M}+\mathrm{H}]^{+}\right): 1683.0064$, found: 1683.0060 ; calc. for $\left[\mathrm{C}_{77} \mathrm{H}_{133} \mathrm{~N}_{23} \mathrm{O}_{19}\right]^{2+}\left([\mathrm{M}+2 \mathrm{H}]^{2+}\right): 842.0069$, found: 842.0069; calc. for $\left[\mathrm{C}_{77} \mathrm{H}_{134} \mathrm{~N}_{23} \mathrm{O}_{19}\right]^{3+}\left([\mathrm{M}+3 \mathrm{H}]^{3+}\right)$ : 561.6737, found: 561.6735 .

[Cys]- $\beta$-pompilidotoxin (48)

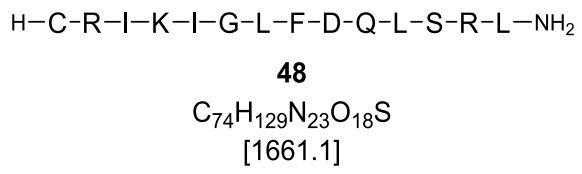

[Cys]- $\beta$-pompilidotoxin (48) was synthesized on rink amide MBHA resin (loading $0.29 \mathrm{mmol} / \mathrm{g}$ ). Therefore, the resin was preloaded following SOP2 using Fmoc-L-Leu-OH as the first amino acid. The peptide was synthesized with manual SPPS following SOP5. Cleavage was performed following SOP6/A for $3 \mathrm{~h}$. The crude product was dissolved in water and purified by preparative HPLC to yield the product 48 as a colourless solid ( $45.3 \mathrm{mg}, 27.3 \mu \mathrm{mol}, 27 \%$ ).

HPLC (analytical, A $\left(99.9 \% \mathrm{H}_{2} \mathrm{O}, 0.10 \% \mathrm{TFA}\right), \mathrm{B}\left(79.9 \% \mathrm{MeCN}, 20.0 \% \mathrm{H}_{2} \mathrm{O}, 0.10 \% \mathrm{TFA}\right)$, gradient $20-50 \%$ B, $30 \mathrm{~min}): R_{t}=23.3 \mathrm{~min}$. 
HR-MS (ESI): calc. for $\left[\mathrm{C}_{74} \mathrm{H}_{130} \mathrm{~N}_{23} \mathrm{O}_{18} \mathrm{~S}\right]^{+}\left([\mathrm{M}+\mathrm{H}]^{+}\right): 1660.9679$, found: 1660.9654; calc. for $\left[\mathrm{C}_{74} \mathrm{H}_{131} \mathrm{~N}_{23} \mathrm{O}_{18} \mathrm{~S}\right]^{2+}\left([\mathrm{M}+2 \mathrm{H}]^{2+}\right): 830.9876$, found: 830.9832; calc. for $\left[\mathrm{C}_{74} \mathrm{H}_{132} \mathrm{~N}_{23} \mathrm{O}_{18} \mathrm{~S}\right]^{3+}\left([\mathrm{M}+3 \mathrm{H}]^{3+}\right)$ : 554.3275, found: 554.3268 .

\section{Alexa Fluor ${ }^{\circledast} 488$ labelled [Cys]- $\beta$-pompilidotoxin (50)}

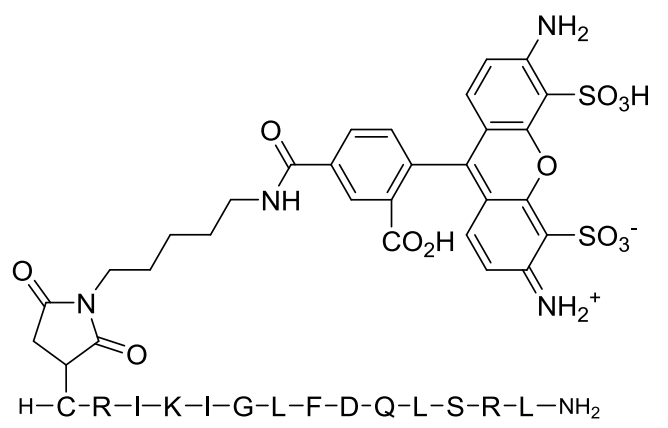

50

$\mathrm{C}_{104} \mathrm{H}_{155} \mathrm{~N}_{27} \mathrm{O}_{30} \mathrm{~S}_{3}$

[2359.7]

Based on the procedure of LUMIPROBE, [Cys]- $\beta$-pompilidotoxin (48) $(0.66 \mathrm{mg}, 0.40 \mu \mathrm{mol}, 0.80$ eq.) was dissolved in $50 \mathrm{mM}$ degassed phosphate buffer $(1 \mathrm{~mL}, \mathrm{pH}=7.08)$ under argon atmosphere. ${ }^{[238]}$ TCEP solution ( $40 \mu \mathrm{L}, 8.00 \mu \mathrm{mol}, 16.0$ eq., $0.20 \mathrm{M}$ solution in $50 \mathrm{mM}$ degassed phosphate buffer) were added and the solution stirred for $5 \mathrm{~min}$. Under exclusion of light Alexa Fluor ${ }^{\circledR} 488 \mathrm{C}_{5}$ maleimide $(50 \mu \mathrm{L}$, $0.50 \mu \mathrm{mol}, 1.00$ eq., $10 \mathrm{mM}$ solution in DMF) was added and the reaction mixture stirred for $2 \mathrm{~h}$ at $\mathrm{rt}$ and stored overnight at $4{ }^{\circ} \mathrm{C}$. The solution was diluted $1: 1$ with acetonitrile and purified by preparative HPLC to yield the product 50 as an orange solid $(0.09 \mu \mathrm{g}, 39.0 \mathrm{nmol}, 10 \%)$.

HPLC (analytical, A $\left(99.9 \% \mathrm{H}_{2} \mathrm{O}, 0.10 \% \mathrm{TFA}\right), \mathrm{B}\left(79.9 \% \mathrm{MeCN}, 20.0 \% \mathrm{H}_{2} \mathrm{O}, 0.10 \% \mathrm{TFA}\right)$, gradient $20-50 \%$ B, $30 \mathrm{~min}$ ): $R_{t}=26.5 \mathrm{~min}$.

HR-MS (ESI): calc. for $\left[\mathrm{C}_{104} \mathrm{H}_{157} \mathrm{~N}_{27} \mathrm{O}_{30} \mathrm{~S}_{3}\right]^{2+}\left([\mathrm{M}+2 \mathrm{H}]^{2+}\right)$ : 1180.0370, found: 1180.0364; calc. for $\left[\mathrm{C}_{104} \mathrm{H}_{155} \mathrm{~N}_{27} \mathrm{Na}_{2} \mathrm{O}_{30} \mathrm{~S}_{3}\right]^{2+}\left([\mathrm{M}+2 \mathrm{Na}]^{2+}\right): 1202.0190$, found: 1202.0190 ; calc. for $\left[\mathrm{C}_{104} \mathrm{H}_{158} \mathrm{~N}_{27} \mathrm{O}_{30} \mathrm{~S}_{3}\right]^{3+}$ $\left([\mathrm{M}+3 \mathrm{H}]^{3+}\right)$ : 787.0271, found: 787.0285 . 


\subsubsection{Synthesis of labelled iberiotoxin (52)}
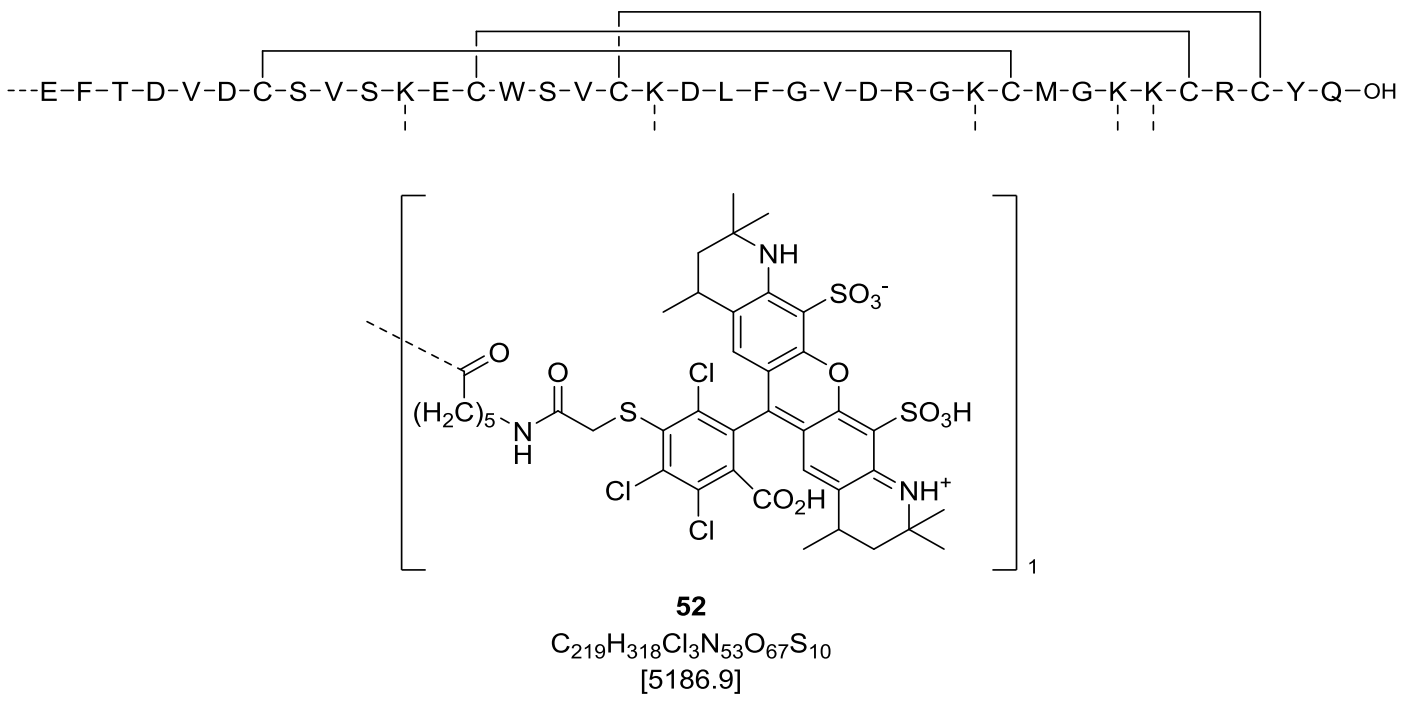

Based on the procedure in the molecular probes ${ }^{\circledR}$ handbook, iberiotoxin (51) (RTI400 ALOMONE LABS, $0.10 \mathrm{mg}, 23.5 \mathrm{nmol}, 1.00 \mathrm{eq}$.) was centrifuged at $10000 \mathrm{xg}$ for $2 \mathrm{~min}$ and under an argon blanket DMF

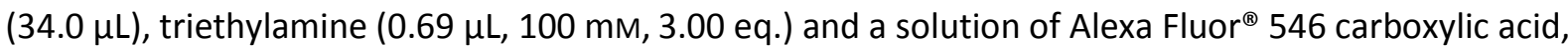
succinimidyl ester (reactive towards amines) $(0.02 \mathrm{mg}, 16.1 \mathrm{nmol}, 0.70$ eq. in $16 \mu \mathrm{L}$ DMF) were added. ${ }^{[233]}$ The solution was stirred overnight at $\mathrm{rt}$ and evaporated under reduced pressure. The resulting residue was dissolved in an appropriate amount of $\mathrm{MeCN} / \mathrm{H}_{2} \mathrm{O}(1: 4, \mathrm{v} / \mathrm{v})$ and purified by $\mathrm{HPLC}$ yielding the product $\mathbf{5 2}$ as a pink solid.

HPLC (analytical, A $\left(99.9 \% \mathrm{H}_{2} \mathrm{O}, 0.10 \% \mathrm{TFA}\right), \mathrm{B}\left(79.9 \% \mathrm{MeCN}, 20.0 \% \mathrm{H}_{2} \mathrm{O}, 0.10 \% \mathrm{TFA}\right)$, gradient $25-50 \%$ B, $30 \mathrm{~min}): R_{t}=24.5 \mathrm{~min}$.

HR-MS (ESI): calc. for $\left[\mathrm{C}_{219} \mathrm{H}_{321} \mathrm{Cl}_{3} \mathrm{~N}_{53} \mathrm{O}_{67} \mathrm{~S}_{10}\right]^{3+}\left([\mathrm{M}+3 \mathrm{H}]^{3+}\right): 1729.9866$, found: 1729.9980 ; calc. for $\left[\mathrm{C}_{219} \mathrm{H}_{322} \mathrm{Cl}_{3} \mathrm{~N}_{53} \mathrm{O}_{67} \mathrm{~S}_{10}\right]^{4+}\left([\mathrm{M}+4 \mathrm{H}]^{4+}\right): 1297.7417$, found: 1297.7464 ; calc. for $\left[\mathrm{C}_{219} \mathrm{H}_{323} \mathrm{Cl}_{3} \mathrm{~N}_{53} \mathrm{O}_{67} \mathrm{~S}_{10}\right]^{5+}$ $\left([\mathrm{M}+5 \mathrm{H}]^{5+}\right): 1038.3948$, found: 1038.4042 . 


\subsubsection{Syntheses of modified cyclic adenosine-3',5'-monophosphates}

\section{5-hexynal (55)}

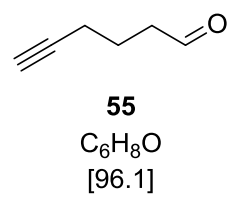

According to the procedure of Kocsis et al., pyridinium chlorochromate $(9.28 \mathrm{~g}, 43.0 \mathrm{mmol}, 2.00$ eq.) was dissolved in DCM (85 mL) under an argon atmosphere. ${ }^{[226]}$ 5-Hexynol (54) $(2.4 \mathrm{~mL}, 2.11 \mathrm{~g}$, $21.5 \mathrm{mmol}, 1.00 \mathrm{eq}$.) was added and the mixture stirred for $2 \mathrm{~h}$. Diethyl ether $(70 \mathrm{~mL})$ and silica $(25.9 \mathrm{~g})$ were added and the mixture stirred for $30 \mathrm{~min}$. After filtration over silica and washing with diethyl ether, the solution was evaporated under reduced pressure. The crude product was purified by flash column chromatography (pentane/diethyl ether 10:1, v/v) to yield the product 55 as a slightly yellow solid (528 mg, $5.49 \mathrm{mmol}, 26 \%)$. The NMR data is in accordance to the literature. ${ }^{[239]}$

${ }^{1} \mathrm{H}-\mathrm{NMR}\left(300 \mathrm{MHz}, \mathrm{CDCl}_{3}\right): \delta_{H}(\mathrm{ppm})=1.76-1.85\left(\mathrm{~m}, 2 \mathrm{H}, \mathrm{CH}_{2} \mathrm{CH}_{2} \mathrm{CHO}\right), 1.95\left(\mathrm{t},{ }^{4} J_{\mathrm{H}, \mathrm{H}}=2.6 \mathrm{~Hz}, 1 \mathrm{H}, \mathrm{CCH}\right)$, $2.23\left(\mathrm{td},{ }^{3,4} J_{\mathrm{H}, \mathrm{H}}=6.0,2.7 \mathrm{~Hz}, 2 \mathrm{H}, \mathrm{CH}_{2} \mathrm{CCH}\right), 2.57\left(\mathrm{td},{ }^{3,3} J_{\mathrm{H}, \mathrm{H}}=7.2,1.3 \mathrm{~Hz}, 2 \mathrm{H}, \mathrm{CH}_{2} \mathrm{CHO}\right), 9.76\left(\mathrm{t},{ }^{3} J_{\mathrm{H}, \mathrm{H}}=1.3 \mathrm{~Hz}\right.$, $1 \mathrm{H}, \mathrm{CHO})$.

\section{$N^{6}$-Hex-5-yn-1-yladenosine-3',5'-cyclic monophosphate tri-n-ethylammonium salt (57)}

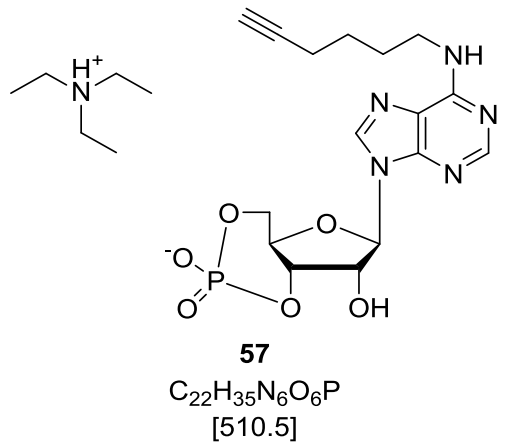

Based on the procedure of KATAOKA et al., adenosine-3',5'-cyclic monophosphate (53) $(0.50 \mathrm{~g}$, $1.52 \mathrm{mmol}, 1.00$ eq.) was dissolved in water $(2.5 \mathrm{~mL})$ and ethanol $(2.5 \mathrm{~mL})$, tri- $n$-butylamine $(356 \mu \mathrm{L}$, $1.52 \mathrm{mmol}, 1.00$ eq.) was added and the mixture stirred until the residue was dissolved $(1 \mathrm{~h}){ }^{[225]}$ The solvent was evaporated under reduced pressure, co-evaporated with dioxane and the residue dried under reduced pressure. Adenosine-- $3^{\prime}, 5^{\prime}$-cyclic monophosphate tri- $n$-butylammonium salt (56) (0.50 g, $972 \mu \mathrm{mol}, 1.00$ eq.) was dissolved in acetic acid $\left(9 \mathrm{~mL}\right.$ ), heated to $50^{\circ} \mathrm{C}$ and 5-hexynal (55) 
(528 mg, $5.49 \mathrm{mmol}, 5.65$ eq.) was added. After $30 \mathrm{~min}$ sodium cyanoborohydride ( $305 \mathrm{mg}, 4.86 \mathrm{mmol}$, 5.00 eq.) was added and the reaction mixture stirred overnight at $50^{\circ} \mathrm{C}$. The reaction was quenched with water and the solvent was evaporated under reduced pressure. HPLC purification yielded the pure product 57 as a colourless solid (34.8 $\mathrm{mg}, 68.2 \mu \mathrm{mol}, 7 \%$ ).

HPLC (semipreparative, A (0.10 M TEAA buffer pH 7), B (70\% MeCN, 30\% 0.10 M TEAA pH 7), gradient $5-60 \%$ B, $25 \mathrm{~min}): \mathrm{R}_{\mathrm{t}}=19.3 \mathrm{~min}$.

${ }^{1} \mathrm{H}-\mathrm{NMR}\left(300 \mathrm{MHz}, \mathrm{D}_{2} \mathrm{O}, 35{ }^{\circ} \mathrm{C}\right): \delta_{H}(\mathrm{ppm})=1.31\left(\mathrm{t},{ }^{3} \mathrm{~J}_{\mathrm{H}, \mathrm{H}}=7.3 \mathrm{~Hz}, 9 \mathrm{H}, \mathrm{CH}_{3}\right), 1.53-1.65(\mathrm{~m}, 2 \mathrm{H}$, $\mathrm{CH}_{2} \mathrm{CH}_{2} \mathrm{CCH}$ ), 1.69-1.78(m, $\left.2 \mathrm{H}, \mathrm{NHCH}_{2} \mathrm{CH}_{2}\right), 2.23\left(\mathrm{td}, 3,4 J_{\mathrm{H}, \mathrm{H}}=6.9,2.6 \mathrm{~Hz}, 2 \mathrm{H}, \mathrm{CH}_{2} \mathrm{CCH}\right), 2.37(\mathrm{t}$, $\left.{ }^{4} J_{\mathrm{H}, \mathrm{H}}=2.6 \mathrm{~Hz}, 1 \mathrm{H}, \mathrm{CCH}\right), 3.23\left(\mathrm{q},{ }^{3} J_{\mathrm{H}, \mathrm{H}}=7.3 \mathrm{~Hz}, 6 \mathrm{H}, \mathrm{CH}_{2} \mathrm{CH}_{3}\right), 3.49\left(\mathrm{t},{ }^{3} J_{\mathrm{H}, \mathrm{H}}=6.8 \mathrm{~Hz}, 2 \mathrm{H}, \mathrm{NHCH}_{2}\right), 4.41-4.84$ $\left(\mathrm{m}, 5 \mathrm{H}, \mathbf{H 2} 2^{\prime}, \mathbf{H} 3^{\prime}, \mathbf{H} 4^{\prime}, \mathbf{H} 5^{\prime}\right), 6.10\left(\mathrm{~s}, 1 \mathrm{H}, \mathbf{H} 1^{\prime}\right), 8.14(\mathrm{~s}, 1 \mathrm{H}, \mathrm{H} 8), 8.16(\mathrm{~s}, 1 \mathrm{H}, \mathrm{H} 2)$.

${ }^{13} \mathrm{C}-\mathrm{NMR}\left(126 \mathrm{MHz}, \mathrm{D}_{2} \mathrm{O}, 35{ }^{\circ} \mathrm{C}\right): \delta_{C}(\mathrm{ppm})=5.6\left(\mathrm{CH}_{3}\right), 14.7\left(\mathrm{CH}_{2} \mathrm{CCH}\right), 22.4\left(\mathrm{CH}_{2} \mathrm{CH}_{2} \mathrm{CCH}\right), 25.0$ $\left(\mathrm{NHCH}_{2} \mathrm{CH}_{2}\right), 37.6\left(\mathrm{NHCH}_{2}\right), 44.0\left(\mathrm{CH}_{2} \mathrm{CH}_{3}\right), 64.5\left(\mathrm{~d},{ }^{2} \mathrm{~J}_{\mathrm{C}, \mathrm{P}}=6.9 \mathrm{~Hz}, \mathrm{C5}{ }^{\prime}\right), 65.3(\mathrm{CCH}), 69.0\left(\mathrm{~d},{ }^{2} \mathrm{~J}_{\mathrm{C}, \mathrm{P}}=4.3 \mathrm{~Hz}\right.$, C3'), $69.6\left(d,{ }^{3} J_{C, P}=7.9 \mathrm{~Hz}, \mathrm{C2}{ }^{\prime}\right), 74.5\left(\mathrm{~d},{ }^{3} \mathrm{~J}_{\mathrm{C}, \mathrm{P}}=4.5 \mathrm{~Hz}, \mathrm{C4} 4^{\prime}\right), 83.0\left(\mathrm{CH}_{2} \mathrm{CCH}\right), 88.6\left(\mathrm{C} 1^{\prime}\right), 115.9$ (C5), 136.0 (C8), 144.2 (C4), 150.0 (C2), 151.4 (C6).

${ }^{31} \mathrm{P}-\mathrm{NMR}\left(122 \mathrm{MHz}, \mathrm{D}_{2} \mathrm{O}, 35^{\circ} \mathrm{C}\right): \delta_{P}(\mathrm{ppm})=-2.85$.

HR-MS (ESI): calc. for $\left[\mathrm{C}_{16} \mathrm{H}_{21} \mathrm{~N}_{5} \mathrm{O}_{6} \mathrm{P}\right]^{+}\left([\mathrm{M}+\mathrm{H}]^{+}\right): 410.1224$, found: 410.1226 ; calc. for $\left[\mathrm{C}_{16} \mathrm{H}_{20} \mathrm{~N}_{5} \mathrm{NaO}_{6} \mathrm{P}\right]^{+}$ $\left([\mathrm{M}+\mathrm{Na}]^{+}\right): 432.1043$, found: 432.1043 ; calc. for $\left[\mathrm{C}_{16} \mathrm{H}_{19} \mathrm{~N}_{5} \mathrm{O}_{6} \mathrm{P}\right]^{-}\left([\mathrm{M}-\mathrm{H}]^{-}\right): 408.1078$, found: 408.1077 . 
Alexa Fluor ${ }^{\circledR} 488$ labelled $N^{6}$-hex-5-yn-1-yladenosine-3',5'-cyclic monophosphate tri- $n$ ethylammonium salt (58)

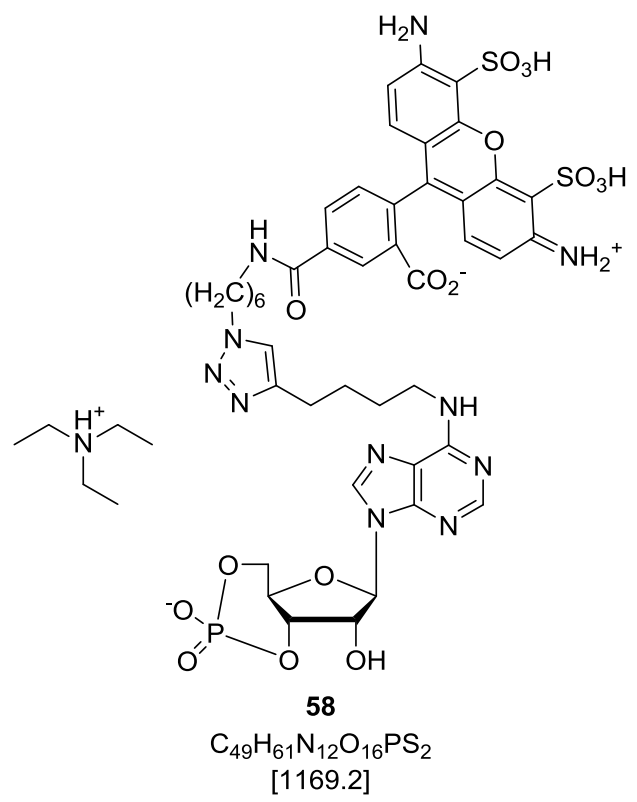

Based on the procedure of SEELA et al. and the manual for Alexa Fluor ${ }^{\circledR} 488$ azide, Alexa Fluor $^{\circledR} 488$ 5-carboxamido-(6-azidohexanyl), bis(triethylammonium salt) (0.50 mg, $581 \mathrm{nmol}, 1.06$ eq.) was dissolved in DMF (9 $\mu \mathrm{L})$ and combined with $N^{6}$-hex-5-yn-1-yladenosine-3', $5^{\prime}$-cyclic monophosphate tri$n$-ethylammonium salt (57) $(0.28 \mathrm{mg}, 548 \mathrm{nmol}, 1.00$ eq.) dissolved in DMF (8 $\mu \mathrm{L}) .{ }^{[227]}$ Sodium ascorbate (1.74 $\mu \mathrm{L}, 0.1 \mathrm{M}$ solution in water, $174 \mathrm{nmol}, 0.32$ eq.) and copper (II) sulphate pentahydrate (1.03 $\mu \mathrm{L}$, $0.05 \mathrm{M}$ solution in DMF, $51.3 \mathrm{nmol}, 0.09$ eq.) were added, the solution was centrifuged shortly and stirred for $16 \mathrm{~h}$ at $\mathrm{rt}$. The solvent was evaporated under reduced pressure, the residue dissolved in $0.1 \mathrm{M}$ TEAA buffer and purified by HPLC to yield the product 58 as an orange solid $(0.08 \mathrm{mg}, 65.8 \mathrm{nmol}$, $12 \%)$.

HPLC (analytical, A (0.10 M TEAA buffer pH 7), B (70\% MeCN, 30\% 0.10 M TEAA buffer pH 7), gradient $0-40 \%$ B, $30 \mathrm{~min}): \mathrm{R}_{\mathrm{t}}=23.4 \mathrm{~min}$.

HR-MS (ESI): calc. for $\left[\mathrm{C}_{43} \mathrm{H}_{45} \mathrm{~N}_{11} \mathrm{O}_{16} \mathrm{PS}_{2}\right]^{-}\left([\mathrm{M}-\mathrm{H}]^{-}\right)$: 1066.2230, found: 1066.2247; calc. for $\left[\mathrm{C}_{43} \mathrm{H}_{44} \mathrm{~N}_{11} \mathrm{NaO}_{16} \mathrm{PS}_{2}\right]^{-} \quad\left([\mathrm{M}-2 \mathrm{H}+\mathrm{Na}]^{-}\right):$1088.2050, found: $1088.2049 ;$ calc. for $\left[\mathrm{C}_{43} \mathrm{H}_{43} \mathrm{~N}_{11} \mathrm{Na}_{2} \mathrm{O}_{16} \mathrm{PS}_{2}\right]^{-}\left([\mathrm{M}-3 \mathrm{H}+2 \mathrm{Na}]^{-}\right):$1110.1869, found: 1110.1867. 
1-Bromo-5-hexyne (89)

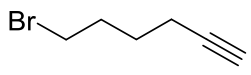

89

$\mathrm{C}_{6} \mathrm{H}_{9} \mathrm{Br}$

[161.0]

According to the procedure of SHARMA et al., phosphorus tribromide (1.71 mL, $18.2 \mathrm{mmol}, 2.80$ eq.) was added dropwise to 5-hexynol (54) $(5.62 \mathrm{~mL}, 50.9 \mathrm{mmol}, 1.00$ eq.) in anhydrous diethyl ether $(18 \mathrm{~mL})$ at $-5^{\circ} \mathrm{C} \cdot{ }^{[229]}$ The reaction was stirred for $2 \mathrm{~h}$ at $-5{ }^{\circ} \mathrm{C}$, warmed to $\mathrm{rt}$ and quenched with cold saturated $\mathrm{NaHCO}_{3}(\mathrm{aq})(10 \mathrm{~mL})$. The organic phase was washed with saturated $\mathrm{NaHCO}_{3}(\mathrm{aq})(10 \mathrm{~mL})$ and the combined aqueous phases were extracted with diethyl ether $(10 \mathrm{~mL})$. The solvent was removed under reduced pressure and the crude product distillated $\left(70{ }^{\circ} \mathrm{C}, 23 \mathrm{mbar}\right.$ ) to yield the product 89 as a colourless liquid $(1.89 \mathrm{~g}, 11.7 \mathrm{mmol}, 23 \%)$.

${ }^{1} \mathrm{H}-\mathrm{NMR}(600 \mathrm{MHz}, \mathrm{CDCl}): \delta_{H}(\mathrm{ppm})=1.61-1.70\left(\mathrm{~m}, 2 \mathrm{H}, \mathrm{Br}\left(\mathrm{CH}_{2}\right)_{2} \mathrm{CH}_{2}\right), 1.96-2.00\left(\mathrm{~m}, 3 \mathrm{H}, \mathrm{CH}, \mathrm{BrCH}_{2} \mathrm{CH}_{2}\right)$, $2.23\left(\mathrm{td},{ }^{3,4} \mathrm{~J}_{\mathrm{H}, \mathrm{H}}=7.0,2.7 \mathrm{~Hz}, 2 \mathrm{H}, \mathrm{CH}_{2} \mathrm{CCH}\right), 3.43\left(\mathrm{t}, 2 \mathrm{H},{ }^{3} \mathrm{~J}_{\mathrm{H}, \mathrm{H}}=6.7 \mathrm{~Hz}, \mathrm{BrCH}_{2}\right)$.

${ }^{13} \mathrm{C}-\mathrm{NMR}\left(126 \mathrm{MHz}, \mathrm{CDCl}_{3}\right): \delta_{C}(\mathrm{ppm})=17.7\left(\mathrm{CH}_{2} \mathrm{CCH}\right), 26.9\left(\mathrm{Br}\left(\mathrm{CH}_{2}\right)_{2} \mathrm{CH}_{2}\right), 31.7\left(\mathrm{BrCH}_{2} \mathrm{CH}_{2}\right)$, 33.2 $\left(\mathrm{BrCH}_{2}\right)$, $69.0(\mathrm{CH}), 83.7(\mathrm{CCH})$.

2'O-Hex-5-yn-1-yladenosine-3', 5'-cyclic monophosphate tri-n-ethylammonium salt (62)

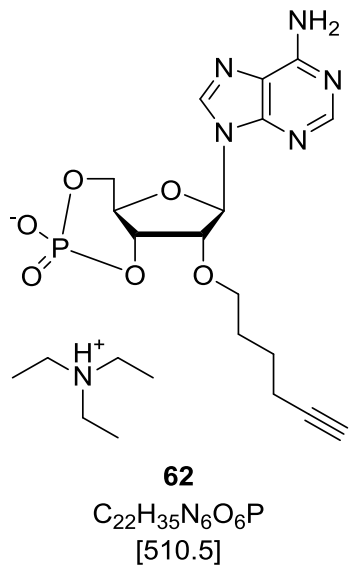

Based on the procedure of KATAOKA et al., adenosine-3',5'-cyclic monophosphate (53) $(110 \mathrm{mg}$, $333 \mu \mathrm{mol}, 1.00$ eq.) was added to a stirred solution of $\mathrm{KOH}(149 \mathrm{mg}, 2.66 \mathrm{mmol}, 8.00$ eq.) in water (3 mL). ${ }^{[228]}$ A solution of 18-crown-6 (264 mg, $999 \mu \mathrm{mol}, 3.00$ eq.) in dioxane (3 mL) was added, followed by 1-bromo-5-hexyne (89) (322 mg, $2.00 \mathrm{mmol}, 6.00$ eq.). The mixture was stirred at $50-60{ }^{\circ} \mathrm{C}$ for $2 \mathrm{~d}$. After $1 \mathrm{~d}$ additional dioxane $(12 \mathrm{~mL}$ ) was added. The mixture was adjusted to $\mathrm{pH} 7$ with $2 \mathrm{~N} \mathrm{HCl}(\mathrm{aq})$ 
and the solvent removed under reduced pressure. HPLC purification yielded the pure product $\mathbf{6 2}$ as a colourless solid (94.2 mg, $185 \mu \mathrm{mol}, 55 \%)$.

HPLC (analytical, $0.95 \mathrm{~mL} / \mathrm{min}, \mathrm{A}$ (0.10 M TEAA buffer pH 7), B (70\% MeCN, 30\% $0.10 \mathrm{M}$ TEAA buffer $\mathrm{pH} 7$ ), gradient $5-50 \% \mathrm{~B}, 25 \mathrm{~min}): \mathrm{R}_{\mathrm{t}}=18.8 \mathrm{~min}$.

$\left.{ }^{1} \mathrm{H}-\mathrm{NMR}\left(300 \mathrm{MHz},\left[\mathrm{D}_{6}\right] \mathrm{DMSO}, 35^{\circ} \mathrm{C}\right): \delta_{H}(\mathrm{ppm})=1.09\left(\mathrm{t},{ }^{3}\right)_{\mathrm{H}, \mathrm{H}}=7.2 \mathrm{~Hz}, 9 \mathrm{H}, \mathrm{CH}_{3}\right), 1.47-1.68(\mathrm{~m}, 4 \mathrm{H}$, $\mathrm{OCH}_{2} \mathrm{CH}_{2} \mathrm{CH}_{2}$ ), $2.18\left(\mathrm{td},{ }^{3,4} J_{\mathrm{H}, \mathrm{H}}=6.9,2.6 \mathrm{~Hz}, 2 \mathrm{H}, \mathrm{CH}_{2} \mathrm{CCH}\right.$ ), 2.69 (d, ${ }^{4} J_{\mathrm{H}, \mathrm{H}}=2.6 \mathrm{~Hz}, 1 \mathrm{H}, \mathrm{CCH}$ ), 2.80 (q, $\left.{ }^{3} J_{\mathrm{H}, \mathrm{H}}=7.2 \mathrm{~Hz}, 6 \mathrm{H}, \mathrm{CH}_{2} \mathrm{CH}_{3}\right), 3.51-3.72\left(\mathrm{~m}, 2 \mathrm{H}, \mathrm{OCH}_{2}\right), 3.87-4.19\left(\mathrm{~m}, 3 \mathrm{H}, \mathrm{H}^{\prime}, \mathrm{H}^{\prime}\right), 4.41\left(\mathrm{~d},{ }^{3} \mathrm{~J}_{\mathrm{H}, \mathrm{H}}=5.2 \mathrm{~Hz}\right.$, $\left.1 \mathrm{H}, \mathbf{H} 2^{\prime}\right), 4.77-4.83\left(\mathrm{~m}, 1 \mathrm{H}, \mathbf{H} 4^{\prime}\right), 6.02\left(\mathrm{~s}, 1 \mathrm{H}, \mathbf{H}^{\prime}\right), 7.28\left(\mathrm{~s}, 2 \mathrm{H}, \mathrm{NH}_{2}\right), 8.16(\mathrm{~s}, 1 \mathrm{H}, \mathrm{H} 2), 8.27(\mathrm{~s}, 1 \mathrm{H}, \mathbf{H} 8)$.

${ }^{13} \mathrm{C}-\mathrm{NMR}\left(126 \mathrm{MHz},\left[\mathrm{D}_{6}\right] \mathrm{DMSO}, 35{ }^{\circ} \mathrm{C}\right): \delta_{\mathrm{C}}(\mathrm{ppm})=9.8\left(\mathrm{CH}_{3}\right), 17.4\left(\mathrm{CH}_{2} \mathrm{CCH}\right), 24.6\left(\mathrm{CH}_{2} \mathrm{CH}_{2} \mathrm{CCH}\right), 28.3$ $\left(\mathrm{OCH}_{2} \mathrm{CH}_{2}\right), 45.5\left(\mathrm{CH}_{2} \mathrm{CH}_{3}\right), 65.6\left(\mathrm{~d},{ }^{2} \mathrm{~J}_{\mathrm{C}, \mathrm{P}}=6.6 \mathrm{~Hz}, \mathrm{C}^{\prime}\right), 69.4\left(\mathrm{OCH}_{2}\right), 71.1(\mathrm{CCH}), 72.4\left(\mathrm{~d},{ }^{2} \mathrm{~J}_{\mathrm{C}, \mathrm{P}}=3.4 \mathrm{~Hz}\right.$, $\left.\mathrm{C}^{\prime}\right), 77.0\left(\mathrm{~d},{ }^{3} \mathrm{~J}_{\mathrm{C}, \mathrm{P}}=4.5 \mathrm{~Hz}, \mathrm{C} 4^{\prime}\right), 79.2\left(\mathrm{~d},{ }^{3} \mathrm{~J}_{\mathrm{C}, \mathrm{P}}=7.4 \mathrm{~Hz}, \mathrm{C2}{ }^{\prime}\right), 84.3\left(\mathrm{CH}_{2} \mathrm{CCCH}\right), 89.6$ (C1'), 119.1 (C5), 139.6 (C8), 148.7 (C4), 152.8 (C2), 156.0 (C6).

${ }^{31} \mathrm{P}-\mathrm{NMR}\left(122 \mathrm{MHz},\left[\mathrm{D}_{6}\right] \mathrm{DMSO}, 35^{\circ} \mathrm{C}\right): \delta_{p}(\mathrm{ppm})=-4.02$.

HR-MS (ESI): calc. for $\left[\mathrm{C}_{16} \mathrm{H}_{19} \mathrm{~N}_{5} \mathrm{O}_{6} \mathrm{P}\right]^{-}\left([\mathrm{M}-\mathrm{H}]^{-}\right): 408.1078$, found: 408.1071.

Alexa Fluor ${ }^{\circledR} 555$ labelled 2'O-hex-5-yn-1-yladenosine-3',5'-cyclic monophosphate tri-nethylammonium salt (63)

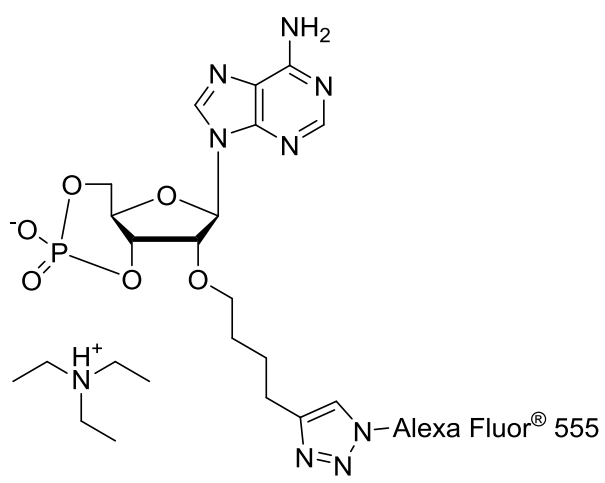

63

Based on the procedure of SEELA et al. and the manual for Alexa Fluor ${ }^{\circledR} 555$ azide, Alexa Fluor ${ }^{\circledR} 555$ azide triethylammonium salt $(0.50 \mathrm{mg}, 588 \mathrm{nmol}, 1.00 \mathrm{eq}$.) was dissolved in DMF $(9 \mu \mathrm{L})$ and combined with 2'O-hex-5-yn-1-yladenosine-3',5'-cyclic monophosphate tri-n-ethylammonium salt (62) $(0.36 \mathrm{mg}$, $706 \mathrm{nmol}, 1.20$ eq.) dissolved in DMF $(8 \mu \mathrm{L}) .{ }^{[227]}$ Sodium ascorbate $(1.76 \mu \mathrm{L}, 0.10 \mathrm{M}$ solution in water, $174 \mathrm{nmol}, 0.30$ eq.) and copper (II) sulphate pentahydrate (1.04 $\mu \mathrm{L}, 0.05 \mathrm{M}$ solution in DMF, $51.3 \mathrm{nmol}$, 0.09 eq.) were added, the solution was centrifuged shortly and stirred for $16 \mathrm{~h}$ at $\mathrm{rt}$. The solvent was evaporated under reduced pressure, the residue dissolved in $0.10 \mathrm{M}$ TEAA buffer and purified by HPLC to give the product 63 as a pink solid (113 nmol, 19\%). 
HPLC (analytical, $0.95 \mathrm{~mL} / \mathrm{min}, \mathrm{A}(0.10 \mathrm{M}$ triethylammonium acetate buffer $\mathrm{pH}$ 7), B (70\% MeCN, 30\% $0.10 \mathrm{M}$ triethylammonium acetate buffer $\mathrm{pH}$ 7), gradient $5-50 \% \mathrm{~B}, 25 \mathrm{~min}): \mathrm{R}_{\mathrm{t}}=21.8 \mathrm{~min}$.

HR-MS (ESI): calc. for $\left([\mathrm{M}-2 \mathrm{H}]^{2-}\right): 573.6999$ (based on the Alexa Fluor ${ }^{\oplus} 555$ azide MS(ESI) $\left([\mathrm{M}-1 \mathrm{H}]^{-}\right)$: 739.2919), found: 573.7013 . 



\section{Abbreviations}

Acm

$\mathrm{AcOH}$

ATP

BK channel

Boc

BSA

Bzl

CAMP

CAR

CD

Chtx

$\mathrm{Cl}$

CID

CUAAC

DBU

DCC

DCM

DCU

D. discoideum

DIC

DIPEA

DMF

DMNB

DMNPB

DMSO

Dmt

Dpa
Acetoamidomethyl

Acetic acid

Adenosine triphosphate

Big potassium channel

Tert-butyloxycarbonyl

Bovine serum albumin

Benzyl

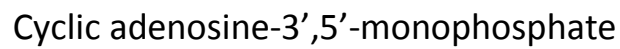

cAMP receptor

Circular dichroism

Charibdotoxin

Chemotactic index

Collision-induced dissociation

Copper(I)-catalysed azide-alkyne cycloaddition

1,8-Diazabicyclo[5.4.0]undec-7-en

1,3-Dicyclohexylcarbodiimide

Dichloromethane

$N, N^{\prime}$-Dicyclohexylurea

Dictyostelium discoideum

$N, N^{\prime}$-Diisopropylcarbodiimide

$\mathrm{N}, \mathrm{N}$-Diisopropylethylamine

Dimethylformamide

3,5-Dimethoxy-o-nitrobenzyl

3-(4,5-Dimethoxy-2-nitrophenyl)-2-butyl

Dimethyl sulphoxide

Dimethoxytrityl

2,2'-Dipicolylamine 


\begin{tabular}{|c|c|}
\hline EDC & 1-Ethyl-3-(3-dimethylaminopropyl)carbodiimide \\
\hline EDTA & Ethylenediaminetetraacetic acid \\
\hline ESI & Electrospray-ionisation \\
\hline EtOAc & Ethyl acetate \\
\hline EtOH & Ethanol \\
\hline FDA & Food and Drug Administration (US) \\
\hline FIAsH-EDT 2 & $4^{\prime}, 5^{\prime}$-Bis(1,3,2-dithioarcolan-2-yl)fluorescein \\
\hline Fmoc & Fluorenylmethyloxycarbonyl \\
\hline GFP & Green fluorescent protein \\
\hline HBTU & $N, N, N^{\prime}, N^{\prime}$-Tetramethyl-O-(1H-benzotriazol-1-yl)uronium hexafluorophosphate \\
\hline $\mathrm{HF}$ & Hydrofluoric acid \\
\hline HOBt & 1-Hydroxybenzotriazole \\
\hline HPLC & High performance liquid chromatography \\
\hline HR-MS & High resolution mass spectrometry \\
\hline Ibtx & Iberiotoxin \\
\hline LC-MS & Liquid chromatography mass spectrometry \\
\hline LplA & Lipoic acid ligase \\
\hline LAP & LpIA acceptor peptide \\
\hline MALDI & Matrix assisted laser desorption/ionisation \\
\hline Mbzl & 4-Methylbenzyl \\
\hline $\mathrm{MeCN}$ & Acetonitrile \\
\hline $\mathrm{MeOH}$ & Methanol \\
\hline MS & Mass spectrometry \\
\hline NB & 2-nitrobenzyl (a PPG) \\
\hline NHS-ester & $N$-Hydroxysuccinimide ester \\
\hline NMP & $N$-Methyl-2-pyrrolidone \\
\hline NMR & Nuclear magnetic resonance \\
\hline NTA & Nitrilotriacetic acid \\
\hline NVOC & 6-nitroveratryloxycarbonyl \\
\hline ORN & Olfactory receptor neuron \\
\hline Pbf & 2,2,4,6,7-Pentamethyldihydrofurane-5-sulphonyl \\
\hline PCC & Pyridinium chlorochromate \\
\hline PDI & Protein-disulphide-isomerase \\
\hline PEG & Polyethylene glycol \\
\hline PGA & Penicillin $\mathrm{G}$ acylase \\
\hline
\end{tabular}




\begin{tabular}{|c|c|}
\hline pGlu & Pyroglutamate \\
\hline Phacm & Phenylacetoamidomethyl \\
\hline Pmtx & Pompilidotoxin \\
\hline $\mathrm{PNPCl}$ & 4-Nitrophenyl chloroformate \\
\hline POI & Protein of interest \\
\hline PPG & Photoremovable protecting group \\
\hline PTM & Post-translational modification \\
\hline RP-HPLC & Reverse phase HPLC \\
\hline RuAAC & Ruthenium(II)-catalysed alkyne-azide cycloaddition \\
\hline SOP & Standard operating procedure \\
\hline SPAAC & Strain-promoted azide-alkyne cycloaddition \\
\hline SPPS & Solid phase peptide synthesis \\
\hline SPyr & 2-Pyridinesulphenyl \\
\hline$S^{t} B u$ & tert-Butylthio \\
\hline STX & Saxitoxin \\
\hline TBTA & Tris[(1-benzyl-1H-1,2,3-triazol-4-yl)methyl]amine \\
\hline${ }^{t} \mathrm{Bu}$ & tert-Butyl \\
\hline TCEP & Tris(2-carboxyethyl)phosphine \\
\hline TEAA & Triethylammonium acetate \\
\hline TES & Triethylsilane \\
\hline TFA & Trifluoroacetic acid \\
\hline TFE & 2,2,2-Trifluoroethanol \\
\hline TIS & Triisopropylsilane \\
\hline TLC & Thin layer chromatography \\
\hline TM & Target molecule \\
\hline Trt & Trityl \\
\hline TTX & Tetrodotoxin \\
\hline VGCC & Voltage-gated calcium channel \\
\hline VGSC & Voltage-gated sodium channel \\
\hline$v / v$ & Volume to volume \\
\hline
\end{tabular}





\section{References}

[1] E. M. Sletten, C. R. Bertozzi, Angew. Chem. Int. Ed. 2009, 48, 6974-6998.

[2] U. Resch-Genger, M. Grabolle, S. Cavaliere-Jaricot, R. Nitschke, T. Nann, Nat. Methods 2008, $5,763-775$.

[3] H. Sahoo, RSC Adv. 2012, 2, 7017-7029.

[4] A. Waggoner, Curr. Opin. Chem. Biol. 2006, 10, 62-66.

[5] M. Chalfie, Y. Tu, G. Euskirchen, W. Ward, D. Prasher, Science 1994, 263, 802-805.

[6] D. Jung, K. Min, J. Jung, W. Jang, Y. Kwon, Mol. Biosyst. 2013, 9, 862-872.

[7] B. Alberts, A. Johnson, J. Lewis, D. Morgan, M. Raff, K. Roberts, P. Walter, Molecular Biology of the Cell, Garland Science, New York, 2014.

[8] D. A. Zacharias, J. D. Violin, A. C. Newton, R. Y. Tsien, Science 2002, 296, 913-916.

[9] H. Murakami, T. Hohsaka, Y. Ashizuka, K. Hashimoto, M. Sisido, Biomacromolecules 2000, 1, $118-125$.

[10] D. Pan, H. Qin, B. S. Cooperman, RNA 2009, 15, 346-354.

[11] L. A. Marraffini, A. C. DeDent, O. Schneewind, Microbiol. Mol. Biol. Rev. 2006, 70, 192-221.

[12] S. Samantaray, U. Marathe, S. Dasgupta, V. K. Nandicoori, R. P. Roy, J. Am. Chem. Soc. 2008, $130,2132-2133$.

[13] M. Fernández-Suárez, H. Baruah, L. Martínez-Hernández, K. T. Xie, J. M. Baskin, C. R. Bertozzi, A. Y. Ting, Nat. Biotechnol. 2007, 25, 1483-1487.

[14] T. W. Muir, D. Sondhi, P. A. Cole, Proc. Natl. Acad. Sci. U. S. A. 1998, 95, 6705-6710.

[15] I. Ghosh, N. Considine, E. Maunus, L. Sun, A. Zhang, J. Buswell, T. C. Evans, M.-Q. Xu, Methods Mol. Biol. 2011, 705, 87-107.

[16] S. Chattopadhaya, L. P. Tan, S. Q. Yao, Nat. Protoc. 2006, 1, 2386-2398.

[17] B. Griffin, S. Adams, R. Tsien, Science 1998, 281, 269-272. 
[18] E. Hochuli, H. Döbeli, A. Schacher, J. Chromatogr. A 1987, 411, 177-184.

[19] E. G. Guignet, R. Hovius, H. Vogel, Nat. Biotechnol. 2004, 22, 440-444.

[20] A. Ojida, K. Honda, D. Shinmi, S. Kiyonaka, Y. Mori, I. Hamachi, J. Am. Chem. Soc. 2006, 128, 10452-10459.

[21] M. D. Partis, D. G. Griffiths, G. C. Roberts, R. B. Beechey, J. Protein Chem. 1983, 2, 263-277.

[22] P. Dawson, T. Muir, I. Clark-Lewis, S. Kent, Science 1994, 266, 776-779.

[23] C. W. Tornøe, C. Christensen, M. Meldal, J. Org. Chem. 2002, 67, 3057-3064.

[24] V. V. Rostovtsev, L. G. Green, V. V. Fokin, K. B. Sharpless, Angew. Chem. Int. Ed. 2002, 41, 2596-2599.

[25] N. J. Agard, J. A. Prescher, C. R. Bertozzi, J. Am. Chem. Soc. 2004, 126, 15046-15047.

[26] T. R. Chan, R. Hilgraf, K. B. Sharpless, V. V Fokin, Org. Lett. 2004, 6, 2853-2855.

[27] W. S. Brotherton, H. A. Michaels, J. T. Simmons, R. J. Clark, N. S. Dalal, L. Zhu, Org. Lett. 2009, $11,4954-4957$.

[28] C. I. Schilling, N. Jung, M. Biskup, U. Schepers, S. Bräse, Chem. Soc. Rev. 2011, 40, 4840-4871.

[29] M. L. Blackman, M. Royzen, J. M. Fox, J. Am. Chem. Soc. 2008, 130, 13518-13519.

[30] A. R. Massensini, J. Suckling, M. J. Brammer, T. Moraes-Santos, M. V Gomez, M. A. RomanoSilva, J. Neurosci. Methods 2002, 116, 189-196.

[31] N. Sinai, A. Meir, O. Bogin, Modulator, alomone labs 2006, 22-24.

[32] B. Pragl, A. Koschak, M. Trieb, G. Obermair, W. A. Kaufmann, U. Gerster, E. Blanc, C. Hahn, H. Prinz, G. Schu, H. Darbon, 2002, 416-425.

[33] G. Freudenthaler, M. Axmann, H. Schindler, B. Pragl, H.-G. Knaus, G. J. Schütz, Histochem. Cell Biol. 2002, 117, 197-202.

[34] C. Beeton, H. Wulff, S. Singh, S. Botsko, G. Crossley, G. A. Gutman, M. D. Cahalan, M. Pennington, K. G. Chandy, J. Biol. Chem. 2003, 278, 9928-9937.

[35] C. Schreiter, J.-M. Segura, H. Vogel, R. Hovius, K. Martinez, M. Gjoni, Reversible Sequential Binding Assays WO 2006105985 A1, 2006.

[36] C. Jimenez-Gonzalez, G. J. McLaren, N. Dale, Eur. J. Neurosci. 2003, 18, 2175-2187.

[37] M. Stevens, S. Peigneur, J. Tytgat, Front. Pharmacol. 2011, 2, 1-13.

[38] C. M. Colbert, E. Pan, Nat. Neurosci. 2002, 5, 533-538.

[39] D. A. Wollner, W. A. Catterall, Proc. Natl. Acad. Sci. U. S. A. 1986, 83, 8424-8428. 
[40] E. Schiavon, M. Stevens, A. J. Zaharenko, K. Konno, J. Tytgat, E. Wanke, FEBS J. 2010, 277, 918-930.

[41] N. P. Issa, A. J. Hudspeth, Proc. Natl. Acad. Sci. U. S. A. 1994, 91, 7578-7582.

[42] G. Bao, Detection and Functional Analysis of Ca 2+ Microdomains and BK Channels in Olfactory Receptor Neurons of Larval Xenopus Laevis, Dissertation, Georg-August-Universität Göttingen, 2010.

[43] L. J. Cruz, W. R. Gray, B. M. Olivera, Arch. Biochem. Biophys. 1978, 190, 539-548.

[44] B. M. Olivera, W. R. Gray, R. Zeikus, J. M. McIntosh, J. Varga, J. Rivier, V. de Santos, L. J. Cruz, Science 1985, 230, 1338-1343.

[45] Q. Kaas, J.-C. Westermann, R. Halai, C. K. L. Wang, D. J. Craik, Bioinformatics 2008, 24, 445446.

[46] Q. Kaas, R. Yu, A.-H. Jin, S. Dutertre, D. J. Craik, Nucleic Acids Res. 2012, 40, D325-D330.

[47] K. B. Akondi, M. Muttenthaler, S. Dutertre, Q. Kaas, D. J. Craik, R. J. Lewis, P. F. Alewood, Chem. Rev. 2014, 114, 5815-5847.

[48] I. A. Sharpe, J. Gehrmann, M. L. Loughnan, L. Thomas, D. A. Adams, A. Atkins, E. Palant, D. J. Craik, D. J. Adams, P. F. Alewood, R. J. Lewis, Nat. Neurosci. 2001, 4, 902-907.

[49] I. A. Sharpe, L. Thomas, M. Loughnan, L. Motin, E. Palant, D. E. Croker, D. Alewood, S. Chen, R. M. Graham, P. F. Alewood, D. J. Adams, R. J. Lewis, J. Biol. Chem. 2003, 278, 34451-34457.

[50] R. T. Layer, J. M. McIntosh, Mar. Drugs 1995, 4, 119-142.

[51] B. M. Olivera, L. J. Cruz, Toxicon 2001, 39, 7-14.

[52] R. S. Norton, Molecules 2010, 15, 2825-2844.

[53] P. Alewood, G. Hopping, C. Armishaw, Aust. J. Chem. 2003, 56, 769-774.

[54] G. P. Miljanich, Curr. Med. Chem. 2004, 11, 3029-3040.

[55] G. Bulaj, B. M. Olivera, Antioxid. Redox Signal. 2008, 10, 141-155.

[56] M. J. Espiritu, C. C. Cabalteja, C. K. Sugai, J.-P. Bingham, Amino Acids 2014, 46, 125-151.

[57] Z. Xia, Y. Chen, Y. Zhu, F. Wang, X. Xu, J. Zhan, BioDrugs 2006, 20, 275-281.

[58] C. Pi, J. Liu, L. Wang, X. Jiang, Y. Liu, C. Peng, S. Chen, A. Xu, J. Biotechnol. 2007, 128, 184-193.

[59] Y. Wu, L. Wang, M. Zhou, X. Jiang, X. Zhu, Y. Chen, S. Luo, Y. You, Z. Ren, A. Xu, Peptides 2014, $56,77-83$

[60] R. B. Merrifield, J. Am. Chem. Soc. 1963, 85, 2149-2154. 
[61] K. J. Jensen, P. Tofteng Shelton, S. L. Pedersen, Eds., Peptide Synthesis and Applications, Humana Press, New York, 2013.

[62] M. Amblard, J.-A. Fehrentz, J. Martinez, G. Subra, Mol. Biotechnol. 2006, 33, 239-254.

[63] G. B. Fields, R. L. Noble, Int. J. Pept. Protein Res. 1990, 35, 161-214.

[64] M. Schnölzer, P. Alewood, A. Jones, D. Alewood, S. B. H. Kent, Int. J. Pept. Res. Ther. 1992, 40, 180-193.

[65] M. Goodman, C. Toniolo, L. Moroder, A. Felix, Eds., Houben-Weyl Methods in Organic Chemistry, Volume E22b, Synthesis of Peptides and Peptidomimetics, Thieme Medical Publishers Inc., Stuttgart, 2004.

[66] J. L. Arolas, F. X. Aviles, J. Y. Chang, S. Ventura, Trends Biochem. Sci. 2006, 31, 292-301.

[67] M. Góngora-Benítez, J. Tulla-Puche, F. Albericio, Chem. Rev. 2014, 114, 901-926.

[68] M. Iwaoka, F. Kumakura, M. Yoneda, T. Nakahara, K. Henmi, H. Aonuma, H. Nakatani, S. Tomoda, J. Biochem. 2008, 144, 121-130.

[69] B. S. Mamathambika, J. C. Bardwell, Annu. Rev. Cell Dev. Biol. 2008, 24, 211-235.

[70] D. S. Rehder, C. R. Borges, Biochemistry 2010, 49, 7748-7755.

[71] V. I. Abkevich, E. I. Shakhnovich, J. Mol. Biol. 2000, 300, 975-985.

[72] T. M. Postma, F. Albericio, European J. Org. Chem. 2014, 3519-3530.

[73] C. Boulègue, H.-J. Musiol, V. Prasad, L. Moroder, Chem. Today 2006, 24, 24-36.

[74] J. Requejo-Isidro, J. Chem. Biol. 2013, 6, 97-120.

[75] B. Kamber, A. Hartmann, K. Eisler, B. Riniker, H. Rink, P. Sieber, W. Rittel, Helv. Chim. Acta 1980, 63, 899-915.

[76] H. Lamthanh, C. Roumestand, C. Deprun, A. Ménez, Int. J. Pept. Protein Res. 1993, 41, 85-95.

[77] M. Góngora-Benítez, A. Basso, T. Bruckdorfer, M. Royo, J. Tulla-Puche, F. Albericio, Chem. Eur. J. 2012, 18, 16166-16176.

[78] M. Royo, J. Alsina, E. Giralt, U. Slomcyznska, F. Albericio, J. Chem. Soc. Perkin Trans. 1 1995, 9, 1095-1102.

[79] L. Moroder, H.-J. Musiol, N. Schaschke, L. Chen, B. Hargittai, G. Barany, Houben-Weyl Methods in Organic Chemistry, Volume E22a, Synthesis of Peptides and Peptidomimetics, Thieme Medical Publishers Inc., Stuttgart, 2003.

[80] I. Annis, B. Hargittai, G. Barany, Methods Enzymol. 1997, 289, 198-221.

[81] T. Lindner, U. Haberkorn, W. Mier, J. Pept. Sci. 2012, 18, S175-S176. 
[82] H. Huang, R. I. Carey, J. Pept. Res. 1998, 51, 290-296.

[83] A. Isidro-Llobet, M. Alvarez, F. Albericio, Chem. Rev. 2009, 109, 2455-2504.

[84] A. Cuthbertson, B. Indrevoll, Org. Lett. 2003, 5, 2955-2957.

[85] A. Schulz, E. Klüver, S. Schulz-Maronde, K. Adermann, Biopolymers 2005, 80, 34-49.

[86] E. Klüver, S. Schulz-Maronde, S. Scheid, B. Meyer, W. Forssmann, K. Adermann, Biochemistry 2005, 44, 9804-9816.

[87] Y. Hidaka, H. Kubota, S. Yoshimura, H. Ito, Y. Takeda, Y. Shimonishi, Bull. Chem. Soc. Jpn. 1988, $61,1265-1271$.

[88] Y. Shimonishi, Y. Hidaka, M. Koizumi, M. Hane, S. Aimoto, T. Takeda, T. Miwatani, Y. Takeda, FEBS Lett. 1987, 215, 165-170.

[89] R. M. Brady, J. B. Baell, R. S. Norton, Mar. Drugs 2013, 11, 2293-2313.

[90] C. J. Armishaw, N. L. Daly, S. T. Nevin, D. J. Adams, D. J. Craik, P. F. Alewood, J. Biol. Chem. 2006, 281, 14136-14143.

[91] J. Bondebjerg, M. Grunnet, T. Jespersen, M. Meldal, Chembiochem 2003, 4, 186-194.

[92] B. Hargittai, N. A. Solé, D. R. Groebe, S. N. Abramson, G. Barany, J. Med. Chem. 2000, 43, 4787-4792.

[93] A. J. Robinson, J. Elaridi, B. J. Van Lierop, S. Mujcinovic, W. R. Jackson, J. Pept. Sci. 2007, 13, 280-285.

[94] S. Pegoraro, S. Fiori, S. Rudolph-Böhner, T. X. Watanabe, L. Moroder, J. Mol. Biol. 1998, 284, 779-792.

[95] D. J. Craik, D. J. Adams, ACS Chem. Biol. 2007, 2, 457-468.

[96] C. Schöneich, F. Zhao, J. Yang, B. L. Miller, in Ther. Protein Pept. Formul. Deliv. 675 (Eds.: Z. Shahrokh, V. Sluzky, J.L. Cleland, S.J. Shire, T.W. Randolph), American Chemical Society, Washington, DC, 1997, pp. 79-89.

[97] A. A. Wakankar, R. T. Borchardt, J. Pharm. Sci. 2006, 95, 2321-2336.

[98] K. J. Nielsen, D. A. Adams, P. F. Alewood, R. J. Lewis, L. Thomas, T. Schroeder, D. J. Craik, Biochemistry 1999, 38, 6741-6751.

[99] C. I. Schroeder, M. L. Smythe, R. J. Lewis, Mol. Divers. 2004, 8, 127-134.

[100] N. Satkunanathan, B. Livett, K. Gayler, D. Sandall, J. Down, Z. Khalil, Brain Res. 2005, 1059, 149-158.

[101] J. T. Blanchfield, J. L. Dutton, R. C. Hogg, O. P. Gallagher, D. J. Craik, A. Jones, D. J. Adams, R. J. Lewis, P. F. Alewood, I. Toth, J. Med. Chem. 2003, 46, 1266-1272. 
[102] K. J. Nielsen, M. Watson, D. J. Adams, A. K. Hammarström, P. W. Gage, J. M. Hill, D. J. Craik, L. Thomas, D. Adams, P. F. Alewood, R. J. Lewis, J. Biol. Chem. 2002, 277, 27247-27255.

[103] A. Brust, A. E. Tickle, J. Pept. Sci. 2007, 13, 133-141.

[104] C. K. Nielsen, R. J. Lewis, D. Alewood, R. Drinkwater, E. Palant, M. Patterson, T. L. Yaksh, D. McCumber, M. T. Smith, Pain 2005, 118, 112-124.

[105] B. R. Green, P. Catlin, M.-M. Zhang, B. Fiedler, W. Bayudan, A. Morrison, R. S. Norton, B. J. Smith, D. Yoshikami, B. M. Olivera, G. Bulaj, Chem. Biol. 2007, 14, 399-407.

[106] K. P. R. Nilsson, E. S. Lovelace, C. E. Caesar, N. Tynngård, P. F. Alewood, H. M. Johansson, I. A. Sharpe, R. J. Lewis, N. L. Daly, D. J. Craik, Biopolymers 2005, 80, 815-823.

[107] A. Nicke, M. L. Loughnan, E. L. Millard, P. F. Alewood, D. J. Adams, N. L. Daly, D. J. Craik, R. J. Lewis, J. Biol. Chem. 2003, 278, 3137-3144.

[108] E. S. Lovelace, C. J. Armishaw, M. L. Colgrave, M. E. Wahlstrom, P. F. Alewood, N. L. Daly, D. J. Craik, J. Med. Chem. 2006, 49, 6561-6568.

[109] R. J. Clark, H. Fischer, L. Dempster, N. L. Daly, K. J. Rosengren, S. T. Nevin, F. A. Meunier, D. J. Adams, D. J. Craik, Proc. Natl. Acad. Sci. U. S. A. 2005, 102, 13767-13772.

[110] G. Bulaj, P. J. West, J. E. Garrett, M. Watkins, M.-M. Zhang, R. S. Norton, B. J. Smith, D. Yoshikami, B. M. Olivera, Biochemistry 2005, 44, 7259-7265.

[111] J. Payandeh, T. Scheuer, N. Zheng, W. A. Catterall, Nature 2011, 475, 353-358.

[112] J. Payandeh, T. M. Gamal El-Din, T. Scheuer, N. Zheng, W. A. Catterall, Nature 2012, 486, 135139.

[113] X. Zhang, W. Ren, P. DeCaen, C. Yan, X. Tao, L. Tang, J. Wang, K. Hasegawa, T. Kumasaka, J. He, J. Wang, D. E. Clapham, N. Yan, Nature 2012, 486, 130-134.

[114] E. C. McCusker, C. Bagnéris, C. E. Naylor, A. R. Cole, N. D’Avanzo, C. G. Nichols, B. A. Wallace, Nat. Commun. 2012, 3, 1102.

[115] D. Shaya, F. Findeisen, F. Abderemane-Ali, C. Arrigoni, S. Wong, S. R. Nurva, G. Loussouarn, D. L. Minor, J. Mol. Biol. 2014, 426, 467-483.

[116] S. Mahdavi, S. Kuyucak, PLoS One 2014, 9, e105300.

[117] K. J. Shon, B. M. Olivera, M. Watkins, R. B. Jacobsen, W. R. Gray, C. Z. Floresca, L. J. Cruz, D. R. Hillyard, A. Brink, H. Terlau, D. Yoshikami, J. Neurosci. 1998, 18, 4473-4481.

[118] R. Chen, A. Robinson, S.-H. Chung, PLoS One 2014, 9, e93267.

[119] R. J. Lewis, S. Dutertre, I. Vetter, M. J. Christie, Pharmacol. Rev. 2012, 64, 259-298.

[120] M. M. Zhang, J. R. McArthur, L. Azam, G. Bulaj, B. M. Olivera, R. J. French, D. Yoshikami, Channels 2014, 3, 32-38. 
[121] M.-M. Zhang, B. R. Green, P. Catlin, B. Fiedler, L. Azam, A. Chadwick, H. Terlau, J. R. McArthur, R. J. French, J. Gulyas, J. E. Rivier, B. J. Smith, R. S. Norton, B. M. Olivera, D. Yoshikami, G. Bulaj, J. Biol. Chem. 2007, 282, 30699-30706.

[122] D. Chelius, K. Jing, A. Lueras, D. S. Rehder, T. M. Dillon, A. Vizel, R. S. Rajan, T. Li, M. J. Treuheit, P. V. Bondarenko, Anal. Chem. 2006, 78, 2370-2376.

[123] D. L. Nelson, A. L. Lehninger, M. M. Cox, Lehninger Principles of Biochemistry, W. H. Freeman, New York, 2008.

[124] C. A. Kapono, P. Thapa, C. C. Cabalteja, D. Guendisch, A. C. Collier, J.-P. Bingham, Toxicon 2013, 70, 170-178.

[125] W. R. Gray, A. Luque, B. M. Olivera, J. Barrett, L. J. Cruz, J. Biol. Chem. 1981, 256, 4734-4740.

[126] C. I. Schroeder, J. Ekberg, K. J. Nielsen, D. Adams, M. L. Loughnan, L. Thomas, D. J. Adams, P. F. Alewood, R. J. Lewis, J. Biol. Chem. 2008, 283, 21621-21628.

[127] S. Yao, M.-M. Zhang, D. Yoshikami, L. Azam, B. M. Olivera, G. Bulaj, R. S. Norton, Biochemistry 2008, 47, 10940-10949.

[128] A. M. Steiner, K. J. Woycechowsky, B. M. Olivera, G. Bulaj, Angew. Chem. Int. Ed. 2012, 51, 5580-5584.

[129] A. Walewska, M.-M. Zhang, J. J. Skalicky, D. Yoshikami, B. M. Olivera, G. Bulaj, Angew. Chem. Int. Ed. 2009, 48, 2221-2224.

[130] M.-M. Zhang, T. S. Han, B. M. Olivera, G. Bulaj, D. Yoshikami, Biochemistry 2010, 49, 48044812.

[131] T. S. Han, M.-M. Zhang, K. H. Gowd, A. Walewska, D. Yoshikami, B. M. Olivera, G. Bulaj, ACS Med. Chem. Lett. 2010, 1, 140-144.

[132] K. K. Khoo, Z. P. Feng, B. J. Smith, M.-M. Zhang, D. Yoshikami, B. M. Olivera, G. Bulaj, R. S. Norton, Biochemistry 2009, 48, 1210-1219.

[133] K. K. Khoo, M. J. Wilson, B. J. Smith, M. Zhang, J. Gulyas, D. Yoshikami, J. E. Rivier, G. Bulaj, R. S. Norton, 2011, 7558-7566.

[134] C. I. Schroeder, D. Adams, L. Thomas, P. F. Alewood, R. J. Lewis, Biopolymers 2012, 98, 161165.

[135] K. B. Akondi, R. J. Lewis, P. F. Alewood, Biopolymers 2014, 101, 347-354.

[136] M. Stevens, S. Peigneur, N. Dyubankova, E. Lescrinier, P. Herdewijn, J. Tytgat, J. Biol. Chem. 2012, 287, 31382-31392.

[137] R. M. Brady, M. Zhang, R. Gable, R. S. Norton, J. B. Baell, Bioorg. Med. Chem. Lett. 2013, 23, 4892-4895.

[138] P. E. Schneggenburger, B. Worbs, U. Diederichsen, J. Pept. Sci. 2010, 16, 10-14. 
[139] T. Sminia, D. Pedersen, Synlett 2012, 23, 2643-2646.

[140] A. K. Boal, I. Guryanov, A. Moretto, M. Crisma, E. L. Lanni, C. Toniolo, R. H. Grubbs, D. J. O'Leary, J. Am. Chem. Soc. 2007, 129, 6986-6987.

[141] S. Cortekar, Synthese Dimerer Cystinknoten-Mikroproteine Im Hinblick Auf Bivalente Enzyminhibition, Books On Demand GmbH, Norderstedt, 2008.

[142] Application Note BIO-0002: Microwave Synthesis: Aspartimide Formation Studies, CEM Corporation, 2011.

[143] Application Note BIO-0003: Microwave Synthesis: Racemization Studies, CEM Corporation, 2011.

[144] A. M. Steiner, G. Bulaj, J. Pept. Sci. 2011, 17, 1-7.

[145] O. Avrutina, Cystine-Knot Microproteins: Total Synthesis, Modifications and Application to Drug Design, Sierke Verlag, Göttingen, 2007.

[146] A. A. Miloslavina, E. Leipold, M. Kijas, A. Stark, S. H. Heinemann, D. Imhof, J. Pept. Sci. 2009, $15,72-77$.

[147] P. Heimer, A. A. Tietze, M. Böhm, R. Giernoth, A. Kuchenbuch, A. Stark, E. Leipold, S. H. Heinemann, C. Kandt, D. Imhof, Chembiochem 2014, 15, 2754-2765.

[148] M. Okumura, S. Shimamoto, Y. Hidaka, FEBS J. 2012, 279, 2283-2295.

[149] R. Ramage, S. Irving, C. McInnes, Tetrahedron Lett. 1993, 34, 6599-6602.

[150] D. R. Grassetti, J. F. Murray, Arch. Biochem. Biophys. 1967, 119, 41-49.

[151] D. R. Grassetti, J. F. Murray, J. Chromatogr. A 1969, 41, 121-123.

[152] Y. Han, F. Albericio, G. Barany, J. Org. Chem. 1997, 62, 4307-4312.

[153] T. Kaiser, G. . Nicholson, H. . Kohlbau, W. Voelter, Tetrahedron Lett. 1996, 37, 1187-1190.

[154] P. Sieber, K. Eisler, B. Kamber, B. Riniker, W. Rittel, F. Märki, M. De Gasparo, Biol. Chem. 1978, $359,113-124$.

[155] T. J. Wallace, J. J. Mahon, J. Org. Chem. 1965, 30, 1502-1506.

[156] J. P. Tam, C.-R. Wu, W. Liu, J.-W. Zhang, J. Am. Chem. Soc. 1991, 113, 6657-6662.

[157] R. Casaretto, R. Nyfeler, Peptides 1990, ESCOM, Leiden, 1991.

[158] Cysteine Derivatives, Global Marketing, Bachem Group, 2014.

[159] K. M. Harris, S. Flemer Jr, R. J. Hondal, J. Pept. Sci. 2007, 13, 81-93. 
[160] C. H. Panse, Development of Functionalized Derivatives for the Application in a Novel Bioorthogonal Ligation Strategy and for the Design of IHF Mimicking Peptides, Dissertation, Georg-August-Universität Göttingen, 2014.

[161] X.-Y. Li, T.-H. Li, J.-S. Guo, Y. Wei, X.-B. Jing, X.-S. Chen, Y.-B. Huang, Biotechnol. Prog. 2012, 28, 856-861.

[162] B. C. Boren, S. Narayan, L. K. Rasmussen, L. Zhang, H. Zhao, Z. Lin, G. Jia, V. V Fokin, J. Am. Chem. Soc. 2008, 130, 8923-8930.

[163] C. Uttamapinant, A. Tangpeerachaikul, S. Grecian, S. Clarke, U. Singh, P. Slade, K. R. Gee, A. Y. Ting, Angew. Chem. 2012, 124, 5954-5958.

[164] V. D. Bock, H. Hiemstra, J. H. van Maarseveen, European J. Org. Chem. 2006, 2006, 51-68.

[165] M. Empting, O. Avrutina, R. Meusinger, S. Fabritz, M. Reinwarth, M. Biesalski, S. Voigt, G. Buntkowsky, H. Kolmar, Angew. Chem. Int. Ed. 2011, 50, 5207-5211.

[166] P. White, Ed., Novabiochem ${ }^{\circledR}$ Catalog “Synthetis Notes," 2012.

[167] K. Akaji, M. Yoshida, T. Tatsumi, T. Kimura, Y. Fujiwara, Y. Kiso, J. Chem. Soc. Chem. Commun. 1990, 288-290.

[168] S. S. Wang, B. S. H. Wang, J. L. Hughes, E. J. Leopold, C. R. Wu, J. P. Tam, Int. J. Pept. Protein Res. 1992, 40, 344-349.

[169] L. Poppe, J. O. Hui, J. Ligutti, J. K. Murray, P. D. Schnier, Anal. Chem. 2012, 84, 262-266.

[170] K. K. Khoo, K. Gupta, B. R. Green, M.-M. Zhang, M. Watkins, B. M. Olivera, P. Balaram, D. Yoshikami, G. Bulaj, R. S. Norton, Biochemistry 2012, 51, 9826-9835.

[171] Z. Kuang, M.-M. Zhang, K. Gupta, J. Gajewiak, J. Gulyas, P. Balaram, J. E. Rivier, B. M. Olivera, D. Yoshikami, G. Bulaj, R. S. Norton, ACS Chem. Biol. 2013, 8, 1344-1351.

[172] A. P. Pelliccioli, J. Wirz, Photochem. Photobiol. Sci. 2002, 1, 441-458.

[173] P. Klán, T. Šolomek, C. G. Bochet, A. Blanc, R. Givens, M. Rubina, V. Popik, A. Kostikov, J. Wirz, Chem. Rev. 2013, 113, 119-191.

[174] H. Yu, J. Li, D. Wu, Z. Qiu, Y. Zhang, Chem. Soc. Rev. 2010, 39, 464-473.

[175] J. H. Kaplan, B. Forbush, J. F. Hoffman, Biochemistry 1978, 17, 1929-1935.

[176] L. Davis, J. W. Chin, Nat. Rev. Mol. Cell Biol. 2012, 13, 168-182.

[177] C. Grewer, J. Jäger, B. K. Carpenter, G. P. Hess, Biochemistry 2000, 39, 2063-2070.

[178] T. Schmierer, S. Laimgruber, K. Haiser, K. Kiewisch, J. Neugebauer, P. Gilch, Phys. Chem. Chem. Phys. 2010, 12, 15653-15664.

[179] Y. V Il'ichev, M. A. Schwörer, J. Wirz, J. Am. Chem. Soc. 2004, 126, 4581-4595. 
[180] M. Gaplovsky, Y. V Il'ichev, Y. Kamdzhilov, S. V Kombarova, M. Mac, M. A. Schwörer, J. Wirz, Photochem. Photobiol. Sci. 2005, 4, 33-42.

[181] J. E. T. Corrie, A. Barth, V. R. N. Munasinghe, D. R. Trentham, M. C. Hutter, J. Am. Chem. Soc. 2003, 125, 8546-8554.

[182] J. A. Barltrop, P. J. Plant, P. Schofield, Chem. Commun. 1966, 822-823.

[183] G. Ciamician, P. Silber, Berichte der Dtsch. Chem. Gesellschaft 1901, 34, 2040-2046.

[184] P. Wang, Asian J. Org. Chem. 2013, 2, 452-464.

[185] C. Bochet, J. Chem. Soc. Perkin Trans. 1 2002, 125-142.

[186] S. R. Adams, J. P. Y. Kao, R. Y. Tsien, J. Am. Chem. Soc. 1989, 111, 7957-7968.

[187] J. S. Wood, M. Koszelak, J. Liu, D. S. Lawrence, J. Am. Chem. Soc. 1998, 120, 7145-7146.

[188] N. Fomina, C. McFearin, M. Sermsakdi, O. Edigin, A. Almutairi, J. Am. Chem. Soc. 2010, 132, 9540-9542.

[189] C. de Gracia Lux, J. Olejniczak, N. Fomina, M. L. Viger, A. Almutairi, J. Polym. Sci. Part A Polym. Chem. 2013, 51, 3783-3790.

[190] S. Bourgault, M. Létourneau, A. Fournier, Peptides 2007, 28, 1074-1082.

[191] J. C. Sheehan, J. Preston, P. A. Cruickshank, J. Am. Chem. Soc. 1965, 87, 2492-2493.

[192] S. Petersen, J. M. Alonso, A. Specht, P. Duodu, M. Goeldner, A. del Campo, Angew. Chem. Int. Ed. 2008, 47, 3192-3195.

[193] A. Specht, J.-S. Thomann, K. Alarcon, W. Wittayanan, D. Ogden, T. Furuta, Y. Kurakawa, M. Goeldner, Chembiochem 2006, 7, 1690-1695.

[194] L. F. Tietze, M. Müller, S.-C. Duefert, K. Schmuck, I. Schuberth, Chem. Eur. J. 2013, 19, 17261731.

[195] S. Zhou, O. Mozziconacci, B. A. Kerwin, C. Schöneich, Pharm. Res. 2013, 30, 1291-1299.

[196] K. Konno, A. Miwa, H. Takayama, M. Hisada, Y. Itagaki, H. Naoki, T. Yasuhara, N. Kawai, Neurosci. Lett. 1997, 238, 99-102.

[197] K. Konno, M. Hisada, Y. Itagaki, H. Naoki, N. Kawai, A. Miwa, T. Yasuhara, H. Takayama, Biochem. Biophys. Res. Commun. 1998, 250, 612-616.

[198] Y. Sahara, M. Gotoh, K. Konno, A. Miwa, H. Tsubokawa, H. P. Robinson, N. Kawai, Eur. J. Neurosci. 2000, 12, 1961-1970.

[199] E. Kinoshita, H. Maejima, K. Yamaoka, K. Konno, N. Kawai, E. Shimizu, S. Yokote, H. Nakayama, I. Seyama, Mol. Pharmacol. 2001, 59, 1457-1463. 
[200] K. Konno, M. Hisada, H. Naoki, Y. Itagaki, T. Yasuhara, Y. Nakata, A. Miwa, N. Kawai, Neurosci. Lett. 2000, 285, 29-32.

[201] A. Galvez, G. Gimenez-Gallego, J. P. Reuben, L. Roy-Contancin, P. Feigenbaum, G. J. Kaczorowski, M. L. Garcia, J. Biol. Chem. 1990, 265, 11083-11090.

[202] S. Candia, M. L. Garcia, R. Latorre, Biophys. J. 1992, 63, 583-590.

[203] H. Knaus, C. Schwarzer, R. O. A. Koch, A. Eberhart, G. J. Kaczorowski, H. Glossmann, F. Wunder, O. Pongs, M. L. Garcia, G. Sperk, J. Neurosci. 1996, 16, 955-963.

[204] A. Koschak, R. O. Koch, J. Liu, G. J. Kaczorowski, P. H. Reinhart, M. L. Garcia, H.-G. Knaus, Biochemistry 2000, 36, 1943-1952.

[205] M. Grunnet, W. A. Kaufmann, J. Biol. Chem. 2004, 279, 36445-36453.

[206] A. Hafidi, M. Beurg, D. Dulon, Neuroscience 2005, 130, 475-484.

[207] J.-P. Bingham, S. Bian, Z.-Y. Tan, Z. Takacs, E. Moczydlowski, Bioconjugate Chem. 2006, 17, 689-699.

[208] F. Bontems, B. Gilquin, C. Roumestand, A. Ménez, F. Toma, Biochemistry 1992, 31, 77567764.

[209] P. Stampe, L. Kolmakova-Partensky, C. Miller, Biochemistry 1994, 33, 443-450.

[210] C.-S. Park, C. Miller, Biochemistry 1992, 31, 7749-7755.

[211] B. A. Johnson, E. E. Sugg, Biochemistry 1992, 31, 8151-8159.

[212] J. Bingham, J. B. Chun, M. R. Ruzicka, Q. X. Li, Z.-Y. Tan, Y. A. Kaulin, D. R. Englebretsen, E. G. Moczydlowski, Peptides 2009, 30, 1049-1057.

[213] Y. Artemenko, T. J. Lampert, P. N. Devreotes, Cell. Mol. Life Sci. 2014, 71, 3711-3747.

[214] G. Servant, O. D. Weiner, P. Herzmark, T. Balla, J. W. Sedat, H. R. Bourne, Science 2000, 287, 1037-1040.

[215] J. Condeelis, R. H. Singer, J. E. Segall, Annu. Rev. Cell Dev. Biol. 2005, 21, 695-718.

[216] K. F. Swaney, C.-H. Huang, P. N. Devreotes, Annu. Rev. Biophys. 2010, 39, 265-289.

[217] E. Schäfer, M. Tarantola, E. Polo, C. Westendorf, N. Oikawa, E. Bodenschatz, B. Geil, A. Janshoff, PLoS One 2013, 8, e54172.

[218] G. Gerisch, U. Wick, Biochem. Biophys. Res. Commun. 1975, 65, 364-370.

[219] P. Schaap, Development 2011, 138, 387-396.

[220] Y. Iwadate, S. Yumura, J. Cell Sci. 2008, 121, 1314-1324.

[221] M. Ueda, Y. Sako, T. Tanaka, P. Devreotes, T. Yanagida, Science 2001, 294, 864-867. 
[222] J. M. Mato, B. Jastorff, M. Morr, T. M. Konijn, Biochim. Biophys. Acta 1978, 544, 309-314.

[223] P. J. Van Haastert, E. Kien, J. Biol. Chem. 1983, 258, 9636-9642.

[224] P. Schaap, M. Van Ments-Cohen, R. D. M. Soede, R. Brandt, R. A. Firtel, W. Dostmann, H.-G. Genieser, B. Jastorff, P. J. M. Van Haastert, J. Biol. Chem. 1993, 268, 6323-6331.

[225] S. Kataoka, J. Isono, N. Yamaji, M. Kato, T. Kawada, S. Imai, Chem. Pharm. Bull. 1988, 36, 2212-2219.

[226] L. S. Kocsis, E. Benedetti, K. M. Brummond, Org. Lett. 2012, 14, 4430-4443.

[227] F. Seela, S. A. Ingale, J. Org. Chem. 2010, 75, 284-295.

[228] S. Kataoka, J. Imai, N. Yamaji, M. Kato, T. Kawada, S. Imai, Chem. Pharm. Bull. 1990, 38, 15961600.

[229] S. Sharma, A. C. Oehlschlager, J. Org. Chem. 1989, 54, 5064-5073.

[230] C. Westendorf, J. Negrete, A. J. Bae, R. Sandmann, E. Bodenschatz, C. Beta, Proc. Natl. Acad. Sci. U. S. A. 2013, 110, 3853-3858.

[231] G. R. Fulmer, A. J. M. Miller, N. H. Sherden, H. E. Gottlieb, A. Nudelman, B. M. Stoltz, J. E. Bercaw, K. I. Goldberg, Organometallics 2010, 29, 2176-2179.

[232] C. N. Pace, F. Vajdos, L. Fee, G. Grimsley, T. Gray, Protein Sci. 1995, 4, 2411-2423.

[233] Life technologies Corporation, The Molecular Probes ${ }^{\circledR}$ Handbook, 2010.

[234] T. J. Measey, F. Gai, Langmuir 2012, 28, 12588-12592.

[235] M. Gude, J. Ryf, P. D. White, Lett. Pept. Sci. 2002, 9, 203-206.

[236] H. T. ten Brink, D. T. S. Rijkers, R. M. J. Liskamp, J. Org. Chem. 2006, 71, 1817-1824.

[237] R. J. Amir, N. Pessah, M. Shamis, D. Shabat, Angew. Chem. Int. Ed. 2003, 42, 4494-4499.

[238] Lumiprobe, "http://de.lumiprobe.com/protocols/protein-maleimide-labeling," 2015.

[239] T. Böttcher, S. A. Sieber, Angew. Chem. Int. Ed. 2008, 47, 4600-4603. 


\section{Acknowledgements}

Mein besonderer Dank gilt Prof. DR. ULF Diederichsen für die interessante Themenstellung, die gewährte wissenschaftliche Freiheit und die entspannte Arbeitsatmosphäre während der gesamten Zeit der Dissertation.

Ebenso danke ich Prof. DR. ANDREAS JANSHOFF für die Übernahme des Korreferats und die freundliche Unterstützung, sowie die Einleitung der Kooperation mit MARCO TARANTOLA bezüglich der Verwendung gelabelten cAMPs.

Prof. Dr. lutz Ackermann, Prof. Dr. Konrad Koszinowski, Prof. Dr. Claudia höbartner und Dr. Inke SIEWERT danke ich für die Bereitschaft meiner Prüfungskommission anzugehören.

Für die ständige Diskussions- und Hilfsbereitschaft beim Erlernen der biologischen und physikalischen Fragestellungen möchte ich mich bei Dr. Andreas Neef, Dr. Marco TARANTola und Dr. Guobin BaO bedanken. TING WANG und DR. GUOBIN BAO danke ich außerdem für die schnelle Messung der Toxine.

DR. Holm FraUendorff und seinen Mitarbeitern sowie DiPL.-CheM. ReINHOLd MACHINEK und der gesamten NMR-Abteilung danke ich für die Aufnahme der Massen- und NMR-Spektren.

Angela Heinemann, Aoife Neville und Anita Jaehnke danke ich für die Hilfe in allen organisatorischen Belangen.

Den von mir betreuten Bachelorstudenten, Abteilungspraktikanten und Erasmusstudenten ESTEL CANet MARTINeZ, Bernd WALDECKER, BJÖRn GÖRICKE und insbesondere IRYNA PORTNOVA danke ich für die Unterstützung meiner Forschungsarbeit.

Allen aktuellen und ehemaligen Mitarbeiter der Arbeitskreis DIEDERICHSEN danke ich für gute Aufnahme in den Arbeitskreis und die schöne Zeit während meiner Dissertation. 
Insbesondere möchte ich bei meinen aktuellen und ehemaligen Laborkollegen ULRIKE ROST, DR. SAMIT Guha, Zeynep Kanlidere, Janine Wegner, Julia Schneider, Dr. Tatiana Baranova, Dominik Herkt, Florian RÜPING und DR. MARTA GASCON MOYA für die schöne und lustige Zeit im Labor 108 bedanken.

Für das Korrekturlesen dieser Arbeit danke ich RAIK ARTSCHWAGER, ULRIKE ROST, FLORIAN CZERNY, AOIFE Neville, Dr. Andreas Neef, Dr. Guobin Bao, Christoph Blum, Cornelia Panse und Selda Kabatas.

Für die gemeinsam verbrachte Zeit außerhalb der Arbeit, danke ich meinen Freunden aus Göttingen insbesondere ULRIKE ROST und FLORIAN CZERNY sowie den Volleyballern. FLORIAN CZERNY danke ich außerdem für die Lustigkeit und seine Gentlemenart mit der er den Laboralltag erträglicher gemacht hat. ÄÄNGI danke ich für ihre herzliche Art und das morgendliche Drücken, die zum Wohlbefinden während der Doktorarbeitszeit beigetragen haben.

Von tiefstem Herzen danke ich URIKE ROST für Ihre tagtägliche Unterstützung egal in welchen Belangen, sei es zum Ermuntern, wenn mal wieder nichts so läuft wie es soll, dem täglichen Plausch hinter der Säule, dem gemeinsamen Albern beim Volleyballspielen, den vielen Kleinigkeiten, die sie hilfsbereit erledigt und für ihre offene, ehrliche und erfrischende Art mit der sie mir einfach immer guttut.

Bei RAIK ARTSCHWAGER bedanke ich mich für die schönen gemeinsamen Stunden, das Aufbauen in schlechten Gefühlslagen, die Spontanität, die Kopfstände, die vielen Zug- und Flugreisen nur um uns ein Wochenende zu sehen, und dafür, dass du es immer schaffst mir nahe zu sein egal wie groß die Distanz ist.

Meiner Familie (inklusive RomıNA) danke ich für die Unterstützung und das mir entgegengebrachte Verständnis während der auch teils gnatschigen Stunden meiner Doktorarbeit. 


\section{Curriculum Vitae}

\section{Personal Information}

Name

Date/Place of Birth

Nationality

Email

\section{Scientific Education}

$04 / 2015$

05/2011 - 04/2014

$10 / 2008-04 / 2011$

10/2009 - 04/2010

10/2005 - 09/2008
Hanna Agnes Radzey

$28^{\text {th }}$ December 1985, Bremen

German

hradzey@web.de

\section{Disputation}

PhD thesis in the group of Prof. Dr Ulf Diederichsen, Institute of Organic and Biomolecular Chemistry, Georg-August Universität, Göttingen, Germany

"Synthesis of fluorescent toxin and nucleotide derivatives to specifically address membrane proteins"

M. Sc. Chemistry, Universität Bielefeld, Bielefeld, Germany.

- Master thesis in the group of Prof. Dr N. Schaschke: "Synthesis of (2S,3S)-3-(hydrazinecarbonyl)oxirane-2-carboxylic acid based cathepsin C inhibitors"

Study abroad in the group of Dr R. W. Baker, University of Sydney, Sydney, Australia.

B. Sc. Biochemistry, Universität Bielefeld, Bielefeld, Germany.

- Bachelor thesis in the group of Prof. Dr N. Sewald: "Enantioselective synthesis of $(4 R, 5 S)$-4-hydroxy-5-phenyltetrahydrofuran-2-ones" 


\section{Publications}

2013

2012

2009

\section{Teaching Experiences}

05-08/2014

05-07/2014

05-07/2013

05-07/2012

10/2013-04/2014

01-03/2013

10/2011-03/2012

2008-2009
Hanna Radzey, Markus Rethmeier, Dennis Klimpel, Maresa Grundhuber, Christian P. Sommerhoff, Norbert Schaschke, CHEMMEDCHEM 2013, “E64c-Hydrazide: A Lead Structure for the Development of Irreversible Cathepsin C Inhibitors", 8, 1314-1321.

Robert W. Baker, Hanna Radzey, Nigel T. Lucas, Peter Turner, Organometallics 2012, "Stereospecific Syntheses and Structures of Planar Chiral Bidentate $\eta^{5}: \kappa S$-Indenyl-Sulfanyl and -Sulfinyl Complexes of Rhodium(III)", 31, 5622-5633.

Benedikt Sammet, Hanna Radzey, Beate Neumann, Hans-Georg Stammler, Norbert Sewald, Synlett 2009, "Cryptophycin-39 Unit A Precursor Synthesis by a Tandem Shi Epoxidation and Lactonization Reaction of trans-Styryl Acetic Acid", 3, 417-420.

Supervision of a Bachelor thesis.

Teaching assistant: Organic chemistry laboratory course for biochemistry students.

Teaching assistant: "Stereochemistry" seminar.

Teaching assistant: Chemistry laboratory course for medicine students.

Teaching assistant: "Synthetic methods in organic chemistry" seminar.

Supervision of the binational degree program "B. Sc. Chemistry" 